\title{
Improving care for patients with rheumatic diseases
}

Citation for published version (APA):

van Eijk-Hustings, Y. J. L. (2014). Improving care for patients with rheumatic diseases. [Doctoral Thesis, Maastricht University]. Maastricht University. https://doi.org/10.26481/dis.20140313ye

Document status and date:

Published: 01/01/2014

DOI:

10.26481/dis.20140313ye

Document Version:

Publisher's PDF, also known as Version of record

\section{Please check the document version of this publication:}

- A submitted manuscript is the version of the article upon submission and before peer-review. There can be important differences between the submitted version and the official published version of record.

People interested in the research are advised to contact the author for the final version of the publication, or visit the DOI to the publisher's website.

- The final author version and the galley proof are versions of the publication after peer review.

- The final published version features the final layout of the paper including the volume, issue and page numbers.

Link to publication

\footnotetext{
General rights rights.

- You may freely distribute the URL identifying the publication in the public portal. please follow below link for the End User Agreement:

www.umlib.nl/taverne-license

Take down policy

If you believe that this document breaches copyright please contact us at:

repository@maastrichtuniversity.nl

providing details and we will investigate your claim.
}

Copyright and moral rights for the publications made accessible in the public portal are retained by the authors and/or other copyright owners and it is a condition of accessing publications that users recognise and abide by the legal requirements associated with these

- Users may download and print one copy of any publication from the public portal for the purpose of private study or research.

- You may not further distribute the material or use it for any profit-making activity or commercial gain

If the publication is distributed under the terms of Article $25 \mathrm{fa}$ of the Dutch Copyright Act, indicated by the "Taverne" license above, 


\section{Improving care for patients \\ with rheumatic diseases}

Yvonne JL van Eijk-Hustings 
The research presented in this thesis was performed at Maastricht University Medical Centre (MUMC+), Department of Patient \& Care and Department of Rheumatology, in collaboration with CAPHRI, School for Public Health and Primary Care, Maastricht University.

The research was funded by MUMC+, Department of Patient \& Care, and by

- Care renewal grants of health insurance companies in the region (Chapters 2, 3 and 4);

- Robuust, organisation for regional support of primary care in the South of the Netherlands, and the health insurance companies VGZ and CZ (Chapter 5);

- The European League Against Rheumatism (EULAR) (Chapters 6 and 7);

○ V\&VN, Dutch Nurses' Association, unit Rheumatology (Chapter 8).

The printing of this thesis was financially supported by the Dutch Arthritis Association, Teva Nederland BV, Roche Nederland BV, Pfizer Nederland BV, the Dutch Fibromyalgia Association (F.E.S.)

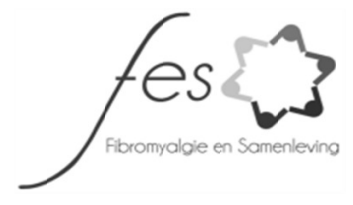

(C) Copyright: Yvonne van Eijk-Hustings, 2014

ISBN/EAN 978-94-6108-000-4

Cover design: Mieke Coeckelbergh en Jef Geybels www.miekecoeckelbergh.be

Printed by: Gildeprint Drukkerijen www.gildeprint.nl 


\title{
Improving care for patients
}

\section{with rheumatic diseases}

\author{
Proefschrift \\ ter verkrijging van de graad van doctor aan de Universiteit Maastricht, \\ op gezag van de Rector Magnificus, Prof. Dr. L. L. G. Soete \\ volgens het besluit van het College van Decanen \\ in het openbaar te verdedigen \\ op donderdag 13 maart 2014 om 16.00 uur
}

door

Yvonne Josephine Leonie van Eijk-Hustings 


\section{Promotores}

Prof. dr. R. B. M. Landewé, Amsterdams Medisch Centrum, Amsterdam \& Atrium Medisch Centrum, Heerlen

Prof. dr. A. E. R. C. H. Boonen

\section{Copromotores}

Dr. M.E.A.L. Kroese

Dr. A. M. van Tubergen

\section{Beoordelingscommissie}

Prof. dr. J. F. M. Metsemakers, (voorzitter)

Prof. dr. J. M. W. Hazes, Erasmus Medisch Centrum, Rotterdam

Prof. dr. M. J. Schuurmans, Universitair Medisch Centrum, Utrecht

Dr. D. Vosse 
'The most beautiful experience we can have is the mysterious. It is the source of true art and true science.' Albert Einstein 



\section{Contents}

$\begin{array}{lll}\text { Chapter } 1 \quad \text { General introduction } & 9\end{array}$

Part I Improving care for patients with fibromyalgia $\quad 21$

Chapter 2 Challenges in demonstrating the effectiveness of multidisciplinary 23 treatment on quality of life, participation and health care utilisation in patients with fibromyalgia: a randomised controlled trial

Chapter 3 Course of cost-of-illness in recently diagnosed patients with fibromyalgia who are offered one of three different interventions in a pragmatic trial

Chapter 4 Predictors for health improvement in patients with fibromyalgia: a 2-year follow-up study

Chapter 5 Supporting health care professionals systematically to improve the quality and person-centredness of fibromyalgia management in primary health care

Part II Improving care for patients with chronic inflammatory arthritis

Chapter 6 EULAR recommendations for the role of the nurse in the 89 management of chronic inflammatory arthritis

Chapter 7 Dissemination and evaluation of the EULAR recommendations for the role of the nurse in the management of chronic inflammatory arthritis: a multinational survey among nurses, rheumatologists and patients

Chapter 8 Patients' needs and expectations with regard to rheumatology nursing care: results of multicentre focus group interviews

Chapter 9 Summary and general discussion

Samenvatting

Dankwoord

Curriculum Vitae

Publications

Presentations related to this thesis 

Chapter 1

General introduction 


\section{Improving chronic illness care: new models for care delivery}

The burden of chronic conditions, including rheumatic diseases, increases [1] and in order to ensure access to appropriate and comprehensive care, a redesign of the health care system is necessary [2]. Care for the chronically ill differs from acute care in many ways. Acute care is characterised by incidental, short-term and reactive interventions. In contrast, chronic care challenges the health care system to pursue a planned, long-term, and proactive approach, focussing on keeping an individual as healthy as possible [3]. Key issues for chronic care are i) adherence to practice guidelines, ii) a high level of coordination, iii) an active follow-up, and iv) patients trained to manage their illness themselves. Being an active participator in the care process requires self-management skills from patients. Strategies and effective interventions that support patients' selfmanagement should therefore be available [4].

New models for care delivery comprise new roles for allied health professionals, the use of new technology (or the use of existing technology in a new and novel way), and a redesign of support systems [5]. These new models for quality improvement in chronic illness care indicate that strategies for improvement should be multidimensional, i.e. they should take the whole system into account [3]. It is clear that care for chronically ill as described above, requires fine tuning with regard to resources that are available in the community and in the health care system, e.g. sports and activities for healthy movement and physiotherapy. It also requires the development of appropriate, effective interventions that support patients' self-management, and the provision of decision support for health care professionals. Finally, it is mandatory to define clear roles, even beyond traditional tasks, for all members of the multidisciplinary team, and to provide appropriate training and education to fulfil these roles. The connection between all activities for care improvement enhances results of the single elements [6].

\section{Care for patients with rheumatic diseases}

Numerous rheumatic diseases have been recognised and defined and jointly they form the most prevalent chronic conditions in the world: $10 \%-20 \%$ of the adult population suffers from any kind of rheumatism [7]. In general, care delivery for patients with rheumatic diseases includes diagnosis, treatment and management, but also prevention of comorbidities. Care aims to reduce disability, to restore function and autonomy, and to support patients in dealing with the consequences of having a chronic disease.

The content and the context of care delivery for patients with rheumatic diseases depend on the nature of the disease and on international, national and regional agreements about treatment, follow-up and collaboration between professionals [8-18]. A growing insight in advantages of a multidisciplinary and comprehensive approach has resulted in a more holistic oriented care [19-23]. 
Traditionally, the general practitioner and the rheumatologist are responsible for the management, but often other professionals, such as the physiotherapist, occupational therapist, social worker, psychologist, podotherapist or dietician, address specific problems that occur in the course of the disease.

Rheumatology nurses are increasingly recognised as valued members of the multidisciplinary teams. They support patients in a broad spectrum of disease-related problems. Rheumatology nursing care focuses on health promotion and aims to ensure patients' capability to participating in treatment decisions, managing their own symptoms and risks of treatment [24-26], and to support patients' coping with the disease [27]. In order to achieve these goals, nursing care comprises monitoring of disease consequences at the level of daily activities, participation and psychosocial consequences, patient education, support and education for relatives, and counselling $[19,28]$. Nursing care further provides an assessment of problems and a coordination of services, all of which have been valued by patients $[29,30]$.

The rheumatology nursing specialty has developed alongside rheumatology as a separate medical specialism [31, 32]. Increasingly, nurses are involved in monitoring disease activity, drug treatment, and drug side effects, and in managing exacerbations [33, 34]. In addition, they play an increasing role in the diagnostic process [35, 36]. This role development of rheumatology nurses reflects a tendency towards evidence-based and proactive care for patients with chronic diseases in which nurses combine nursing care with medical tasks [37, 38].

For certain rheumatic diseases, current literature suggests that rheumatology patients are dissatisfied with the quality of health care. More than $30 \%$ of the patients with fibromyalgia, which is a non-inflammatory chronic pain disorder without satisfactory medical treatment options, consider that the current care should be improved. They report a delay in diagnosis and feel that their symptoms are not managed well [39]. In addition, the care for patients with rheumatoid arthritis, a well-defined disease characterised by chronic inflammatory arthritis and with multiple medical treatments available, has been found to be suboptimal too. Care is not consistent with guidelines for early, aggressive treatment and access to care is not optimal [40]. This thesis is therefore focussed on activities aiming to improve the holistic care for patients with fibromyalgia and for patients with chronic inflammatory diseases.

\section{Issues for care improvement in rheumatology}

\section{Fibromyalgia}

Fibromyalgia (FM) is a disorder characterised by generalised musculoskeletal pain, fatigue, the perception of muscle weakness, sleep and concentration disturbances. In addition, other vaguely defined symptoms may be present. The severity of symptoms varies among patients [41]. Comorbid disorders, such as depression and anxiety, occur frequently and 
contribute to a poor quality of life [42]. The prevalence of FM is estimated between $0.5 \%$ $5 \%$ and the large majority of the patients (90\%) is female in the working age [43]. Unlike chronic inflammatory diseases, FM does not result in structural deformities, but many patients perceive functional limitations in daily activities at home and at work. The impact on the patient's life and the societal burden of the disorder (high health care resource expenditures and an inability to work) is substantial and justifies an ongoing search for appropriate care $[44,45]$.

Research on underlying pathophysiological mechanisms, such as central sensitization, has resulted in a better understanding of the disorder, but the precise cause is still unknown. Cure is an unrealistic treatment goal and the evidence about effective interventions is limited, making the management of FM a challenging issue $[46,47]$. In the literature, a preference for multimodal and/or multidisciplinary approaches is advocated $[11,12,22$, 48-50]. This approach may comprise physiotherapy, cognitive-behavioral therapy completed with patient education and social support, as well as pharmacological interventions [51-54]. Increasingly, a timely intervention is considered pivotal in order to prevent further function loss and pain behaviour [55] and obviously, the availability of and access to such an intervention is essential.

The heterogeneity in study populations of FM patients is compelling and shows that the complexity of problems varies widely, but it also hampers appropriate care and treatment. The variety of phenotypes suggests that a tailored approach may be better than a generic approach and that a broad pallet of potential interventions, which are provided according to the individual's needs, may be required. Research in this field suggests satisfactory results [56] and attempts have been made to provide more practical tools for a rapid evaluation of complexity [57]. Over $80 \%$ of the patients with FM are managed in primary care by general practitioners and physiotherapists, and a large diversity of interventions is applied [58]. This diversity shows that existing guidelines are not sufficient to support the professionals in taking decisions about appropriate management $[12,59]$.

\section{Chronic inflammatory arthritis}

Diseases such as rheumatoid arthritis (RA), axial spondyloarthritis (SpA) or ankylosing spondylitis (AS) and peripheral spondyloarthritis are systemic in nature and are characterised by chronic inflammation. In RA, inflammation is predominantly present in the peripheral joints whereas in AS, the axial skeleton (spine, sacroiliac joints) is mainly affected. Abnormal reactions of the immune system are at the basis of these diseases. Inflammation may result in pain, fatigue, stiffness, and limitations in daily functioning. Deformities of the joints or spine may occur and contribute to functional limitations. Symptoms usually occur in a circular pattern of flares and periods with low disease activity, which are rather unpredictable. The worldwide prevalences are estimated $0.5 \%$ - 
$1 \%$ for RA, and $1 \%-1.5 \%$ for SpA [7]. Gender differences occur: RA is 2 to 4 times more common in women than in men and develops in the working age, whilst SpA has an approximately equal gender distribution and usually develops in the teens or twenties [7]. The treatment of chronic inflammatory arthritis focuses first and above all on interfering with the immune system. Early treatment regimens including conventional Disease Modifying Anti-Rheumatic Drugs (DMARDs) have shown their effectiveness [60, 61]. Moreover, an increased insight in immunologic processes has resulted in the development of biologic drugs which improved the possibilities to suppress disease activity in the last decennia [62]. Increasingly, the treatment target is clinical remission or, if that is not possible, low disease activity [15]. In many patients, the new treatment regimens and the use of biologic drugs have resulted in a revolutionary decrease of disease activity and in improved functional capacity and work participation. Even if low disease activity is achieved, the impact of the disease on the patient's daily life remains present $[63,64]$. The impact of inflammatory arthritis may be increased by the presence of an underlying depression disorder, a well-known comorbidity [65].

A multidisciplinary approach aims to ensure appropriate care for each patient with chronic inflammatory arthritis. In its management, the role of rheumatology nurses has changed, incorporating technical and patient-management skills that were previously belonging to the physician's domain [66]. Patients are involved in treatment decisions (shared decision making) as a full understanding and a full agreement may enhance compliance [67]. The immunosuppressant nature of the medications that are used in the therapy may contribute to a higher risk of infection. Treatment therefore requires vigilant monitoring by professionals as well as an attentive attitude of patients in order to recognise the appropriate symptoms so that they can ask for timely help [24, 68, 69]. Also, patientcentredness is considered an important quality dimension [70, 71]. The patient's perspective is considered pivotal in determining the required content and organisation of care, and also in making decisions about the quality of care $[72,73]$.

Nurse-centred interventions are considered essential to effectively tackle the challenges of chronic illness in an economic and integrated fashion [33, 34, 74-76]. Evaluation among patients has shown acceptability and satisfaction with the care provided [77]. However, there is a lack of clear definitions about the content of care and the role and competences of nurses. Also, the precise tasks and responsibilities of the team members depend on national and local regulations and contexts [78]. Furthermore, rheumatology as a nursing specialty does not exist in all countries. Consequently, care given by rheumatology nurses is not equally available for all patients with rheumatic diseases.

The demands on knowledge and skills of nurses have increased accordingly. Knowledge about disease state, clinical expertise in administration, and monitoring of adverse events is required [24], as well as skills with regard to patient-centred support, patient education, information sharing, and coordination of care [25]. The content of nursing education 
differs across countries, since curricula are not homogeneous and often not clearly described.

\section{Main research questions}

The main research questions in this thesis reflect the opportunities for care improvement that were outlined before. For fibromyalgia the focus is on the availability of resources, e.g. effective interventions, and on decision support, and the following research questions were formulated:

1. Is an intensive multidisciplinary intervention with aftercare for newly diagnosed patients with fibromyalgia effective in reducing the use of health care resources and in improving participation and quality of life?

2. How do costs develop in newly diagnosed patients with fibromyalgia that receive different types of interventions?

3. What are the potential predictors of health improvement in newly diagnosed patients with fibromyalgia?

4. How can we support health care professionals in primary care in order to improve the management of fibromyalgia?

With respect to inflammatory arthritis, care improvement focuses on emphasising the role of the rheumatology nurse and the following research questions were formulated:

1. What is the best standard for rheumatology nursing care?

2. What is the level of agreement with this standard among different countries, and what are barriers for implementation?

3. What are patients' priorities for rheumatology nursing care?

\section{Outline of the thesis}

This thesis describes our research with regard to care improvement for patients with fibromyalgia and chronic inflammatory arthritis. The background is introduced in

Chapter 1.

Part I of the thesis focuses on patients with fibromyalgia.

Chapter 2 describes the evaluation of a multidisciplinary intervention with aftercare for recently diagnosed patients. The effectiveness of the intervention was assessed in a randomised controlled trial comparing the results of the intervention with aerobic exercise and with usual care.

Economic consequences are increasingly important and have been taken into account.

Chapter 3 reports on the 2-year cost-of-illness in patients of the above mentioned cohort receiving three different types of interventions. 
An analysis of predictors for improved health in the cohort recently diagnosed patients after two years is presented in Chapter 4.

The final chapter of Part I focuses on care improvement in primary care. Results of a project in which an educational program, a multidisciplinary guideline and a checklist for referral for general practitioners and physiotherapists were developed, are described in Chapter 5 .

Part II of this thesis focuses on the role of the nurse in the care for patients with inflammatory arthritis. In order to standardise care, European League Against Rheumatism (EULAR) recommendations for the role of the nurse in the management of inflammatory arthritis have been developed by an international and multidisciplinary task force and are presented in Chapter 6.

In Chapter 7 the dissemination and the external evaluation of the recommendations among nurses, rheumatologists and patients in 22 European countries and in the United States of America are described. This chapter also provides recommendations for further implementation.

More research is needed about the effects of nursing interventions. Patients' priorities should direct the research agenda and therefore patients' opinions and expectations were explored. The results of the latter study are described in Chapter 8.

Finally, the research presented in this thesis is summarised and discussed in Chapter 9. 


\section{References}

1. www.who.int [accessed 2013 February].

2. Deal CL, Hooker RS, Harrington TM, et al. The United States Rheumatology Workforce. Arthritis Rheum. 2007;56(3):722-9.

3. Wagner EH, Austin BT, Von Korff M. Improving outcomes in chronic illness. Manag Care Q. 1996;4(2):1225.

4. Wagner EH. Chronic disease management: what will it take to improve care for chronic illness? Effect Clin Pract. 1998;1(1):2-4.

5. Joynt J, Kimball B. Innovative Care Delivery Models: Identifying New Models that Effectively Leverage Nurses: Health Workforce solutions. 2008.

6. Coleman K, Austin BT, Brach C, Wagner EH. Evidence On The Chronic Care Model In The New Milennium. Health Affairs. 2009;28(1):75-85.

7. Wong R, Davis AM, Badley E, Grewal R, Mohammed M. Prevalence of arthritis and rheumatic diseases around the world: a growing burden and implications for Health Care needs. Models of Care in Arthritis, Bone \& Joint Disease (MOCA). 2010;MOCA2010-07/

8. Flikweert S, Van der Heijde D, Wiersma $\mathrm{Tj}$, et al. Landelijke Transmurale Afspraak Reumatoïde artritis. Huisarts Wet 2002;45:544-7.

9. van der Horst- Bruinsma I, Franssen M, Oostveen J, et al. Richtlijn voor de diagnostiek en behandeling van Ankyloserende Spondylitis: Nederlandse Vereniging voor Reumatologie.2002.

10. Reumatische ziekten en syndromen: Fibromyalgie: Nederlandse Vereniging voor Reumatologie.2002.

11. Hauser W, Thieme K, Turk DC. Guidelines on the management of fibromyalgia syndrome - A systematic review. Eur J Pain. 2010;14(1):5-10.

12. Carville SF, Arendt-Nielsen S, Bliddal H, et al. EULAR evidence-based recommendations for the management of fibromyalgia syndrome. Ann Rheum Dis. 2008 ;67(4):536-41.

13. Gossec L, Smolen JS, Gaujoux-Viala C, et al. European League Against Rheumatism recommendations for the management of psoriatic arthritis with pharmacological therapies. Ann Rheum Dis. 2012;71:4-12.

14. Braun J, van den Berg R, Baraliakos X, et al. 2010 update of the ASAS/EULAR recommendations for the management of ankylosing spondylitis. Ann Rheum Dis.2011;70:896-904.

15. Smolen J, Aletaha D, Bijlsma J, et al. Treating rheumatoid arthritis to target: recommendations of an international task force. Ann Rheum Dis. 2010;69:631-7.

16. Lineker SC, Bell MJ, Boyle J, et al. Implementing arthritis clinical practice guidelines in primary care. Med Teach. 2009;31 (3):230-7.

17. Hennell S. New NICE rheumatoid arthritis guideline offers a key role for specialist nurses. Nurs Times. 2009;105 (10):20.

18. Newsome G. Guidelines for the management of rheumatoid arthritis: 2002 update. J Am Acad Nurse Pract. 200;14 (10):432-7.

19. Madigan A, FitzGerald O. Multidisciplinary patient care in rheumatoid arthritis: evolving concepts in nursing practice. Baillieres Best Pract Res Clin Rheumatol. 1999;13(4):661-74.

20. Vliet Vlieland TPM. Multidisciplinary team care and outcomes in rheumatoid arthritis. Curr Opin Rheumatol. 2004;16 (2):153-6.

21. Vliet Vlieland TPM, Hazes JMW. Efficacy of multidisciplinary team care programs in rheumatoid arthritis. Seminars in Arthrit Rheum. 1997;27 (2):110-22.

22. Burckhardt CS. Multidisciplinary approaches for management of fibromyalgia. Current pharmaceutical design. 2006;12(1):59-66.

23. Mengshoel AM, Forseth KO, Haugen M, et al. Multidisciplinary approach to fibromyalgia. A pilot study. Clin Rheumatol. 1995;14(2):165-70.

24. Dexter TR. Role of the rheumatology infusion nurse... including discussion with Saleh A, Dilliard JA, Dexter TR, Ruffing V, Daul PM, Dolan DG, Neuberger GB, Grace E. Johns Hopkins Advanced Studies in Nursing. 2008;6(2):39-44.

25. Oliver $\mathrm{S}$. The role of the clinical nurse specialist in the assessment and management of biologic therapies. Musculoskeletal Care. 2011;9(1):54-62.

26. Willis J. Joint initiative... how an award-winning rheumatology nurse gets patients involved in treatment. Nurs Times. 1999;95(23):34-5.

27. Newbold D. Coping with rheumatoid arthritis. How can specialist nurses influence it and promote better outcomes? J Clin Nurs. 1996;5 (6):373-80. 
28. Arthur V. Nursing care of patients with rheumatoid arthritis. Br J Nurs. 1994;3(7):325-7.

29. Hill J. Nursing clinics for arthritics. Nurs Times. 1985;81(38):33-4.

30. Pigg JS. Rheumatoid arthritis: how allied health professionals can help... seventh in a special series of articles on diagnosis and management of rheumatoid arthritis. J Musculoskelet Med. 1995;12(2):27.

31. Hale C, Hill J. Locating the evidence base for musculoskeletal nursing: An overview of the rheumatology nursing literature. Int J Nurs Studies. 2006;43:507-18.

32. Pigg JS. Rheumatology nursing: Evolution of the role and functions of a subspecialty. Arthritis Care Res.1990;3 (3):109-15.

33. Hill J, Bird A, Harmer R, Wright V, Lawton C. An evaluation of the effectiveness, safety and acceptability of a nurse practitioner in a rheumatology outpatient clinic. Br J Rheumatol. 1994;33(3):283-8.

34. Hill J, Thorpe R, Bird H. Outcomes for patients with RA: a rheumatology nurse practitioner clinic compared to standard outpatient care. Musculoskeletal Care. 2003;1 (1):5-20.

35. El Miedany Y, Palmer D, El Gaafary M. Diagnosis of early arthritis: outcomes of a nurse-led clinic. Br J Nurs. 2006;15(7):394-9.

36. Kroese MEAL, Schulpen GJC, Bessems MCM, et al. Substitution of specialized rheumatology nurses for rheumatologists in the diagnostic process of fibromyalgia: a randomized controlled trial. Arthritis Care Res. 2008;59(9):1299-305.

37. Laurant M, Reeves D, Hermens R, Braspenning J, Grol R, Sibbald B. Substitution of doctors by nurses in primary care. Cochrane Database of Systematic Reviews 2004;Issue 4(Art. No.: CD001271. DOI: 10.1002/14651858.CD001271.pub2.).

38. Loveman E, Royle P, Waugh N. Specialist nurses in diabetes mellitus. Cochrane Database of Systematic Reviews. 2003;Issue 2(Art. No.: CD003286. DOI: 10.1002/14651858.CD003286).

39. Choy E, Perrot S, Leon $T$, et al. A patient survey of the impact of fibromyalgia and the journey to diagnosis. BMC Health Serv Res 2010;10:102.

40. Lacaille D, Anis AH, Guh DP, Esdaille JM. Gaps in care for rheumatoid arthritis: a population study. Arthritis Rheum. 2005;53(2):241-8.

41. Wolfe F, Clauw DJ, Fitzcharles MA, et al. The American College of Rheumatology preliminary diagnostic criteria for fibromyalgia and measurement of symptom severity. Arthrit Care Res. 2010;62(5):600-10.

42. Wolfe F, Smythe HA, Yunus MB, et al. The American College of Rheumatology 1990 Criteria for the Classification of Fibromyalgia. Report of the Multicenter Criteria Committee. Arthritis Rheum. 1990;33(2):160-72.

43. White KP, Harth M. Classification, epidemiology, and natural history of fibromyalgia. Curr Pain Headache Rep. 2001;5(4):320-9.

44. Boonen A, van den Heuvel R, van Tubergen A, et al. Large differences in cost of illness and wellbeing between patients with fibromyalgia, chronic low back pain, or ankylosing spondylitis. Ann Rheum Dis. 2005;64(3):396-402.

45. White LA, Birnbaum HG, Kaltenboeck A, Tang J, Mallett D, Robinson RL. Employees with fibromyalgia: medical comorbidity, healthcare costs, and work loss. J Occup Environ Med. 2008;50(1):13-24.

46. Karjalainen $\mathrm{K}$, Malmivaara A, van Tulder M, et al. Multidisciplinary rehabilitation for fibromyalgia and musculoskeletal pain in working age adults. Cochrane database of systematic reviews Online Update Software ISE: 1469 493X. 2000(2):Cd001984.

47. Hauser W, Bernardy K, Arnold B, Offenbacher M, Schiltenwolf M. Efficacy of multicomponent treatment in fibromyalgia syndrome: a meta-analysis of randomized controlled clinical trials. Arthritis Rheum. 2009;61(2):216-24.

48. Clauw DJ. Fibromyalgia: update on mechanisms and management. J Clin Rheumatol. 2007;13(2):102-9.

49. Goldenberg DL, Burckhardt C, Crofford L. Management of fibromyalgia syndrome. JAMA. 2004;292(19):2388-95.

50. van Koulil S, Effting M, Kraaimaat FW, et al. Cognitive-behavioural therapies and exercise programmes for patients with fibromyalgia: state of the art and future directions. Ann Rheum Dis. 2007;66(5):571-81.

51. Williams DA. Psychological and behavioural therapies in fibromyalgia and related syndromes. Best practice and research Clin Rheumatol. 2003;17(4):649-65.

52. Busch A, Schachter CL, Peloso PM, Bombardier C. Exercise for treating fibromyalgia syndrome. Cochrane database of systematic reviews Online Update Software. 2002(3):Cd003786.

53. Burckhardt CS. Education programmes for fibromyalgia patients:description and evaluation. Balliere's Clin Rheumatol. 1994;8(4):935-55. 
54. Arnold LM, Keck PE Jr, Welge JA. Antidepressant treatment of fibromyalgia. A meta-analysis and review. Psychosomatics. 2000;41(2):104-13.

55. Keefe FJ, Rumble ME, Scipio CD, Giordano LA, Perri LM. Psychological aspects of persistent pain: current state of the science. J Pain. 2004;5:195-211.

56. van Koulil S, van Lankveld W, Kraaimaat FW, et al. Tailored cognitive-behavioral therapy and exercise training for high-risk fibromyalgia patients. Arthritis Care Res (Hoboken). 2010;62(10):1377-85.

57. Vallejo MA, Rivera J, Esteve-Vives J, on behalf of Group ICAF. Development of a self-reporting tool to obtain a combined index of severity of fibromyalgia (ICAF). Health Qual Life Outcomes;8:2 2010;8:2.

58. Kroese ME, Schulpen GJ, Sonneveld HM, Vrijhoef HJ. Therapeutic approaches to fibromyalgia in the Netherlands: a comparison between 1998 and 2005. J Eval Clin Pract. 2008;14(2):321-5.

59. Hauser W, Arnold B, Eich W, et al. Management of fibromyalgia syndrome - an interdisciplinary evidence-based guideline. Ger Med Sci. 2008;6:Doc14.

60. Boers M, Verhoeven AC, Markusse HM, et al. Randomised comparison of combined step-down prednisolone, methotrexate and sulphasalazine with sulphasalazine alone in early rheumatoid arthritis. Lancet. 1997;350(9074):309-18.

61. Weinblatt ME, Coblyn JS, Fox DA, et al. Efficacy of low-dose methotrexate in rheumatoid arthritis. $\mathrm{N}$ Engl J Med. 1985;312(13):818-22.

62. Furst DE, Breedveld FC, Kalden JR, et al. Updated consensus statement on biological agents, specifically tumour necrosis factor alpha (TNFalpha) blocking agents and interleukin-1 receptor antagonist (IL-1ra), for the treatment of rheumatic diseases. Ann Rheum Dis. 2004;Suppl 2:ii2-ii12.

63. Hughes JG, van Middendorp H, Kool MB, Geenen R, Dobkin PL, Makelainen P. Exploring the impact of rheumatoid arthritis on patients' lives... including commentary by van Middendorp $\mathrm{H}$ et al. Int J Ther Rehab. 2009;16(11):594-601.

64. Repping-Wuts H, Fransen J, van Achterberg T, Bleijenberg G, van Riel P. Persistent severe fatigue in patients with rheumatoid arthritis. J Clin Nurs. 2007;16(11c):377-83.

65. Hill CL, Gill T, Taylor AW, Daly A, Grande ED, Adams RJ. Psychological factors and quality of life in arthritis: A population-based study. Clin Rheumatol. 2007;26:049-54.

66. Hill J. Development and effectiveness of nurse-led arthritis clinics. Drug Benefit Trends. 2005;17 (6):26270 .

67. Joosten EA, DeFuentes-Merillas L, de Weert GH, Sensky T, van der Staak CP, CA. dJ. Systematic review of the effects of shared decision-making on patient satisfaction, treatment adherence and health status. Psychother Psychosom. 2008;77(4):219-26.

68. Ruffing V. Pharmacologic management of patients with rheumatoid arthritis. Johns Hopkins Advanced Studies in Nursing. 2007;5 (1):15-22.

69. Ruffing V. Maximizing outcomes for patients with rheumatoid arthritis: An update for rheumatology nurses. Johns Hopkins Advanced Studies in Nursing. 2007;5 (1):6-7.

70. Mead N, Bower P. Patient-centredness: a conceptual framework and review of the empirical literature. Social Sci Med. 2000;51:1087-110.

71. van der Eijk M, Faber M, Al Shamma S, Munneke M, Bloem B. Moving towards patient-centered healthcare for patients with Parkinson's disease. Parkonsonism Related Dis. 2011;17:360-4.

72. Saag KG, Yazdany J, Alexander C, et al. Defining quality of care in rheumatology: the American College of Rheumatology white paper on quality measurement. Arthritis Care Res (Hoboken). 2011;63(1):2-9.

73. Jacobi C, Boshuizen H, Rupp I, Dinant H, van den Bos G. Quality of rheumatoid arthritis care: the patient's perspective. Int J Qual Health Care. 2004;16(1):73-81.

74. Tijhuis GJ, Zwinderman AH, Hazes JMW, Breedveld FC, Vlieland PMT. Two-year follow-up of a randomized controlled trial of a clinical nurse specialist intervention, inpatient, and day patient team care in rheumatoid arthritis. J Adv Nurs. 2003;41(1):34-43.

75. Tijhuis GJ, Zwinderman AH, Hazes JMW, Wb, Breedveld FC, Vliet Vlieland TPM. A randomized comparison of care provided by a clinical nurse specialist, an inpatient team, and a day patient team in rheumatoid arthritis. Arthritis Care Res. 2002;47(5):525-31.

76. Van Den Hout WB, Tijhuis GJ, Hazes JMW, Breedveld FC, Vliet Vlieland TPM. Cost effectiveness and cost utility analysis of multidisciplinary care in patients with rheumatoid arthritis: A randomised comparison of clinical nurse specialist care, inpatient team care, and day patient team care. Ann Rheum Dis. 2003 01;62 (4):308-15.

77. Hill J. Patient evaluation of a rheumatology nursing clinic. Nurs Times. 1986 2-8;82(27):42-3. 
General introduction

78. Leary A, Crouch H, Lezard A, Rawcliffe C, Boden L, A. R. Dimensions of clinical nurse specialist work in the UK. Nursing Standard. 2008-2009;23(15-17):40-4. 
Part I

\section{Improving care for patients with fibromyalgia}

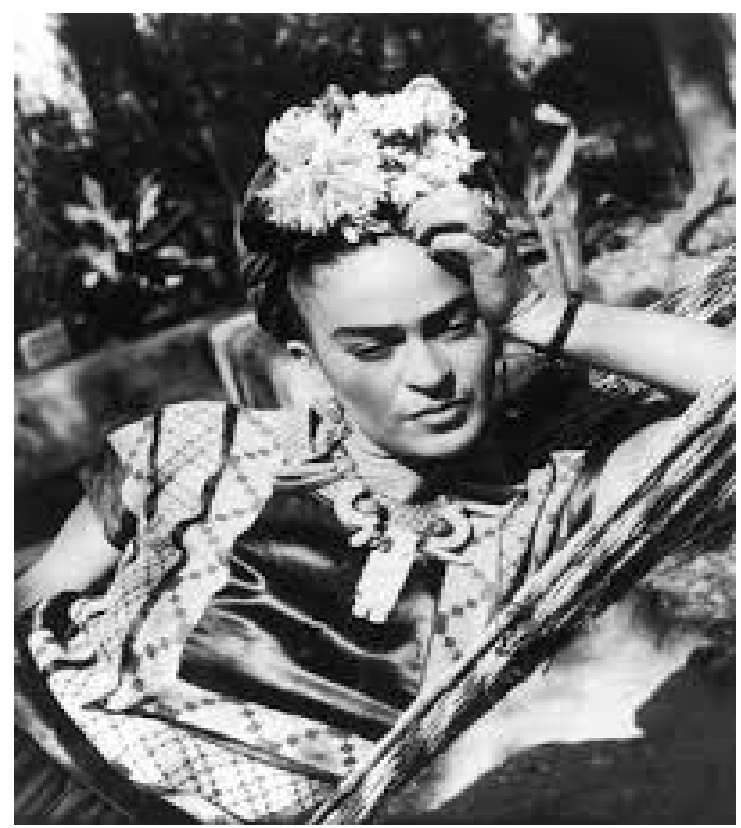

Frida Kahlo (1907-1954), Mexican painter

'To explain Frida's chronic illness, we offer an alternative diagnosis. Our opinion is that she suffered posttraumatic fibromyalgia. This prevalent syndrome is characterized by persistent widespread pain, chronic fatigue, sleep disorders, and vegetative symptoms, and by the presence of tender points in well-defined anatomic areas.'

Martinez-Lavin M, Amigo M-C, Coindreau J, Canoso J. Fibromyalgia in Frida Kahlo's life and art. Arthritis \& Rheumatism. 2000; 43(3):708-709. 


\section{Chapter 2}

Challenges in demonstrating the effectiveness of multidisciplinary treatment on quality of life, participation and health care utilisation in patients with fibromyalgia: a randomised controlled trial

Van Eijk-Hustings Y, Kroese M, Tan F, Boonen A, Bessems-Beks M, Landewé R. 


\section{Abstract}

Objective. The aim of this study was to examine the effectiveness of a multidisciplinary intervention with aftercare, compared to aerobic exercise and usual care in recently diagnosed patients with fibromyalgia.

Methods. In a Zelen-like design, eligible patients from the outpatient rheumatology clinics of three medical centres in the South of the Netherlands were consecutively recruited and pre-randomised to the multidisciplinary intervention $(n=108)$, aerobic exercise $(n=47)$ or usual care $(n=48)$. The multidisciplinary intervention consisted of a 12-week course of socio-therapy, physiotherapy, psychotherapy and creative arts therapy (three half days per week), followed by five aftercare meetings in nine months. Aerobic exercise was given twice a week in a 12-week course. Usual care varied but incorporated at least education and life style advice. Primary outcomes were health-related quality of life, participation and health care utilisation. Secondary outcome was the Fibromyalgia Impact Questionnaire. Total follow-up in the study was 21-24 months.

Results. As willingness to participate in the aerobic exercise intervention was limited, this group has been analysed but interpretation of the data is considered arguable. Within the multidisciplinary intervention group, a statistically significantly improved health-related quality of life, and a statistically significant reduction in number of hours sick leave, number of contacts with General Practitioners, and number of contacts with medical specialists was found. Moreover, statistically significant improvements were found on the Fibromyalgia Impact Questionnaire, which increased after the intervention. However, no statistically significantly between-group differences were found at the endpoint of the study.

Conclusion. The multidisciplinary intervention seemed to yield positive effects, but firm conclusions with regard to effectiveness cannot be formulated due to small between group differences and limitations of the study. 


\section{Introduction}

Fibromyalgia (FM) is a chronic pain disorder with a worldwide prevalence of $0.5 \%-5 \%$, preferentially affecting women in the working age [1]. The most prominent manifestation of FM is widespread, persistent musculoskeletal pain. In addition, a variety of other manifestations such as fatigue, concentration problems, depression, anxiety and symptoms of irritable bowel syndrome may occur [2], resulting in a loss of well-being, participation and functioning [3, 4]. The economic burden of FM is considerable as it is associated with high utilisation of health care resources and loss of working days [5-7].

Because of its multifaceted nature, FM is assumed to be managed best by multimodal and/or multidisciplinary approaches [8, 9]. A meta-analysis of non-pharmacological, multimodal interventions showed limited effects [10], contributing to the ongoing discussion on the content, duration, intensity, adherence and long term effects of these programs $[10,11]$. Increasingly, experts consider that early intervention can enhance treatment efficacy, as they expect this to prevent pain behaviour and adaptation to dysfunctioning [12]. Health care utilisation and participation in major life areas are increasingly valued as important outcomes, in addition to classic outcome measures that concentrate on key domains of FM like pain, fatigue and physical functioning [13].

An intensive, multidisciplinary intervention with aftercare for patients with recently diagnosed FM was developed and tested in a pilot study among 100 patients with nine months follow-up. The approach was found feasible and the pilot study suggested a sustained improvement in quality of life and functioning during the treatment and aftercare period [14]. A larger, randomised controlled study with a follow-up time extending the duration of the intervention was considered pivotal in order to examine the sustainability of effects and to understand non-specific effects opposed to specific effects which are attributable to the multidisciplinary intervention. In the present study, the intensive multidisciplinary program with aftercare is tested in a randomised controlled trial (RCT) with health-related quality of life (HR-Qol), participation and health care utilisation as primary outcomes.

\section{Patients and methods}

\section{Study participants and design}

The study was designed as a pragmatic RCT [15], comparing the effectiveness of the multidisciplinary intervention (MD) with aerobic exercise ( $A E$ ) and usual care (UC). In the period from January 2004 until August 2006, recently (< three months) diagnosed FM patients according to the American College of Rheumatology criteria [2], literate and between 18 and 65 years old, were consecutively recruited from the outpatient rheumatology clinics of three medical centres in the South of the Netherlands (Maastricht University Medical Centre (MUMC), Atrium Medical Centre, Heerlen and Orbis Medical 
Centre, Sittard). To avoid biased results by patients' expectations, a pre-randomised Zelen-like study-design [16] was chosen.

Eligible patients were asked to participate in, as they were told, 'an observational study on the natural course of FM', and at the same time they were asked whether they were willing to participate in future studies. After informed consent, they were randomly assigned to the treatment arms. Randomisation was performed using computer generated random numbers in opaque, sealed envelopes, following the order of consent to participate in the observational study. Only those who were randomised to $M D$ or $A E$ were invited to participate in the intervention without being informed about the alternative treatment conditions. Patients in the UC group were not informed about any intervention.

Because of the intensity of the MD program, patients randomised to the MD group were interviewed by the research assistant and excluded from participation in the intervention in case of 1) pregnancy, 2) involvement in litigation concerning work disability procedures, 3) use of other non-pharmacological treatments such as psychological or physical treatment, interfering with the intervention, 4) alcohol or drugs abuse and 5) use of walking devices.

The study was approved by the Medical Ethical Committees of the three medical centres and is registered under number ISRCTN32542621.

\section{Interventions}

The MD intervention was designed as a 2-phased group program, aiming to optimise daily functioning through coping with pain and disability. The total program took one year and was offered in an outpatient convalescence setting, affiliated to MUMC.

Phase I consisted of a 12-week course, three half days per week, with two therapy sessions of 1,5 hours duration per day. A trained and experienced multidisciplinary team offered a program of socio-therapy, physiotherapy, psychotherapy and creative arts therapy, using group interaction as an additional tool but also paying attention to the patient's specific needs. Socio-therapy was given twice a week at the start and the end of the week. It included education and connected the parts of the program. It was based on transactional analysis $[17,18]$ and aimed to increase social behaviour strategies and social support.

Physiotherapy was given twice a week. The program was focused on graded activity, based on time-contingent instead of pain-contingent training and aimed to improve physical fitness and functioning, and at learning to enjoy exercise. It comprised aerobic exercises, strength training of arms and legs, different forms of relaxation, and exercises focusing on alternative patterns of movement in order to improve awareness and reduce muscle tone during daily activities. The program was scheduled based on the individual patient's results on the 6-minute walk test, the 3-minute step test and on three minutes 
of working with the shoulder press measured by the physiotherapist at the start of the program. If necessary, instruction and support by an occupational therapist could take part of the physiotherapy. Psychotherapy was given once a week and consisted of general information about fibromyalgia and pain mechanisms. Methods of core qualities [19], rational emotive therapy [20-22] and transactional analysis [17, 18] were used in the sessions. Creative arts therapy was given once a week and focussed on the opportunity to express feelings by visual arts instead of verbal expressions. The first phase was built up around four themes, used in all therapies:

Theme 1. Communication: discover suppressed feelings and emotions;

Theme 2. Take care of yourself: discover limitations and learn to draw the line;

Theme 3. Stress, strength, anger and conflict: discover qualities;

Theme 4. Balance: a new start.

Phase II was an aftercare program and consisted of five meetings, scheduled over a period of nine months. The purpose of these meetings was to repeat the key messages about coping in order to preserve the behavioral change achieved in phase I. In addition to these meetings, a maximum of seven individual therapy sessions with one of the therapists could be scheduled if considered necessary by therapist and patient. An MD group with 9 to 10 patients started every six weeks. If too small number of patients wanted to participate in the intervention, additional patients from the outpatient clinic who did not participate in the study were added to fill the groups.

The AE intervention consisted of a 12-week group course which was given twice a week by a trained physiotherapist in a community gym, on the floor. Every session started with a 10-minute warming-up, comprising aerobic exercise and stretching, followed by an aerobic part during 30 minutes. The low-intensity aerobic part aimed to reach $55 \%-64 \%$ of the predicted maximum heart rate. Patients were instructed to check heart rate by selfcontrol after the warming-up and after the aerobic part a few times during the course. They were asked to communicate this with the trainer to check if the intensity of their aerobic training was sufficient. Then, resistance training was applied during 15 minutes to strengthen major muscle groups. During the course, the intensity of the resistance training increased in weights, frequency and tempo. Finally, every session was finished with a 5minute cool-down [23]. Participants received a Digital Video Disc presenting exercises to do at home, and they were advised to perform these once a week. These home exercises were not monitored. The AE group should also consist of 9 to 10 persons and started when enough participants for the intervention were available.

The UC arm received care as usual that comprised at least individualised education about FM and lifestyle advice by a rheumatologist or a specialised rheumatology nurse within one or two consultations, but could also include a diversity of other treatments such as physiotherapy, or social support from the rheumatology nurse. 


\section{Outcome measures}

Primary outcomes were HR-Qol, participation and health care utilisation. The secondary outcome was the impact of FM on daily functioning. All outcome measures were selfreported. At inflow in the study, all patients provided data on demographic and disease characteristics. Total follow-up of the study was 21 to 24 months for the three groups. Follow-up duration varied since patients started the intervention at different time points. Follow-up questionnaires were sent to all patients immediately following the 12-week program and 18 months afterwards, the endpoint of the study. Because the UC group did not receive a planned intervention, the measurements of each respondent were randomly linked to respondents in either the MD group or the $A E$ group to achieve similar time points.

HR-Qol was measured by the 5-dimensional EuroQol (EQ-5D) [24, 25]. The EQ-5D is a validated instrument to assess general health-related quality of life. This instrument consists of two components: a descriptive system that expresses a societal value for health (range from -0.59 to 1.00 , worst possible to best possible health) and an overall impression of health, measured by a Visual Analogue Scale (VAS, range from 0 to 100, worst possible to best possible health).

Participation comprised work productivity, unpaid tasks and chores (e.g. household), leisure (e.g. sports, hobbies) and social activities. A self-developed questionnaire measured contractual hours paid work and hours sick leave retrospectively. Time spent on unpaid tasks, chores, leisure and social activities in the past two months was measured by an adapted activity questionnaire [26].

The use of FM-related health care resources was measured retrospectively by a 2-monthly cost questionnaire [27]. Questions considered number of contacts with general practitioners (GPs), medical specialists (e.g. rheumatologists, orthopaedists), physiotherapists and other paramedical therapists (e.g. psychotherapists).

The impact of FM on daily functioning was assessed by the Fibromyalgia Impact Questionnaire (FIQ) $[28,29]$, a 10-item multidimensional instrument on function in the past week. The 10 items are physical functioning, numbers of days feel good, number of days missed work, interference of symptoms with ability to activities, pain, fatigue, unrefreshed sleep, stiffness, anxiety and depression. Each item-score was standardised on a 0-10 scale and a FIQ-total score (0-100) was calculated [28].

\section{Sample size calculation}

Sample size calculation was based on results of the pilot study on HR-Qol [14], because no robust data on expected change in the other primary outcomes were available in the literature. With a 0.15 units difference on the EQ-5D, standard deviation $=0.32, \beta=0.20$ and $\alpha=0.05$, and allowing for a drop-out of $30 \%$, a total of 204 patients was needed. In this 3-arm pragmatic clinical trial with MD expected to show most (durable) effect, an 
unbalanced design was chosen in the following ratio: $M D$ vs $A E$ vs $U C=2$ vs 1 vs 1 , so that the majority of patients would get MD as their treatment.

\section{Statistical analyses}

Data were analysed using the intention-to-treat principle. Due to the limited willingness to participate in the interventions after randomisation, per-protocol analyses were also performed. Patients dropping out from the intervention continued their participation in the observational study, so follow-up data were obtained. Missing questionnaires that appeared not only in the group of patients who participated in the interventions but also in the group of non-participants varied per measurement. Missing data were carefully investigated and found to be random. A multilevel analysis (mixed effects model) was used to assess longitudinal effectiveness [30]. In this analysis, all available data are used and therefore, also patients with incomplete data could be included [31]. As differences in the outcome variables occurred at inflow of the study, these values were added in the final models.

Effect sizes (ESs) (Cohen's d) and their confidence intervals (Cls) were calculated for between-group differences at the endpoint of the study [32,33]. Cohen defined an ES of $\geq$ 0.2 as small, $\geq 0.5$ as moderate and $\geq 0.8$ as large [32]. ES calculations were based on the results of the mixed model analyses and were considered as statistically significant if zero was not included in the $\mathrm{Cl}$ [33]. Data were analysed using SPSS, version 18.0 (SPSS Inc., Chicago, IL).

\section{Results}

A study flowchart is presented in Figure 2.1. From 242 eligible patients, 203 consented to participate in the observational study. They were randomised and allocated to the MD group ( $n=108)$, the AE group ( $n=47)$, and the UC group $(n=48)$. After randomisation, the actual willingness to participate in the interventions was limited. In the MD group, seven patients did not attend $>70 \%$ of the scheduled sessions, as the intensity was difficult to combine with the care for their children, or interfered with other problems. Other reasons for attrition were difficulties with transportation and a lack of motivation. In the AE group, less than half of the randomised patients consented to start the intervention. Reasons mentioned were a lack of interest and difficulties with transportation. With regard to 12 patients, we do not know the reason. Of those who started the intervention, only eight patients attended $>70 \%$ of the scheduled sessions. Reasons mentioned were physical problems and difficulties in combining the program with the care for their children. With regard to seven patients, we do not know the reason. 


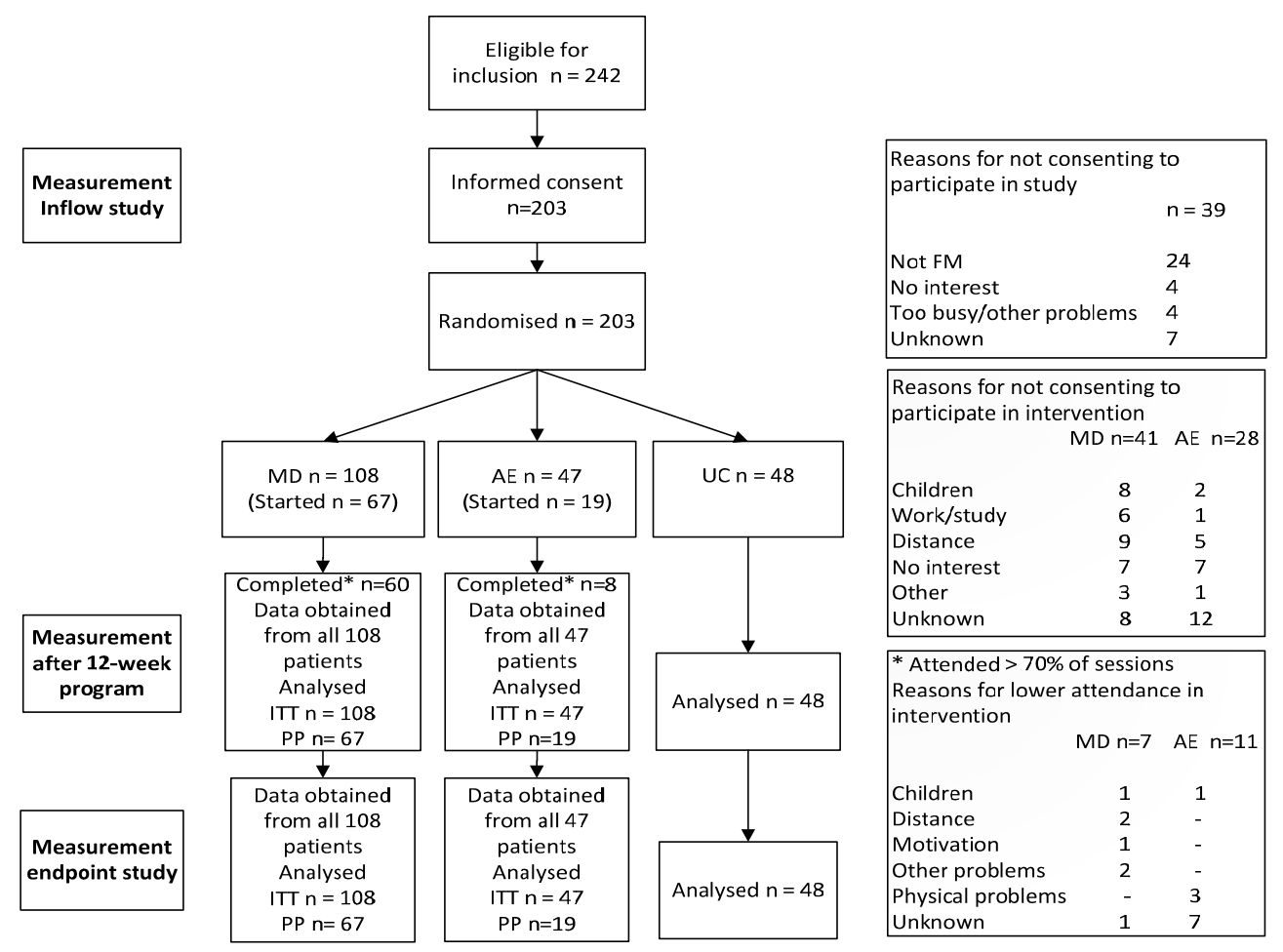

Figure 2.1 Study flowchart

MD multidisciplinary intervention, AE aerobic exercise, UC usual care

ITT intention-to-treat, PP per-protocol

Table 2.1 Characteristics study population at inflow in the study

\begin{tabular}{|c|c|c|c|c|c|}
\hline & \multicolumn{2}{|c|}{ MD $n=108$} & \multicolumn{2}{|c|}{$A E n=47$} & \multirow[t]{2}{*}{ UC $n=48$} \\
\hline & $\begin{array}{l}\text { Started } \\
n=67\end{array}$ & $\begin{array}{c}\text { Not } \\
\text { started } \\
n=41\end{array}$ & $\begin{array}{l}\text { Started } \\
\mathrm{n}=19\end{array}$ & $\begin{array}{c}\text { Not } \\
\text { started } \\
n=28\end{array}$ & \\
\hline Age, mean (SD), years & $41.6(8.8)$ & $41.3(11.0)$ & $43.9(7.6)$ & $39.1(9.6)$ & 42.9 (11.0) \\
\hline Female, $\%$ & 94.0 & 92.7 & 100 & 100 & 97.9 \\
\hline $\begin{array}{l}\text { Duration of FM-related symptoms } \\
\text { before diagnosis, mean (SD), years }\end{array}$ & $7.1(6.8)$ & $6.1(5.4)$ & $6.2(7.0)$ & $7.3(6.1)$ & $7.1(6.4)$ \\
\hline $\begin{array}{l}\text { Married/cohabiting, \% } \\
\text { Educational level, \% }\end{array}$ & 80.6 & 90.2 & 84.2 & 85.7 & 83.4 \\
\hline Low & 56.7 & 58.5 & 68.4 & 53.6 & 38.7 \\
\hline Medium & 29.9 & 31.7 & 26.3 & 35.7 & 40.9 \\
\hline High & 13.4 & 9.8 & 5.2 & 10.7 & 20.4 \\
\hline Employed, \% & 52.5 & 48.8 & 57.9 & 57.1 & 50.0 \\
\hline
\end{tabular}

MD multidisciplinary intervention, AE aerobic exercise. UC usual care 
Table 2.1 shows the characteristics of the study population at inflow in the study. Most participants were women and average FM-related symptom duration was seven years. Characteristics did not differ statistically significantly between patients who started the interventions and patients who did not start. As willingness to participate in the AE group was limited, this group has been analysed but interpretation of the data is considered arguable.

Overall, intention-to-treat analyses showed improvements within the MD group and small differences between the groups at the endpoint of the study. Per protocol-analyses differed to some extent, but showed similar trends, as is shown in the tables.

Within the MD group, statistically significant improvements were found in HR-Qol and improvements increased after finishing the 12-week program. Between the MD group and the UC group, a small, not statistically significant, difference at the endpoint of the study (ES $0.22, \mathrm{Cl}-0.12$ to 0.56 ) was found on the EQ-VAS in favour of the MD group (Table 2.2).

Table 2.2 Within-group and between-group results with regard to HR-Qol

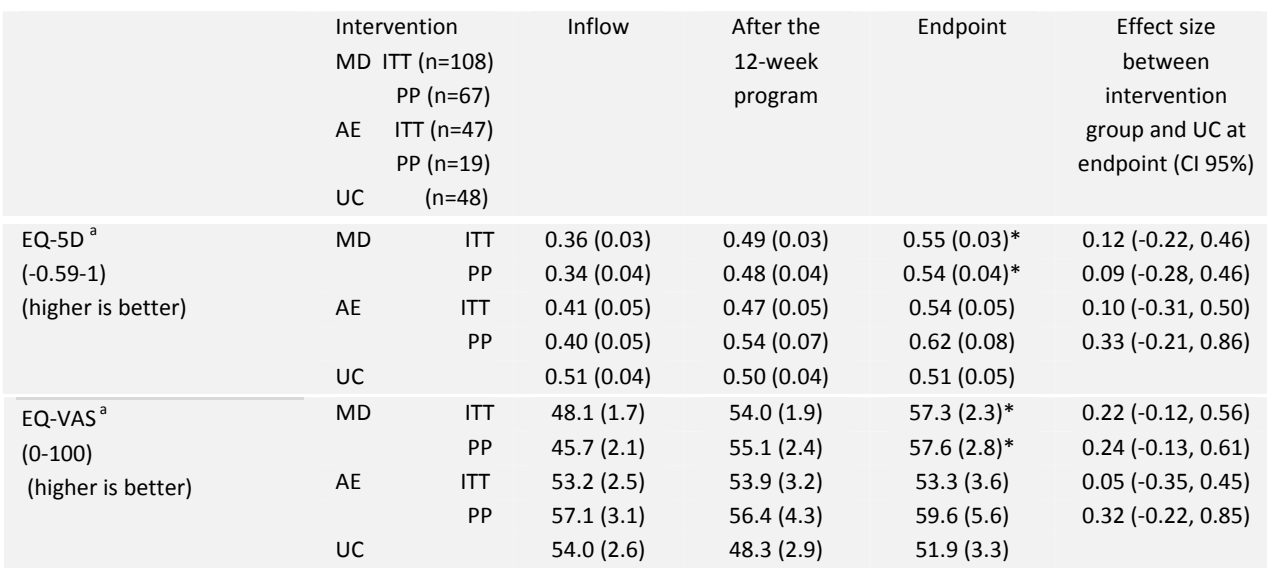

MD multidisciplinary intervention, AE aerobic exercise, UC usual care.

ITT intention-to-treat, PP per-protocol

$* \mathrm{p}<0.05$, difference within group; $* * \mathrm{p}<0.001$, difference within group

${ }^{a}$ Estimated marginal means (standard error) based on mixed model analysis with random intercept/random slope

Results for participation are presented in Table 2.3. Within the MD group, a statistically significant reduction of hours sick leave was found and this decrease continued in the course of the study. Between the MD group and the UC group, a small, not statistically significant, difference at the endpoint of the study (ES $-0.23, \mathrm{Cl}-0.57$ to 0.11 ) was found in hours unpaid tasks and chores. 
Table 2.3 Within-group and between-group results with regard to participation

\begin{tabular}{|c|c|c|c|c|c|c|}
\hline & $\begin{array}{l}\text { Inte } \\
\mathrm{MD} \\
\mathrm{AE}\end{array}$ & $\begin{array}{l}\text { rvention } \\
\text { ITT }(n=108) \\
\text { PP }(n=67) \\
\text { ITT }(n=47) \\
\text { PP } \quad(n=19)\end{array}$ & Inflow & $\begin{array}{l}\text { After the } \\
12 \text {-week } \\
\text { program }\end{array}$ & Endpoint & $\begin{array}{c}\text { Effect size } \\
\text { between } \\
\text { intervention } \\
\text { group and } \mathrm{UC} \text { at } \\
\text { endpoint ( } \mathrm{Cl} 95 \%)\end{array}$ \\
\hline & UC & $(n=48)$ & & & & \\
\hline \multirow{5}{*}{$\begin{array}{c}\text { Contractual hours paid work } \\
\text { per week }^{\text {b }}\end{array}$} & \multirow[t]{2}{*}{ MD } & ITT & $13.1(1.3)$ & $11.3(0.8)$ & $11.0(0.8)$ & $0.00(-0.34,0.34)$ \\
\hline & & PP & $13.4(1.7)$ & $10.2(1.0)$ & $10.1(1.0)$ & $-0.10(-0.47,0.27)$ \\
\hline & \multirow[t]{2}{*}{$\mathrm{AE}$} & $\mathrm{ITT}$ & $13.4(2.0)$ & $10.7(1.3)$ & $11.4(1.3)$ & $-0.01(-0.41,0.39)$ \\
\hline & & PP & $13.5(1.2)$ & $10.6(1.7)$ & 11.4 (1.9) & $0.04(-0.49,0.57)$ \\
\hline & \multicolumn{2}{|l|}{ UC } & $11.6(2.0)$ & $12.3(1.2)$ & $11.0(1.1)$ & \\
\hline \multirow[t]{5}{*}{ Hours sick leave per week ${ }^{b}$} & \multirow[t]{2}{*}{ MD } & ITT & $9.2(1.0)$ & $4.8(0.8)$ & $1.2(0.8)^{* *}$ & $0.13(-0.21,0.47)$ \\
\hline & & PP & $10.4(1.2)$ & $5.5(1.0)$ & $0.8(1.0)^{* *}$ & $0.18(-0.19,0.55)$ \\
\hline & \multirow[t]{2}{*}{$\mathrm{AE}$} & ITT & $5.8(1.2)$ & $3.4(1.2)$ & $2.5(1.2)$ & $0.04(-0.37,0.44)$ \\
\hline & & PP & $7.6(1.5)$ & $3.7(1.7)$ & $1.2(1.9)$ & $0.13(-0.40,0.66)$ \\
\hline & UC & & $3.3(1.2)$ & $3.7(1.2)$ & $2.3(1.0)$ & \\
\hline \multirow{5}{*}{$\begin{array}{l}\text { Hours unpaid tasks and } \\
\text { chores per week }^{b}\end{array}$} & \multirow[t]{2}{*}{ MD } & ITT & $33.6(2.2)$ & $28.4(1.8)$ & $27.6(1.8)$ & $-0.23(-0.57,0.11)$ \\
\hline & & PP & $29.2(2.7)$ & $26.1(2.2)$ & $27.4(2.2)$ & $-0.25(-0.62,0.12)$ \\
\hline & \multirow[t]{2}{*}{$\mathrm{AE}$} & ITT & $35.3(3.5)$ & $27.6(2.9)$ & $22.2(2.9)^{*}$ & $-0.56(-0.93,-0.11)$ \\
\hline & & PP & $35.0(3.6)$ & $23.1(4.1)$ & $16.5(4.4)^{*}$ & $-0.82(-1.37,-0.27)$ \\
\hline & UC & & $28.5(2.9)$ & $28.6(2.7)$ & $32.0(2.6)$ & \\
\hline \multirow{5}{*}{$\begin{array}{l}\text { Hours leisure and social } \\
\text { activities per week }{ }^{\text {b }}\end{array}$} & \multirow[t]{2}{*}{ MD } & ITT & $12.0(0.9)$ & $12.0(0.9)$ & $12.7(0.9)$ & $0.03(-0.31,0.37)$ \\
\hline & & PP & $12.4(1.2)$ & $13.0(1.1)$ & $12.7(1.1)$ & $0.03(-0.34,0.40)$ \\
\hline & \multirow[t]{2}{*}{$\mathrm{AE}$} & $\mathrm{ITT}$ & $10.7(1.2)$ & $11.3(1.4)$ & $10.3(1.4)$ & $-0.23(-0.61,0.20)$ \\
\hline & & PP & $10.2(1.4)$ & $11.7(1.9)$ & $9.9(2.1)$ & $-0.26(-0.80,0.27)$ \\
\hline & UC & & $12.4(1.4)$ & $12.5(1.4)$ & $12.4(1.3)$ & \\
\hline
\end{tabular}

MD multidisciplinary intervention, AE aerobic exercise, UC usual care.

ITT intention-to-treat, PP per-protocol

$* \mathrm{p}<0.05$, difference within group; ${ }^{* *} \mathrm{p}<0.001$, difference within group

b Estimated marginal means (standard error) based on mixed model analysis with random intercept

Table 2.4 shows the results with regard to health care utilisation. Within the MD group, a statistically significant reduction in number of contacts with GPs was found. Between the MD group and the UC group a small, not statistically significant, difference at the endpoint of the study (ES $-0.28, \mathrm{Cl}-0.66$ to 0.09 ) was found in favour of the UC group. Within both the MD and the UC group, a statistically significant reduction in number of contacts with medical specialists was found during the course of the study. Between the MD group and the UC group, a small, not statistically significant, difference at the endpoint of the study (ES -0.28, Cl -0.62 to 0.06 ) was found with regard to number of contacts with other paramedical professionals, in favour of the UC group. 
Table 2.4 Within-group and between-group results with regard to health care utilisation

\begin{tabular}{|c|c|c|c|c|c|c|}
\hline & $\begin{array}{l}\text { Inter } \\
\text { MD } \\
\text { AE } \\
\text { UC }\end{array}$ & \begin{tabular}{ll}
\multicolumn{2}{c}{ rvention } \\
ITT & $(n=108)$ \\
PP & $(n=67)$ \\
ITT & $(n=47)$ \\
PP & $(n=19)$ \\
& $(n=48)$
\end{tabular} & Inflow & $\begin{array}{l}\text { After the } \\
\text { 12- } \\
\text { week } \\
\text { program }\end{array}$ & Endpoint & $\begin{array}{c}\text { Effect size } \\
\text { between } \\
\text { intervention } \\
\text { group and } \mathrm{UC} \text { at } \\
\text { endpoint ( } \mathrm{Cl} 95 \%)\end{array}$ \\
\hline \multirow[t]{5}{*}{$\mathrm{Nr}$ of contacts GPs ${ }^{\mathrm{b} c}$} & MD & ITT & $2.3(0.3)$ & $1.0(0.2)$ & $0.9(0.2)^{* *}$ & $-0.11(-0.45,0.23)$ \\
\hline & & PP & $2.6(0.4)$ & $0.7(0.3)$ & $1.3(0.3)^{*}$ & $-0.28(-0.66,0.09)$ \\
\hline & $\mathrm{AE}$ & ITT & $3.3(0.8)$ & $1.5(0.4)$ & $1.0(0.4)^{*}$ & $-0.10(-0.48,0.32)$ \\
\hline & & PP & $4.0(0.9)$ & $1.7(0.5)$ & $1.0(0.6)$ & $-0.15(-0.68,0.39)$ \\
\hline & UC & & $1.4(0.3)$ & $0.5(0.3)$ & $0.7(0.3)$ & \\
\hline \multirow{5}{*}{$\begin{array}{l}\mathrm{Nr} \text { of contacts } \\
\text { medical specialists }{ }^{b c}\end{array}$} & MD & ITT & $1.9(0.1)$ & $0.1(0.1)$ & $0.3(0.1)^{* *}$ & $-0.14(-0.48,0.20)$ \\
\hline & & $\mathrm{PP}$ & $2.1(0.1)$ & $0.2(0.1)$ & $0.3(0.1)^{* *}$ & $-0.17(-0.54,0.20)$ \\
\hline & $\mathrm{AE}$ & ITT & $1.9(0.2)$ & $0.3(0.1)$ & $0.4(0.1)^{* *}$ & $-0.29(-0.58,0.22)$ \\
\hline & & PP & $1.9(0.1)$ & $0.3(0.2)$ & $0.2(0.2)^{* *}$ & $-0.03(-0.56,0.50)$ \\
\hline & UC & & $1.6(0.1)$ & $0.2(0.1)$ & $0.2(0.1)^{* *}$ & \\
\hline \multirow{5}{*}{$\begin{array}{l}\text { Nr of contacts } \\
\text { physiotherapists }{ }^{b c}\end{array}$} & MD & ITT & $2.7(0.5)$ & $2.2(0.5)$ & $2.6(0.5)$ & $0.04(-0.30,0.38)$ \\
\hline & & PP & $2.6(0.6)$ & $2.1(0.7)$ & $3.1(0.7)$ & $-0.06(-0.43,0.31)$ \\
\hline & $\mathrm{AE}$ & ITT & $1.9(0.2)$ & $0.3(0.1)$ & $0.4(0.1)^{* *}$ & $-0.29(-0.58,0.22)$ \\
\hline & & PP & $4.0(1.1)$ & $2.3(1.2)$ & $2.2(1.3)$ & $0.11(-0.42,0.64)$ \\
\hline & UC & & $1.0(0.5)$ & $3.4(0.7)$ & $2.8(0.7)$ & \\
\hline \multirow{5}{*}{$\begin{array}{l}\text { Nr of contacts } \\
\text { other paramedical } \\
\text { professionals }^{b c}\end{array}$} & MD & ITT & $1.1(0.3)$ & $0.8(0.3)$ & $1.0(0.3)$ & $-0.28(-0.62,0.06)$ \\
\hline & & PP & $1.3(0.4)$ & $0.7(0.4)$ & $1.3(0.4)$ & $-0.36(-0.73,0.02)$ \\
\hline & $\mathrm{AE}$ & ITT & $1.1(0.4)$ & $0.6(0.5)$ & $2.1(0.5)$ & $-0.68(-1.00,-018)$ \\
\hline & & PP & $0.7(0.6)$ & $0.7(0.6)$ & $0.4(0.7)$ & $-0.74(-1.28,-0.19)$ \\
\hline & UC & & $0.6(0.2)$ & $0.8(0.4)$ & $0.2(0.4)$ & \\
\hline
\end{tabular}

MD multidisciplinary intervention, AE aerobic exercise, UC usual care.

ITT intention-to-treat, PP per-protocol

$* \mathrm{p}<0.05$, difference within group; ${ }^{* *} \mathrm{p}<0.001$, difference within group

b Estimated marginal means (standard error) based on mixed model analysis with random intercept

c Total number consultations over a period of 2 months prior to measurement

Differences in impact of FM on daily functioning are presented in Table 2.5. Within the MD group, statistically significant improvements were found on almost all FIQ-subscales and on the FIQ-total score and improvements increased in the course of the study. Between the MD and the UC group a small, not statistically significant, difference at the endpoint of the study (ES $0.25, \mathrm{Cl}-0.09$ to 0.59 ) was found with regard to the FIQ-total score in favour of the MD group. 
Table 2.5 Within-group and between-group results with regard to impact of FM on daily functioning

\begin{tabular}{|c|c|c|c|c|c|c|}
\hline $\begin{array}{l}\text { Fibromyalgia Impact } \\
\text { Questionnaire }\end{array}$ & $\begin{array}{l}\text { Interven } \\
\text { MD ITT } \\
\text { PP } \\
\text { AE ITT } \\
\text { PP } \\
\text { UC }\end{array}$ & $\begin{array}{l}\text { tion } \\
(n=108) \\
(n=67) \\
(n=47) \\
(n=19) \\
(n=48)\end{array}$ & Inflow & $\begin{array}{l}\text { After the } \\
\text { 12-week } \\
\text { program }\end{array}$ & Endpoint & $\begin{array}{c}\text { Effect size } \\
\text { between } \\
\text { intervention group } \\
\text { and } \mathrm{UC} \text { at } \\
\text { endpoint( } \mathrm{Cl} 95 \%)\end{array}$ \\
\hline $\begin{array}{l}\text { Physical function }{ }^{a} \\
(0-10 \text {, lower is better) }\end{array}$ & UC & $\begin{array}{r}\mathrm{ITT} \\
\mathrm{PP} \\
\mathrm{ITT} \\
\mathrm{PP}\end{array}$ & $\begin{array}{l}4.2(0.2) \\
4.5(0.2) \\
3.6(0.2) \\
3.7(0.2) \\
3.4(0.3)\end{array}$ & $\begin{array}{l}3.9(0.2) \\
4.1(0.2) \\
3.7(0.3) \\
3.6(0.4) \\
4.0(0.3)\end{array}$ & $\begin{array}{l}3.6(0.2) \\
3.7(0.3) \\
3.6(0.4) \\
3.6(0.6) \\
3.9(0.3)\end{array}$ & $\begin{array}{l}0.12(-0.22,0.46) \\
0.08(-0.29,0.45) \\
0.11(-0.29,0.52) \\
0.12(-0.41,0.65)\end{array}$ \\
\hline $\begin{array}{l}\text { Days feel good }{ }^{a} \\
(0-10 \text {, lower is better })\end{array}$ & UC & $\begin{array}{r}\text { ITT } \\
\text { PP } \\
\text { ITT } \\
\text { PP }\end{array}$ & $\begin{array}{l}7.3(0.2) \\
7.8(0.3) \\
6.9(0.3) \\
6.9(0.5) \\
6.0(0.4)\end{array}$ & $\begin{array}{l}5.6(0.3) \\
5.7(0.3) \\
5.5(0.4) \\
5.0(0.6) \\
6.5(0.4)\end{array}$ & $\begin{array}{c}5.2(0.3)^{* *} \\
5.5(0.4)^{* *} \\
4.6(0.5) \\
4.5(0.8)^{*} \\
5.9(0.5)\end{array}$ & $\begin{array}{l}0.24(-0.10,0.58) \\
0.15(-0.22,0.52) \\
0.41(0.00,0.81) \\
0.44(-0.09,0.98)\end{array}$ \\
\hline $\begin{array}{l}\text { Days not missed work }{ }^{a} \\
(0-10, \text { lower is better })\end{array}$ & UC & $\begin{array}{r}\text { ITT } \\
\text { PP } \\
\text { ITT } \\
\text { PP }\end{array}$ & $\begin{array}{l}2.8(0.5) \\
3.6(0.7) \\
2.0(0.5) \\
2.8(0.9) \\
0.7(0.4)\end{array}$ & $\begin{array}{l}2.1(0.5) \\
2.4(0.6) \\
0.4(0.5) \\
0.5(0.8) \\
1.1(0.7)\end{array}$ & $\begin{array}{l}1.0(0.4)^{*} \\
0.5(0.6)^{*} \\
1.6(0.7) \\
1.7(1.0) \\
0.7(0.7)\end{array}$ & $\begin{array}{c}-0.06(-0.40,0.28) \\
0.04(-0.33,0.41) \\
-0.18(-0.59,0.22) \\
-0.21(-0.74,0.32)\end{array}$ \\
\hline $\begin{array}{l}\text { Job ability }{ }^{a} \\
(0-10 \text {, lower is better) }\end{array}$ & UC & $\begin{array}{r}\mathrm{ITT} \\
\mathrm{PP} \\
\mathrm{ITT} \\
\mathrm{PP}\end{array}$ & $\begin{array}{l}7.4(0.3) \\
8.0(0.3) \\
6.3(0.3) \\
5.9(0.4) \\
5.8(0.4)\end{array}$ & $\begin{array}{l}6.0(0.3) \\
6.4(0.4) \\
5.6(0.4) \\
6.0(0.6) \\
6.1(0.4)\end{array}$ & $\begin{array}{c}5.6(0.3)^{* *} \\
5.6(0.4)^{* *} \\
5.1(0.5) \\
4.3(0.8) \\
5.8(0.5)\end{array}$ & $\begin{array}{c}0.06(-0.28,0.40) \\
0.06(-0.31,0.43) \\
0.20(-0.20,0.60 \\
0.43(-0.10,0.97)\end{array}$ \\
\hline $\begin{array}{l}\text { Pain }{ }^{a} \\
(0-10 \text {, lower is better) }\end{array}$ & $\begin{array}{l}\text { AE } \\
\text { UC }\end{array}$ & $\begin{array}{r}\text { ITT } \\
\text { PP } \\
\text { ITT } \\
\text { PP }\end{array}$ & $\begin{array}{l}6.3(0.2) \\
6.3(0.2) \\
6.2(0.3) \\
6.1(0.3) \\
5.5(0.3)\end{array}$ & $\begin{array}{l}5.5(0.2) \\
5.4(0.2) \\
5.3(0.3) \\
5.3(0.4) \\
5.7(0.3)\end{array}$ & $\begin{array}{c}5.3(0.2)^{* *} \\
5.4(0.3)^{*} \\
5.2(0.4) \\
4.2(0.5) \\
5.3(0.3)\end{array}$ & $\begin{array}{c}-0.01(-0.35,0.33) \\
-0.06(-0.43,0.31) \\
0.05(-0.36,0.44) \\
0.46(-0.08,0.99)\end{array}$ \\
\hline $\begin{array}{l}\text { Fatigue a } \\
(0-10 \text {, lower is better) }\end{array}$ & UC & $\begin{array}{r}\text { ITT } \\
\text { PP } \\
\text { ITT } \\
\text { PP }\end{array}$ & $\begin{array}{l}8.3(0.2) \\
8.3(0.2) \\
8.0(0.2) \\
7.7(0.3) \\
7.4(0.3)\end{array}$ & $\begin{array}{l}7.5(0.2) \\
7.4(0.3) \\
7.4(0.2) \\
7.2(0.5) \\
7.2(0.3)\end{array}$ & $\begin{array}{c}7.0(0.3)^{* *} \\
7.2(0.3)^{*} \\
7.0(0.4) \\
6.0(0.6) \\
7.5(0.4)\end{array}$ & $\begin{array}{l}0.18(-0.16,0.52) \\
0.12(-0.25,0.49) \\
0.18(-0.22,0.59) \\
0.57(0.03,1.11)\end{array}$ \\
\hline $\begin{array}{l}\text { Unrefreshed sleep }{ }^{\text {a }} \\
(0-10, \text { lower is better })\end{array}$ & UC & $\begin{array}{r}\text { ITT } \\
\text { PP } \\
\text { ITT } \\
\text { PP }\end{array}$ & $\begin{array}{c}8.2(0.2) \\
8.5(0.2) \\
8.1(0.26) \\
7.7(0.3) \\
7.6(0.3)\end{array}$ & $\begin{array}{l}7.5(0.2) \\
7.3(0.3) \\
7.0(0.33) \\
6.8(0.5) \\
7.2(0.3)\end{array}$ & $\begin{array}{l}7.1(0.3)^{* *} \\
7.2(0.3)^{* *} \\
7.2(0.40)^{*} \\
6.3(0.6) \\
7.6(0.4)\end{array}$ & $\begin{array}{l}0.19(-0.15,0.53) \\
0.16(-0.21,0.53) \\
0.16(-0.60,0.90) \\
0.50(-0.04,1.03)\end{array}$ \\
\hline $\begin{array}{l}\text { Stiffness }{ }^{a} \\
(0-10, \text { lower is better) }\end{array}$ & UC & $\begin{array}{r}\mathrm{ITT} \\
\mathrm{PP} \\
\mathrm{ITT} \\
\mathrm{PP}\end{array}$ & $\begin{array}{l}7.1(0.2) \\
7.1(0.2) \\
7.3(0.2) \\
7.2(0.4) \\
6.8(0.4)\end{array}$ & $\begin{array}{l}6.7(0.2) \\
6.6(0.3) \\
6.2(0.3) \\
5.5(0.5) \\
6.3(0.3)\end{array}$ & $\begin{array}{l}6.1(0.3)^{*} \\
6.1(0.3) \\
5.9(0.4)^{*} \\
4.9(0.7) \\
6.3(0.4)\end{array}$ & $\begin{array}{l}0.07(-0.27,0.41) \\
0.07(-0.30,0.44) \\
0.14(-0.26,0.54) \\
0.49(-0.05,1.03)\end{array}$ \\
\hline $\begin{array}{l}\text { Anxiety }{ }^{a} \\
(0-10, \text { lower is better) }\end{array}$ & MD & $\begin{array}{r}\text { ITT } \\
\text { PP } \\
\text { ITT } \\
\text { PP }\end{array}$ & $\begin{array}{l}5.9(0.3) \\
6.0(0.3) \\
4.9(0.3) \\
5.2(0.4) \\
4.8(0.4)\end{array}$ & $\begin{array}{l}5.0(0.2) \\
4.9(0.3) \\
4.6(0.4) \\
4.9(0.6) \\
5.2(0.4)\end{array}$ & $\begin{array}{l}4.7(0.3)^{*} \\
4.4(0.4)^{*} \\
5.0(0.5) \\
4.9(0.7) \\
4.8(0.4)\end{array}$ & $\begin{array}{l}0.03(-0.31,0.37) \\
0.14(-0.24,0.51) \\
-0.06(-0.46,0.34) \\
-0.03(-0.56,0.50)\end{array}$ \\
\hline
\end{tabular}


Table 2.5 continued

\begin{tabular}{|c|c|c|c|c|c|c|}
\hline Depression $^{a}$ & MD & ITT & $5.2(0.3)$ & $4.1(0.3)$ & $3.9(0.3)^{*}$ & $0.10(-0.24,0.44)$ \\
\hline \multirow[t]{4}{*}{ (0-10, lower is better) } & & PP & $5.2(0.3)$ & $4.0(0.3)$ & $3.9(0.3)^{*}$ & $0.10(-0.27,0.47)$ \\
\hline & $\mathrm{AE}$ & $\mathrm{ITT}$ & $4.8(0.3)$ & $4.6(0.4)$ & $5.0(0.5)$ & $0.09(-0.31,0.49)$ \\
\hline & & PP & $4.9(0.4)$ & $4.1(0.6)$ & $3.6(0.7)$ & $0.20(-0.33,0.73)$ \\
\hline & UC & & $4.2(0.4)$ & $4.5(0.4)$ & $4.2(0.4)$ & \\
\hline FIQ-total ${ }^{a}$ & MD & ITT & $64.5(1.4)$ & $55.1(1.5)$ & $50.9(2.0)^{* *}$ & $0.25(-0.09,0.59)$ \\
\hline \multirow[t]{4}{*}{ ( $0-100$, lower is better) } & & PP & $66.3(1.8)$ & $54.6(1.9)$ & $51.2(2.3)^{* *}$ & $0.25(-0.12,0.62)$ \\
\hline & $\mathrm{AE}$ & ITT & $60.0(2.1)$ & $53.2(2.4)$ & $52.0(3.2)^{*}$ & $0.22(-0.20,0.61)$ \\
\hline & & PP & $59.2(2.5)$ & $52.3(3.6)$ & $47.4(4.7)$ & $0.42(-0.12,0.95)$ \\
\hline & UC & & $55.4(2.3)$ & $58.1(2.3)$ & $56.2(2.9)$ & \\
\hline
\end{tabular}

MD multidisciplinary intervention, AE aerobic exercise, UC usual care.

ITT intention-to-treat, PP per-protocol

$* p<0.05$, difference within group; $* * p<0.001$, difference within group

${ }^{a}$ Estimated marginal means (standard error) based on mixed model analysis with random intercept/random slope

\section{Discussion}

To our knowledge, this is the first trial in recently diagnosed FM patients examining the effect of a multidisciplinary intervention on HR-Qol, participation, and health care utilisation. Patients in the MD group experienced statistically significant improvements in HR-Qol and reduced their absence from paid work, visits to GPs and visits to medical specialists. Improvements were found immediately after completion of the intervention, largely sustained and even increased, also during the follow-up period which was one year after completion of the 2-phased program. Patients in the UC group experienced no changes in HR-Qol and only a statistically significantly reduction in the number of contacts with medical specialists was found. However, at the end of the study, the differences between the MD group and the UC group were small and not statistically significant for any of the outcomes studied.

Despite relevant improvements, HR-Qol was still low at the end of the trial confirming the large impact of FM on quality of life [34]. While overall health care utilisation tended to decrease, the high number of visits to physiotherapists during the study may be explained by the advice to perform physical activity and muscle training which was given in all groups as usual. In the Dutch health care system, patients may prefer reimbursed opportunities, like physiotherapy, above community programs. Results from interventions in FM patients with regard to health care utilisation are limited [35, 36]. It is arguable if diagnosing the disorder may have some treatment effect in itself [37]. However, improvements in the UC group suggest that it influenced our results with regard to the reduction in health care utilisation. Results on the FIQ are largely comparable with results from other studies but in contrast to other studies the found results sustained and even increased in the MD group, also during the follow-up period, which was one year after 
finishing the 2-phased program [11].

The MD intervention was characterised by a low attrition, resembling the situation in the pilot-study, which suggests that the treatment indeed has met the needs and expectations of the patients that consented to participate [14]. The limited consent to participate in the $A E$ group is similar to what was seen in other studies and suggests that $A E$ meets the needs of only a select group of FM patients [38]. We mainly aimed to study the impact of the intervention in patients in the early stages of the disease. Surprisingly, the mean symptom duration in the study population turned out to be seven years. Apparently, patients retrospectively recognised earlier symptoms as FM symptoms.

Some methodological challenges appeared in the study. First, in view of known difficulties to perform blinded or placebo-control group studies in multidisciplinary interventions, a Zelen-design was chosen in order to avoid bias by expectation. Following this design, patients were invited to participate in the interventions only after randomisation, immediately after they were diagnosed by the rheumatologist. Some patients asked for a time period to learn more about FM and to get more insight in their needs before starting the intervention. Consequently, they sometimes decided not to start after all. Although this likely reflects what happens in clinical practice it also affected the power of the study. More insight in the variation of expectations and attitudes from patients towards nonpharmacological interventions is needed, preferably in the light of available evidence about such interventions. An in-depth exploration of the patient's expectations and attitude may be an alternative for the Zelen-design to address the issue of expectationbias in future research on effective interventions for FM [39]. Expectation bias in RCTs is usually ignored since patients can refuse to participate when they are invited. Second, invariably the largest changes were found in the MD group. Despite randomisation, the MD group turned out to be group with the worst condition at inflow and thus had the largest potential for improvement. Although these data are suggestive for regression to the mean, the choice for mixed model analysis results in an accurate representation of the improvements over time. However, the baseline differences affect the interpretation of the study results as it cannot be excluded that improvements would have been similar if the groups were comparable at inflow in the study. Third, as in many studies, heterogeneity of the study population appeared. Some literature showed more homogeneity and promising results, due to selection of patients [40] or to intangible effects [41, 42]. However, given the large number of studies, discussion about the tools to classify FM patients into different phenotypic subgroups is still going on. Finally, when interpreting results it should be taken into account that these results apply to patients referred to rheumatology outpatient clinics and cannot be generalised to patients in other settings such as patients in a GP setting.

In summary, this pragmatic trial in recently diagnosed patients with FM, which comprised several outcomes of societal relevance, was not able to show statistically significantly 
between-group differences at the end of the study. The absence of between-group differences can be partially explained by both (a) a lack of statistical power of our study, attributable to a limited willingness for participation in the interventions, and (b) baselines between-group differences despite randomisation. Notwithstanding, the study findings do give insight in changes that occur in longitudinal outcomes, independent from interventions. They furthermore contribute to insight in barriers for the implementation of care programs for patients with FM. Methodological limitations of the study prevent to draw a firm conclusion about specific effects attributable to the multidisciplinary intervention. 


\section{References}

1. White KP, Harth M. Classification, epidemiology, and natural history of fibromyalgia. Curr Pain Headache Rep. 2001;5(4):320-9.

2. Wolfe F, Smythe HA, Yunus MB, et al. The American College of Rheumatology 1990 Criteria for the Classification of Fibromyalgia. Report of the Multicenter Criteria Committee. Arthritis Rheum. 1990;33(2):160-72.

3. Arnold LM, Crofford LJ, Mease PJ, et al. Patient perspectives on the impact of fibromyalgia. Patient Educ Counsel. 2008;73(1):114-20.

4. Assefi NP, Coy TV, Uslan D, Smith WR, Buchwald D. Financial, occupational, and personal consequences of disability in patients with chronic fatigue syndrome and fibromyalgia compared to other fatiguing conditions. J Rheumatol. 2003;30(4):804-8.

5. Boonen A, van den Heuvel R, van Tubergen A, et al. Large differences in cost of illness and wellbeing between patients with fibromyalgia, chronic low back pain, or ankylosing spondylitis. Ann Rheum Dis. 2005;64(3):396-402.

6. White KP, Speechley M, Harth M, Ostbye T. The London Fibromyalgia Epidemiology Study: comparing the demographic and clinical characteristics in 100 random community cases of fibromyalgia versus controls. J Rheumatol. 1999;26(7):1577-85.

7. White LA, Birnbaum HG, Kaltenboeck A, Tang J, Mallett D, Robinson RL. Employees with fibromyalgia: medical comorbidity, healthcare costs, and work loss. J Occup Environ Med. 2008;50(1):13-24.

8. Burckhardt CS. Multidisciplinary approaches for management of fibromyalgia. Curr Pharm Des. 2006;12(1):59-66.

9. Clauw DJ. Fibromyalgia: update on mechanisms and management. J Clin Rheumatol. 2007;13(2):102-9.

10. Hauser W, Bernardy K, Arnold B, Offenbacher M, Schiltenwolf M. Efficacy of multicomponent treatment in fibromyalgia syndrome: a meta-analysis of randomized controlled clinical trials. Arthritis Rheum. 2009;15;61(2):216-24.

11. van Koulil S, Effting M, Kraaimaat FW, et al. Cognitive-behavioural therapies and exercise programmes for patients with fibromyalgia: state of the art and future directions. Ann Rheum Dis. 2007;66(5):571-81.

12. van der Werf SP, de Vree B, Alberts $M$, van der Meer JW, Bleijenberg G. Natural course and predicting self-reported improvement in patients with chronic fatigue syndrome with a relatively short illness duration. J Psychosom Res. 2002;53(3):749-53.

13. Carville SF, Choy EH. Systematic review of discriminating power of outcome measures used in clinical trials of fibromyalgia. J Rheumatol. 2008;35(11):2094-105.

14. Kroese M, Schulpen G, Bessems M, Nijhuis F, Severens J, Landewe R. The feasibility and efficacy of a multidisciplinary intervention with aftercare meetings for fibromyalgia. Clin Rheumatol. 2009;28(8):9239.

15. Schwartz D, Lellouch J. Explanatory and pragmatic attitudes in therapeutical trials. J Chronic Dis. 1967;20(8):637-48.

16. Zelen M. A new design for randomized clinical trials. N Eng J Med 1979;300(22):1242-5.

17. Berne E. Transactional analysis: A new and effective method of group therapy. Am J Psychoth. 1958;12:735-43.

18. Berne E, Steiner CM, Dusay JM. Transactional analysis. In: Groves JE, (ed). Essential papers on short term dynamic therapy Essential papers in psychoanalysis. New York, NY, US: New York University Press;1996;149-70.

19. Ofman D. Core Qualities; a gateway to human resources. 2001. Schiedam: Scriptum;

20. Ellis A. Rational-emotive therapy. J Cont Psychoth. 1969;1(2):82-90.

21. Ellis A. Overcoming resistance: A rational emotive behavior therapy integrated approach (2nd ed.). New York, NY, US: Springer Publishing Co. 2002.

22. Rothschild BH. RET and chronic pain. In: Dryden W, Hill LK, (ed). Innovations in rational-emotive therapy. Thousand Oaks, CA, US: Sage Publications. 1993;91-115.

23. American, College, Sports, Medicine. Position Stand: The recommended quantity and quality of exercise for developing and maintaining cardiorespiratory and muscular fitness, and flexibility in healthy adults. Medicine \& science in sports \& exercise. 1998;30(975-991).

24. The EuroQol Group. EuroQol-a new facility for the measurement of health-related quality of life. Health Policy. 1990;16(3):199-208.

25. Dolan P. Modeling valuations for EuroQol health states. Medical care. 1997;35(11):1095-108. 
26. Post MWM. Utrechtse activiteitenlijst in: van Asbeck F.W.A. (ea) Handboek dwarslaesierevalidatie. Houten/Diegum: Bohn, Stafleu\&van Longum; 1998.

27. Goossens MEJB, Mölken MPMHR-v, Vlaeyen JWS, van der Linden SMJP. The cost diary: a method to measure direct and indirect costs in cost-effectiveness research. J Clin Epid. 2000;53(7):688.

28. Bennett R. The Fibromyalgia Impact Questionnaire (FIQ): a review of its development, current version, operating characteristics and uses. Clin Exp Rheumatol. 2005;23(5 Suppl 39):S154-62.

29. Burckhardt CS, Clark SR, Bennett RM. The fibromyalgia impact questionnaire: development and validation. J Rheumatol. 1991;18(5):728-33.

30. Tan FES. Best practices in analysis of longitudinal data: a multilevel approach. Jason W Osborne: Best practices in quantitative methods. Los Angeles: Sage publications; 2008;451-71.

31. Molenberghs G, Kenward ME. Missing Data in Clinical Studies.Chapter III 7: Wiley. 2007.

32. Cohen J. Statistical power analysis for the behavioral sciences. 2 ed. Hillsdale, NJ: Lawrence Erlbaum Associates. 1998.

33. Nakagawa S, Cuthill IC. Effect size, confidence interval and statistical significance: a practical guide for biologists. Biological review. 2007;82:591-605.

34. Verbunt JA, Pernot DH, Smeets RJ. Disability and quality of life in patients with fibromyalgia. Health Qual Life Outcomes. 2008;6:8.

35. Hammond A, Freeman K. Community patient education and exercise for people with fibromyalgia: a parallel group randomized controlled trial. Clin Rehabil. 2006;20(10):835-46.

36. Lorig KR, Ritter PL, Laurent DD, Plant K. The internet-based arthritis self-management program: a oneyear randomized trial for patients with arthritis or fibromyalgia. Arthritis Rheum. 2008;15;59(7):1009-17.

37. Kroese M, Severens J, Schulpen G, Bessems M, Nijhuis F, Landewe R. Specialized Rheumatology Nurse Substitutes for Rheumatologists in the Diagnostic Process of Fibromyalgia: A Cost-Consequence Analysis and a Randomized Controlled Trial. J Rheumatol. 2011;38(7):doi:10.3899/jrheum.100753.

38. van Santen M, Bolwijn P, Landewe R, et al. High or low intensity aerobic fitness training in fibromyalgia: does it matter? J Rheumatol. 2002;29(3):582-7.

39. Campbell M, Fitzpatrick R, Haines A, et al. Framework for design and evaluation of complex interventions to improve health. BMJ. 2000; 321: doi: 10.1136/bmj.321.7262.694.

40. van Koulil S, van Lankveld W, Kraaimaat FW, et al. Tailored cognitive-behavioral therapy and exercise training for high-risk fibromyalgia patients. Arthritis Care Res. (Hoboken) 2010;62(10):1377-85.

41. van Eijk-Hustings Y, Boonen A, Landewé R. A randomized trial of Tai Chi for fibromyalgia (author reply 2266-7). N Engl J Med. 2010;363(23); 2266-7.

42. Wang $\mathrm{C}$, Schmid $\mathrm{CH}$, Rones R, et al. A Randomized Trial of Tai Chi for Fibromyalgia. N Engl J Med 2010;363(8):743-54. 


\section{Chapter 3}

Course of cost-of-illness in recently diagnosed patients with fibromyalgia who are offered one of three different interventions in a pragmatic trial

Van Eijk-Hustings $\mathrm{Y}$, Kroese M, Creemers A, Landewé R, Boonen A.

Submitted. 


\section{Abstract}

Objective. The aim of this study was to understand the course of costs over a 2-year period in a cohort of recently diagnosed fibromyalgia patients who are offered one of three possible interventions.

Methods. Following the diagnosis, patients were assigned to a multidisciplinary program (MD), aerobic exercise (AE) or usual care (UC). Health care costs and costs for patients and families were collected by means of 2-monthly questionnaires. Mixed linear model analyses (MLM) were used to examine the course of costs over time. Linear regression was used to explore predictors of health care costs in the post treatment period.

Results. 203 participants, 90\% women, mean (SD) age 41.7 (9.8) years, were included in the cohort. Intervention costs per patient varied from $€ 864$ to $€ 1,392$ for $M D$, and were $€ 121$ for AE. Health care costs in each group decreased after diagnosis. MLM indicated that further health care costs, excluding the program costs of $M D$ and $A E$, increased again over time, but in the UC group this increase already started pre-treatment. In contrast, patient \& family costs increased over time in all groups without initial decrease after diagnosis. Annualised health care costs at post treatment varied between $€ 1,872$ and $€ 2,310$ per patient and were associated with worse functioning and high health care costs at diagnosis.

Conclusion. In patients with FM, health care costs decrease after diagnosis. Offering patients a specific treatment program after the diagnostic phase incurs substantial costs, and only marginally reduces the increase in costs that is seen in patients receiving UC. 


\section{Introduction}

Fibromyalgia (FM) is characterised by chronic widespread musculoskeletal pain, often accompanied by other clinical manifestations such as fatigue and stiffness, but also cognitive dysfunction or mood disorders [1, 2]. FM typically affects women in the working age. The prevalence of FM as reported among adults in Europe and in the US varies between $2 \%$ and $4 \%[3,4]$. While the aetiology of FM is unknown, the impact for the patient is high in terms of physical and mental suffering [5]. Moreover, FM is associated with substantial health care resource utilisation and productivity loss, resulting in considerable societal cost-of-illness [3, 6-8]. The average societal cost per patient of FM is comparable or even higher than of rheumatoid arthritis (RA) or ankylosing spondylitis (AS). When accounting for the prevalence, however, the societal burden of FM is higher than that of RA or AS $[9,10]$.

A variety of interventions have been studied, among which multi-modal nonpharmacological programs as well as pharmacological therapies [11, 12]. However, the effectiveness of these interventions showed conflicting results [13-17]. In the absence of substantial clinical effects, the cost-effectiveness of treatments in FM is disappointing. The importance of a prompt diagnosis and the start of an early intervention are increasingly recognised $[18,19]$, but results about effects of early interventions are limited to one randomised controlled trial on integrated group therapy that showed sustained improvement in patients with shorter disease duration [20]. Research based on claims databases suggested an influence of the diagnosis of FM itself on health care costs, but results are conflicting; two studies showed that a diagnosis of FM increases costs, primarily attributable to an increased use of medication in the course of the disease in usual care [21, 22], while two others suggested a reduction in costs attributable to a decrease in the number of visits to health care providers [23, 24]. The clinical burden of FM and the gaps of available evidence based treatment recommendations justify a continuous quest for innovations aimed at improving the outcomes [11, 12]. Such innovations should show effectiveness but also cost-effectiveness.

The present research aims to provide insight in costs over a 2-year period in a cohort of FM patients that were recently diagnosed by a rheumatologist and were assigned in a pragmatic trial to one of three different interventions: a partially individualised multidisciplinary intervention with aftercare (MD), aerobic exercise (AE) and usual care (UC).

\section{Methods}

A 2-year analysis of costs in a pragmatic trial embedded in an observational study. 


\section{Participants}

A cohort of 203 recently diagnosed FM patients (according to the American College of Rheumatology criteria) [1] from the Rheumatology Department were asked to participate in an observational study. Patients that consented were randomised to $M D(n=108), A E$ $(n=47)$, or $U C(n=48)$. Patients assigned to MD or $A E$ were again asked to consent to participate in the programs. The study was approved by the Medical Ethical Committees of the participating medical centres. The precise procedures in this pragmatic trial, registration number ISRCTN32542621, have been published elsewhere [25].

\section{Interventions}

The MD intervention program was a 2-phased group program of one year. Phase I consisted of a 12-week course (three half days per week) with two therapy sessions of 1,5 hours per day of socio-therapy, physiotherapy, psychotherapy or creative arts therapy. Phase II was an aftercare program that was provided over the course of the remaining year and consisted of five group meetings, scheduled over a period of nine months. In addition to these meetings, a maximum of seven individual therapy sessions with one of the therapists could be scheduled if considered necessary by the therapist and/or the patient. The AE intervention program was a 12-week group course which was given twice a week by a trained physiotherapist in a community gym, based on recommendations for exercise [26]. The UC arm received only 'care as usual' that comprised at least individualised education about FM and lifestyle advice by a rheumatologist or a specialised rheumatology nurse within one or two consultations, but could also include referral to other treatments, such as physiotherapy, or social support from the rheumatology nurse.

\section{Baseline variables}

Demographic characteristics (age, gender, education) and health status were assessed by means of patient-reported questionnaires at entry in the observational study. Health status comprised symptom duration and Fibromyalgia Impact Questionnaire (FIQ) that consists of 10 items on health in the past week: physical functioning, numbers of days feel good, number of days missed work, interference of symptoms with ability to activities, pain, fatigue, unrefreshed sleep, stiffness, anxiety, and depression [27]. Each item-score was standardised on a 0-10 scale after which a FIQ-total score (0-100) was calculated [27].

\section{Cost questionnaires and cost valuation}

Self-reported health care resource use and costs for patients and their families served as a basis for the cost analysis and were collected by means of a 2-monthly questionnaire over a total study period of two years. In each questionnaire patients had to indicate the number of visits to general practitioners (GPs), medical specialists, physiotherapists, and other paramedical therapists such as psychologists, the prescribed medication taken, the 
kind of assistive devices purchased, and the number of hours professional home help received during the two months prior to measurement [28]. Next, patients had to indicate the frequency with which they had participated in different types of health activities, the number and type of over the counter drugs that were purchased, the number of hours help from spouses, other relatives, or paid household help received, and the number of prepared meals used, during the two months prior to measurement [28].

From these items, costs were calculated. Health care costs were calculated by multiplying the number of each resource used with its unit cost, derived from the Dutch Cost Manual or the Pharmacoeconomic Compass. If prices were not available, market prices or tariffs were used [29-31]. With regard to 'patient \& family costs', the number of resources used were multiplied by patient reported price or unit costs, or, in the case of informal home care, by shadow prices [31]. Finally, total health care costs or patient \& family costs were calculated by summing the costs from each resource category. Costs for travel expenses per patient were included in the total costs for visits. Total direct costs were the sum of health care costs and patient \& family costs. All cost items and price values are presented in Table 3.1.

\section{Intervention costs}

The time input from all health care providers in the MD or AE group sessions were the basis of the calculation of all direct costs of the interventions. Total costs were calculated by summing the product of each hour of work by the salary per hour, including $39 \%$ charges for social security. For the total intervention period, $45 \%$ charges for overhead, such as for use of accommodation, were added [31]. Then, the total calculated costs for $M D$ or $A E$ were divided by the mean number of participants per group, resulting in a price per person per program. Intervention costs were included for every person that started the interventions, even if patients did not complete the programs. Again, costs for travel expenses were included in all visits. If the sources for costs provided a unit cost for a year before 2010, costs were indexed using the Dutch consumer price index rate (Centraal Bureau voor de Statistiek, Den Haag, Netherlands, www.cbs.nl) [31] (see Table 3.1).

\section{Periods of interest}

To understand the course of resource utilisation and average costs over different clinical meaningful episodes, we distinguished four periods: the diagnostic phase, representing the two months before referral to the rheumatologists and the rheumatologist's diagnosis of FM (diagnosis), the average 2-monthly costs in the period after the diagnosis, but before the intervention (pre-treatment), the costs during the intervention (during treatment) and the average 2-monthly costs in the period after the intervention (post treatment). The start of the MD and AE program varied in time among individual patients. As a consequence, the average number of questionnaires available for the period between 
diagnosis, but before the start of the MD or AE programs varied between 2 and 6, and after the programs between 5 and 9 , while the main intervention period itself was always represented by one questionnaire. Since the UC group did not receive a planned intervention, the number of questionnaires for each period of interest were randomly linked to respondents in either the MD group or the $A E$ group to achieve similar time periods.

Table 3.1 Cost categories, units and sources of estimate, costs in Euro $(€)$ per unit (including travelling expenses)

\begin{tabular}{|c|c|c|}
\hline Cost category & Source of estimate & Cost per unit, $€$ \\
\hline \multicolumn{3}{|l|}{ Interventions } \\
\hline \multicolumn{3}{|l|}{ Multidisciplinary program } \\
\hline Phase I: program & Hakkaart-van Roijen, calculated [31] & 863.94/program \\
\hline Phase II: aftercare & Hakkaart van Roijen, calculated [31] & $85.79 /$ program \\
\hline Individual socio therapy & Hakkaart-van Roijen, calculated [31] & $50.23 /$ contact \\
\hline Individual creative therapy & Hakkaart van Roijen, calculated [31] & $50.23 /$ contact \\
\hline Individual psychotherapy & Hakkaart-van Roijen, calculated [31] & $63.17 /$ contact \\
\hline Aerobic exercise & Hakkaart van Roijen, calculated [31] & 120.47/program \\
\hline \multicolumn{3}{|l|}{ Health care costs } \\
\hline \multicolumn{3}{|l|}{ General practitioner } \\
\hline Practice & Hakkaart-van Roijen [31] & $31.58 /$ contact \\
\hline Home visits & Hakkaart-van Roijen [31] & $43.56 /$ contact \\
\hline Telephone & Hakkaart-van Roijen [31] & $14.18 /$ contact \\
\hline Out of hours services, practice & Hakkaart-van Roijen [31] & $67.42 /$ contact \\
\hline Out of hours services, telephone & Hakkaart-van Roijen [31] & $26.26 /$ contact \\
\hline \multicolumn{3}{|l|}{ Medical specialist outpatient service } \\
\hline Academic & Hakkaart-van Roijen [31] & $135.08 /$ contact \\
\hline Not academic & Hakkaart-van Roijen [31] & $69.23 /$ contact \\
\hline \multicolumn{3}{|l|}{ Paramedical professionals } \\
\hline Physiotherapy & Hakkaart-van Roijen [31] & 39.91/contact \\
\hline Cesar or Mensendieck therapy & Hakkaart-van Roijen [31] & $38.90 /$ contact \\
\hline Occupational therapy & Hakkaart-van Roijen [31] & $38.90 /$ contact \\
\hline Social work & Hakkaart-van Roijen [31] & $69.29 /$ contact \\
\hline Activity therapy & Hakkaart-van Roijen, calculated [31] ${ }^{\text {(a) }}$ & 19.90/contact \\
\hline Psychotherapy & Hakkaart-van Roijen [31] & $82.96 /$ contact \\
\hline Other & Patient reported costs & Various/contact \\
\hline Prescribed medications & Pharmaco therapeutic compass 2007 [29] & Various/DDD ${ }^{(b)}$ \\
\hline Assistive devices & Estimated market price ${ }^{\text {(c) }}$ & Various \\
\hline Professional home help & Hours $[31]$ & $24.31 /$ hour \\
\hline \multicolumn{3}{|l|}{ Patient and family costs } \\
\hline Health activities & Patient reported costs & Various \\
\hline Over the counter medications & Patient reported costs & Various \\
\hline Prepared meals & Estimated market price & $7.26 /$ meal \\
\hline Paid home help & Patient reported costs & Various/hour \\
\hline Informal care & Hakkaart-van Roijen [31] & 12.66/hour \\
\hline
\end{tabular}

a. Group session, based on costs for social work: costs individual session/4, b. DDD: daily defined dosage

c. Various websites: www.thuiszorgwinkel.nl, www.groenekruisdomicurazorg.nl, www.medireva.nl 


\section{Statistical analysis}

Patients were analysed in the groups to which they were assigned. Missing data occurred during the course of the study (12\%-30\%), and in order to achieve complete data, missing data were imputed using a non-parametric regression forest method [32].

Health resource use and costs across treatment groups and time points are presented as means (SDs) or medians with interquartile ranges (IQR), or as percentages if appropriate. Mixed linear model analyses (MLM) were used to assess differences between the intervention groups in the longitudinal course of health care costs and patient \& family costs, with the baseline values of the dependent variables as covariates in the models. Mean between-group differences of the direct costs in and excluding intervention costs over the 2-year period were tested using a non-parametric bootstrap method to obtain $95 \%$ confidence intervals.

To explore predictors of the health care costs after the treatment program, a linear regression analysis on the square roots transformed costs was performed, entering as predictors age, symptom duration, educational level, FIQ-total score, and health care costs in the diagnostic phase. Data imputation was performed using R2.10.1 and all other analyses were performed using IBM SPSS Statistics 20.0.

\section{Results}

Baseline characteristics of the patients are presented in Table 3.2. The mean age was 41 years, and the majority of patients were female. Between $13 \%$ and $20 \%$, had a high educational level and about half of the patients were employed. Results on the effectiveness of the three interventions within this cohort have been published recently [25].

Table 3.2 Characteristics of the patients at entry into the observational cohort

$\begin{array}{lccc} & \text { MD } & \text { AE } & \text { UC } \\ & (n=108) & (n=47) & (n=48) \\ \text { Age, mean (SD), years } & 41.5(9.6) & 41.0(9.0) & 42.9(11.0) \\ \text { Female, \% } & 93.5 & 100 & 97.9 \\ \text { Duration FM-related symptoms, mean (SD), years } & 6.9(6.2) & 6.9(6.1) & 7.1(6.4) \\ \text { FIQ-total score (0-100), mean (SD) } & 64.5(13.7) & 60.0(12.3) & 55.4(15.1) \\ \text { Married or cohabiting, \% } & 84.2 & 85.1 & 83.4 \\ \text { Educational level, \% } & & & 38.7 \\ \quad \text { Low } & 56.9 & 57.8 & 40.9 \\ \quad \text { Medium } & 30.8 & 33.3 & 20.4 \\ \quad \text { High } & 12.3 & 8.9 & 50.0\end{array}$

MD multidisciplinary intervention, AE aerobic exercise, UC usual care

FIQ Fibromyalgia Impact Questionnaire 
The course of health care as well as patient \& family resource utilisation in the three groups is presented in Table 3.3.

Table 3.3 Health care and patient \& family resource use per patient

\begin{tabular}{|c|c|c|c|c|c|}
\hline $\begin{array}{l}M D n=108 \\
A E n=47 \\
\text { UC } n=48\end{array}$ & & Diagnosis & Pre-treatment ${ }^{A}$ & $\begin{array}{l}\text { During } \\
\text { treatment }\end{array}$ & Post treatment ${ }^{B}$ \\
\hline \multicolumn{6}{|l|}{ Health care } \\
\hline \multirow[t]{3}{*}{ GP } & $\mathrm{MD}$ & $2.3,1.0(0.0,3.0)$ & $1.0,0.5(0.0,1.3)$ & $1.2,1.0(0.0,1.8)$ & $1.1,0.8(0.3,1.6)$ \\
\hline & $\mathrm{AE}$ & $3.3,1.0(0.0,2.0)$ & $1.0,0.5(0.0,1.5)$ & $2.1,1.0(0.0,2.5)$ & $1.2,0.8(0.4,1.7)$ \\
\hline & UC & $1.4,1.0(0.0,2.0)$ & $0.4,0.0(0.0,0.5)$ & $0.5,0.0(0.0,0.5)$ & $0.8,0.9(0.3,1.1)$ \\
\hline \multirow{3}{*}{$\begin{array}{l}\text { Medical } \\
\text { specialists }\end{array}$} & MD & $2.0,2.0(1.0,2.0)$ & $0.3,0.0(0.0,0.4)$ & $0.2,0.0(0.0,0.2)$ & $0.5,0.2(0.0,1.0)$ \\
\hline & $\mathrm{AE}$ & $1.9,2.0(1.0,2.0)$ & $0.4,0.0(0.0,0.5)$ & $0.2,0.0(0.0,0.2)$ & $0.8,0.7(0.1,1.6)$ \\
\hline & UC & $1.6,1.5(1.0,2.0)$ & $0.4,0.0(0.0,0.5)$ & $0.4,0.0(0.0,0.6)$ & $0.5,0.4(0.0,0.9)$ \\
\hline \multirow[t]{3}{*}{ Physiotherapist } & MD & $2.7,0.0(0.0,4.0)$ & $1.8,0.0(0.0,2.0)$ & $2.3,0.0(0.0,2.3)$ & $3.2,2.1(0.3,5.3)$ \\
\hline & $A E$ & $2.9,0.0(0.0,4.0)$ & $2.2,0.0(0.0,4.0)$ & $2.2,1.0(0.0,1.3)$ & $2.3,1.7(1.1,2.1)$ \\
\hline & UC & $1.0,0.0(0.0,3.0)$ & $1.3,0.0(0.0,0.9)$ & $2.6,0.0(0.0,2.6)$ & $2.7,1.6(0.2,2.9)$ \\
\hline Other & MD & $1.1,0.0(0.0,0.0)$ & $0.6,0.0(0.0,0.6)$ & $0.8,0.0(0.0,0.9)$ & $1.9,0.9(0.0,4.1)$ \\
\hline paramedical & $A E$ & $1.1,0.0(0.0,1.0)$ & $1.2,0.5(0.0,1.8)$ & $1.0,0.0(0.0,1.7)$ & $2.0,1.9(0.2,3.5)$ \\
\hline professionals & UC & $0.6,0.0(0.0,0.0)$ & $1.2,0.0(0.0,1.0)$ & $1.2,0.0(0.0,2.6)$ & $1.6,1.3(0.0,3.1)$ \\
\hline \multirow[t]{3}{*}{ Formal home help } & MD & $0.1,0.0(0.0,0.0)$ & $0.2,0.0(0.0,0.0)$ & $0.4,0.0(0.0,0.0)$ & $0.4,0.0(0.0,0.0)$ \\
\hline & $\mathrm{AE}$ & $0.0,0.0(0.0,0.0)$ & $0.0,0.0(0.0,0.0)$ & $1.0,0.0(0.0,0.0)$ & $1.1,0.0(0.0,0.0)$ \\
\hline & UC & $0.1,0.0(0.0,0.0)$ & $0.1,0.0(0.0,0.0)$ & $0.6,0.0(0.0,0.0)$ & $0.5,0.0(0.0,0.0)$ \\
\hline Use prescribed & MD & 73.1 & 58.6 & 60.0 & 52.3 \\
\hline \multirow[t]{2}{*}{ drugs (\% yes) } & $A E$ & 59.6 & 60.5 & 56.3 & 53.0 \\
\hline & UC & 66.7 & 41.3 & 39.5 & 48.5 \\
\hline Use assistive & MD & 5.6 & 7.2 & 3.5 & 3.4 \\
\hline \multirow[t]{2}{*}{ devices (\% yes) } & $\mathrm{AE}$ & 2.1 & 5.8 & 6.3 & 5.5 \\
\hline & UC & 6.3 & 3.2 & 5.3 & 8.8 \\
\hline \multicolumn{6}{|l|}{ Patient \& family } \\
\hline \multirow[t]{3}{*}{ Paid home help } & MD & $0.1,0.0(0.0,0.0)$ & $0.1,0.0(0.0,0.0)$ & $0.0,0.0(0.0,0.0)$ & $0.3,0.0(0.0,0.5)$ \\
\hline & $\mathrm{AE}$ & $0.2,0.0(0.0,0.0)$ & $0.2,0.0(0.0,0.0)$ & $0.4,0.0(0.0,0.8)$ & $0.8,0.0(0.0,1.7)$ \\
\hline & UC & $0.0,0.0(0.0,0.0)$ & $0.2,0.0(0.0,0.0)$ & $0.1,0.0(0.0,0.0)$ & $0.1,0.0(0.0,0.2)$ \\
\hline \multirow[t]{3}{*}{ Informal care } & MD & $0.4,0.0(0.0,0.0)$ & $0.6,0.0(0.0,0.0)$ & $1.6,0.0(0.0,1.5)$ & $0.9,0.0(0.0,1.1)$ \\
\hline & $\mathrm{AE}$ & $0.1,0.0(0.0,0.0)$ & $0.7,0.0(0.0,0.5)$ & $1.2,0.0(0.0,1.3)$ & $1.1,0.4(0.0,1.6)$ \\
\hline & UC & $0.3,0.0(0.0,0.0)$ & $0.3,0.0(0.0,0.0)$ & $0.6,0.0(0.0,0.4)$ & $0.6,0.0(0.0,0.8)$ \\
\hline \multirow[t]{3}{*}{ Prepared meals } & MD & $0.0,0.0(0.0,0.0)$ & $0.0,0.0(0.0,0.0)$ & $0.1,0.0(0.0,0.0)$ & $0.0,0.0(0.0,0.0)$ \\
\hline & $\mathrm{AE}$ & $0.0,0.0(0.0,0.0)$ & $0.0,0.0(0.0,0.0)$ & $0.0,0.0(0.0,0.1)$ & $0.0,0.0(0.0,0.0)$ \\
\hline & UC & $0.0,0.0(0.0,0.0)$ & $0.0,0.0(0.0,0.0)$ & $0.0,0.0(0.0,0.0)$ & $0.0,0.0(0.0,0.0)$ \\
\hline \multirow{3}{*}{$\begin{array}{l}\text { Perform health } \\
\text { activities (\% yes) }\end{array}$} & MD & 24.1 & 21.7 & 29.4 & 33.1 \\
\hline & $\mathrm{AE}$ & 27.7 & 36.0 & 34.4 & 35.0 \\
\hline & UC & 16.7 & 28.6 & 39.5 & 18.8 \\
\hline Use over the & MD & 53.7 & 47.4 & 42.4 & 45.0 \\
\hline counter & $\mathrm{AE}$ & 40.4 & 37.2 & 31.3 & 31.3 \\
\hline medication (\%yes) & UC & 56.3 & 57.1 & 68.4 & 58.8 \\
\hline
\end{tabular}

MD multidisciplinary intervention, AE aerobic exercise, UC usual care

${ }^{A, B}$ Average 2-monthly mean, median (IQR) or percentages of resource use over the period 
Visits to GPs, medical specialists, physiotherapists and other paramedical professionals all decreased in each group after the diagnostic phase. In the AE group, visits to medical specialists and other paramedical professionals further decreased during the intervention program, whereas visits to the physiotherapist increased in the MD and UC group, and the use of formal home help increased in the three groups. After the intervention (post treatment), visits to medical specialists, physiotherapists and other paramedical professionals increased again in each group, but remained lower than in the diagnostic phase for visits to GPs, medical specialist, and medication utilisation, while becoming higher compared to pre-treatment for visits to physiotherapists, paramedical professionals and formal home care. With regard to patient \& family costs, the largest increase in costs was seen in attending health activities, and in need for help, e.g. paid home help or informal care.
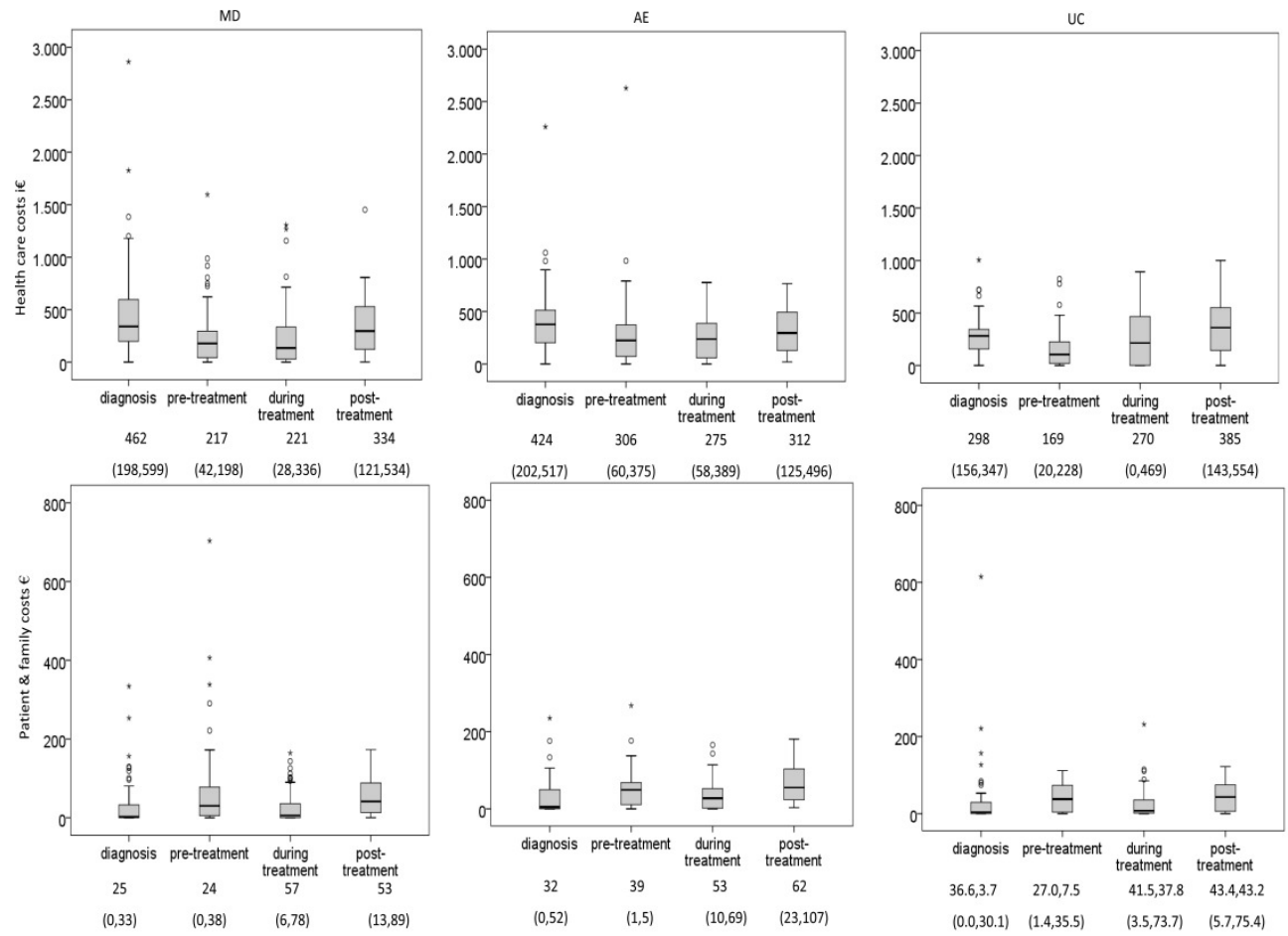

Figure 3.1 The course of health care costs and patient \& family costs The figure presents median, IQR, range and outliers. Costs per 2 month, averaged over the period MD multidisciplinary intervention, AE aerobic exercise, UC usual care

Figure 3.1 shows that the average health care costs, excluding intervention costs, decreased statistically significantly after diagnosis, but before the intervention program in all groups. During the intervention program, costs in the $A E$ group tended to decrease further and remained unchanged in the MD group, but showed a statistically significant 
increase in the UC group. Post treatment, health care costs increased in all groups, although not statistically significant in the AE group. MLM confirmed that time had a different influence on the course of costs in the three groups with statistically significant differences between the MD and UC group ( F = 2.6, $p=0.07)$ and between the AE and UC group ( $F=5.3, p=0.01$ ) (not presented). Patient \& family costs increased in the three groups. MLM indicated no statistically significant between-group differences.

While the changes during and after the intervention program were marginal, the intervention costs for MD were $€ 864$ per person in phase I; for phase II the price depended on the number of individual contacts but varied between $€ 86$ and $€ 528$ per person; for $A E$ the price was $€ 121$ per person. The resulting total direct costs per person (with and without program costs) over the total observation periods after the diagnostic phase are presented in Table 3.4. Total direct costs including the intervention costs were highest in MD. However, between-group differences were not statistically significant.

Table 3.4 Costs in $€$ per patient over the total 2 years after the diagnostic phase

\begin{tabular}{|c|c|c|c|c|c|}
\hline Costs & UC & MD & $\begin{array}{l}\text { Mean } \\
\text { difference } \\
\qquad(\mathrm{Cl}) \neq\end{array}$ & $A E$ & $\begin{array}{c}\text { Mean } \\
\text { difference } \\
(\mathrm{Cl}) \ddagger\end{array}$ \\
\hline Health care costs & $\begin{array}{c}3800,3625 \\
(1681,5788)\end{array}$ & $\begin{array}{c}3510,3151 \\
(1204,5294)\end{array}$ & $\begin{array}{c}-290 \\
(-1134,605)\end{array}$ & $\begin{array}{c}3594,3337 \\
(1990,5103)\end{array}$ & $\begin{array}{c}-207 \\
(-1207,806)\end{array}$ \\
\hline $\begin{array}{l}\text { Patient \& family costs } \\
\text { Total costs }\end{array}$ & $\begin{array}{c}452,453 \\
(100,710)\end{array}$ & $\begin{array}{c}565,426 \\
(147,937)\end{array}$ & $\begin{array}{c}113 \\
(-14,250)\end{array}$ & $\begin{array}{c}678,711 \\
(258,1030)\end{array}$ & $\begin{array}{c}227 \\
(60,388)\end{array}$ \\
\hline $\begin{array}{l}\text { Excluding intervention } \\
\text { costs }\end{array}$ & $\begin{array}{l}4252,3973 \\
(2054,6488)\end{array}$ & $\begin{array}{c}4075,3766 \\
(1872,6167)\end{array}$ & $\begin{array}{c}-177 \\
(-1095,767)\end{array}$ & $\begin{array}{c}4272,3725 \\
(2127,5788)\end{array}$ & $\begin{array}{c}20 \\
(-1067,1158)\end{array}$ \\
\hline $\begin{array}{l}\text { Including intervention } \\
\text { costs }\end{array}$ & $\begin{array}{c}4252,3973 \\
(2054,6488)\end{array}$ & $\begin{array}{c}4740,4510 \\
(2248,6651)\end{array}$ & $\begin{array}{c}488 \\
(-418,1458)\end{array}$ & $\begin{array}{c}4321,3725 \\
(2127,5788)\end{array}$ & $\begin{array}{c}69 \\
(-1025,1202)\end{array}$ \\
\hline
\end{tabular}

When exploring factors that contributed to the level of health care costs incurred by patients once the treatment programs were finished, it showed that high health care costs during the diagnostic phase and a high impact of FM (FIQ) already at entry in the cohort independently predicted post-program costs (see Table 3.5). 
Table 3.5 Prediction of cost in the post treatment period

\begin{tabular}{|c|c|c|c|c|c|c|c|}
\hline \multirow{2}{*}{$\begin{array}{l}\text { Predictors assessed at } \\
\text { diagnosis } \\
(n=203)\end{array}$} & \multicolumn{2}{|c|}{$\begin{array}{l}\text { Unstandardised } \\
\text { Coefficients }\end{array}$} & \multirow{2}{*}{$\begin{array}{l}\text { Standardised } \\
\text { Coefficients } \\
\text { Beta }\end{array}$} & \multirow[t]{2}{*}{$\mathrm{t}$} & \multirow[t]{2}{*}{$\mathrm{p}$-value } & \multicolumn{2}{|c|}{$\begin{array}{l}\text { 95.0\% Confidence } \\
\text { Interval }(\mathrm{Cl}) \text { for } \mathrm{B}\end{array}$} \\
\hline & B & $\begin{array}{l}\text { Std. } \\
\text { Error }\end{array}$ & & & & $\begin{array}{l}\text { Lower } \\
\text { Bound }\end{array}$ & $\begin{array}{l}\text { Upper } \\
\text { Bound }\end{array}$ \\
\hline (Constant) & 6.7 & 3.7 & & 1.8 & 0.07 & -0.595 & 14.065 \\
\hline FIQ-total score & 0.093 & 0.038 & 0.173 & 2.5 & 0.01 & 0.019 & 0.167 \\
\hline Health care costs & 0.004 & 0.001 & 0.187 & 2.7 & 0.01 & 0.001 & 0.007 \\
\hline Age & 0.080 & 0.054 & 0.104 & 1.5 & 0.14 & -0.025 & 0.186 \\
\hline Duration symptoms & 0.117 & 0.083 & 0.096 & 1.4 & 0.16 & -0.046 & 0.281 \\
\hline Education & -0.861 & 0.760 & -0.080 & -1.1 & 0.26 & -2.361 & 0.638 \\
\hline
\end{tabular}

\section{Discussion}

This article describes the course of costs in a cohort of patients that were referred to a rheumatologist who diagnosed them with FM, and offered patients, soon after the diagnosis, one of three interventions along a randomised pragmatic trial. It was found that health care costs decreased immediately following the diagnosis by the rheumatologists in each group, even before the start of specific treatment programs. However, during and after the treatment period the health care costs increased in all three groups, although not statistically significant in the AE group. Trends over time were different for the patient $\&$ family costs, where the initial decrease after diagnosis was not seen and where all groups showed a (non-significant) trend towards increase in costs in the further follow-up and completely independent of the treatment offered. The costs of the MD and $A E$ intervention program contributed substantially to the total costs in these groups.

Since we failed to show any effects of the interventions on different aspects of quality of life, including the 5-dimensional EuroQol (EQ-5D) [33] and FIQ in in our previously published study [25], a classical cost-minimisation study of the pragmatic trial could have been considered. However, such approach would have ignored the course of the costs incurred during diagnosis and the large decrease in costs after the diagnostic phase and before the start of a specific intervention program. Notwithstanding it is clear that the total direct costs including intervention costs tended to be higher (although not statistically significant) in the $\mathrm{MD}$ and $\mathrm{AE}$ group compared to the UC group, suggesting higher costs for similar effects.

The higher costs around the period of diagnosis likely reflect the unmet needs of patients for confirmation of the diagnosis and for a better treatment plan in a period that complaints are high; the decrease in costs (and improvement in health) could partially be attributed to regression to the mean. However, it cannot be excluded that the diagnosis itself contributes to (temporary) reassurance of patients and partly explains the reduction 
in consultations and costs following the diagnosis and even before the start of the treatment programs $[23,34]$. Our findings confirm results of studies that showed reduced costs due to a decreased number of visits to health care providers after diagnosis [23, 24]. Our study comprised a cohort of recently diagnosed patients, but in the cohort there was not necessarily a recent onset of FM. Likely, patients had been managed by their GPs during a longer period. Well trained GPs in the Netherlands can diagnose and manage FM appropriately [35], but it is recognised that some GPs avoid mentioning the diagnosis FM for several reasons. Apparently, a number of patients raise concerns about the exact diagnosis and about the treatment options and these patients can be referred to a rheumatologist.

Overall our study suggests that, also from a cost perspective, usual care is appropriate for many patients. In the usual care setting they receive information and education about healthy behaviour and coping strategies as well as some advice for physiotherapy in order to support healthy movement. Patients are encouraged to implement sports and pacing $[36,379]$. This seems to be confirmed by the increase in patient \& family costs: we found increased costs for participating in health activities, and for increased use of paid help and informal care in all three groups. Occasionally, patients are supported by the rheumatology nurse specialist and by health care professionals in primary care, or can be referred to multidisciplinary group programs, but our previously published study already showed that effects of additional interventions are negligible. Notwithstanding, we cannot exclude that within a group of recently diagnosed FM patients, a subgroup of patients might benefit from MD or $\mathrm{AE}$; an appropriate selection of patients for interventions may result in larger effects and may contribute to cost-effectiveness [38].

At the end of the observational study, the average 2-monthly health care costs per patient were between $€ 312$ and $€ 385$ per two months, which would be between $€ 1,872$ and $€ 2,310$ per year if we would annualise these costs. This is lower than reported in reviews on health care costs of patients with rheumatoid arthritis and ankylosing spondylitis that are under care of rheumatologists and were $€ 3,445$ and $€ 1,992$ per patient per year respectively [39], but in our study, costs for diagnostic procedures and inpatient costs were not included. Further analyses showed that a high impact of FM and high health care utilisation at study entry independently predicted high health care costs at the end of the observational study. While it is not surprising that higher experienced impact of disease results in more costs, it is also interesting to realise that those that were high utilisers of health care resources continued to be high utilisers. Resource utilisation and costs remain important and it remains challenging to gain further insight into the different FM phenotypes that would have a high chance to benefit from the different available interventions in order to reduce impact of disease and its costs.

Some limitations need to be addressed. We have used data from a cohort of patients participating in a trial and missing data occurred within the cohort. Missing data were 
carefully explored and were imputed. Of course, some level of uncertainty cannot be excluded. However, the advanced method that was used for the data imputation limits errors and contributes to valid data. Furthermore, we have analysed associations of baseline variables with high cost-of-illness after two years of follow-up, but the analysis explained only $12 \%$ of the variance, leaving a large proportion unexplained. Finally, we did not include indirect costs in our study. Only $50 \%$ of the patients were employed and this small sample would limit the possibility for a reliable assessment of the course of costs due to productivity loss.

In summary, our results show that after diagnosing FM, the use of health care resources decreases, and the slight increase afterwards is largely independent of the treatments offered. Given the absence of beneficial health effects but additional high intervention costs of $M D$ and $A E$, such treatments cannot be recommended for all patients with FM. Future research should focus on improved selection of patients that will benefit from specific health care innovations. 


\section{References}

1. Wolfe F, Smythe HA, Yunus MB, et al. The American College of Rheumatology 1990 Criteria for the Classification of Fibromyalgia. Report of the Multicenter Criteria Committee. Arthritis Rheum. 1990;33(2):160-72.

2. Wolfe F, Clauw DJ, Fitzcharles MA, et al. The American College of Rheumatology preliminary diagnostic criteria for fibromyalgia and measurement of symptom severity. Arthrit Care Res. 2010;62(5):600-10.

3. White LA, Birnbaum HG, Kaltenboeck A, et al. Employees with fibromyalgia: medical comorbidity, healthcare costs, and work loss. J Occup Environ Med. 2008;50(1):13-24.

4. Wolfe F, Ross K, Anderson J, Russell IJ, Hebert L. The prevalence and characteristics of fibromyalgia in the general population. Arthritis Rheum. 1995;38(1):19-28.

5. Arnold LM, Crofford L, Mease PJ, et al. Patient perspectives on the impact of fibromyalgia. Patient Educ Couns. 2008 Oct;73(1):114-20. PubMed PMID: 18640807. eng.

6. Wolfe F, Anderson J, Harkness D, et al. A prospective, longitudinal, multicenter study of service utilization and costs in fibromyalgia. Arthritis Rheum. 1997;40(9):1560-70.

7. Annemans L, Le Lay K, Taïeb C. Societal and Patient Burden of Fibromyalgia Syndrome. Pharmaeconomics. 2009;27(7):547-59.

8. Berger A, Dukes E, Martin S, et al. Characteristics and healthcare costs of patients with fibromyalgia syndrome. Int J Clin Practice. 2007;61(9):1498-508.

9. Boonen A, van den Heuvel $R$, van Tubergen A, et al. Large differences in cost of illness and wellbeing between patients with fibromyalgia, chronic low back pain, or ankylosing spondylitis. Ann Rheum Dis. 2005;64(3):396-402.

10. Silverman S, Dukes E, Johnston S, et al. The economic burden of fibromyalgia: comparative analysis with rheumatoid arthritis. Curr Med Res Opin. 2009;25(4):829-40.

11. Hauser W, Thieme K, Turk DC. Guidelines on the management of fibromyalgia syndrome - A systematic review. Eur J Pain. 2010;14(1):5-10.

12. Carville SF, Arendt-Nielsen S, et al. EULAR evidence-based recommendations for the management of fibromyalgia syndrome. Ann Rheum Dis. 2008;67(4):536-41.

13. Zijlstra TR, Braakman-Jansen LMA, Taal E, Rasker JJ, van de Laar MAFJ. Cost-effectiveness of Spa treatment for fibromyalgia: general health improvement is not for free. Rheumatol. 2007;46(9):1454-9.

14. Gusi N, Tomas-Carus P. Cost-utility of an 8-month aquatic training for women with fibromyalgia: a randomized controlled trial. Arthritis Res Ther. 2008;10(1):R24.

15. Choy E, Richards S, Bowrin K, et al. Cost effectiveness of pregabalin in the treatment of fibromyalgia from a UK perspective. Curr Med Res Opin. 2010;26(4):965-75.

16. Hauser W, Bernardy K, Arnold B, Offenbacher M, Schiltenwolf M. Efficacy of multicomponent treatment in fibromyalgia syndrome: a meta-analysis of randomized controlled clinical trials. Arthritis Rheum. 2009;61(2):216-24. P

17. van Koulil S, Effting M, Kraaimaat FW, et al. Cognitive-behavioural therapies and exercise programmes for patients with fibromyalgia: state of the art and future directions. Ann Rheum Dis. 2007;66(5):571-81.

18. Kroese MEAL, Schulpen GJC, Bessems MCM, et al. Substitution of specialized rheumatology nurses for rheumatologists in the diagnostic process of fibromyalgia: a randomized controlled trial. Arthrit Care Res. 2008;59(9):1299-305.

19. van der Werf SP, de Vree B, Alberts M, van der Meer JW, Bleijenberg G. Natural course and predicting self-reported improvement in patients with chronic fatigue syndrome with a relatively short illness duration. J Psychosom Res. 2002;53(3):749-53.

20. Keel PJ, Bodoky C, Gerhard U, Muller W. Comparison of integrated group therapy and group relaxation training for fibromyalgia. Clin J Pain. 1998;14(3):232-8.

21. White LA, Robinson RL, Yu AP, et al. Comparison of Health Care Use and Costs in Newy Diagnosed and Established Patients with Fibromyalgia. J Pain. 2009;10(9):976-83.

22. Sanchez RJ, Uribe C, Li H, et al. Longitudinal evaluation of health care utilization and costs during the first three years after a new diagnosis of fibromyalgia. CurrMed Res Opin. 2011;27(3):663-71.

23. Hughes G, Martinez C, Myon E, Taieb C, Wessely S. The impact of a diagnosis of fibromyalgia on health care resource use by primary care patients in the UK: an observational study based on clinical practice. Arthritis Rheum. 2006;54(1):177-83.

24. Annemans L, Wessely S, Spaepen E, et al. Health economic consequences related to the diagnosis of fibromyalgia syndrome. Arthritis Rheum. 2008;58(3):895-902. 
25. van Eijk-Hustings $Y$, Kroese $M$, Tan $F$, Boonen $A$, Bessems-Beks $M$, Landewé R. Challenges in demonstrating the effectiveness of multidisciplinary treatment on quality of life, participation and health care utilisation in patients with fibromyalgia. A randomised controlled trial. Clin Rheumatol 2013;32(2):199-209.

26. American, College, Sports, Medicine. Position Stand: The recommended quantity and quality of exercise for developing and maintaining cardiorespiratory and muscular fitness, and flexibility in healthy adults. Medicine \& science in sports \& exercise. 1998;30(975-991).

27. Bennett R. The Fibromyalgia Impact Questionnaire (FIQ): a review of its development, current version, operating characteristics and uses. Clin Exp Rheumatol. 2005;23(5 Suppl 39):S154-62.

28. Goossens MEJB, Mölken MPMHR-v, Vlaeyen JWS, van der Linden SMJP. The cost diary: a method to measure direct and indirect costs in cost-effectiveness research. J Clin Epid. 2000;53(7):688.

29. Pharmacotherapeutic compass 2007.

30. Estimated market price 2007.

31. Hakkaart-van Roijen L, Tan SS, Bouwmans CAM. Handleiding voor kostenonderzoek: geactualiseerde versie. Instituut voor Medical Technology Assessment, Erasmus Universiteit, Rotterdam: in opdracht van het College voor Zorgverzekeringen. 2010.

32. Breiman L. Random Forests. Machine Learning. 2001;45:5-32.

33. The EuroQol Group. EuroQol-a new facility for the measurement of health-related quality of life. Health Policy. 1990;16(3):199-208.

34. White KP, Nielson WR, Harth M, Ostbye T, Speechley M. Does the label "fibromyalgia" alter health status, function, and health service utilization? A prospective, within-group comparison in a community cohort of adults with chronic widespread pain. Arthritis Rheum. 2002;47(3):260-5.

35. Schulpen GJ, Vierhout WP, van der Heijde DM,et al. Joint consultation of general practitioner and rheumatologist: does it matter? Ann Rheum Dis. 2003;62(2):159-61.

36. van Eijk-Hustings $Y$, Bessems-Beks $M$, Kroese $M$. Samenwerken bij chronische pijn in het bewegingsapparaat: regionale multidisciplinaire richtlijn (in Dutch). 2011. Maastricht: Maastricht University Medical Centre.

37. van Eijk-Hustings $Y$, Kroese $M$, Bessems-Beks $M$, Landewé R, Vrijhoef B. Supporting healthcare professionals systematically to improve the quality and person-centeredness of fibromyalgia management in primary healthcare. Int J Pers Cent Med. 2012;2(4):837-44.

38. van Koulil S, van Lankveld W, Kraaimaat FW, et al. Tailored cognitive-behavioral therapy and exercise training for high-risk fibromyalgia patients. Arthritis Care Res (Hoboken). 2010;62(10):1377-85.

39. Franke LC, Ament AJ, van de Laar MA, Boonen A, Severens JL. Cost-of-illness of rheumatoid arthritis and ankylosing spondylitis. Clin Exp Rheumatol. 2009;27(4 suppl 55):S118-23. 


\section{Chapter 4 \\ Predictors for health improvement in patients with fibromyalgia: a 2-year follow-up study}

Van Eijk-Hustings $\mathrm{Y}$, Kroese M, Boonen A, Bessems-Beks M, Landewé R.

Clinical Rheumatology. 2013;doi: 10.1007/s10067-013-2371-7 [Epub ahead of print]. 


\section{Abstract}

Objective. Fibromyalgia (FM) has a high impact on all aspects of health. The effect from interventions is usually small and characterised by uncertainty. Better insight in predictors for improved health is essential. The present study aimed to understand predictors for patient global impression of change and changes in overall health.

Methods. Data from a longitudinal cohort of recently diagnosed FM patients $(n=203)$ were used. Within this cohort, patients were pre-randomised to either a multidisciplinary $(n=108)$, or an aerobic exercise $(n=47)$ program, or usual care $(n=48)$. Only a limited number of patients started with the programs $(n=86)$ or participated fully, i.e. attended $>$ $70 \%$ of the scheduled sessions $(n=68)$. Patients completed questionnaires covering all components of the International Classification of Functioning, Disability and Health (ICF) biopsychosocial model of health, which was used as a framework to structure potential predictors. Principal component analysis was used to reduce the number of potential predictors. Regression analyses were used to explore associations with the outcome variables.

Results. Principal component analysis yielded five factors representing areas that covered different ICF components and chapters. 'Being employed' and 'full participation in a program' were independently associated with a better global impression of change. A longer duration of FM-related symptoms and more limitations in physical areas of body functions were independently associated with a worse impression of overall health. Higher levels of perceived limitations in physical and mental activities were associated with 'starting to participate in a program' and with 'full participation in a program'.

Conclusion. Recently diagnosed FM patients that report fewer physical limitations may experience more improvement in health if they are at work and have a positive attitude towards participating in an offered health care intervention. These findings give support to an active rather than to a care-avoiding attitude of health care workers in their contacts to these patients. 


\section{Introduction}

Chronic disorders are often complex in nature and may have an impact on all aspects of life of an individual. Optimal management strategies of these disorders aim to maximise physical function and to minimise limitations [1]. Fibromyalgia (FM) is a disorder, characterised by chronic widespread musculoskeletal pain and associated symptoms such as fatigue, sleep disturbance, mood disorders, and cognitive dysfunction [2]. Guidelines for optimal management of FM emphasise a multimodal approach in which attention is given to physical and psychological distress [3, 4]. Evidence on the long-term efficacy of multicomponent therapies is limited [5]. Treatment effects are usually quite small, and heterogeneity in treatment response is a well-known complication in clinical trials of patients with FM [6]. In order to support appropriate treatment strategies, a better insight into factors that are associated with improvement or deterioration in health, as perceived by the patients, is required.

Apart from specific treatment, outcome in chronic illness is associated with many treatment-unrelated variables [7, 8]. In FM, socioeconomic status, pain, and fatigue are recognised risk factors for limitations in participation and sickness absence $[9,10]$. Being employed, and the ability to control one's own life, have been found to contribute to a better health state in patients [9], whereas psychological distress has been found to contribute to a poorer health state [11]. Self-efficacy and perceived control have been described as predictors of behavioral adaptations, symptom presentation and functioning and have been found of importance in self-management [12-14]. Catastrophising and pain-related anxiety have been found to promote fear-avoidant behaviour $[15,16]$, which in turn is associated with dysfunction [17].

One of the challenges in FM research is to define the most relevant outcome to assess the efficacy of interventions. Both the patient's global impression of change ( $\mathrm{PCl}-\mathrm{C}$ ) as well as overall health were considered appropriate measures for perceived health in this study. The Outcome Measures in Rheumatology (OMERACT) initiative has identified pain, fatigue, multidimensional functioning, and 'patient global' as relevant outcomes for clinical trials [18-20]. PGI-C has shown to discriminate between treatments in FM trials [20] and is correlated with instruments that measure the domains pain, fatigue, and multidimensional functioning [18]. Also, patients with FM have been found to feel seriously disabled, and the impact of their disorder on health-related quality of life (HRQol) is high [21, 22].

Another challenge in FM research is the number of highly interrelated outcome variables. A useful framework to study and structure these variables is the International Classification of Functioning, Disability and Health (ICF). This framework confirms that the impact of a disease on health is a result of complex interactions between the different components, including body functions and body structures, activities and participation on the one hand, as well as contextual factors on the other hand, represented by the 
environmental factors as well as personal factors [23, 24]. Body functions not only include physical functions such as muscle power functions and sensation of pain, but also mental functions such as emotional functions and content of thought. Activities and participation refer to carrying out daily routine such as work and employment, and doing housework. Environmental factors include interventions and the support of direct family members.

Personal factors refer to specific elements of the individual's background such as age and gender.

The present study aims to identify factors that may predict changes in perceived health, using the ICF framework as a format to structure these associations.

\section{Patients and methods}

\section{Study participants and design}

Data from a longitudinal cohort of recently diagnosed FM patients $(n=203)$, participating in a clinical trial that compared the effectiveness of multidisciplinary treatment to aerobic exercise or usual care, were used for this study. In the trial, patients between 18 and 65 years of age were asked to participate in an observational study after a diagnosis at the Rheumatology Departments of three medical centres in the South of the Netherlands (Maastricht University Medical Centre, Atrium Medical Centre, Heerlen, and Orbis Medical Centre, Sittard). Only after informed consent, patients were randomised to multidisciplinary treatment $(n=108)$, aerobic exercise $(n=47)$, or usual care $(n=48)$.

The multidisciplinary intervention was a 2-phase group program of one year in total. Phase I consisted of a 12-week course, three half days per week, with two therapy sessions of 1,5-hours duration per day of socio-therapy, physiotherapy, psychotherapy, and creative arts therapy. Phase II was an aftercare program and consisted of five groupmeetings, scheduled over a period of nine months. In addition to these meetings, a maximum of seven individual therapy sessions with one of the therapists could be scheduled if considered necessary by therapist and/or the patient. The aerobic exercise intervention consisted of a 12-week group program which was given twice a week by a trained physiotherapist in a community gym, based on recommendations for exercise [25]. The usual care arm received care that comprised at least individualised education about FM and lifestyle advice by a rheumatologist or a specialised rheumatology nurse in one or two consultations, but could, if considered necessary, also include a diversity of other treatments such as physiotherapy, or social support from the rheumatology nurse. Patients were not aware of the other treatment arms and were only informed about the observational study. In the trial, only a limited number of patients $(n=86)$ started with the allocated program and 68 patients participated fully in the programs, i.e. attended $>70 \%$ of the scheduled sessions (see Figure 4.1). Data from all patients that participated in the observational study were used for the present analyses. The precise procedures in the trial as well as the results regarding effectiveness are described elsewhere [26]. 


\section{Data collection}

After giving informed consent for participation in the observational study, all 203 patients received questionnaires at baseline and at the endpoint, at two years of follow-up. The questionnaires comprised all self-reported outcome measures. Demographic characteristics were included in the questionnaires at baseline.

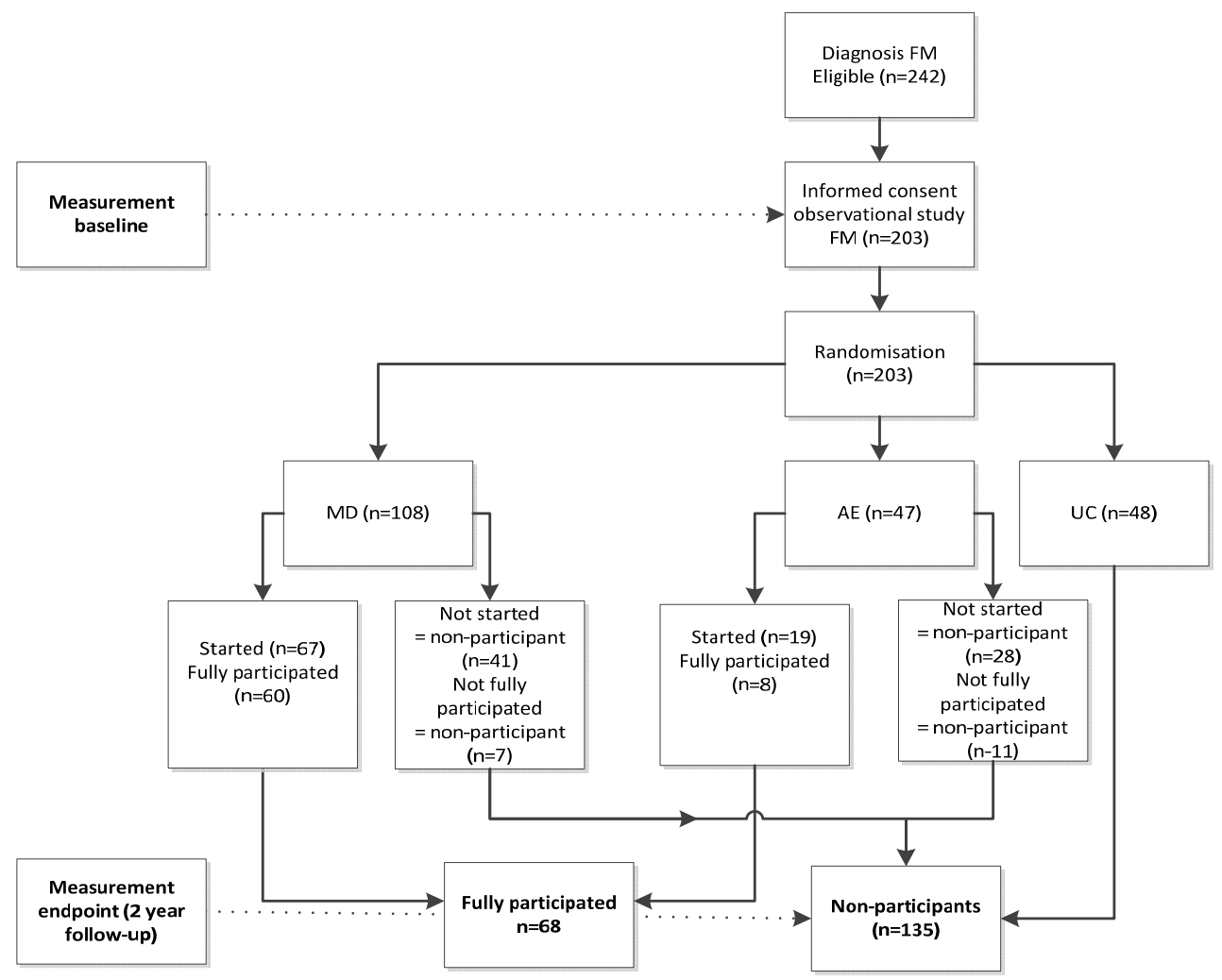

Figure 4.1 Study flowchart

MD multidisciplinary program, AE aerobic exercise, UC usual care

Fully participated: attended $>70 \%$ of the scheduled sessions in an intervention. Non-participants: did not start intervention, or attended $<70 \%$ of the scheduled sessions, or were assigned to usual care

\section{Outcome variables}

PGI-C was assessed by asking 'How are you, compared to the moment you were told to have FM ?'. The patient's rating of change was given on a categorical scale: 1 (completely cured), 2 (much improved), 3 (minimally improved), 4 (no change), 5 (minimally worse), 6 (much worse), and 7 (worst ever). Subsequently, rates 1, 2, and 3 were categorised as 1 (improved), and rates 4 to 7 were categorised as 0 (not improved). 
Change in overall health was measured by the Visual Analogue Scale of the EuroQol (EQVAS) $[27,28]$. The EQ-VAS is an instrument for self-rating current health and ranges from 0 (worst possible health) to 100 (best possible health). The score at baseline was compared to the score at the endpoint of the study.

\section{Potential predictors}

A large number of potential predictors were included, and their position in the ICF framework shows the broadness in the construct of health, related to FM that was covered (see Figure 4.2) [24].

\section{Health}

duration symptoms

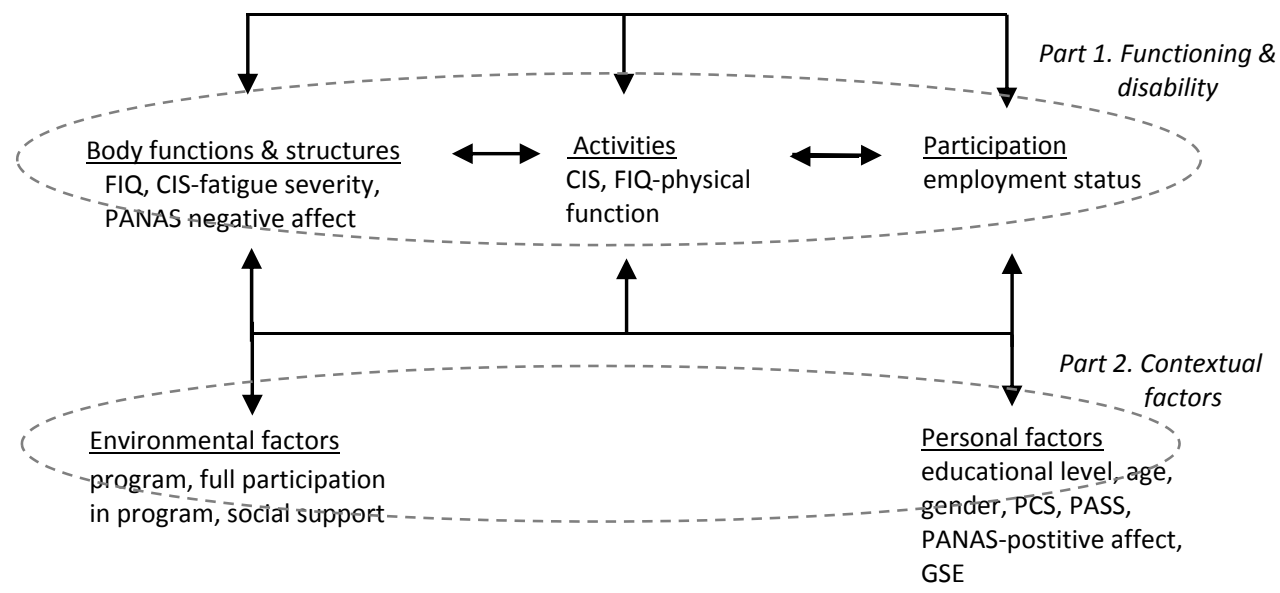

Figure 4.2 The ICF framework with variables used in the analyses

Duration of FM-related symptoms in years and personal demographic factors at baseline that comprised age, gender, employment status, and educational level, were included.

In addition, physical and mental functioning was measured by the Fibromyalgia Impact Questionnaire (FIQ) [29]. The FIQ is a multidimensional instrument and consists of 10 subscales, measuring self-reported function. The 10 subscales concern physical function, days feel good, days missed work, job ability, pain, fatigue, unrefreshed sleep, stiffness, anxiety, and depression in the past week. Each subscale was standardised on a 0-10 scale with higher scores indicating greater impairment [29]. Self-efficacy was measured by the General Self-Efficacy scale [30], higher scores indicate better self-efficacy. Fatigue was measured by the Checklist Individual Strength (CIS-20) [31], which covers four dimensions of fatigue: fatigue severity, motivation, concentration, and physical activity level. Higher scores indicate more fatigue, reduced motivation, more concentration problems, and less activity. Catastrophising was measured by the Pain Catastrophising Scale (PCS) [32], which comprises three components: rumination, magnification, and helplessness. Higher scores 
indicate higher levels of catastrophising. Personality trait was measured by the Positive and Negative Affect Schedule (PANAS) [33]. Higher scores indicate higher positive or negative affect. Fear of pain and anxiety responses to pain were measured by the Pain Anxiety Symptoms Scale (PASS-20) [34]. The PASS-20 is a 4-dimensional questionnaire regarding anxiety responses to pain: cognitive anxiety responses, escape and avoidance behaviour, fear, and physical reactions. Higher scores indicate higher levels of pain-related anxiety responses. Finally, we asked if patients experienced social support by the question 'Does your partner give support in household or care tasks?' In addition, participation in the $\mathrm{MD}$ and in the AE program was registered. Patients that stopped with the intervention and those attending less than $70 \%$ of the scheduled sessions were considered as 'nonparticipants'. Some patients declined the invitation to participate in an intervention and were also considered 'non-participants'.

\section{Statistical analyses}

First, principal component analysis (PCA) was used to group the large number of potentially associated variables into a limited number of meaningful factors. The obtained factor loadings represent the relative importance of each variable for that factor, and were used in the further statistical analyses. Internal consistency of the resulting factors was assessed by Crohnbach's alpha $(\alpha)$. When assigning names to the PCA factors, strict ICF terminology could not be easily applied since one factor included (domains of) questionnaires that covered more ICF chapters, and some subscales could cover actually more ICF components. Notwithstanding, the names chosen for the PCA factors remained faithful to the ICF concept and terminology. Then, simple associations of disease duration, the personal demographic variables, interventions (type to which randomised and participation in the assigned program), and the baseline values of the obtained factor scores with PGI-C and with changes in overall health after two years were explored. The variables that showed statistically significant associations in the simple analyses were used in multivariate logistic and linear regression models.

To obtain more insight in patients' willingness to participate in a program, logistic regression analyses were performed with 'starting participation' and 'full participation' as dependent variables, and the baseline values of the obtained factor scores as independent variables. Missing data (21.7\%) were imputed using a linear trend-to-point procedure. Data were analysed using SPSS version 18.0 (SPSS Inc., Chicago, IL). 


\section{Results}

Table 4.1 presents baseline characteristics of the study population. Demographic characteristics showed a 'usual' FM population of predominantly female patients. Mean age was 42 years and more than $50 \%$ of the patients were at work. In general, the impact of FM on daily life was reported to be substantial. Patients showed on average a high level of fatigue and a poor current health state. Patients that participated fully in the MD program showed a statistically significantly lower level of self-efficacy $\quad(-2.3$ (95\% confidence interval ( $\mathrm{Cl}) 0.6$ to 4.1)) and a statistically significantly higher level of fatigue (7.2 (-14.3 to -0.3$)$ ), compared to those that did not participate. Other differences were not statistically significant.

Table 4.1 Baseline characteristics and potentially associated variables

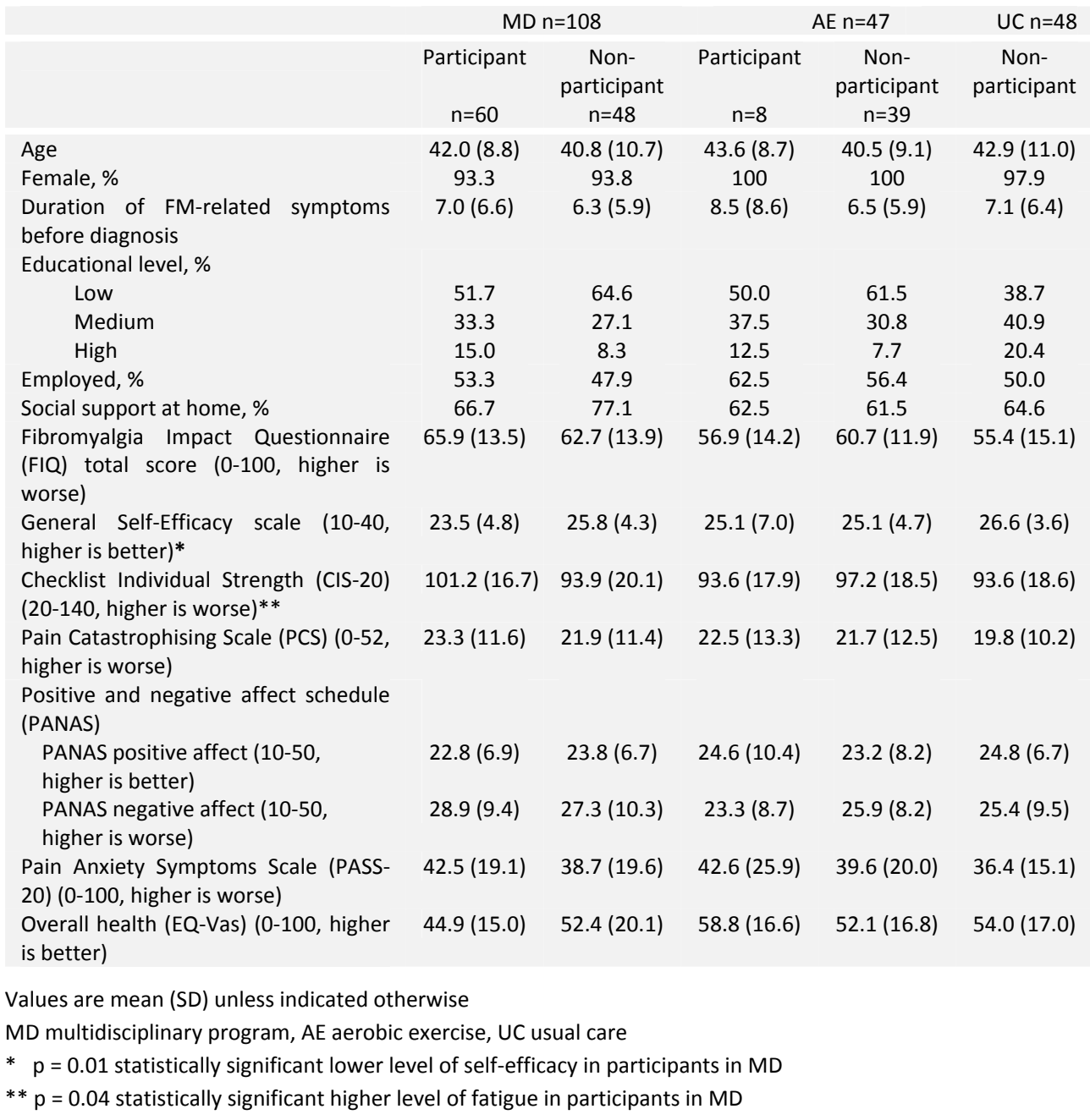


PCA yielded five distinguishable factors that are presented in Table 4.2. The internal consistency was moderate to good (Crohnbach's $\alpha$ ranging from 0.51 to 0.91 ).

Table 4.2 Factors, internal consistency (Crohnbach's $\alpha$ ) and factor loadings of the predictor variables

\begin{tabular}{|c|c|c|c|c|c|}
\hline \multirow[t]{2}{*}{ Questionnaire/subscale } & \multicolumn{5}{|c|}{ Factor } \\
\hline & $\begin{array}{c}\text { Body } \\
\text { functions; } \\
\text { physical }\end{array}$ & $\begin{array}{c}\text { Body } \\
\text { functions; } \\
\text { mental }\end{array}$ & $\begin{array}{c}\text { Activities; } \\
\text { physical or } \\
\text { mental }\end{array}$ & $\begin{array}{l}\text { Personal } \\
\text { factor; } \\
\text { (barrier) } \\
\text { Believes } \\
\text { about pain }\end{array}$ & $\begin{array}{c}\text { Personal } \\
\text { factor; } \\
\text { (facilitator) } \\
\text { Positive } \\
\text { attitude }\end{array}$ \\
\hline Crohnbach's $\alpha$ & 0.67 & 0.62 & 0.51 & 0.91 & 0.69 \\
\hline FIQ unrefreshed sleep & 0.80 & & & & \\
\hline FIQ stiffness & 0.76 & & & & \\
\hline FIQ fatigue & 0.74 & & & & \\
\hline FIQ job ability & 0.58 & & & & \\
\hline FIQ pain & 0.58 & & & & \\
\hline FIQ days feel good & 0.57 & & & & \\
\hline CIS fatigue severity & 0.58 & & & & \\
\hline FIQ anxiety & & 0.76 & & & \\
\hline FIQ depression & & 0.63 & & & \\
\hline PANAS negative affect & & 0.56 & & & \\
\hline CIS physical activity level & & & 0.82 & & \\
\hline CIS concentration & & & 0.63 & & \\
\hline FIQ physical function & & & 0.47 & & \\
\hline PCS magnification & & & & 0.87 & \\
\hline PCS helplessness & & & & 0.85 & \\
\hline PCS rumination & & & & 0.83 & \\
\hline PASS fear & & & & 0.80 & \\
\hline PASS cognitive reactions & & & & 0.75 & \\
\hline PASS escape & & & & 0.72 & \\
\hline PASS physical reactions & & & & 0.68 & \\
\hline PANAS positive affect & & & & & 0.88 \\
\hline CIS motivation & & & & & 0.76 \\
\hline General Self-Efficacy & & & & & 0.41 \\
\hline
\end{tabular}

The subscales 'unrefreshed sleep', 'stiffness', 'fatigue', 'job ability', 'pain', and 'days feel good' of the FIQ and the subscale 'fatigue severity' of the CIS-20 all loaded on one factor that covered physical aspects within the ICF component 'body functions and structures'. The subscales 'anxiety' and 'depression' of the FIQ and the 'PANAS negative affect' loaded on a factor that covered the mental aspects within the ICF component 'body functions and structures'. The subscales 'physical activity level' and 'concentration' of the CIS-20 and the subscale 'physical function' of the FIQ loaded on a factor covering physical and mental aspects within the ICF component 'activities and participation'. All subscales of the PCS and the PASS-20 loaded on the factor 'believes about pain', which, although not yet formally classified in the ICF, are accepted to represent a personal factor [35] and in the literature are considered to be barriers for functioning. On the same line, the 'PANAS positive affect', the subscale 'motivation' of the CIS-20 and the 'General Self-Efficacy scale' loaded on a factor 'positive attitude', also accepted to be a personal factor in the ICF [35], 
but considered a facilitator for functioning. Overall, simple associations with PGI-C and changes in overall health were only weak or moderate. 'Being employed' (r. 0.18) and 'being assigned to the multidisciplinary program' (r. 0.21) were weakly associated with a higher global impression of change, and 'full participation in a program' (r. 0.40) was moderately associated with a higher global impression of change. A longer duration of symptoms (r. -0.24), and limitations in 'activities, physical or mental' (r. -0.14), were weakly associated with a worse impression of overall health. Limitations in "body functions, physical' (r. -0.33) were also moderately associated with a worse impression of overall health, whereas being employed ( $r 0.17)$, and a high educational level ( $r 0.14)$ were weakly associated with an improved impression of overall health. An overview of all associations with PGI-C and changes in overall health is available in Table 4.3.

Table 4.3 Overview of all simple correlation coefficients with the outcomes

\begin{tabular}{|c|c|c|}
\hline & $\begin{array}{l}\text { Improved patient global impression } \\
\text { of change } \\
\text { (Spearman's rho) }\end{array}$ & $\begin{array}{c}\text { Overall } \\
\text { health after } 2 \text { years } \\
\text { (Pearson's rho) }\end{array}$ \\
\hline Age & -0.07 & -0.04 \\
\hline Duration symptoms & -0.12 & $-0.24^{b}$ \\
\hline Gender (female) & 0.02 & 0.09 \\
\hline Employed & $0.18^{\mathrm{a}}$ & $0.17^{\mathrm{a}}$ \\
\hline \multicolumn{3}{|l|}{ Educational level } \\
\hline Low & -0.12 & -0.10 \\
\hline Medium & 0.05 & 0.01 \\
\hline High & 0.10 & $0.14^{a}$ \\
\hline Social support & 0.07 & -0.07 \\
\hline \multicolumn{3}{|l|}{ Allocated itervention } \\
\hline Multidisciplinary & $0.21^{\mathrm{b}}$ & 0.05 \\
\hline Aerobic exercise & -0.11 & -0.01 \\
\hline Full participation in an intervention & $0.40^{\mathrm{b}}$ & 0.11 \\
\hline Body functions, physical & -0.10 & $-0.33^{b}$ \\
\hline Body functions, mental & 0.02 & -0.07 \\
\hline Activities, physical and mental & 0.01 & $-0.14^{a}$ \\
\hline Believes about pain & 0.01 & -0.11 \\
\hline Positive attitude & -0.09 & -0.04 \\
\hline Baseline value overall health & 0.001 & $0.38^{\mathrm{b}}$ \\
\hline
\end{tabular}

With regard to $\mathrm{PGI}-\mathrm{C}, 30.0 \%$ of the patients reported improvement but $70.0 \%$ of the patients did not improve. In the latter group of patients, $29.6 \%$ reported no changes and $40.4 \%$ reported worsening compared to the moment they received a diagnosis of FM. Multivariate analyses showed that the odds of patients to improve on global impression of change was 2.4 times higher (odds ratio (OR), 2.4 (1.2 to 4.8)), for those being employed in comparison to those being unemployed, and the odds of patients to improve on global impression of change was 6.4 times higher (OR, 6.4 (2.9 to 14.5)) for patients fully participating in a program than for non-participants (see Table 4.4). 
Table 4.4 Multivariate analyses of associations with improved patient global impression of change

$\begin{array}{lccc} & \text { OR } & \mathrm{Cl} & \mathrm{p} \text {-value } \\ \text { Employed (1=yes, 0=no) } & 2.4 & 1.2,4.8 & 0.01 \\ \text { Allocated intervention } & & & 0.80 \\ \quad \text { Usual care } & & 0.3,2.5 & 0.85 \\ \text { Multidisciplinary program } & 0.9 & 0.2,2.1 & 0.54 \\ \quad \text { Aerobic exercise program } & 0.7 & 2.9,14.5 & 0.00 \\ \text { Full participation program (1=yes, 0=no) } & 6.4 & & 0.00 \\ \text { Constant } & 0.1 & & \end{array}$

Model R ${ }^{2}$ (Nagelkerke) 0.25

With regard to overall health, $52 \%$ of the patients reported improvement and $48 \%$ reported no improvement. In the latter group 9.9\% of the patients remained unchanged and $38 \%$ worsened compared to baseline. As is shown in the multivariate analyses presented in Table 4.5, a longer duration of symptoms (regression coefficient $(B),-0.5$ (0.9 to -0.1$)$ ) and a higher level of limitations in 'body functions, physical' ( $B,-3.3$ (-6.2 to 0.5)) were independently associated with a worsening in overall health.

Table 4.5 Multivariate analyses of associations with changes in overall health after two years

\begin{tabular}{lccc} 
& $B$ & $\mathrm{Cl}$ & $\mathrm{p}$-value \\
\hline Duration symptoms & -0.5 & $-0.9,-0.1$ & 0.01 \\
Employed & 4.1 & $-0.8,9.0$ & 0.10 \\
High educational level & 6.7 & $-0.5,14.0$ & 0.07 \\
Body functions, physical & -3.3 & $-6.2,-0.5$ & 0.02 \\
Activities, physical and mental & -0.6 & $-3.1,2.0$ & 0.70 \\
Baseline value overall health & 0.3 & $0.1,0.4$ & 0.00 \\
Constant & 38.5 & $27.6,49.4$ & 0.00
\end{tabular}

Model $R^{2}$ (adjusted) 0.20

'Full participation in a program' showed a high correlation with an improved global impression of change. Perceived limitations in 'activities, physical or mental' were statistically significantly associated with 'starting to participate in a program' (OR, 1.8 (1.2 to 2.6)) and with 'full participation in a program' (OR, 1.5 (1.1 to 2.2)). Perceived limitations in 'body functions, physical', in 'body functions, mental', 'believes about pain' and a 'positive attitude' were not associated with either starting to participate in a program or full participation in a program. Results from the exploration of associations with starting to participate in a program full participation in a program are available in Table 4.6. 
Table 4.6 Multivariate analyses of associations between factors and start or full participation in a program

\begin{tabular}{|c|c|c|c|c|c|c|}
\hline & \multicolumn{3}{|c|}{$\begin{array}{l}\text { Starters vs non-starters } \\
\qquad n=86 \text { vs } n=69\end{array}$} & \multicolumn{3}{|c|}{$\begin{array}{l}\text { Participants vs non-participants } \\
\qquad n=68 \text { vs } n=87\end{array}$} \\
\hline & OR & $\mathrm{Cl}$ & $p$-value & OR & $\mathrm{Cl}$ & $p$-value \\
\hline Body functions, physical & 1.0 & $0.7,1.5$ & 0.97 & 0.9 & $0.7,1.4$ & 0.95 \\
\hline Body functions, mental & 1.1 & $0.8,1.1$ & 0.79 & 1.1 & $0.8,1.6$ & 0.63 \\
\hline Activities, physical or mental & 1.8 & $1.2,2.6$ & 0.00 & 1.5 & $1.1,2.2$ & 0.03 \\
\hline Believes about pain & 1.0 & $0.7,1.4$ & 0.98 & 1.0 & $0.9,1.0$ & 0.86 \\
\hline Positive attitude & 1.1 & $0.7,1.1$ & 0.74 & 1.0 & $0.7,1.4$ & 0.88 \\
\hline \multirow[t]{2}{*}{ Constant } & 1.2 & & 0.3 & 0.7 & & 0.08 \\
\hline & \multicolumn{3}{|c|}{ Model R² (Nagelkerke) 0.10} & \multicolumn{3}{|c|}{ Model R² (Nagelkerke) 0.06} \\
\hline
\end{tabular}

\section{Discussion}

In patients recently diagnosed with FM, 'being employed' and 'full participation in a program' are independently associated with improved patient global after two years, while less physical limitations at baseline were independently associated with improved overall health after two years.

Our study aimed at applying the ICF framework to FM outcome in order to understand potential predictors of improved health over time. Many potentially associated variables were incorporated in the study to reflect the major components of the ICF, which supports a holistic approach of health and adheres to the biopsychosocial model of disease. The use of the ICF was insightful to understand the broadness of the predictors that were considered and to see how separate items from the different questionnaires group into factors related to specific ICF chapters. PCA reduced the number of potentially associated and highly correlated variables appropriately and yielded factors that fit the different components of the ICF framework. Because the items of one factor related to more than one chapters, strict use of ICF terminology in the naming of the factors resulting from the PCA was not possible, but the new names that were provided to the factors nicely reflected the broad ICF concepts covered. These findings reflect that the ICF is a useful framework to cover the impact of FM and to structure the associations of variables with outcomes. In addition to other measures for HR-Qol, the ICF framework also covers environmental factors which may contribute to a more comprehensive approach of disease and health [36].

The definition of improved health in FM has been a challenge in this study. When reflecting on an appropriate definition for 'health', a connection with the OMERACT core domain for outcome assessment in clinical trials has been made [18]. PGI-C and changes in overall health were chosen. Interestingly, somewhat different variables were associated with the outcomes. 'Being employed' has been found to be important to patients with FM, both on a personal level and on a societal level [37] which may explain our findings. Although we did not find important differences between patients at work and patients not at work regarding several variables, we cannot exclude that the patients at work were 
'healthier' patients. The association of employment was confirmed with improved patient global impression of change, but not with improved overall health. Furthermore, physical symptoms appeared to be associated with changes in overall health, but not with global impression of change. The association of other personal factors such as coping styles and beliefs was not confirmed with any of the outcomes [13, 14, 38]. Our findings suggest that the chosen outcomes PGI-C and changes in overall health cover different domains of 'health'.

Remarkably, 'full participation in a program' was associated with improved patient global after two years. When interpreting the results, we suggested that 'full participation' may reflect the patient's intrinsic motivation as patients were asked if they were willing to participate in the programs only after randomisation. Although motivation as such was not measured in the study, some potential surrogates such as 'believes about pain' and 'positive attitude' were measured. Several psychological models, used in studies with regard to motivation, share constructs of patients' expectations about the consequences of behaviour, and the influence of patients' perceptions of, or beliefs about, personal control over the behaviour [39]. Therefore, we assumed the variables in the factors 'beliefs about pain' and 'positive attitude' to reflect motivation. However, associations with these personal factors were not found. Either our assumption was not correct or 'full participation' represents a different construct, which we were not able to capture.

Whatever 'full participation' represents, it is a major limitation in many studies with regard to FM and high drop-out rates characterise the trials with regard to single and multicomponent interventions $[5,6,40]$. Our results suggest better outcomes for patients that participated fully in a program. When further exploring this in detail, we found an association between full participation and higher levels of limitations in physical and mental activities. In clinical practice, these findings may indicate that the level of perceived limitations in activities and a motivation to participate in a program should be incorporated in defining criteria for correct referral to interventions.

Although we have found a number of significantly contributory factors to explaining variation in health, the explained variance remained low overall, suggesting that many other and still unknown factors contribute to changes in perceived health. Our findings are based on data from a cohort of FM patients, participating in a trial comparing the effects of an intensive multidisciplinary intervention with aerobic exercise and with usual care. As most patients attended the multidisciplinary intervention, the generalisability of our findings is probably limited to this intervention.

In summary, this study that explored predictors of changes in perceived health in the context of the ICF framework of functioning and health, suggests that recently diagnosed patients with FM may experience a better global impression of health change if they are at work and have a positive attitude towards participating in an offered health care intervention. A longer duration of symptoms and more reported physical limitations 
Chapter 4

negatively contribute to overall health. These findings give support to promoting an active -rather than a care-avoiding- attitude of health care workers in their contacts to recently diagnosed patients with FM, but it also shows that the level of perceived limitations should be taken into account when referring patients to appropriate interventions. 


\section{References}

1. Wagner EH. Chronic disease management: what will it take to improve care for chronic illness? Effect Clin Pract. 1998;1(1):2-4.

2. Mease P. Fibromyalgia syndrome: review of clinical presentation, pathogenesis, outcome measures, and treatment. J Rheumatol. 2005;75:6-21.

3. Carville SF, Arendt-Nielsen S, Bliddal $\mathrm{H}$, et al. EULAR evidence-based recommendations for the management of fibromyalgia syndrome. Ann Rheum Dis. 2008; 67(4):536-41.

4. Hauser W, Arnold B, Eich W, et al. Management of fibromyalgia syndrome - an interdisciplinary evidence-based guideline. Ger Med Sci 2008;6:Doc14.

5. Hauser W, Bernardy K, Arnold B, Offenbacher M, Schiltenwolf M. Efficacy of multicomponent treatment in fibromyalgia syndrome: a meta-analysis of randomized controlled clinical trials. Arthritis Rheum. 2009;15;61(2):216-24.

6. Karjalainen K, Malmivaara A, van Tulder M, et al. Multidisciplinary rehabilitation for fibromyalgia and musculoskeletal pain in working age adults. Cochrane database of systematic reviews. 2000; Online Update Software ISE: 1469 493X. (2):Cd001984.

7. Bodenheimer T, Wagner EH, Grumbach K. Improving primary care for patients with chronic illness: the chronic care model, Part 2. JAMA. 2002;288(15):1909-14.

8. Wagner EH, Austin BT, Von Korff M. Improving outcomes in chronic illness. Manag Care Q. 1996;4(2):1225.

9. Reisine S, Fifield J, Walsh S, Forrest DD. Employment and health status changes among women with fibromyalgia: a five-year study. Arthritis Rheum. 2008;15;59(12):1735-41.

10. Linares M, Pérez I, Pérez $M$, et al. Analysis of the impact of fibromyalgia on quality of life: associated factors. Clin Rheumatol. 2008;27:613-9.

11. Dobkin P, De Civita M, Abrahamowicz M, Baron M, Bernatsky S. Predictors of Health Status in Women With Fibromyalgia: A Prospective Study. Int J Behav Med. 2006;13(2):101-8.

12. Oliver K, Cronan T. Predictors of exercise behaviors among fibromyalgia patients. Prev Med. 2003;35:383-9.

13. Nicassio P, Schoenfeld-Smith K, Radojevic V, Schurman C. Pain coping mechanisms in fibromyalgia: relationship to pain and functional outcomes. J Rheumatol. 1995;22(8):1552-8.

14. Prior K, Bond $M$. The roles of self-efficacy and abnormal illness behaviour in osteoarthritis selfmanagement Psych Health \& Med. 2004; 2(2):177-92.

15. Hasenbring MI, Plaas $\mathrm{H}$, Fischbein B, Willburger $\mathrm{R}$. The relationship between activity and pain in patients 6 months after lumbar disc surgery: do pain-related coping modes act as moderator variables? Eur J Pain. 2006;10(8):701-9.

16. Vlaeyen JW, Kole Snijders AM, Boeren RG, van Eek H. Fear of movement/(re)injury in chronic low back pain and its relation to behavioral performance. Pain. 1995;62(3):363-72.

17. Karsdorp P, Vlaeyen J. Active avoidance but not active pacing is associated with disability in fibromyalgia. Pain 2009;147:29-35.

18. Mease P, Arnold LM, Choy EH, et al. Fibromyalgia syndrome module at OMERACT 9: domain construct. J Rheumatol. 2009; 36(10):2318-29.

19. Mease PJ, Arnold LM, Bennett R, et al. Fibromyalgia syndrome: OMERACT 7 workshop2 J Rheumatol. 2007; 34(6):1415-25.

20. Mease PJ, Clauw DJ, Arnold LM, et al. (2--5) Fibromyalgia syndrome: OMERACT 7 workshop 1 . J Rheumatol. 2007; 32(11):2270-7.

21. Picavet HS, Hoeymans N. Health related quality of life in multiple musculoskeletal diseases: SF-36 and EQ-5D in the DMC3 study. Ann Rheum Dis. 2004; 63(6):723-9.

22. Verbunt JA, Pernot DH, Smeets RJ. Disability and quality of life in patients with fibromyalgia. Health Qual Life Outcomes. 2008; 6:8.

23. Prodinger B, Cieza A, Williams DA, et al. Measuring health in patients with fibromyalgia: content comparison of questionnaires based on the International Classification of Functioning, Disability and Health. Arthritis Rheum. 2008;15;59(5):650-8.

24. WHO International Classification of functioning, disability and health: ICF. 2001 World Health Organization, Geneva. 
25. American, College, Sports, Medicine. Position Stand. The recommended quantity and quality of exercise for developing and maintaining cardiorespiratory and muscular fitness, and flexibility in healthy adults. Med Sci Sports Exerc 1998;30(975-991).

26. van Eijk-Hustings $Y$, Kroese M, Tan F, Boonen A, Bessems-Beks M, Landewé R. Challenges in demonstrating the effectiveness of multidisciplinary treatment on quality of life, participation and health care utilisation in patients with fibromyalgia. A randomised controlled trial. Clin Rheumatol. 2013;32(2):199-209.doi:10.1007/s10067-012-2100-7

27. The EuroQol Group. EuroQol-a new facility for the measurement of health-related quality of life. Health Policy. 1990;16(3):199-208.

28. Dolan P. Modeling valuations for EuroQol health states. Med Care. 1997;35(11):1095-108.

29. Bennett R. The Fibromyalgia Impact Questionnaire (FIQ): a review of its development, current version, operating characteristics and uses. Clin Exp Rheumatol. 2005;23(5 Suppl 39):S154-62.

30. Schwarzer R, \& Jerusalem M. Generalized Self-efficacy scale. In J. Weinman, S.Wright \& M. Johnston, Measures in health psychology: A user's portfolio. Causal and control beliefs (pp.35-37) Windsor, UK: NFER-NELSON. 1995

31. Vercoulen JHHM, Alberts M, Bleijenberg G. De Checklist Individual Strength (CIS). Gedragstherapie 1999;32:131-6.

32. Sullivan MJL, Bishop SR, Pivik J. The pain catastrophizing scale: development and validation. Psych Assess. 1995; 7:524-432.

33. Watson D, Clark LA, Tellegen A. Development and validation of brief measures of positive and negative affect: the PANAS scales. J Pers Soc Psychol. 1988 54(6):1063-70.

34. McCracken LM, Zayfert C, Gross RT. The Pain Anxiety Symptoms Scale: development and validation of a scale to measure fear of pain. Pain. 1992; 50(1):67-73.

35. Geyh S, Müller R, Peter C, et al. Capturing the psychologic-personal perspective in spinal cord injury. Am J Phys Med Rehabil. 2011;90(11 Suppl 2):S79-965):DOI: 10.1097/PHM.0b013e318230fb68.

36. Cieza A, Stucki G. Content comparison of health-related quality of life (HRQOL) instruments based on the international classification of functioning, disability and health (ICF). Qual Life Res. 2005; 14(5):1225-37.

37. Liedberg GM, Henriksson CM. Factors of importance for work disability in women with fibromyalgia: an interview study. Arthritis Rheum. 2002;15;47(3):266-74.

38. Weigl M, Cieza A, Cantista P, Reinhardt J, Stucki G. Determinants of disability in chronic musculoskeletal health conditions: a literature review. Eur J Phys Rehab Med. 2008;44:67-79.

39. Anga D, Kalethb A, Bigattic S, et al. Research to Encourage Exercise for Fibromyalgia (REEF): Use of motivational interviewing design and method. Contemp Clin Trials. 2011;32(1):59-68.

40. Busch A, Schachter CL, Peloso PM, Bombardier C. Exercise for treating fibromyalgia syndrome. Cochrane database of systematic reviews. 2002; Online Update Software (3):Cd003786. 


\section{Chapter 5}

Supporting health care professionals systematically to improve the quality and person-centredness of fibromyalgia management in primary health care

Van Eijk-Hustings $Y$, Kroese M, Bessems-Beks M, Landewé R, Vrijhoef H.

International Journal of Person Centred Medicine. 2012;2(4):837-844. 


\section{Abstract}

Objective. To improve the quality and person-centredness of primary health care for fibromyalgia patients by supporting health care professionals.

Methods. The Chronic Care Model was used as a framework to develop combined interventions: an educational program, a multidisciplinary guideline, and a checklist for referral, for general practitioners and physiotherapists in two regions in the South of the Netherlands. After the educational program, the guideline and the checklist for referral were tested in daily practice during six months. A pre-post design was used to measure changes in fibromyalgia care as perceived by the health care professionals. Changes were measured by the 'Assessment Chronic Illness Care' (ACIC) questionnaire. The questionnaire evaluates team opinions about the level and nature of improvements in response to interventions. Feasibility of the guideline and the checklist for referral were asked for in interviews.

Results. Guideline and checklist for referral were tested by 12 general practitioners and 23 physiotherapists, forming 12 'practice teams'. After the 6-month test period, the ACIC showed statistically significant improvements in all elements of care.

The guideline and the checklist for referral were found feasible.

Conclusion. Health care professionals in primary care reported improvements in fibromyalgia care, but also faced difficulties in changing daily practice. Additional activities are needed for further care improvement. Future research should examine the generalisibility of findings and whether and how an improved quality of care is perceived by fibromyalgia patients. 


\section{Introduction}

The burden of fibromyalgia (FM) for patients and for society is considerable. Patients suffer from chronic widespread musculoskeletal pain and fatigue, frequently accompanied by other symptoms such as concentration problems, sleep disturbance, irritable bowel syndrome and mood disorders [1, 2]. FM results in a poor quality of life, a high utilisation of health care resources and a substantial loss of work days $[3,4]$.

Research has shown a large diversity in interventions and a large number of referrals from primary to secondary or tertiary care and vice versa as professionals are uncertain about appropriate interventions [5]. Furthermore, FM is a controversial disorder. Research has shown conflicting evidence with regard to making the diagnosis. It may contribute to somatisation and to an increased use of health care resources [6], but a reduction of uncertainty in patients may improve coping with the disorder, resulting in lower utilisation of health care resources [7-9].

The patient's suffering as well as the societal consequences of the disorder justify well organised care for people with FM. The Chronic Care Model provides a framework for improvement of chronic illness care (see Figure 5.1) [10]. The framework shows that outcomes of care are a result of combined and effective interventions, simultaneously focused on the level of community services, health care services, health care professionals, and patients. A productive interaction between a well-trained and proactive team of health care professionals and patients is considered pivotal to quality improvement. Self-management support empowers the patient. An active patient in the decision-making process improves agreement between management strategies and patients' values and choices [11].

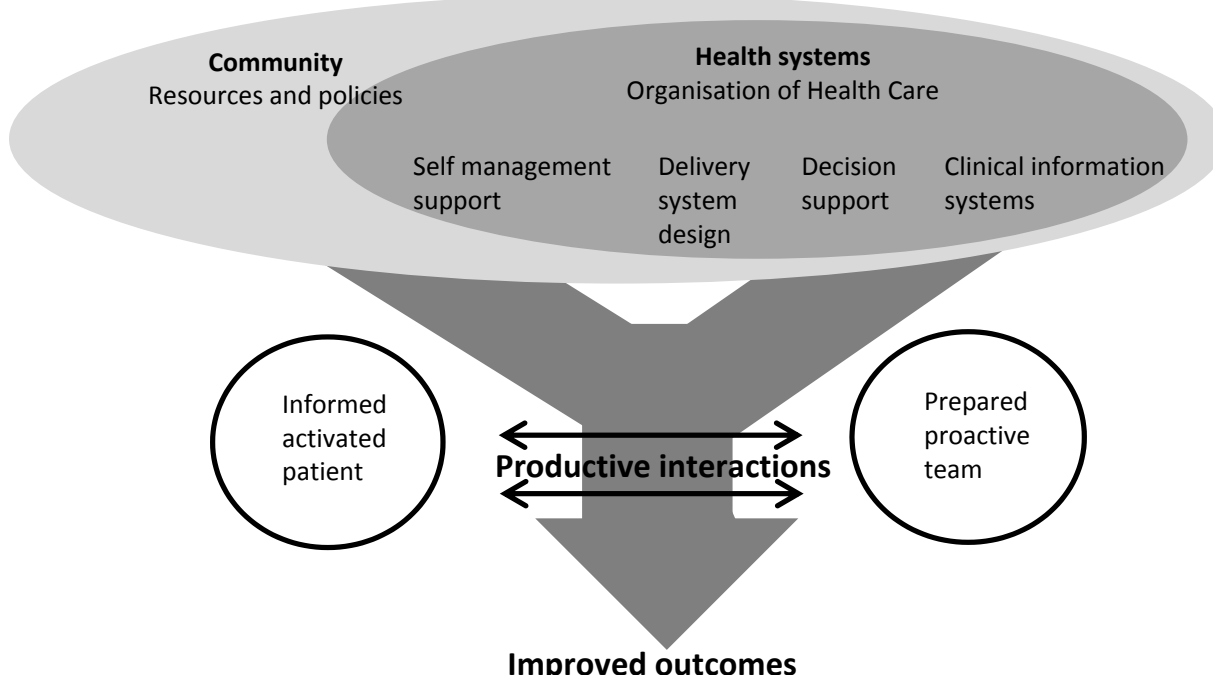

Figure 5.1 The Chronic Care Model 
In the late 1990s, shortcomings in health care services with regard to FM care were observed in the region of Maastricht, the Netherlands. In order to address these shortcomings, a stepwise approach has been chosen to develop a care program for patients with FM, focused on early diagnosis and early intervention. To reduce waiting lists and to improve accessibility to the program, an outpatient nurse-led diagnostic process has been implemented $[12,13]$. In addition to the diagnostic procedure, the rheumatology nurse specialist gives information, education and support to patients, aiming at the enhancement of self-management [12]. If necessary, patients are referred for appropriate interventions. To meet the need for early intervention, a multidisciplinary program with aftercare meetings has been developed. The program aims to optimise selfmanagement and daily functioning through coping with the disorder. It was tested in terms of feasibility [14] and it is currently being evaluated with regard to its effectiveness [15].

It was decided to focus on primary care, as $80 \%$ to $90 \%$ of $\mathrm{FM}$ patients are managed in this setting [5]. In-depth exploration of the nature of ongoing problems highlighted three topics for further quality improvement. First, the knowledge of general practitioners (GPs) and physiotherapists about FM, its underlying mechanisms and treatment should be improved. Second, agreement between professionals about treatment strategies for FM should be improved and third, referral for appropriate treatment options should be facilitated and encouraged.

The project described in this article aimed to address these issues and assessed if quality improvement was achieved with reference to the perspectives of the professionals themselves.

\section{Methods}

\section{Participants}

The project commenced in the East- and West-South of Limburg, the Netherlands, in July 2009 and was of 18 months duration. A steering group, comprising representatives of GPs, physiotherapists, rheumatologists, rehabilitation specialists, and a representative of the patients association for FM (F.E.S.), supported the process. In a regional newsletter a convenience sample of 10 GPs and 10 physiotherapists in the region was invited to participate in the project. Response from GPs was limited and therefore the physiotherapists from both regions, who already consented to participate, were asked to advance the names of GPs with whom they had some nature of existing collaboration. Subsequently, these 63 GPs were sent formal invitations by the project-team. The GPS that finally decided to participate in the project and the matching physiotherapists were labelled as 'practice teams'. 


\section{Interventions}

To improve knowledge of the practice teams, a multidisciplinary educational program was developed, consisting of three interactive sessions of four hours each, over a 3-month period. The first session comprised 'information about FM', 'a biopsychosocial approach for exploration of symptoms', and 'the concept of somatisation'. The second session comprised 'behavioral approach', 'education of patients', 'motivation of patients' and 'graded activity'. The third session comprised 'communication between professionals' and 'communication with patients'. A fourth session, six months later, presented the additional topic 'Motivational Interviewing'. In the third session the practice teams also formulated criteria for information and feedback. The program was accredited by the professional organisations of GPs and physiotherapists.

To improve agreement about diagnosis and treatment strategies, a 4-chapter multidisciplinary guideline has been described (see Box 5.1). The guideline presents evidence, content and organisation of care and every chapter ends with a set of recommendations for good care. Existing international guidelines were used as a basis for the evidence $[8,16,17]$. In addition, 14 interviews with health care professionals and with a patient were performed to collect opinions about the content and organisation of care. A short report of every interview was made and was sent to the interviewee for verification.

\section{Box 5.1 Content multidisciplinary guideline}

Chapter 1. Multidimensional problem exploration and diagnosis of FM.

Describes somatic, cognitive, emotional, behavioral and social aspects of FM.

Presents a checklist for diagnosis.

Chapter 2. Management and treatment strategies.

Describes the concept of somatisation and appropriate interventions e.g. reattribution, symptom registration.

Describes elements of good quality care:

- to give information and education;

- to support healthy movement, e.g. graded activity;

- psychological support;

- system support.

Describes complexity profiles and appropriate interventions per profile:

- complexity profile 1. Information about FM and lifestyle advices;

- complexity profile 2 . As 1 + patient education/ training program;

- complexity profile 3 . As 2 + intensive support for behavioral change;

- complexity profile 4. As 3 + system treatment;

- complexity profile 5 . Individual psychiatric treatment.

Chapter 3. Participation.

Describes the importance of social participation and employment from a patients' and a societal perspective.

Describes regulations for sickness absence and work disability.

Chapter 4. Preconditions for good quality care.

Describes criteria for referral, financial regulations and incentives, coordination of care and education for professionals. 
In order to support targeted interventions, five complexity profiles were introduced, following the work of the Dutch Working Group for Pain Rehabilitation [18]. The profiles are based on the level of the patient's perceived limitations, attitude towards selfmanagement, and insight in his or her own problems (see Box 5.2).

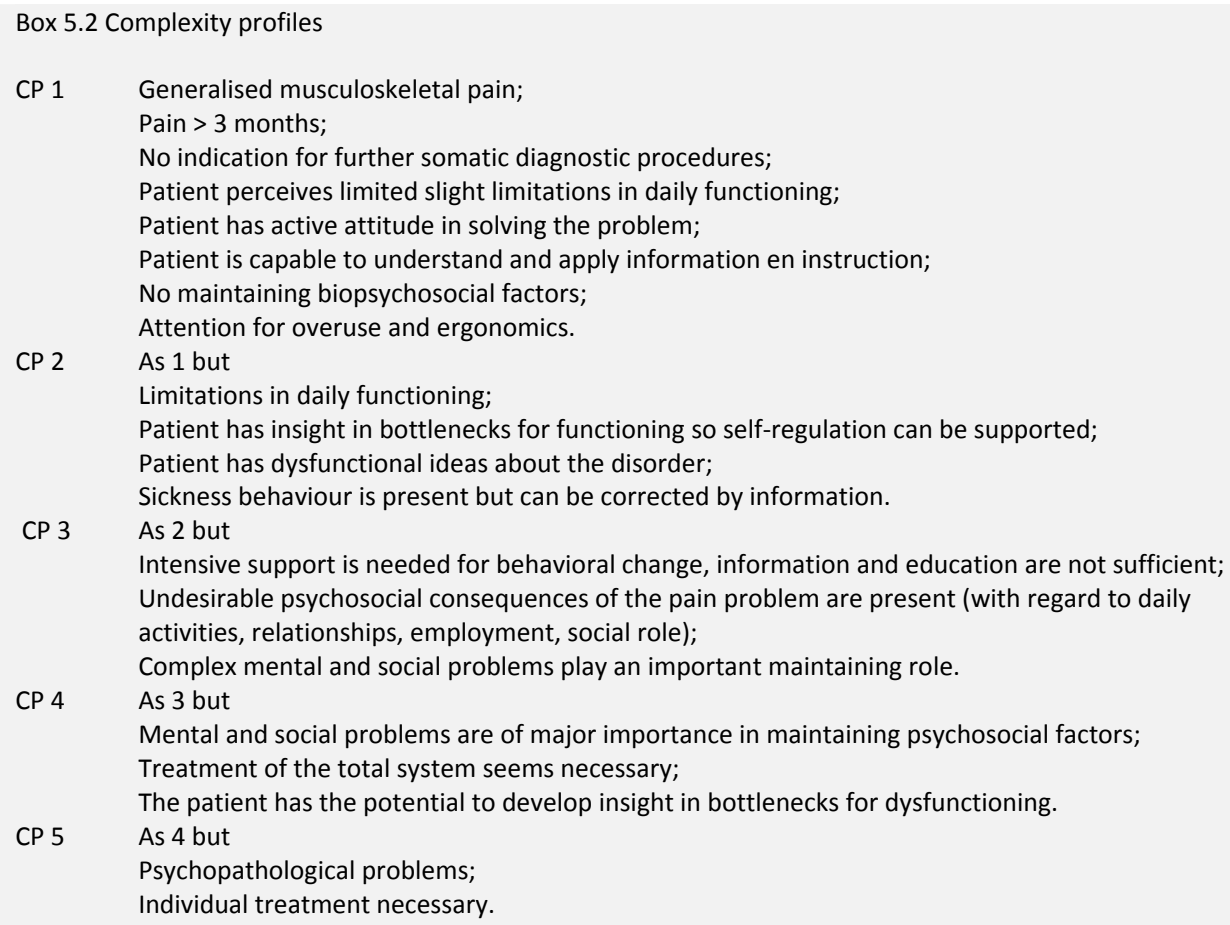

To support appropriate referral, a checklist was developed. The checklist was based on a biopsychosocial approach with the aim of supporting professionals and patients to jointly explore perceived problems and dysfunction. The wording was linked to the guideline. As FM is often accompanied by depression and anxiety, key questions with regard to these comorbidities, based on the Dutch Standards for GPs, were incorporated in the checklist (see Box 5.3) [19, 20]. The patient's understanding and motivation are considered pivotal for treatment success and should be assessed. The checklist should result in a decision about the complexity profile. This profile, the patient's preference, and the availability of interventions in the region, should determine the referral to an optimal treatment. 


\section{Box 5. 3 Checklist for referral}

\section{Item}

1.Depression or anxiety

(Key questions based on the Dutch Standards for GPs)

2.Multidimensional exploration of symptoms

a) somatic Is this chronic widespread musculoskeletal pain and is no further somatic diagnostic procedure needed (see checklist for diagnosis)

b) cognition Does the patient understand bottlenecks for functioning and is there a belief to be able to contribute to a solution Is the patient motivated (stages of behavioral change)

c) emotional Are emotions such as fear, helplessness or anger present

d) behaviour Is there any avoidance behaviour

e) social Influence on daily living (at home, work, relationships)

3.Maintaining psychosocial factors

4.Patient's preference for intervention

5.Availability of relevant treatment options in the region

\section{Answer: consequence}

Yes: treatment according to Standards No: continue

No: further examination

Yes: continue

No: reattribution and symptom registration

Yes: continue

No: motivational interviewing

Yes: continue

Yes, further exploration

No: risk for overuse

Yes: fear of movement

Importance for patient

No: complexity profiles 1 of 2

Yes: complexity profiles 3 en 4

Psychopathic: complexity profile 5

Determines kind of intervention and intensity of intervention

Inform patient

\section{Measurements}

The guideline and the checklist for referral were introduced to the educational program. After completion of the program, the practice teams were asked to test the guideline and the checklist for referral in daily practice over six months. Before and after the 6-month test period, an adapted version of the Assessment Chronic Illness Care (ACIC) questionnaire was applied in interviews with the practice teams [21]. The ACIC evaluates team opinions about the level and nature of improvements that are made in response to quality improvement interventions. In the interviews, the practice teams discussed the questions under the guidance of the first author $(\mathrm{YvE}-\mathrm{H})$ and tried to achieve a consensus score. If they could not achieve consensus, separate scores were recorded.

The adapted version of the ACIC consists of the care elements 'self-management support' (4 items), 'decision support' (4 items), 'delivery system design' (6 items), and 'information systems' (5 items). All items were to be scored on a 0-11 point scale. Higher scores indicated more optimal support for chronic illness care. A score from 0 to 2 represented limited support whereas a score from 3 to 5 represented basic support, a score from 6 to 8 
indicated reasonably good support and a score from 9 to 11 confirmed fully developed chronic illness care.

\section{Statistical analyses}

Descriptive statistics were used to calculate means and standard deviations (SD) for each element and item. Paired sample T-tests were used to calculate differences and $95 \%$ confidence intervals $(\mathrm{Cl})$ between the measurements before and after the 6-month test period. In order to be able to include all results in the analyses, a mean score was calculated for items without a consensus statement, representing the mean of the GP score and the physiotherapist score. Two practice teams were not willing to participate in the measurement after the test period. For these teams, data from the measurement before the test period were imputed. Data were analysed using SPSS version 16.0 (SPSS Inc., Chicago, IL).

\section{Results}

A total of 35 health care professionals, 12 GPs and 23 physiotherapists, participated in the project, forming 12 practice teams. All 23 physiotherapists and 9 GPs participated in the educational program.

After the 6-month test period, the ACIC showed statistically significant improvements with regard to the care elements 'self-management support' $(+1.3, \mathrm{Cl} 0.1$ to 2.5$)$, 'decision support' ( $+2.3, \mathrm{Cl} 1.1$ to 3.6$)$, 'delivery system design' ( $+1.8, \mathrm{Cl} 0.4$ to 3.2 ), and 'information systems' (+1.7, $\mathrm{Cl} 0.2$ to 3.3 ) as is shown in Figure 5.2.

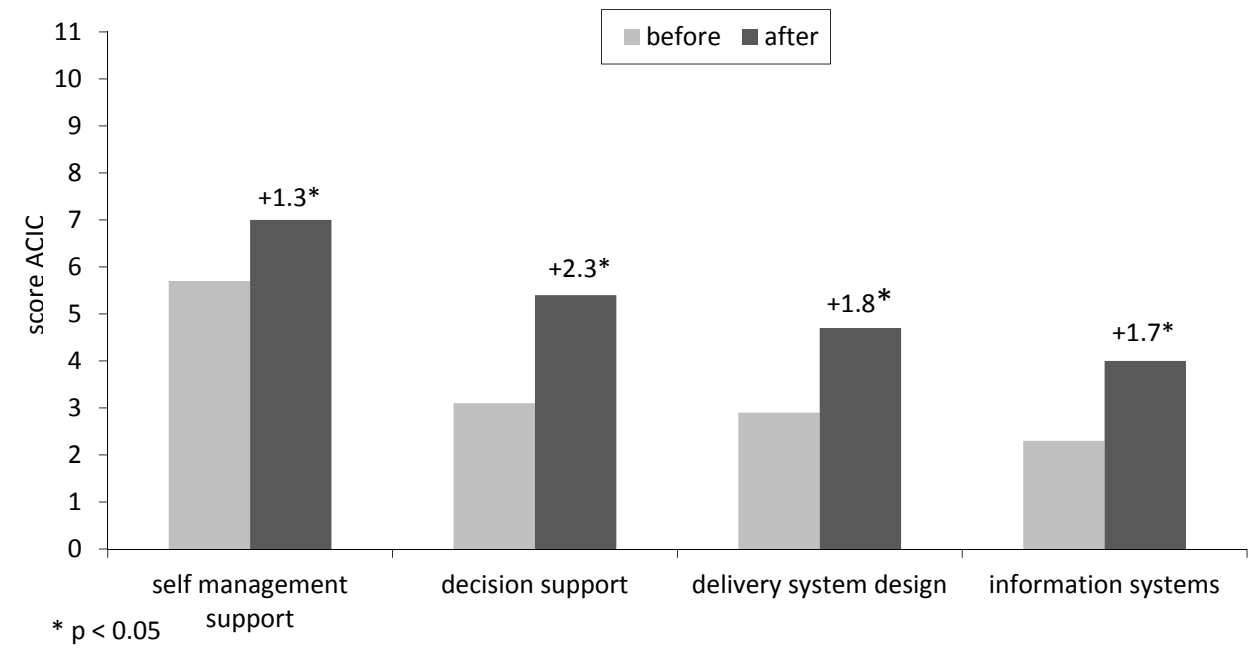

Figure 5.2 Changes in care as perceived by professionals 
Detailed results on the ACIC are presented in Table 5.1. With regard to the care element 'self-management support', the practice teams perceived a statistically significant improvement in addressing patients' and relatives' concerns ( $+1.1, \mathrm{Cl} 0.3$ to 1.9). Scores from 6.0 to 7.9, representing reasonably good support for chronic illness care, were achieved. With regard to the care element 'decision support', the practice teams perceived a statistically significantly improved availability of evidence-based guidelines $(+2.4, \mathrm{Cl} 0.8$ to 4.0$)$, involvement of specialists with regard to $\mathrm{FM}$ in their practice teams (+3.6, $\mathrm{Cl} 1.3$ to 6.0 ) and informing patients about guidelines (+2.1, $\mathrm{Cl} 0.7$ to 3.5). With regard to the care element 'delivery system design', the practice teams perceived statistically significantly improved practice team functioning $(+2.5, \mathrm{Cl} 1.0$ to 4.0$)$, clarity about leadership ( $+2.1, \mathrm{Cl} 0.1$ to 4.1 ), planning of follow-up care $(+1.8, \mathrm{Cl} 0.2$ to 3.5$)$, and continuity of care $(+2.0, \mathrm{Cl} 0.2$ to 3.9$)$. With regard to the care element information systems', health care professionals perceived a statistically significant improved feedback $(+2.4, \mathrm{Cl} 0.6$ to 4.2$)$. The results on all other items of the $\mathrm{ACIC}$ also showed improvement.

Table 5.1 Detailed results on the adapted Assessment Chronic Illness Care questionnaire

\begin{tabular}{|c|c|c|c|}
\hline Care element (range $0-11$ ) & $\begin{array}{c}\text { Before } \\
\text { mean (SD) }\end{array}$ & $\begin{array}{c}\text { After } \\
\text { Mean (SD) }\end{array}$ & $\begin{array}{c}\text { Difference } \\
(95 \% \mathrm{Cl})\end{array}$ \\
\hline $\begin{array}{l}\text { Self-management support } \\
\text { Assessment and documentation of needs } \\
\text { Self-management support } \\
\text { Addressing concerns patients and } \\
\text { relatives } \\
\text { Availability effective interventions }\end{array}$ & $\begin{array}{l}5.2(2.4) \\
5.0(2.2) \\
6.1(1.3) \\
6.5(2.8)\end{array}$ & $\begin{array}{l}6.0(2.6) \\
6.7(2.7) \\
7.2(1.7) \\
7.9(2.2)\end{array}$ & $\begin{array}{l}+0.8(-0.5,2.2) \\
+1.7(0.0,3.5) \\
+1.1(0.3,1.9)^{*} \\
+1.4(-0.8,3.5)\end{array}$ \\
\hline $\begin{array}{l}\text { Decision support } \\
\text { Availability evidence-based guidelines } \\
\text { Involvement of specialists } \\
\text { Provider education } \\
\text { Informing patients about guidelines }\end{array}$ & $\begin{array}{l}3.3(2.7) \\
2.9(2.2) \\
3.3(1.7) \\
2.7(2.2)\end{array}$ & $\begin{array}{l}5.7(2.9) \\
6.5(3.4) \\
4.6(2.4) \\
4.8(2.7)\end{array}$ & $\begin{array}{l}+2.4(0.8,4.0)^{*} \\
+3.6(1.3,6.0)^{*} \\
+1.3(-0.6,3.1) \\
+2.1(0.7,3.5)^{*}\end{array}$ \\
\hline $\begin{array}{l}\text { Delivery system design } \\
\text { Practice team functioning } \\
\text { Leadership } \\
\text { Appointment system } \\
\text { Schedule follow-up } \\
\text { Use of planned visits } \\
\text { Continuity of care }\end{array}$ & $\begin{array}{l}2.4(2.3) \\
1.8(2.3) \\
1.4(1.8) \\
3.0(2.2) \\
4.2(3.4) \\
4.5(2.0)\end{array}$ & $\begin{array}{l}4.9(3.0) \\
3.9(2.5) \\
2.5(2.9) \\
4.8(3.0) \\
5.5(2.6) \\
6.5(1.8)\end{array}$ & $\begin{array}{l}+2.5(1.0,4.0)^{*} \\
+2.1(0.1,4.1)^{*} \\
+1.1(-1.0,3.1) \\
+1.8(0.2,3.5)^{*} \\
+1.3(-0.6,3,2) \\
+2.0(0.2,3.9)^{*}\end{array}$ \\
\hline $\begin{array}{l}\text { Information systems } \\
\text { Registry } \\
\text { Reminders to providers } \\
\text { Feedback } \\
\text { Information about patient needs } \\
\text { Patient treatment plans }\end{array}$ & $\begin{array}{l}1.4(1.6) \\
0.6(1.5) \\
2.4(1.9) \\
2.4(2.3) \\
4.5(2.7)\end{array}$ & $\begin{array}{l}2.4(2.8) \\
2.0(2.3) \\
4.8(2.7) \\
4.4(3.2) \\
6.4(3.2)\end{array}$ & $\begin{array}{l}+1.0(-0.7,2.8) \\
+1.4(-0.3,3.0) \\
+2.4(0.6,4.2)^{*} \\
+2.0(-0.2,4.2) \\
+1.9(-0.1,3.9)\end{array}$ \\
\hline
\end{tabular}


During the test period, the practice teams assessed feasibility of the guideline and the checklist for referral. In the interviews they approved with the contents of the guideline, but adherence in daily practice depends on the availability of interventions. Implementation of the checklist for referral in daily practice will demand further adjustments of daily routine. A multidimensional exploration of symptoms will require extra time in consultations, which is often not available.

\section{Discussion}

The project described in this article aimed to improve quality and person-centredness of FM management in primary care through support for health care professionals. Practice teams of GPs and physiotherapists attended an educational program and tested a multidisciplinary guideline and a checklist for referral in daily practice. The practice teams reported feasibility of the guideline and the checklist for referral, and improvements with regard to all care elements of the $\mathrm{ACIC}$ after the 6-month test period.

All participants had confirmed to be interested in FM care which may have influenced the results positively. On the other hand, measurement at baseline was performed after the educational program in which GPs and physiotherapists worked together in small groups. Fine tuning between them and awareness of usual care may have improved even before the test period and therefore the magnitude of the found improvement may be an underestimation of the results.

Appropriate knowledge and skills about early recognition of FM in primary care is required [22]. According to the practice teams, the educational program contributed to increased knowledge and skills, but this was not assessed in this project. The contents of the guideline are in accordance with existing international guidelines with regard to treatment strategies [23] and feasibility was confirmed. In the near future, the guideline will be further discussed within the professional organisations of GPs and physiotherapists, and adapted if necessary. The implementation of the checklist for referral in daily practice demands adjustments of daily routine. This problem may be solved by further redesign, for example, substitution of tasks from GPs to other professionals, such as nurses [24].

The willingness to participate in the project among GPs was limited and reasons were mainly 'not interested' or 'too busy'. As GPs have an important role to play in the early recognition of $\mathrm{FM}$, the limited interest in $\mathrm{FM}$ care may contribute to a delay in diagnosing FM and delivering appropriate treatment. This may increase the risk of chronicity, which is considered a negative predictor of treatment outcome [25]. Another point of concern is the ongoing discrepancy between primary and secondary care with regard to a diagnosis of FM. A mutual agreement about name and treatment strategies may enhance communication and collaboration between both, and may contribute to defragmentation of care. 
The generalisablity of findings has to be examined in future research. An experimental design is required to assess the impact of the interventions on professionals' knowledge and behaviour. Ongoing research will examine the patient's perceived quality of FM care.

Following the multiple intervention consisting of an educational program, a multidisciplinary guideline and a checklist for referral, GPs and physiotherapists reported improved management of FM, but also faced difficulties in daily practice. Additional quality improvement activities are needed to improve the quality and person-centredness of clinical care.

\section{Acknowledgements}

We thank the health care professionals in the working groups for their time and expertise, the health care professionals willing to act as test practices for their time and effort to participate in the educational program, and to test the guideline and the checklist for referral, and the health care professionals and patients acting as interviewees in this project for their time and contribution. 


\section{References}

1. Arnold LM, Crofford LJ, Mease PJ, et al. Patient perspectives on the impact of fibromyalgia. Patient Educ Counsel. 2008;73(1):114-20.

2. Wolfe F, Clauw DJ, Fitzcharles MA, et al. The American College of Rheumatology preliminary diagnostic criteria for fibromyalgia and measurement of symptom severity. Arthritis Care Res (Hoboken). 2010;62(5):600-10.

3. Boonen A, van den Heuvel $R$, van Tubergen A, et al. Large differences in cost of illness and wellbeing between patients with fibromyalgia, chronic low back pain, or ankylosing spondylitis. Ann Rheum Dis. 2005;64(3):396-402.

4. White LA, Birnbaum HG, Kaltenboeck A, Tang J, Mallett D, Robinson RL. Employees with fibromyalgia: medical comorbidity, healthcare costs, and work loss. J Occ Environment Med. 2008;50(1):13-24.

5. Kroese ME, Schulpen GJ, Sonneveld HM, Vrijhoef HJ. Therapeutic approaches to fibromyalgia in the Netherlands: a comparison between 1998 and 2005. J Eval Clin Pract. 2008;14(2):321-5.

6. Clauw DJ. Fibromyalgia: update on mechanisms and management. J Clin Rheumatol. 2007;13(2):102-9.

7. Bennett R. Fibromyalgia, chronic fatigue syndrome, and myofascial pain. Curr Opin Rheumatol. 1998;10(2):95-103.

8. Goldenberg DL, Burckhardt C, Crofford L. Management of fibromyalgia syndrome. JAMA. 2004;292(19):2388-95.

9. White KP, Nielson WR, Harth M, Ostbye T, Speechley M. Does the label "fibromyalgia" alter health status, function, and health service utilization? A prospective, within-group comparison in a community cohort of adults with chronic widespread pain. Arthritis Rheum. 2002; 47(3):260-5.

10. Wagner EH, Austin BT, Von Korff M. Improving outcomes in chronic illness. Manag Care Q. 1996;4(2):1225.

11. Joosten EA, DeFuentes Merillas L, de Weert GH, Sensky T, van der Staak CP, de Jong CA. Systematic review of the effects of shared decision-making on patient satisfaction, treatment adherence and health status. Psychother Psychosom. 2008;77(4):219-26.

12. Kroese MEAL, Schulpen GJC, Bessems MCM, Severens JL, Nijhuis FJ, Geusens PP, Landewé RB. Substitution of specialized rheumatology nurses for rheumatologists in the diagnostic process of fibromyalgia: a randomized controlled trial. Arthritis Care Res. 2008;59(9):1299-305.

13. Kroese M, Severens J, Schulpen G, Bessems M, Nijhuis F, Landewe R. Specialized Rheumatology Nurse Substitutes for Rheumatologists in the Diagnostic Process of Fibromyalgia: A Cost-Consequence Analysis and a Randomized Controlled Trial. J Rheumatol. 2011;38(7):doi:10.3899/jrheum.100753.

14. Kroese M, Schulpen G, Bessems M, Nijhuis F, Severens J, Landewe R. The feasibility and efficacy of a multidisciplinary intervention with aftercare meetings for fibromyalgia. Clin Rheumatol. 2009;28(8):9239.

15. van Eijk - Hustings $Y$, Kroese M, Bessems - Beks M, Boonen A, Landewé R. Multidisciplinary treatment with aftercare meetings compared to aerobic exercise and usual care in fibromyalgia. First results of a randomised controlled trial [abstract]. Ann Rheum Dis 2008; 67(supp 11):262.

16. Hauser W, Arnold B, Eich W, et al. Management of fibromyalgia syndrome - an interdisciplinary evidence-based guideline. German Med Sci. 2008;6:Doc14.

17. Carville SF, Arendt-Nielsen S, Bliddal $H$ et al. EULAR evidence-based recommendations for the management of fibromyalgia syndrome. Ann Rheum Dis. 2008;67(4):536-41.

18. http://www.revalidatiegeneeskunde.nl/vereniging/werkgroepen/wpn. accessed 2011 (in Dutch)

19. Terluin B, Van Heest FB, Van der Meer K, et al. NHG-Standaard Angststoornissen. Huisarts Wet. 2004;47(1):26-37.(in Dutch)

20. Van Marwijk HWJ, Grundmeijer HGLM, Bijl D VGM, et al. NHG-Standaard Depressieve stoornis (depressie) (eerste herziening). Huisarts Wet. 2003;46(11):614-33. (in Dutch)

21. Lemmens K, Strating $M$, Huijsman R, Nieboer A. Professional commitment to changing chronic illness care: results from disease management programmes. Int J Qual Health Care. 2009;21(4):233-42.

22. Boyer A, M M, Calatayud N, Roig S, Cantero C. Comparing fibromyalgia patients from primary care and rheumatology settings: clinical and psychosocial features. Rheumatol Int. 2009;29:1151-60.

23. Hauser W, Thieme K, Turk DC. Guidelines on the management of fibromyalgia syndrome - A systematic review. Eur J Pain. 2010; 14(1):5-10.

24. Ryan S, Hassell A, Thwaites C, Manley K, Home D. Developing a new model of care for patients with chronic musculoskeletal pain. J Nurs Man. 2007;15(8):825-9. 
25. Schulte E, Hermann K, Berghöfer A, et al. Referral practices in patients suffering from non-malignant pain. Eur J Pain.2010;14(3):308e1-e10 
Part II

\section{Improving care for patients with chronic}

\section{inflammatory arthritis}

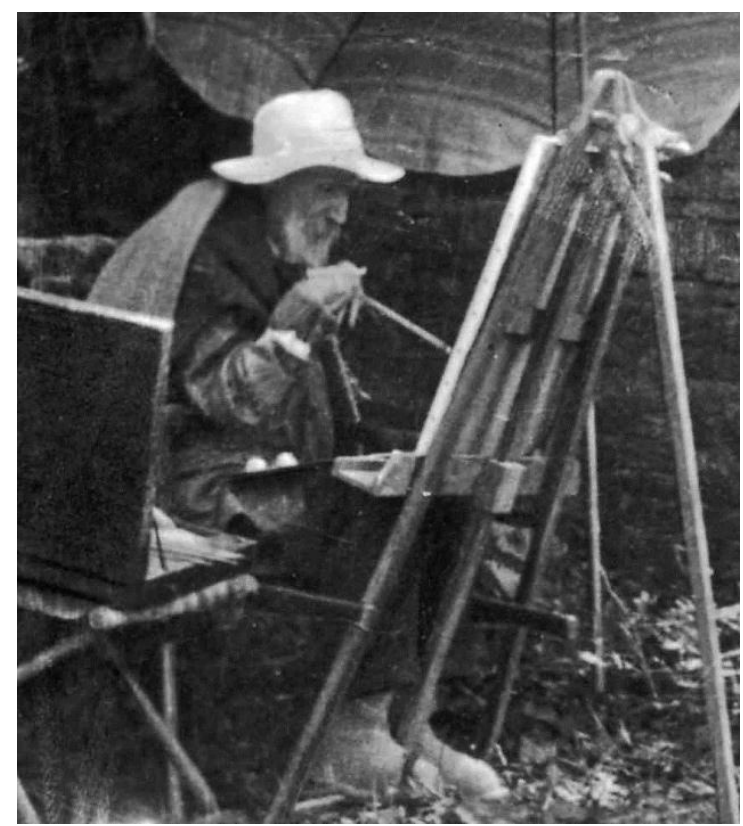

Pierre-Auguste Renoir (1841-1919), French impressionist

Pierre-Auguste Renoir suffered from severe rheumatoid arthritis for the last 25 years of his life. 'Renoir did not humbled himself and painted more than 400 pictures with an incessant activity until the end of his life. The day he died he had spent several hours painting a still life and said to his assistant: I think I am beginning to know something about painting.'

Boonen A, van de Rest J, Dequeker J, van der Linden S. How Renoir coped with rheumatoid arthritis. BMJ 1997;315:1704-1708 


\section{Chapter 6 \\ EULAR recommendations for the role of the nurse in the management of chronic inflammatory arthritis}

Van Eijk-Hustings $Y$, van Tubergen A, Boström C, Braychenko E, Buss B, Felix J, Firth J, Hammond $A$, Harston $B$, Hernandez $C$, Huzjak M, Korandová J, Kukkurainen ML, Landewé R, Mezieres M, Milincovic M, Moretti A, Oliver S, Primdahl J, Scholte-Voshaar M, de la Torre-Aboki J, Waite-Jones J, Westhovens R, Zangi H, Heiberg T, Hill J.

Annals of the Rheumatic Diseases. 2012;71:13-19.

Also published as

Van Eijk-Hustings $Y$, Landewé R, van Tubergen A. European League Against Rheumatism (EULAR): le rôle des infirmiers dans le traitement de l'arthrite inflammatoire chronique (also in Dutch). Ortho-Rhumato. 2012;10(1):10-16.

and

Van Eijk-Hustings Y, Landewé R, van Tubergen A. EULAR aanbevelingen voor de rol van de verpleegkundige in de behandeling van mensen met chronische inflammatoire artritis.

Nederlands Tijdschrift voor Reumatologie. 2011;4:9-14. 


\section{Abstract}

Objective. The authors aim to develop European League Against Rheumatism recommendations for the role of the nurse in the management of patients with chronic inflammatory arthritis, to identify a research agenda and to determine an educational agenda.

Methods. A task force made up of a multidisciplinary expert panel including nurses, rheumatologists, occupational therapist, physiotherapist, psychologist, epidemiologist and patient representatives, representing 14 European countries, carried out the development of the recommendations, following the European League Against Rheumatism standardised operating procedures.

The task force met twice. In the first meeting the aims of the task force were defined, and eight research questions were developed. This was followed by a comprehensive, systematic literature search. In the second meeting, the results from the literature review were presented to the task force that subsequently formulated the recommendations, research agenda, and educational agenda.

Results. In total, 10 recommendations were formulated. Seven recommendations covered the contribution of nurses to care and management: education, satisfaction with care, access to care, disease management, psychosocial support, self-management, and efficiency of care. Three recommendations focused on professional support for nurses: availability of guidelines or protocols, access to education, and encouragement to undertake extended roles. The strength of the recommendations varied from A to $C$, dependent on category of evidence (1A-3), and a high level of agreement was achieved. Additionally, the task force agreed upon 10 topics for future research and an educational agenda.

Conclusion. 10 recommendations for the role of the nurse in the management of chronic inflammatory arthritis were developed, using a combination of evidence-based and expert consensus approach. 


\section{Introduction}

In rheumatology, registered nurses often act as the interface between patients and other members of the multidisciplinary team. As a result of new treatment regimens and organisational developments, the role of the nurse is undergoing great change. However, there are large differences across countries and regions. In several European countries, rheumatology as a nursing specialty does not exist, whereas in other countries, it has developed into a recognised specialty with nurses undertaking advanced and extended roles [1]. These include self-management support, patient education and counselling, intra-articular injections, recommendation for and the prescription of drug treatments, referral to other health professionals, hospital admission of patients, manning telephone advice lines, and monitoring disease-modifying and biologic treatments [2-8]. Nurse-led clinics have been established, and their effectiveness has been shown to bring added value to patients' outcomes [9-11] at a lower cost [12]. While some countries have accepted that interventions undertaken by nurses are essential to effectively tackle the challenges of chronic illness in an economic and integrated fashion, this concept has not developed everywhere.

The aim of the present study was to evaluate the currently available literature according to the European League Against Rheumatism (EULAR) standardised operating procedures in order to provide recommendations for the role of the nurse in the management of chronic inflammatory arthritis (CIA) [13]. This evidence-based approach was complemented by an expert consensus approach.

\section{Methods}

A multidisciplinary task force made up of 15 nurses, a rheumatologist, an occupational therapist, a psychologist, a physiotherapist, two patient representatives and a research fellow, representing several European countries, met twice under the leadership of two conveners and a rheumatologist/clinical epidemiologist. During the first meeting, the task force formulated eight research questions. These questions served as a guide to the systematic literature review (SLR) and subsequently as the basis for the recommendations. The term ' $\mathrm{CI}$ ' ' was confined to rheumatoid arthritis (RA), ankylosing spondylitis and psoriatic arthritis, thereby excluding other systemic inflammatory conditions (e.g. systemic lupus erythematosus) and non-inflammatory disorders (e.g. fibromyalgia).

The target population for the recommendations was chosen to be health care professionals working in the field of rheumatology (rheumatologists, nurses and other disciplines), patients and policy makers.

After translation of the research questions into relevant search terms, an extensive SLR of MEDLINE, Embase, Cochrane CENTRAL, Cumulative Index for Nursing and Allied Health Literature (CINAHL) and PsycINFO was performed in August 2010. Two main search terms 
- 'inflammatory arthritis' and 'nurse' - were searched for in titles, key words, or full texts using Medical Subject Headings (MeSH), subheadings, thesaurus or free text words and truncation symbols. No limitations with regard to publication type, research type, language or time period were applied. Selected titles and abstracts were screened independently for eligibility by AvT and YvE-H. Eligibility criteria were 'inflammatory arthritis', 'interventions undertaken by nurses' and 'relevant outcomes to answer the research questions'. The selection was shared with the other members of the task force, and suggestions and comments by the experts complemented the result of the SLR. Additionally, abstracts from American College of Rheumatology (ACR) and EULAR meetings (2008-2010) were searched (selection procedure is shown in Figure 6.1).

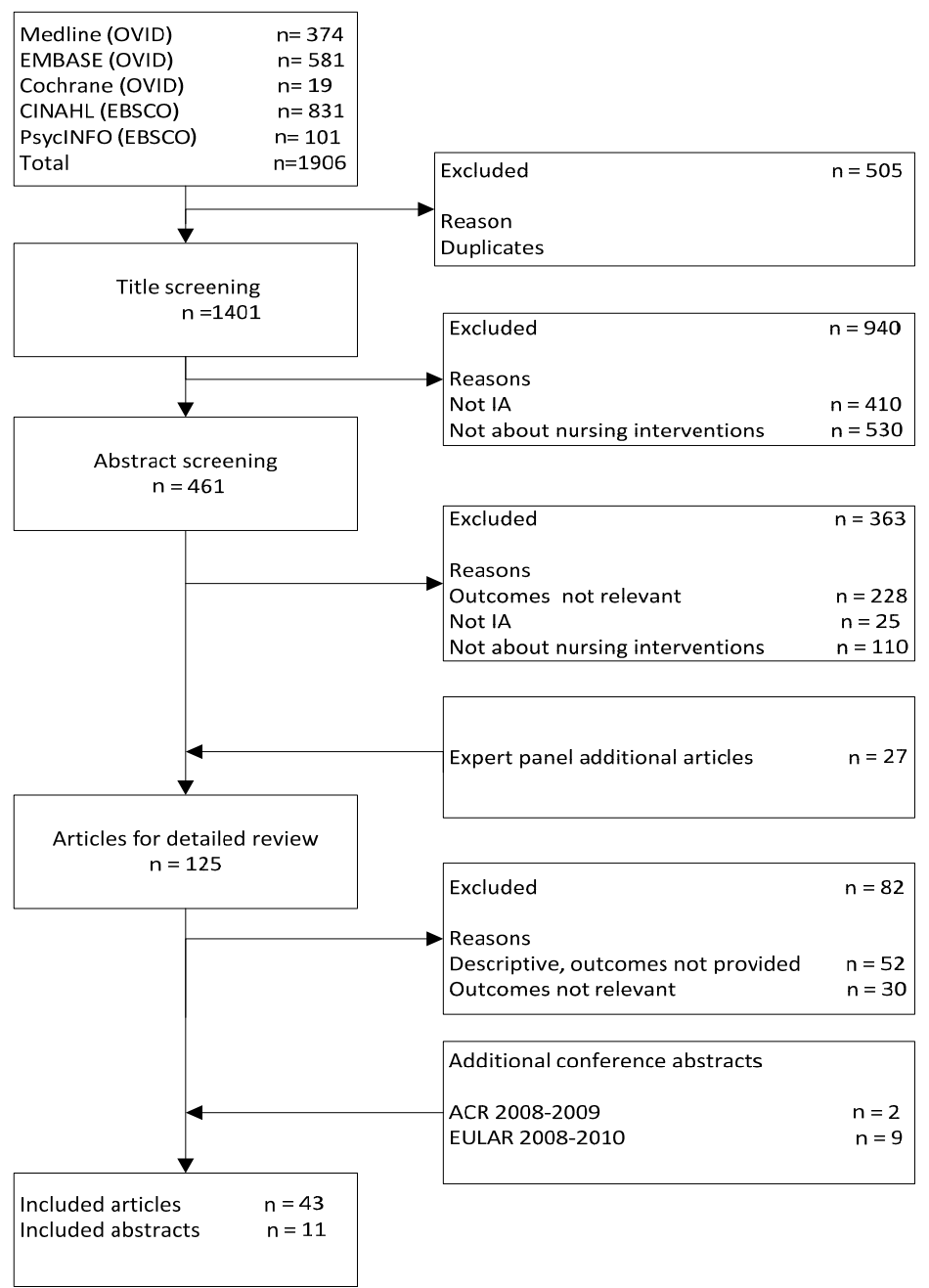

Figure 6.1 Flowchart results of the systematic literature review: 10-13 August 2010 
During the second meeting, the formulation of the recommendations was discussed by the entire group until consensus was reached. The recommendations were graded based on the level of evidence of the literature found (Table 6.1 and 6.2) [13]. This was sent to each participant for final approval and voting on a scale from 0 to 10 . Finally, the task force agreed upon the formulation of a research agenda and an educational agenda.

Table 6.1 Determination of level of evidence

$\begin{array}{ll}\text { Category } & \text { Evidence } \\ \text { 1A } & \text { From meta-analysis of randomised controlled trials } \\ \text { 1B } & \text { From at least one randomised controlled trial } \\ \text { 2A } & \text { From at least one controlled study without randomisation } \\ \text { 2B } & \text { From at least one type of quasi-experimental study } \\ 3 & \text { From descriptive studies, such as comparative studies, correlation studies, or case control } \\ 4 & \text { studies } \\ & \text { From expert committee reports or opinions and/or clinical experience of respected } \\ & \text { authorities }\end{array}$

Table 6.2 Strength of recommendation

$\begin{array}{ll}\text { Strength } & \text { Directly based on } \\ \text { A } & \text { Category } 1 \text { evidence } \\ \text { B } & \text { Category } 2 \text { evidence or extrapolated recommendations from Category } 1 \text { evidence } \\ \text { C } & \text { Category } 3 \text { evidence or extrapolated recommendations from Category } 1 \text { or } 2 \text { evidence } \\ \text { D } & \text { Category } 4 \text { evidence or extrapolated recommendations from Category } 2 \text { or } 3 \text { evidence }\end{array}$

\section{Results}

In total, 54 studies met the inclusion criteria. The selection comprised 1 meta-analysis, 8 randomised controlled trials (RCTs), 2 controlled clinical trials, 9 quasi-experimental studies, and 34 descriptive studies. As the majority of the studies were descriptive, it was acknowledged that there was a high risk of bias.

Table 1 shows the 10 recommendations with a level of evidence ranging from $1 \mathrm{~A}$ to 3 . The strength of recommendations varied from $A$ to $C$ and a high level of expert agreement was achieved.

\section{Recommendations}

All recommendations relate to care delivered by registered nurses with a specific training in rheumatology. This care includes monitoring of disease consequences on the level of daily activities, participation and psychosocial consequences and, increasingly, the monitoring of disease activity, drug treatment, and drug side effects.

The task force judged that the level of evidence for the role of the nurse is far greater in the management of RA than in the management of ankylosing spondylitis and psoriatic arthritis, and therefore, the recommendations should be regarded as points to consider for patients with these conditions. 
The order of the recommendations follows the discussion in the task force. The first three recommendations are formulated from the patient's perspective, the other recommendations are formulated from the nurse's perspective (see Table 6.3).

Table 6.3 Recommendations for rheumatology nursing management of CIA [relevant references]

\section{Recommendations}

1 Patients should have access to a nurse for education to improve knowledge of $\mathrm{CIA}$ and its management throughout the course of their disease $[9,10,16-18]$

2 Patients should have access to nurse consultations in order to experience improved communication, continuity and satisfaction with care $[9,10,22-31]$

3 Patients should have access to nurse-led telephone services to enhance continuity of care and to provide ongoing support [3236]

4 Nurses should participate in comprehensive disease management to control disease activity, to reduce symptoms and to improve patient-preferred outcomes [9-11,23,31,37-42]

5 Nurses should identify, assess and address psychosocial issues to minimise the chance of patients' anxiety and depression $[9,10,30,31,37,39,45-47]$

6 Nurses should promote self-management skills in order that patients might achieve a greater sense of control, self-efficacy and empowerment $[11,37,45,49-54]$

7 Nurses should provide care that is based on protocols and guidelines according to national and local contexts $[41,42,57-$ 61]

8 Nurses should have access to and undertake continuous education in order to improve and maintain knowledge and skills $[62,65,66,70-73]$

9 Nurses should be encouraged to undertake extended roles after specialised training and according to national regulations $[9-12,26,27,29,42,62]$

10 Nurses should carry out interventions and monitoring as part of comprehensive disease management in order to achieve cost savings $[9,12,30,32-34,36,42,49,54,61,69]$

\begin{tabular}{|c|c|c|}
\hline $\begin{array}{l}\text { Category } \\
\text { of } \\
\text { evidence }\end{array}$ & $\begin{array}{l}\text { Strength } \\
\text { recommen } \\
\text { dation }\end{array}$ & $\begin{array}{l}\text { Agreement } \\
(0-10 \\
\text { mean (SD)) }\end{array}$ \\
\hline $1 B$ & $A$ & $9.9(0.2)$ \\
\hline $1 \mathrm{~B}$ & A & $9.1(0.6)$ \\
\hline 3 & C & $9.2(0.8)$ \\
\hline $1 \mathrm{~A}$ & A & $9.4(0.8)$ \\
\hline $1 \mathrm{~B}$ & A & $9.4(0.7)$ \\
\hline 3 & C & $9.7(0.5)$ \\
\hline 3 & C & $8.4(1.0)$ \\
\hline 3 & $C$ & $9.7(0.5)$ \\
\hline 3 & C & $9.5(0.8)$ \\
\hline $1 \mathrm{~B}$ & $\mathrm{C}$ & $8.8(1.3)$ \\
\hline
\end{tabular}

$\mathrm{CIA}$ : chronic inflammatory arthritis

1. Patients should have access to a nurse for education to improve knowledge of CIA and its management throughout the course of their disease.

Patient education is defined as a planned process aiming to improve coping strategies and increase self-care abilities [14, 15]. A statistically significant increase in the patient's knowledge of the disease process, treatment strategies (e.g. drug therapy), physiotherapy, and self-management strategies, (e.g. joint protection techniques) was found in patients 
with RA who were educated during monitoring [10], or who received a specific educational program from nurses [16-18]. Moreover, statistically significant greater levels of knowledge were found in patients monitored and educated by a nurse compared to patients monitored by doctors [9].

Involvement in disease management allows nurses to offer timely education to newly diagnosed and established patients. In addition to information about their disease and treatments, education should address risk factors for comorbidities, such as cardiovascular problems [19]. Nurses can also play an important role in educating patients about the principles of 'treat to target' [20] in order to enhance adherence. Overall, the literature demonstrates that education by nurses improves patients' knowledge of their disease and disease-related issues.

2. Patients should have access to nurse consultations in order to experience improved communication, continuity and satisfaction with care.

Satisfaction with care is considered an indicator of the quality of care [21]. The majority of the studies showed statistically significant increased satisfaction with information, empathy, technical quality and attitude of the professional, as well as access to care in patients with RA when monitored by a nurse compared to monitoring by doctors or other health professionals $[9,10,22-24]$. There were no differences in patient satisfaction after intra-articular injections given by either a nurse or a doctor [25]. Patients valued nurses' communication skills and nursing care in terms of advice to use assistive devices, referral to other members of the multidisciplinary team and education [26, 27]. Quality and continuity of care in nurse-led clinics were perceived as good [28]. Holistic care and patient-centred information were found to contribute to patient satisfaction [29].

However, some studies report conflicting evidence. One study did not find statistically significant changes in patients' satisfaction after monitoring by a nurse practitioner [30]. In another study, patients' satisfaction with multidisciplinary team care was found to be significantly higher than care coordinated by a clinical nurse specialist [31].

Nurses tend to be accessible to patients and can facilitate access to services. Continuity of care provides the opportunity to establish a confidential and longstanding patientprofessional relationship that is to be considered important by patients. Despite some conflicting evidence, the task force concluded that disease monitoring or follow-up care by nurses enhances patients' perceptions of care.

3. Patients should have access to nurse-led telephone services to enhance continuity of care and to provide ongoing support.

The unpredictable, fluctuating nature of rheumatic diseases means that rapid access to advice is of utmost importance for patients. Telephone helplines were found to support accessibility to care [32]. Patients perceived that telephone helplines support enhanced 
continuity of care and provided them with access to a knowledgeable practitioner who would often be the first point of contact at times of need. Mostly, patients stated that they would call again if needed [32-35]. The contents of the service that was offered by the helplines was not clearly described in all studies, and its focus varied. Some services provided regular follow-up [33], while others focussed on support by answering diseaserelated questions or worries that might avoid unnecessary consultations with general practitioners [32]. There were also examples of helplines that focused specifically on triage to identify patients that required fast-track clinical assessment [36]. In countries where telephone services are not available, information and support is sometimes given by email. In general, both means of support contribute to enabling patient accessibility and appropriate care.

4. Nurses should participate in comprehensive disease management to control disease activity, to reduce symptoms and to improve patient-preferred outcomes.

Nurses have increasingly combined providing support to patients in a broad spectrum of disease-related problems, such as psychosocial problems and limitations in participation, with disease monitoring. Several studies showed that nurse-led care results in equivalent suppression of disease activity in patients with RA, in comparison with medical care [9-11, 23, 31, 37-39]. Moreover, appropriately trained nurses were able to detect early arthritis [40], make referrals, determine necessary interventions, and change medications [41, 42]. Patients with RA also perceived statistically significant less pain [9] and fatigue when monitored by nurses, compared to doctors [10]. Research showed that these symptoms contribute to patients' perceptions of disease impact, and therefore, patients consider them as preferred outcomes in clinical trials [43].

There is evidence that nurses can manage $\mathrm{CIA}$ appropriately, that they can contribute to symptom control, and that they can play a role in the early detection of arthritis.

5. Nurses should identify, assess and address psychosocial issues to minimise the chance of patients' anxiety and depression.

The psychosocial impact of CIA is considerable, and anxiety and depression are both wellknown comorbidities in RA [44]. One study found a statistically significant reduction in anxiety and depression in patients with RA after monitoring by a nurse [9]. Others showed equivalent reductions in anxiety and depression in patients receiving nurse-led or medical care $[10,37]$.

It has been shown that cognitive-behavioral interventions provided by a nurse can statistically significant improve the emotional well-being in patients with RA [45]. Moreover, quality of life was comparable between patients receiving either nurse-led or multidisciplinary team care $[30,31,39]$. Psychosocial adjustment, which is considered as overall adaptation to the impact of RA, was comparable in patients monitored by either a 
nurse or a doctor, but patients monitored by a nurse reported supplementary increased social activities [46]. Patients valued the opportunity to discuss the wider implications of their condition with a nurse [47]. Counselling in psychological issues is considered important, but undertaking this role depends strongly on the level of the problems, the skills of the nurse and the ability to access other sources of support when required - for example, the availability of psychologists in assisting with these tasks. Therefore, the task force considered identifying problems and referring to other professionals when needed as key components of nursing care.

6. Nurses should promote self-management skills in order that patients might achieve a greater sense of control, self-efficacy and empowerment.

Self-efficacy refers to the belief that one can successfully execute the behaviour required to attain certain goals and, thus, to feel in control [48]. Research shows that nurses are likely to contribute to increased perceived control, levels of self-efficacy and empowerment. Patients reviewed by a clinical nurse specialist in a drug-monitoring clinic perceived clinically relevant increased perception of control [11]. After a cognitivebehavioral intervention provided by nurses, patients demonstrated a statistically significant increase in personal coping resources, such as competency beliefs and decrease of helplessness [45]. Nurse-led management, information and support have been shown to increase self-efficacy beliefs and self-reliance of patients $[49,50]$ as well as to contribute to patient empowerment [50-52].

However, some studies were unable to demonstrate any changes in lifestyle, selfmanagement behaviour or self-efficacy after interventions undertaken by nurses $[37,53$, 54].

Support with regard to self-management comprises all actions that encourage patients to manage their own disease, and this is a task for all members of the multidisciplinary team. As self-management support is multifaceted, the task force considered this as an important role of the nurse, rather than a single intervention undertaken by nurses.

7. Nurses should provide care that is based on protocols and guidelines according to national and local contexts.

Guidelines provide research-based options for decisions whereas protocols describe steps to be taken to reduce variation in the treatment of patients [55]. Guidelines and protocols are essential for all health care professionals to ensure safe and high-quality care. Often these guidelines and protocols will be adapted to a national or local context [56].

It has been demonstrated that structured implementation material supported nurses in the guidance of patients with a complex treatment regimen. Furthermore, nurses' perceived capability for guidance increased statistically significant after an educational session [57]. Guidelines have been found to support nurses' clinical decision-making skills 
with regard to assessment and treatment [58], referral [42], supplementary prescription [41], and therefore contribute to evidence-based nursing [59] and holistic care [41, 58]. Protocols have been found to support continuity and safety of care in terms of immediate and appropriate adjustments of treatment $[41,42,60]$ and enabled nurses to discriminate between early arthritis and other conditions [61].

However, standardised care should be implemented alongside national and regional regulations yet enable an individualised, patient-centred approach. Overall, guidelines and protocols are likely to support nurses in providing evidence-based care.

8. Nurses should have access to and undertake continuous education in order to improve and maintain knowledge and skills.

The literature demonstrates that nurses undertake a wide variety of interventions, including self-management support, education, counselling, drug monitoring, drug prescription and administration of intra-articular injections [62-69]. In a survey undertaken in the UK, the majority of the nurses felt confident in their abilities to undertake these tasks [65]. The self-confidence of nurses is supported by knowledge of rheumatic diseases and their treatment, skills in relation to education, counselling and training, collaboration with other health professionals, and manual skills [70]. Furthermore, nurse education needs to be tailored to reflect research findings if nurses are to maintain and enhance their knowledge and skills appropriately [62, 70]. Studies have demonstrated that the contents of consultations and issues for patient education and counselling are dependent on the educational level of nurses [71-73]. However, it has been reported that knowledge and skills do not appear to be sufficiently covered by basic and advanced training at present [66].

Educational opportunities in nursing vary to a large extent if an educational curriculum is not defined accurately. Given the complexity of the tasks and activities that are performed by nurses, ongoing access to well defined education on a basic, advanced and extended level is needed.

9. Nurses should be encouraged to undertake extended roles after specialised training and according to national regulations.

Increasingly, nursing care expands from a more basic level to an advanced or an extended level. The rationale for these developments comes from several perspectives. From the patient's perspective, holistic care, patient-centred information and communication skills of nurses are appreciated, and improved outcomes such as knowledge, satisfaction, physical and psychological symptoms, were found [9-11, 26, 27, 29, 42]. From the professional's perspective, job satisfaction is enhanced by greater autonomy and by optimal use of nurses' qualities and skills [42, 62]. From an organisational perspective, advanced and extended roles may prevent fragmentation of care and promote efficiency 
and accessibility [12, 62]. Key components for achieving extended roles include performing outpatient procedures, prescribing drugs and treatment, and taking a lead in the organisation of local health services [62].

However, some concerns about extended nursing roles have been raised among members of the medical and the nursing professions about being 'placebo-doctors' or 'second-rate doctors' [26, 62]. If role development is patient-focused, aiming to meet patients' identified needs and to improve overall patient care, the extended role of the nurse should be regarded as a complement to the medical role and not only as a substitution of medical tasks.

The competencies and skills of the nurse should be considered and optimised to further improve patient care, to enhance and mobilise nursing competency, and to improve efficiency of care.

10. Nurses should carry out interventions and monitoring as part of comprehensive disease management in order to achieve cost savings.

Innovative nurse-led care has advanced to increase efficiency of care. Coordinated care by a clinical nurse specialist was shown to be statistically significantly cost-effective, compared with multidisciplinary inpatient or day-patient care [12]. Additional costs for a nurse practitioner to a medical team were found to be partially compensated by taking over tasks from other team members [30]. Moreover, nurse-led monitoring led to decreased medical referrals [42] or decreased the length of stay in a rehabilitation program for patients with RA [49], all pointing to cost savings. Furthermore, rheumatology telephone helplines are likely to contribute to cost savings by decreasing the number of unnecessary doctor consultations [32, 34, 36] and by reducing follow-up waiting time [33]. Accessibility of care also improved with the nurse being able to discriminate different categories of early arthritis [61]. Recent preliminary data suggest a positive cost-benefit of the role of nurse specialists by preventing unscheduled care and hospital admissions [69]. However, compared to usual care from a rheumatologist, patients seen by a nurse were more frequently referred to occupational therapists, and this difference was statistically significant $[9,54]$. It is arguable whether this phenomenon is a consequence of the greater emphasis that nurses placed on joint protection and improving functioning in daily living [9] and, therefore, could be considered as quality improvement of care rather than increase in costs [54]. There is need for high-quality economic analyses in future research.

\section{Research agenda}

In addition to the developed recommendations, a research agenda and an educational agenda were formulated. The research agenda highlights where there is weak or lacking evidence to further optimise the role of the nurse in the management of $\mathrm{CIA}$ and is shown in Box 6.1. 


\section{Box 6.1 Research agenda}

1. To study the contribution of the nurse in improving access to care and in facilitating the effective utilisation of care provided by members of the multidisciplinary team

2. To study the role of nurses in optimising 'treat to target' in early disease

3. To study the contribution of the nurse in improving patient-preferred outcomes

4. To compare the different components of nursing care in each European country in relation to knowledge and competencies

5. To perform cost-effectiveness studies across different European countries, on the role of the nurse in basic and advanced practice

6. To study the long-term effects of interventions by a nurse on quality of life, psychosocial and general well-being

7. To study the contribution of the nurse in improving self-management and self-efficacy

8. To study the impact of interventions by a nurse on the patient's employment status and social participation

9. To define the contribution of the nurse in the prevention of comorbidities

10. To study the recommendations in different patient populations including ankylosing spondylitis and psoriatic arthritis

\section{Educational agenda}

The educational agenda was defined to support educational opportunities for nurses and to guarantee quality in nursing care (shown in Box 6.2).

\section{Box 6.2 Educational agenda}

1. To develop a competency framework for nurses

2. To develop educational nursing programs at the basic and advanced level

\section{Discussion}

Nurses are the largest group of health care professionals, and their role development in the provision of team care for patients with rheumatic diseases follows a worldwide tendency to more proactive, evidence-based care for patients with chronic disorders with nurses fulfilling extended roles [74, 75]. The role of nurses in the management of $\mathrm{CIA}$ appeared to differ greatly between countries and across regions due to their educational level, training and expertise, as well as to national and regional regulations and contexts, and funding issues related to overall health care provision.

Evidence for the additional value of nurses was most obvious when disease monitoring by nurses was combined with support for patients in a broad spectrum of disease-related problems [9-11]. However, role, tasks, and qualifications should be clearly described in frameworks to practice that include protocols and guidelines.

Nurses tend to be accessible for patients. Given their qualities and skills with regard to coordination of care [31,39], they may facilitate increased access to multidisciplinary team care. In practice, however, some tasks may be provided by other health professionals, depending on local accessibility and competency. It is arguable whether 
these tasks have the same quality when provided by different health professionals. This study explicitly deals with nurses, because this profession is often not clearly visible in multidisciplinary team care, but their role should be considered in the context of care delivery of other health care providers and an active role of patients. By their continuous presence, nurses can identify and communicate specific areas that can be addressed by other members of the multidisciplinary team.

Ten recommendations for the role of the nurse in the management of patients with $\mathrm{CIA}$ were developed. There are some limitations to these recommendations that need to be addressed. First, the task force decided to include all types of studies that could give insight in nursing care, as only a limited number of RCTs exist and RCTs alone may not adequately cover the topic [76, 77]. Qualitative studies provide important insight in patients' individual needs, functional limitations, and the extent to which different types of care meet those needs [78], all of which may improve quality of care [21, 28, 79]. However, these studies are rated with a lower level of evidence than RCTs, and subsequently, there is a high risk of bias. By including the additional and clinically relevant information retrieved from these non-controlled studies and combining this with a consensus approach, the task force considered that this has ultimately led to more inclusive recommendations. Second, the task force intended to formulate strong statements that were useful in emphasising the role of the rheumatology nurse throughout Europe. The opinion of the task force members, all representatives from nurses as well as other relevant parties, was considered of additional value in deciding on the strength of the recommendations. This may have contributed to an overestimation of the strength of recommendations. However, the high level of agreement within the task force supported the method used. Agreement with the recommendations by nurses, rheumatologists, health care professionals in daily practice, but also patients will soon be validated simultaneously with dissemination of the recommendations.

The research agenda will support future directions of nursing research, and it is important that high-quality studies, with clear descriptions of nursing roles and interventions, will be conducted as the role of the nurse in care is currently often not clearly stated in studies [80]. Given the research issues and themes of importance, qualitative and quantitative insights into nursing care are needed.

The educational agenda will support access to high-quality education for nurses, will enhance clarity about knowledge, skills and competencies required by nurses, and will reduce diversity of the nursing role within and between countries.

The dissemination and implementation of the recommendations will need overall support from EULAR. Implementing these recommendations, including education, demands a clear implementation strategy in which barriers will need to be assessed. The extent to which such barriers can be addressed will be influenced by national and local regulations. 
In conclusion, this study provides 10 evidence-based and expert opinion-based recommendations on the role of the nurse in the management of CIA. These recommendations provide a basis for emphasising and optimising rheumatology nursing care in order to contribute to a more standardised level of professional nursing across Europe.

\section{Acknowledgements}

We thank Sofia Ramiro (PhD candidate) and Wies Limpens (Maastricht University Library) for their contribution to the systematic literature review. 


\section{References}

1. Carr A. Defining the Extended Clinical Role for Allied Health Professionals in Rheumatology. ARC Conference Proceedings NO 12, Arthritis Research Campaign, Chesterfield. 2001.

2. Bands VE. Nursing care of patients with rheumatoid arthritis. John Hopkins Advanced Studies in Nursing. 2007;5(1):23-31.

3. Daul P, Grisanti J. Monitoring response to therapy in rheumatoid arthritis: Perspectives from the clinic. Bulletin of the NYU Hospital for Joint Diseases. 2009;67(2):236-42.

4. Hill J, Hale C. Clinical skills: evidence-based nursing care of people with rheumatoid arthritis. Br J Nurs. 2004;13(14):852-7.

5. Oliver S. Improving long-term outcomes for rheumatoid arthritis: evidence-based care. Primary Health Care. 2010;20(9):30-9.

6. Palmer D, El Miedany Y. Biological nurse specialist: goodwill to good practice. Br J Nurs. 2010;19(8):47780.

7. Thwaites C, Ryan S, Hassell A. A survey of rheumatology nurse specialists providing telephone helpline advice within England and Wales. Rheumatology (Oxford). 2008;47:522-5

8. Meadows A, Sheenan NJ. Prescribing and injecting: the expanding role of the rheumatology nurse. Musculoskeletal Care. 2005;3:176-8.

9. Hill J, Bird A, Harmer R, et al. An evaluation of the effectiveness, safety and acceptability of a nurse practitioner in a rheumatology outpatient clinic. Br J Rheumatol. 1994;33(3):283-8.

10. Hill J, Thorpe R, Bird H. Outcomes for patients with RA: a rheumatology nurse practitioner clinic compared to standard outpatient care. Musculoskeletal Care. 2003;1(1):5-20.

11. Ryan $S$, Hassell $A B$, Lewis $M$, et al. Impact of a rheumatology expert nurse on the wellbeing of patients attending a drug monitoring clinic. J Adv Nurs. 2006;53(3):277-86.

12. Van Den Hout WB, Tijhuis GJ, Hazes JMW, et al. Cost effectiveness and cost utility analysis of multidisciplinary care in patients with rheumatoid arthritis: A randomised comparison of clinical nurse specialist care, inpatient team care, and day patient team care. Ann Rheum Dis. 2003;62(4):308-15.

13. Dougados M, Betteridge N, Burmester GR, et al. EULAR standardised operating procedures for the elaboration, evaluation, dissemination, and implementation of recommendations endorsed by the EULAR standing committees. Ann Rheum Dis. 2004;63(9):1172-6.

14. Hirano P, Laurent D, Lorig K. Arthritis patient education studies, 1987- 1991: a review of the literature. Patient Educ Couns. 1994;24:9-54.

15. Lorig K, Konkol L, Gonzalez V. Arthritis patient education: a review of the literature. Patient Educ Couns. 1987;10:207-52.

16. Burma MR, Rachow JW, Kolluri S, Saag KG. Methotrexate patient education: a quality improvement study. Arthritis Care Res. 1996;9(3):216-22.

17. Grahame R, West J. The role of the rheumatology nurse practitioner in primary care: An experiment in the further education of the practice nurse. Br J Rheumatol. 1996;35(6):581-8.

18. Rodriguez Lc, Bilbao A, Naranjo A, et al. Patient education in rheumatoid arthritis: Its influence in the disease outcome. Rev Esp Reumatol. 1996;23(2):40-8.

19. Peters MJ, Symmons DP, McCarey D, et al. EULAR evidence-based recommendations for cardiovascular risk management in patients with rheumatoid arthritis and other forms of inflammatory arthritis. Ann Rheum Dis. 2009;69(2):325-31.

20. Smolen J, Aletaha D, Bijlsma J,et al. Treating rheumatoid arthritis to target: recommendations of an international task force. Ann Rheum Dis. 2010;69:631-7.

21. Jacobi C, Boshuizen H, Rupp I, et al. Quality of rheumatoid arthritis care: the patient's perspective. Int J Qual Health Care. 2004;16(1):73-81.

22. Arthur V, Clifford C. Rheumatology: A study of patient satisfaction with follow-up monitoring care. J Clin Nurs. 2004;13(3):325-31.

23. Koksvik H, Magnussen A, Zangi H. Patient satisfaction with nurse-led care in a rheumatology outpatient clinic [abstract]. Two year follow-up of a randomised controlled trial. Ann Rheum Dis. 2009;68(Suppl 3):770.

24. Van Eijk Y, Boonen A, Schulpen G, et al. Safety and patient satisfaction of infliximab administration in an extramural setting supervised by a rheumatology specialist nurse. Ann Rheum Dis. 2006;65(2):276.

25. Edwards J, Hassell A. Intra-articular and soft tissue injections by nurses: preparation for expanded practice. Nurs Stand. 2000;14(33):43-6. 
26. Hill J. Patient evaluation of a rheumatology nursing clinic. Nurs Times. 1986;82(27):42-3.

27. Wright $\mathrm{VI}$, Hopkins R. Patients' perceptions of staff in a department of rheumatology. Br J Rheumatol. 1990;29(5):374-6.

28. Temmink D, Hutten JB, Francke AL, et al. Quality and continuity of care in Dutch nurse clinics for people with rheumatic diseases. Int J Qual Health Care. 2000;12(2):89-95.

29. Makelainen $P$, Vehvilainen-Julkunen K, Pietila AM. Rheumatoid arthritis patient education: RA patients' experience. J Clin Nurs. 2009;18(14):2058-65.

30. Van Der Sluis CK, Datema L, Saan I, et al. Effects of a nurse practitioner on a multidisciplinary consultation team. J Adv Nurs. 2009;65(3):625-33.

31. Tijhuis GJ, Zwinderman AH, Hazes JMW, et al. A randomized comparison of care provided by a clinical nurse specialist, an inpatient team, and a day patient team in rheumatoid arthritis. Arthritis Rheum. 2002;47(5):525-31.

32. Hughes RA, Carr ME, Huggett A, et al. Review of the function of a telephone helpline in the treatment of outpatients with rheumatoid arthritis. Ann Rheum Dis. 2002;61(4):341-5.

33. Hennell S, Spark E, Wood B, et al. An evaluation of nurse-led rheumatology telephone clinics. Musculoskeletal Care. 2005;3(4):233-40.

34. Newton P, Buckley $\mathrm{H}$, Ali $\mathrm{H}$, et al. Rheumatology telephone helpline and its role in provision of care to patients [abstract]. Ann Rheum Dis. 2008;67(Suppl II):583.

35. Wylie E, McAteer C, Collins D. An audit of patient and staff views of a rheumatology telephone helpline service [abstract]. ACR. 2008;1888.

36. Leung ML. The usefulness of rheumatology nurse managed telephone helpline in enhancing patient care and reducing unnecessary early clinic attendance [abstract]. Ann Rheum Dis. 2008;67(Suppl II):669.

37. Ndosi M, Hill J, Hale C. Is nurse-led care for RA patients clinically effective? [abstract]. ACR. $2009 ; 1981$.

38. Ndosi M, Vinall K, Hale C, et al. Does nurse-led care have an effect in RA disease activity? A metaanalysis [abstract]. Ann Rheum Dis. 2010;69(Suppl 3):722.

39. Tijhuis GJ, Zwinderman AH, Hazes JMW, et al. Two-year follow-up of a randomized controlled trial of a clinical nurse specialist intervention, inpatient, and day patient team care in rheumatoid arthritis. J Adv Nurs. 2003;41(1):34-43.

40. Gormley GJ, Steele WK, Gilliland A, et al. Can diagnostic triage by general practitioners or rheumatology nurses improve the positive predictive value of referrals to early arthritis clinics? Rheumatology (Oxford). 2003;42(6):763-8.

41. Hennell S, Spark E, Wood B, et al. Supplementary prescribing for rheumatology patients: an evaluation. Nurse Prescriber. 2005;2(5).

42. Ryan S. Nurse-led drug monitoring in the rheumatology clinic. Nurs Stand. 1997;11(24):45-7.

43. Gossec L, Dougados M, Rincheval N, et al. Elaboration of the preliminary Rheumatoid Arthritis Impact of Disease (RAID) score: a EULAR initiative. Ann Rheum Dis. 2009;68(11):1680-5.

44. Hill CL, Gill T, Taylor AW, et al. Psychological factors and quality of life in arthritis: A population-based study. Clin Rheumatol. 2007;26:049-54.

45. Sinclair VG, Wallston KA, Dwyer KA, et al. Effects of a cognitive-behavioral intervention for women with rheumatoid arthritis. Res Nurs Health. 1998;21(4):315-26.

46. Earle JR, Perricone PJ, Maultsby DM, et al. Psycho-social adjustment of rheumatoid arthritis patients from two alternative treatment settings. J Rheumatol. 1979;6(1):80-7.

47. Ryan S. Rheumatology: Sharing care in an outpatient clinic. Nurs Stand. 1995;10(6):23-5.

48. Bandura A. Self-efficacy: toward a unifying theory of behavioral change.Psychol Rev. 1977;84:191-215.

49. Barry J, McQuade C, Livingstone T. Using nurse case management to promote self-efficacy in individuals with rheumatoid arthritis. Rehabil Nurs. 1998;23(6):300-4.

50. Kallas KD. Establishing a self-administered medication program. J Nurs Adm. 1984;14(11):38-42.

51. Arvidsson SB, Peterson A, Nilsson I, et al. A nurse-led rheumatology clinic's impact on empowering patients with rheumatoid arthritis: A qualitative study. Nurs Health Sci. 2006;8(3):133-9.

52. Larsson I, Arvidsson S, Bergman S, et al. Patients' perceptions of drug information given by a rheumatology nurse: a phenomenographic study. Musculoskeletal Care. 2010;8(1):36-45.

53. Gordon MM, Thomson EA, Madhok R, et al. Can intervention modify adverse lifestyle variables in a rheumatoid population? Results of a pilot study. Ann Rheum Dis. 2002;61(1):66-9.

54. Temmink D, Hutten JBF, Francke AL, et al. Rheumatology outpatient nurse clinics: A valuable addition? Arthritis Rheum. 2001;45(3):280-6. 
55. Grol R, Grimshaw J. Evidence-based implementation of evidence-based medicine. Jt Comm J Qual Improv. 1999;25(10):503-13.

56. http://www.institute.nhs.uk/quality and service improvement tools/quality and service improveme nt tools/protocol based care.html. [accessed February 2011].

57. van Tuyl LH, Plass AM, Lems WF, et al. Facilitating the Use of COBRA Combination Therapy in Early Rheumatoid Arthritis: A Pilot Implementation Study. J Rheumatol. 2009;36(7):1380-6.

58. Oliver S. Multidisciplinary disease management in rheumatology. Prof Nurse. 2003;19(3):137-41.

59. Voorneveld H, Duymaer van Twist L, Veldhuizen C. Development of a guideline for rheumatology nurses in the Netherlands about supervision, education and administer biological agents [abstract]. Ann Rheum Dis. 2008;67(Suppl II):670.

60. Hennell SL, Wood BB, Spark EW. Competency and the use of clinical management plans in rheumatology practice. Nurse Prescribing. 2004;2(1):26.

61. El Miedany Y, Palmer D, El Gaafary M. Diagnosis of early arthritis: outcomes of a nurse-led clinic. Br J Nurs. 2006;15(7):394-9.

62. Goh L, Samanta J, Samanta A. Rheumatology nurse practitioners' perceptions of their role. Musculoskeletal Care. 2006;4(2):88-100.

63. Hehir M, Carr M, Davis B, Radford S, Robertson L, Tipler S, et al. Nursing support at the onset of rheumatoid arthritis: Time and space for emotions, practicalities and self-management. Musculoskeletal Care. 2008;6(2):124-34.

64. Hill J, Oliver S, Finney D. Rheumatology nurses and health professionals in the UK: who are they and what do they do? [abstract]. Ann Rheum Dis. 2010;69(Suppl 3):744.

65. Hill J, Ryan S, Oliver S. The clinical practice and perceived competencies of rheumatology nurse specialists in the UK [abstract]. Ann Rheum Dis. 2010;69(Suppl 3):725.

66. Hurkmans E, R G, Verhoef J, Vliet Vlieland TP. Rheumatology health professionals' perspectives on their current and future tasks and education [abstract]. Ann Rheum Dis. 2010;69(Suppl 3):89.

67. Long $A F$, Kneafsey $R$, Ryan $J$, et al. The role of the nurse within the multi-professional rehabilitation team. J Adv Nurs. 2002;37(1):70-8.

68. Long AF, Kneafsey R, Ryan J. Rehabilitation practice: challenges to effective team working. Int J Nurs Stud. 2003;40(6):663-73.

69. Oliver S, Leary A. Describing the complexity and value of the nurse specialist role in rheumatology in the UK using information technology [abstract]. Ann Rheum Dis. 2010;69(Suppl 3):717.

70. Juhola H, Kukkurainen ML, Suominen T. Rheumatology nurses' work-related empowerment. Musculoskeletal Care. 2007;5(2):91-7.

71. Makelainen P, Vehvilainen-Julkunen K, Pietila AM. Rheumatoid arthritis patients' education - Contents and methods. J Clin Nurs. 2007;16(11C):258-67.

72. Ryan S, Wylie E. An exploratory survey of the practice of rheumatology nurses addressing the sexuality of patients with rheumatoid arthritis. Musculoskeletal Care. 2005;3(1):44-53.

73. Sierakowska M, Krajewska-Kulak E, Lewko J, et al. The education of patients with rheumatoid arthritis-the knowledge and expectation of patients-the opinions of rheumatology nurses. Rocz Akad Med Bialymst 2005;50(Suppl 1):107-10.

74. Laurant $M$, Reeves D, Hermens $R$, et al. Substitution of doctors by nurses in primary care. Cochrane Database Syst Rev. 2005;18(2):CD001271.

75. Loveman E, Royle P, Waugh N. Specialist nurses in diabetes mellitus. Cochrane Database Syst Rev. 2003;2:CD003286.

76. Craig P, Dieppe P, Macintyre S, et al. Developing and evaluating complex interventions: the new Medical Research Council guidance. BMJ. 2008;337:979-83.

77. Campbell M, Fitzpatrick R, Haines A, et al. Framework for design and evaluation of complex interventions to improve health. BMJ. 2000;16;321(7262):694-6.

78. Ward V, Hill J, Hale C, et al. Patient priorities of care in rheumatology outpatient clinics: a qualitative study. Musculoskeletal Care. 2007;5(4):216-28.

79. Oliver S. Achieving quality care in rheumatoid arthritis. Practice Nursing. 2009;20(9):460.

80. Esselens G, Westhovens R, Verschueren P. Effectiveness of an integrated outpatient care program compared with present-day standard care in early rheumatoid arthritis. Musculoskeletal Care. 2009;7(1):1-16. 


\section{Chapter 7}

\section{Dissemination and evaluation of the EULAR}

recommendations for the role of the nurse in the management of chronic inflammatory arthritis: results of a multinational survey among nurses, rheumatologists and patients 


\begin{abstract}
Objective. To a) disseminate-, b) assess agreement with-, c) assess application of-, and d) identify potential barriers for implementation of the European League Against Rheumatism (EULAR) recommendations for the role of the nurse in the management of chronic inflammatory arthritis (CIA) among nurses, rheumatologists and patients.

Methods. A web-based survey was distributed across Europe and the United States of America (USA) using snowball sampling. Levels of agreement and application were assessed using a 0-10 rating scale (0: none, 10: full agreement/application). Reasons for disagreement and potential barriers to application of each recommendation were sought. Regional differences with respect to agreement and application were explored.

Results. In total, 967 nurses, 548 rheumatologists and 2,034 patients from 23 countries participated. Median level of agreement was high in all three groups ranging from 8 to 10 per recommendation. Median level of application was substantially lower ranging from 0 to 8 per recommendation. Agreement and application were lowest in Eastern- and Central Europe. The most commonly reported reasons for incomplete agreement were 'too many other responsibilities' (nurses), 'doubts about knowledge of the nurse' (rheumatologists) and 'fear of losing contact with the rheumatologist' (patients). The most commonly reported barriers to the application were time constraints and unavailability of service. Rheumatologists' responses suggested that nurses had insufficient knowledge to provide the recommended care.

Conclusion. The EULAR recommendations for the role of the nurse in the management of CIA have been disseminated among nurses, rheumatologists and patients across Europe and USA. Agreement with these recommendations is high, but application is lower and differed across regions.
\end{abstract}




\section{Introduction}

Recently, 10 European League Against Rheumatism (EULAR) recommendations for the role of the nurse in the management of chronic inflammatory arthritis (CIA) have been developed [1]. The recommendations cover the contribution of rheumatology nurses to the care and management of patients with $\mathrm{CIA}$, and additionally cover requirements for the professional performance of nurses working in the field of rheumatology (see Box 7.1).

Box 7.1 EULAR recommendations for the role of the nurse

1. Patients should have access to a nurse for education to improve knowledge of $\mathrm{CIA}$ and its management throughout the course of their disease

2. Patients should have access to nurse consultations in order to experience improved communication, continuity and satisfaction with care

3. Patients should have access to nurse-led telephone services to enhance continuity of care and to provide on-going support

4. Nurses should participate in comprehensive disease management to control disease activity, to reduce symptoms and to improve patient preferred outcomes

5. Nurses should identify, assess and address psychosocial issues to minimise the chance of patients' anxiety and depression

6. Nurses should promote self-management skills in order that patients might achieve a greater sense of control, self-efficacy and empowerment

7. Nurses should provide care that is based on protocols and guidelines according to national and local contexts

8. Nurses should have access to and undertake continuous education in order to improve and maintain knowledge and skills

9. Nurses should be encouraged to undertake extended roles after specialised training and according to national regulations

10. Nurses should carry out interventions and monitoring as part of comprehensive disease management, in order to achieve cost savings

The recommendations aim to achieve a more standardised level of professional rheumatology nursing care. However, a successful change of clinical practice, in accordance with these recommendations, requires an effective implementation strategy [2]. Knowledge of the recommendations and adoption by the major stakeholders of care, i.e. nurses, rheumatologists and patients, is a prerequisite but is not sufficient on its own [3]. Additional interventions are necessary and may include techniques such as involving key opinion leaders, organising education and training for professionals, providing feedback, sending reminders, and providing incentives. However, evidence about effective single interventions is limited [4-6]. A multifaceted and broader approach on several levels (e.g. health professionals and patients, social context, organisations, and political and economic contexts) is recommended [7]. In order to develop tailored interventions that can support implementation, knowledge about potential barriers for acceptance and application of the recommendations in daily practice is essential [3, 7-9].

The objectives of the present study were to: a) disseminate-,b) assess agreement with-, c) assess application of-, and d) identify potential barriers for implementation of the EULAR 
recommendations for the role of the nurse in the management of CIA among nurses, rheumatologists and patients.

\section{Methods}

The study was performed by means of a cross-sectional survey among the target population across Europe and the United States of America (USA).

A steering committee, comprising eight experts in rheumatology nursing, a patient representative, and a rheumatologist/clinical epidemiologist, from the United Kingdom (UK), France, Spain, Italy, Germany, and the Netherlands, was responsible for designing and carrying out the study. The committee met once after completion of the survey to discuss the results.

\section{Development of questionnaires}

The survey was developed with three slightly different English versions of the questionnaire for nurses, rheumatologists, and patients. The questionnaire consisted of demographic variables, followed by the text of each of the recommendations with questions on the level of agreement and application per recommendation. For each recommendation, responses were rated on a 0-10 scale, with 10 being the highest level of agreement or the highest level of care provision in accordance with the recommendations. Additionally, reasons for incomplete agreement or barriers to the provision of care in accordance with the recommendations were sought. For respondents' convenience, potential reasons or barriers, based on the findings of a previous EULAR health professional survey [10], and on clinical experience from the members of the steering committee, were offered, with the opportunity for respondents to add items. The questionnaires were piloted on three groups: 1) the members of the EULAR nursing task force involved in the development of the recommendations, 2) a convenience sample of nurses, rheumatologists and patients invited by the former task force members, and 3) a small group of health professionals, active within EULAR. In total, 46 persons (18 nurses, 9 rheumatologists, 15 patients and 4 other health professionals) participated in the pilot study. Their comments were used to refine the final versions of the questionnaires.

\section{Distribution of the questionnaires}

For as many European countries as possible and in the USA, a national principal investigator (PI) and a key leading rheumatologist were appointed. They were jointly responsible for deciding upon the most appropriate strategy for dissemination of the questionnaires in their country. This often included emailing professional and patient support groups with the details and link to the survey. In the non-English speaking countries, they were also responsible for the translation of the questionnaires into their own language. During the survey period, Pls and key leaders were informed twice about 
the actual number of responses in their country and were asked to further stimulate the dissemination of the questionnaires.

The questionnaires were transformed into a web-based format and for each target group, a link to the survey, with an option to choose from 17 languages, was available between June and August 2012. The participants were asked to send the web link of this questionnaire to their colleagues within and outside the hospital or to fellow patients (snowball sampling technique) [11]. Sample size followed convenience sampling and as many participants as possible were included. Possible reasons for not participating were communicated by the PIs after the survey.

\section{Statistical analysis}

Descriptive analyses were used to calculate the key outcomes: conceptual agreement with-, application of-, reasons for incomplete agreement with- and barriers to the application of each recommendation.

Possible regional differences were explored. First, the participating countries were grouped into 6 regions: Northern-, Western-, Southern-, Eastern- and Central Europa, and the USA. Subsequently, differences in level of agreement and level of application between the regions were assessed using non-parametric Kruskal-Wallis tests within the group of nurses, rheumatologists and patients, respectively.

All analyses were performed using IBM SPSS Statistics 20.0.

\section{Results}

\section{Population}

In total, 3,594 persons responded: 967 nurses, 548 rheumatologists and 2,034 patients, from 23 countries. Characteristics of the study population are presented in Table 7.1. The nurses had a mean (SD) of 10.4 (8.0) years of clinical experience in rheumatology, for the rheumatologists this was 16.4 (9.7) years. The majority of the patients had rheumatoid arthritis with a mean (SD) disease duration of 14.4 (11.9) years.

Table 7.2 presents an overview of the number of respondents per country. The largest number of nurse respondents were from the USA $(n=142)$ while the largest number of rheumatologist $(n=65)$ and patient $(n=384)$ respondents were from France. The proportion of patients with access to nursing care varied widely across countries, from $5.1 \%$ in Cyprus to $88.9 \%$ in the UK. 
Table 7.1 Characteristics of the study population

$\begin{array}{lccc} & \text { Nurses } & \text { Rheumatologists } & \begin{array}{c}\text { Patients } \\ (n=2,034)\end{array} \\ \begin{array}{l}\text { Age, mean (SD), years } \\ (n=967)\end{array} & 45.6(9.9) & 46.2(10.6) & 49.2(14.1) \\ \text { Clinical experience in rheumatology, mean (SD), years } & 10.4(8.0) & 16.4(9.7) & - \\ \text { Disease RA:AS:PsA, \% } & - & - & 62.8: 24.8: 12.4 \\ \text { Disease duration, mean (SD), years } & - & - & 14.4(11.9) \\ \text { Highest level of education, \% } & & - & 29.0 \\ \quad \text { Low } & - & - & 33.2 \\ \quad \text { Medium } & 52.1 & 100 & 37.8 \\ \quad \text { High (university or higher vocational education) } & 47.9 & 58.9 & 41.6 \\ \text { Hospital, \% } & & 31.2 & 40.9 \\ \quad \text { Academic } & 44.0 & 9.9 & 17.5\end{array}$

RA: rheumatoid arthritis, AS: ankylosing spondylitis, PsA: psoriatic arthritis

-: not applicable

Table 7.2 Responses per country

\begin{tabular}{|c|c|c|c|c|}
\hline Region/country & $\begin{array}{l}\text { Nurses } \\
n=967\end{array}$ & $\begin{array}{l}\text { Rheumatologists } \\
\qquad n=548\end{array}$ & $\begin{array}{l}\text { Patients } \\
n=2,034\end{array}$ & $\begin{array}{c}\text { Access to nursing } \\
\text { care as stated by the } \\
\text { patients (\%yes) }\end{array}$ \\
\hline \multicolumn{5}{|l|}{ Northern Europe } \\
\hline Norway & 33 & 19 & 82 & 48.1 \\
\hline Sweden & 91 & 38 & 139 & 63.6 \\
\hline Finland & 38 & 22 & 318 & 66.7 \\
\hline Denmark & 83 & 37 & 131 & 64.6 \\
\hline \multicolumn{5}{|l|}{ Western Europe } \\
\hline United Kingdom & 46 & 12 & 261 & 88.9 \\
\hline Ireland & 15 & 8 & 41 & 56.1 \\
\hline Netherlands & 88 & 25 & 72 & 84.3 \\
\hline Belgium & 35 & 18 & 71 & 53.6 \\
\hline France & 104 & 65 & 384 & 22.3 \\
\hline \multicolumn{5}{|l|}{ Southern Europe } \\
\hline Spain & 19 & 38 & 8 & 37.5 \\
\hline Portugal & 18 & 24 & 14 & 78.6 \\
\hline Italy & 71 & 56 & 63 & 28.6 \\
\hline Greece & 3 & 25 & 25 & 44.0 \\
\hline Cyprus & 3 & 2 & 39 & 5.1 \\
\hline Turkey & 4 & 24 & 54 & 13.0 \\
\hline \multicolumn{5}{|l|}{ Eastern Europe } \\
\hline Russia & 28 & 28 & 167 & 12.0 \\
\hline Romania & 38 & 59 & 23 & 21.7 \\
\hline CzechRepublic & 20 & 1 & 3 & 66.7 \\
\hline Slovenia & 15 & 3 & 9 & 22.2 \\
\hline \multicolumn{5}{|l|}{ Central Europe } \\
\hline Germany & 69 & 8 & 107 & 16.0 \\
\hline Austria & 1 & 13 & 0 & Unknown \\
\hline Switzerland & 3 & 11 & 4 & 25.0 \\
\hline USA & 142 & 12 & 19 & 36.8 \\
\hline
\end{tabular}




\section{Level of agreement and level of application}

Figure 7.1 presents the level of agreement and the level of application per recommendation, from nurses, rheumatologists and patients, respectively.
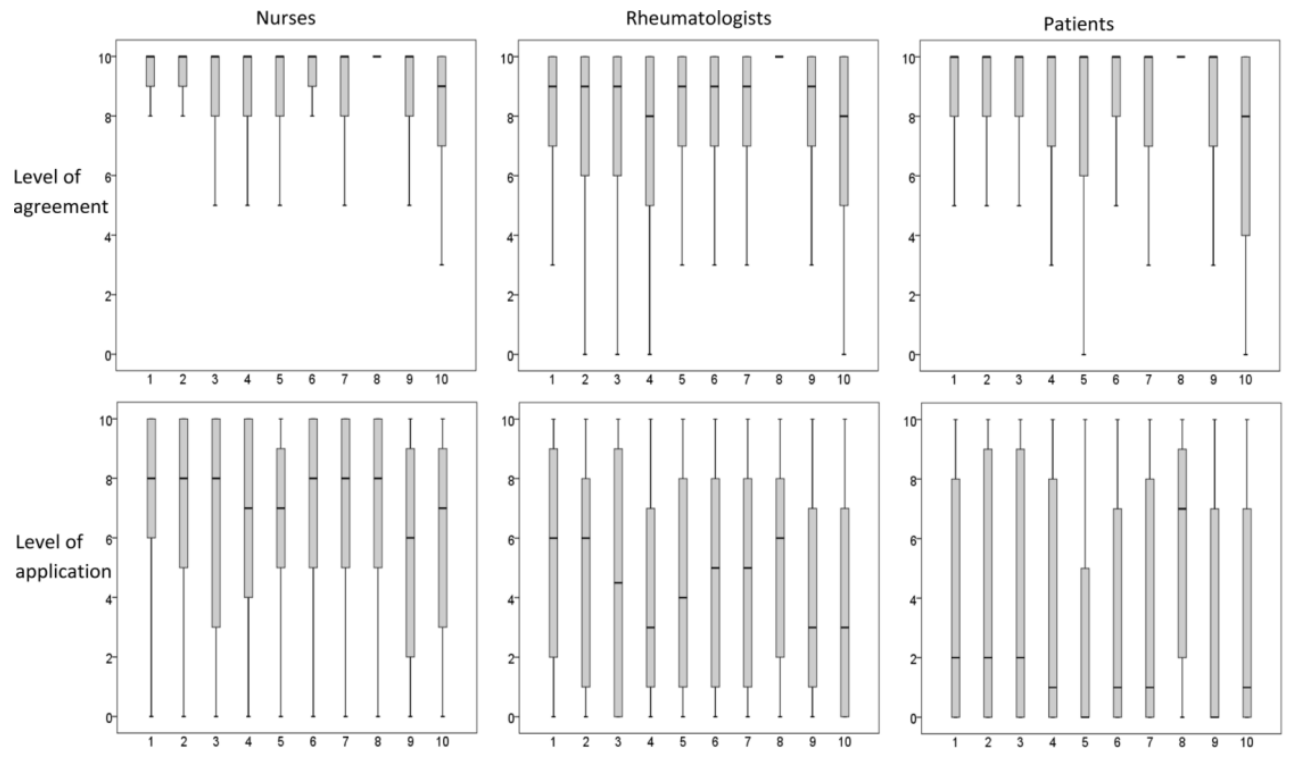

Figure 7.1 Level of agreement and level of application (median, spread and interquartile range) per recommendation, for nurses, rheumatologists and patients

Overall, the level of agreement was high in all three groups, median 8 to 10 per recommendation. All three groups fully agreed with recommendation 8 ('Nurses should have access to and undertake continuous education'). Among nurses and patients, the variation was largest for recommendation 10 ('Nurses should carry out interventions and monitoring in order to achieve cost savings'). In all recommendations, the variation among rheumatologists was larger than among nurses or patients.

In contrast, the level of application was substantially lower, median 0 to 8 , and the variation was much larger in each group and for each recommendation. In the three groups, the lowest level of application was found for recommendation 9 ('Nurses should be encouraged to undertake extended roles'). Additionally, a low level of application was reported by nurses and rheumatologists for recommendation 4 ('Nurses should participate in comprehensive disease management') and recommendation 10 ('Nurses should carry out interventions and monitoring in order to achieve cost savings'). A low level of application was also reported by nurses and patients for recommendation 5 ('Nurses should identify, assess and address psychosocial issues '). 


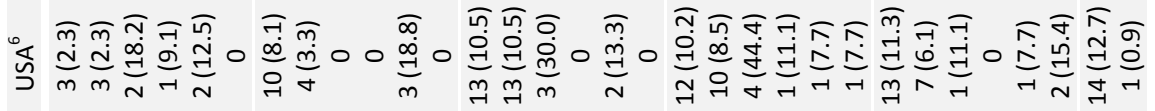

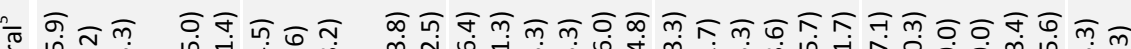

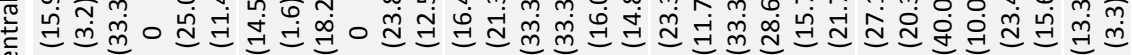

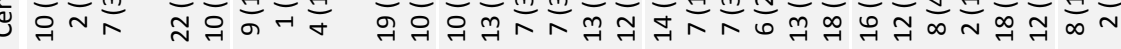

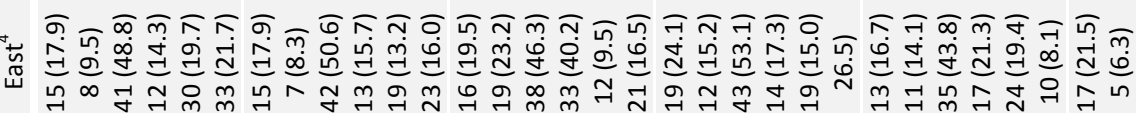

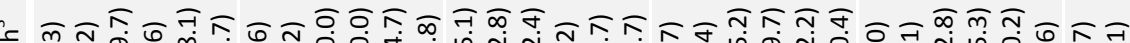
声

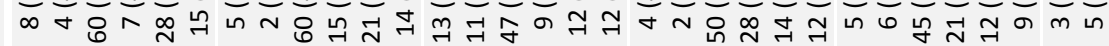

무

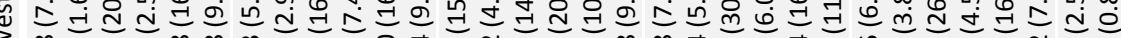
了

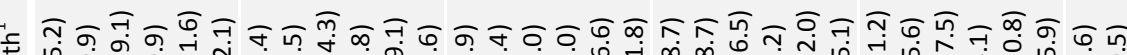

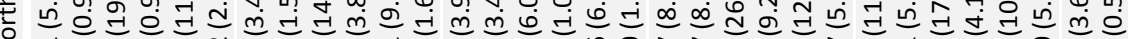
z

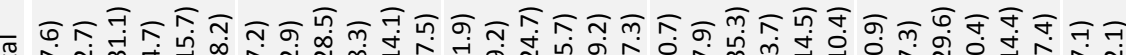

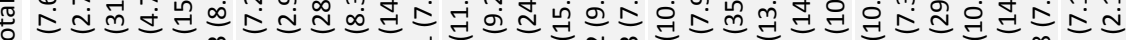

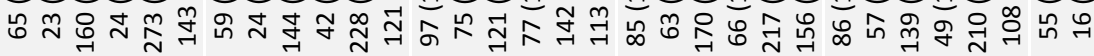

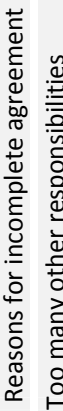

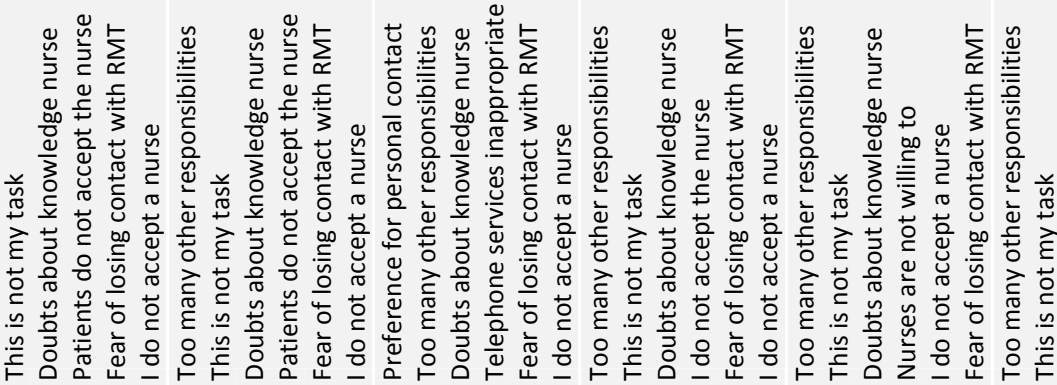

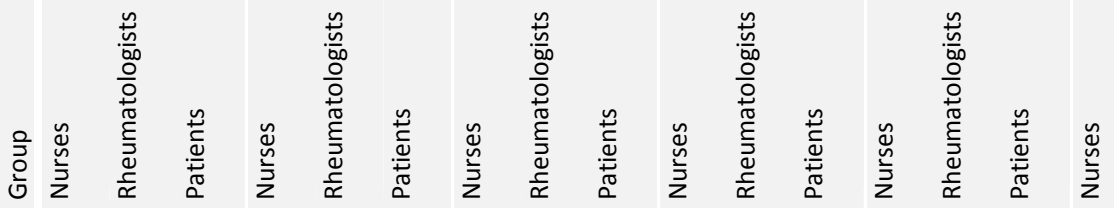




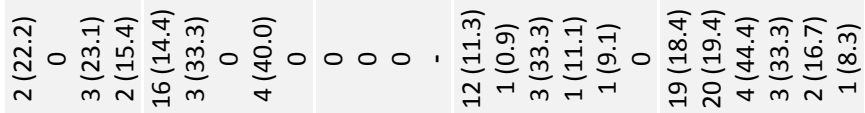

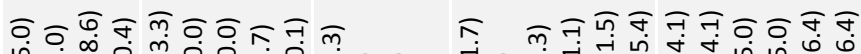

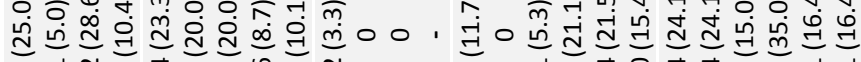

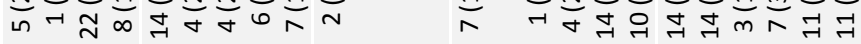

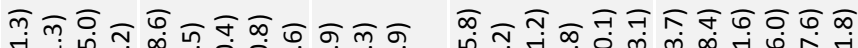

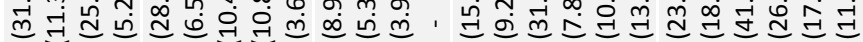
นn

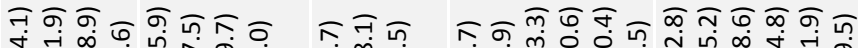

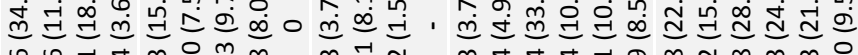

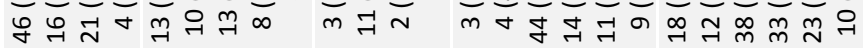

무줗ํ क

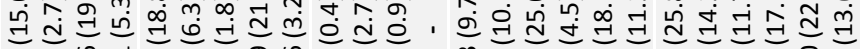
न $m$ 当 $\bar{m}$ 年

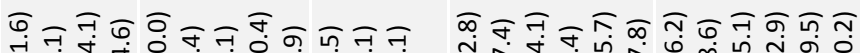

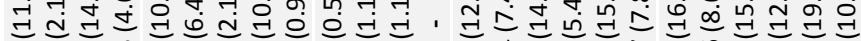

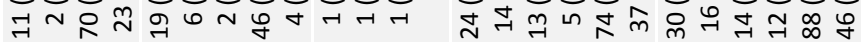

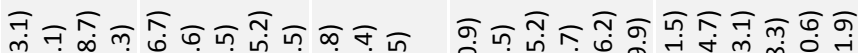

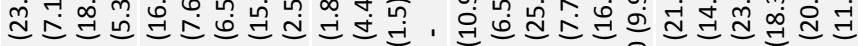
郘吕志
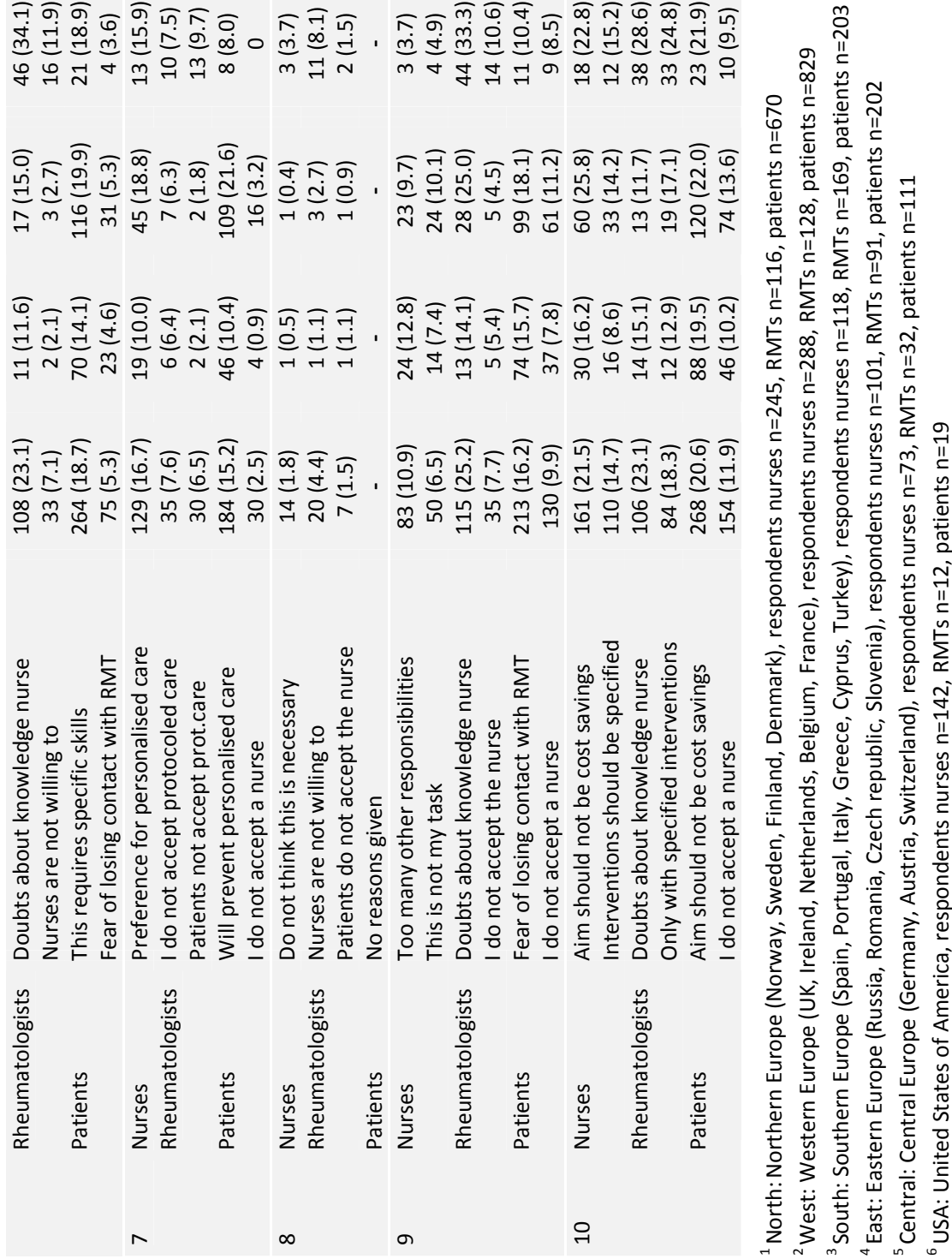


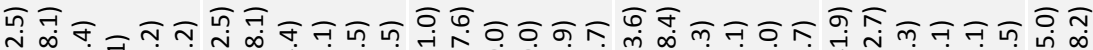

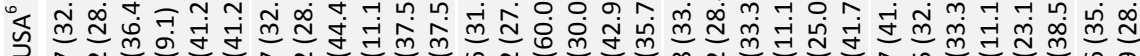

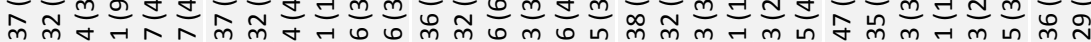

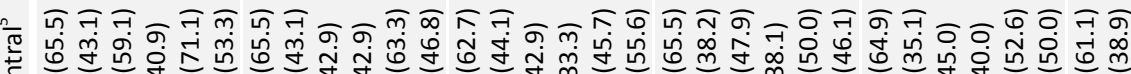

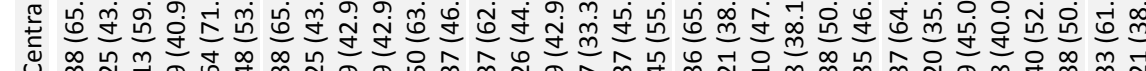

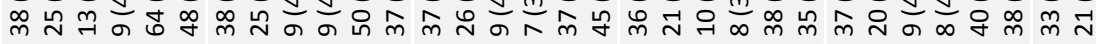

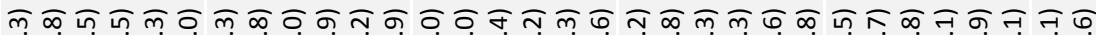

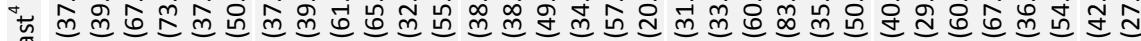

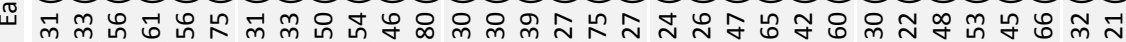

m สุณ

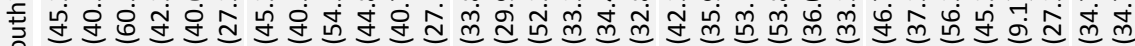

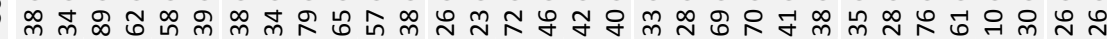

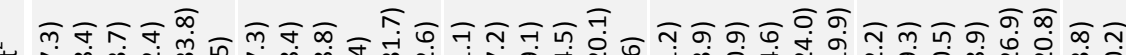

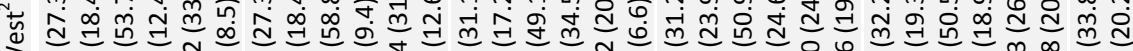

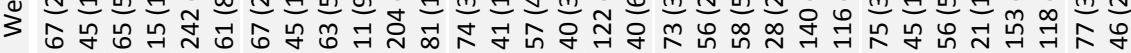

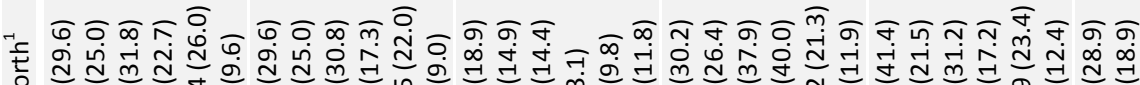

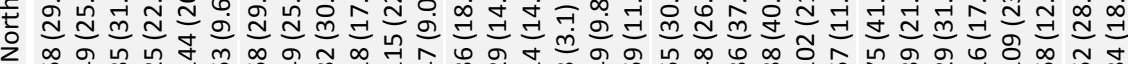

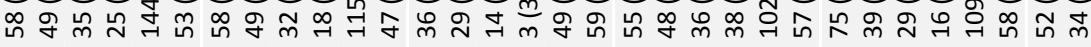

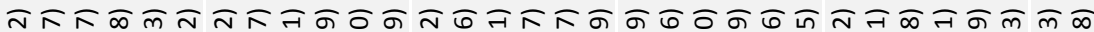

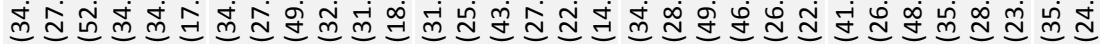

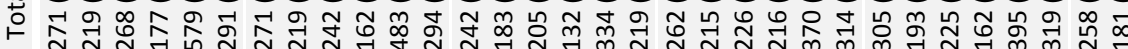

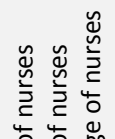

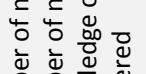

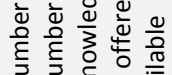

至

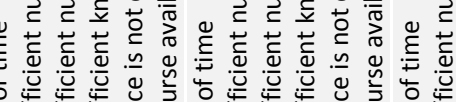

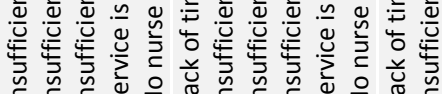

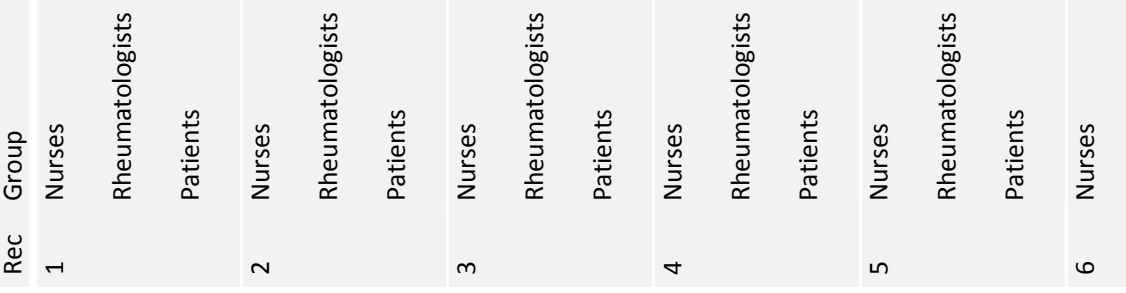


ซ

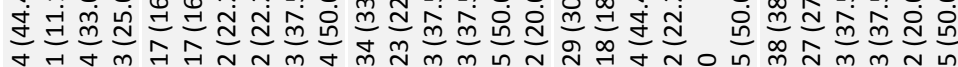

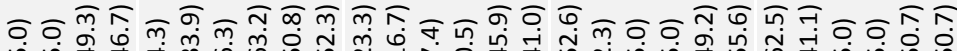

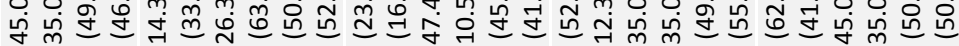

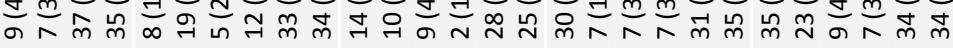

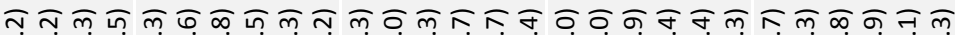

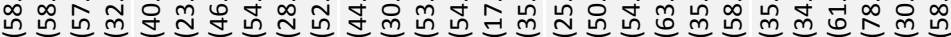
守

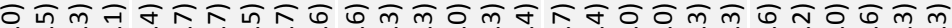

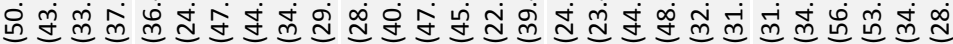
ธิ

न न Jき

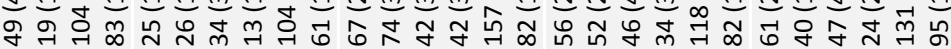

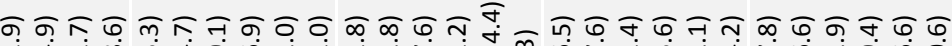

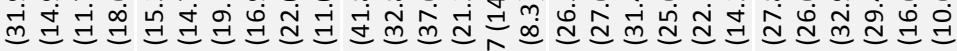

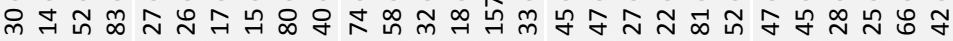

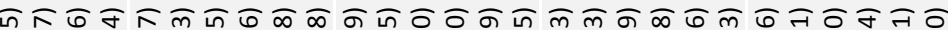

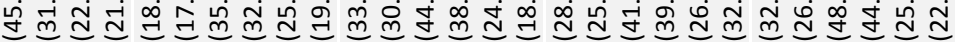

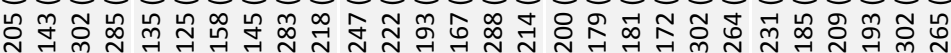
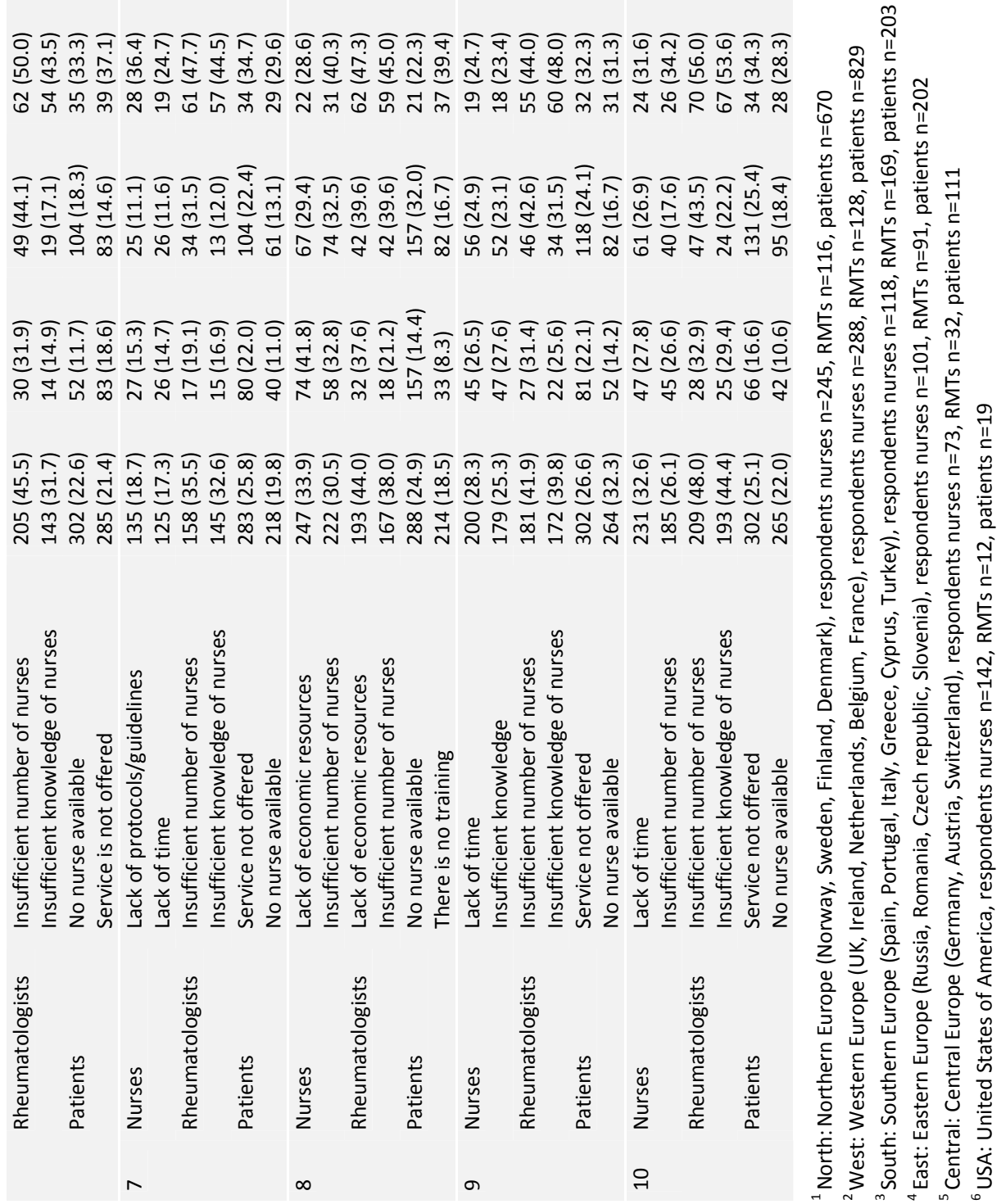


\section{Reasons for incomplete agreement}

Participants who did not fully agree with a recommendation, i.e. indicated a level of agreement of $<10$, identified their reasons for this. The two most frequently reported reasons per group and per region are presented in Table 7.3. The most frequently reported reasons for incomplete agreement were 'having too many other responsibilities' (nurses), 'doubts about knowledge of the nurse' (rheumatologists) and 'fear of losing contact with the rheumatologist' (patients).

\section{Barriers to the application}

If a recommendation was not fully applied, i.e. the level of application was $<10$, participants identified barriers to the application of the recommendation. Table 7.4 presents the two most frequently reported barriers per group and per region. The most frequently reported barriers were 'lack of time' (nurses), 'insufficient number of nurses' (rheumatologists), and 'the service is not offered' or 'no nurse available' (patients). In addition, 'lack of economic resources' was reported by nurses and rheumatologists, whereas rheumatologists also reported 'insufficient knowledge of the nurses to provide care as stated in the recommendations'.

\section{Regional differences}

Regional differences with respect to the level of agreement and the level of application were explored for each recommendation and in the three groups.

The median level of agreement was high in each region and varied from 6 to 10 among nurses, from 5 to 10 among rheumatologists and from 8 to 10 among patients. In the three groups, regional differences for the level of agreement were statistically significant for most recommendations. Exceptions were recommendation 8 ('Nurses should have access to and undertake continuous education') which was not statistically significant among nurses and patients from the different regions; recommendation 5 ('Nurses should identify, assess and address psychosocial issues ') and recommendation 9 ('Nurses should be encouraged to undertake extended roles') which were not statistically significant among rheumatologists from the different regions; and recommendation 10 ('Nurses should carry out interventions and monitoring in order to achieve cost savings') which was not statistically significant among patients from the different regions.

The lowest levels of agreement were found in Eastern- and Central Europe for all recommendations, except for recommendation 6 ('Nurses should promote selfmanagement skills'), where the rheumatologists' level of agreement was lowest in Southern- and Central Europe; recommendation 7 ('Nurses should provide care that is based on protocols and guidelines') where the rheumatologists' and patients' level of agreement was lowest in Central Europe and in the USA; and recommendation 9 ('Nurses should be encouraged to undertake extended roles') where the rheumatologists' level of 
agreement was lowest in Western- and Southern Europe.

The median level of application of the recommendations was substantially lower in each region and varied from 3 to 9 among nurses, from 0 to 10 among rheumatologists and from 0 to 8 among patients. Regional differences in the level of application were statistically significant for all recommendations and in each of the three groups.

The level of application was lowest in Southern-, Eastern- and Central Europe for all recommendations, except for recommendation 8 ('Nurses should have access to and undertake continuous education') where the nurses' level of application was lowest in Northern-, Southern-, and Eastern Europe.

Acceptance of the nurse to perform specific roles as stated in the recommendations, was frequently reported as a reason for incomplete agreement with the recommendations by rheumatologists and patients from Eastern- and Central Europe.

In Eastern Europe, insufficient number of nurses', 'insufficient knowledge of nurses' and 'no nurse available' were more frequently reported as the main reason for not fully applying the recommendations by nurses, rheumatologists, and patients respectively.

Tables 7.5 and 7.6 present level of agreement and level of application per recommendation, for each group and region, and the results regarding regional differences between North- (i.e. Northern Europe: Norway, Sweden, Finland, Denmark, respondents nurses $n=245$, rheumatologists $n=116$, patients $n=670$ ), West- (i.e. Western Europe: UK, Ireland, Netherlands, Belgium, France, respondents nurses $n=288$, rheumatologists $n=128$, patients $n=829$ ), South- (i.e. Southern Europe: Spain, Portugal, Italy, Greece, Cyprus, Turkey, respondents nurses $n=118$, rheumatologists $n=169$, patients $n=203$ ), East- (i.e. Eastern Europe: Russia, Romania, Czech republic, Slovenia, respondents nurses $n=101$, rheumatologists $n=91$, patients $n=202$ ), Central (i.e. Central Europe: Germany, Austria, Switzerland, respondents nurses $n=73$, rheumatologists $n=32$, patients $n=111$ ) and the USA (respondents nurses $n=142$, rheumatologists $n=12$, patients $n=19$ ). 


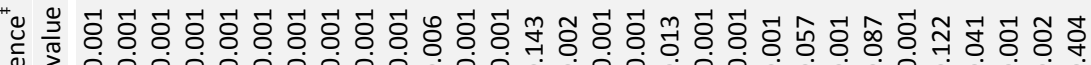

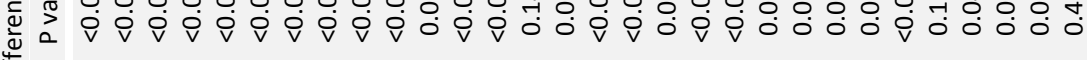
$\div$

तั

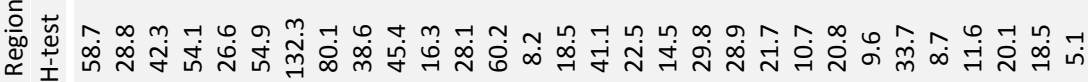

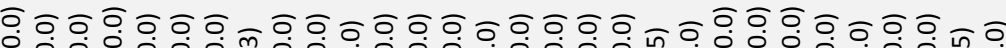

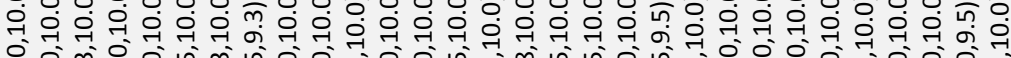
« 0 o

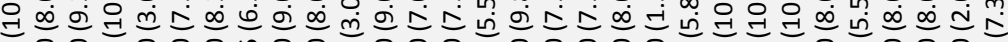

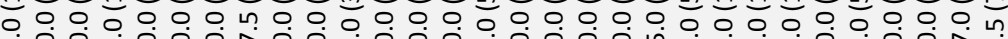

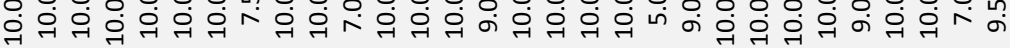

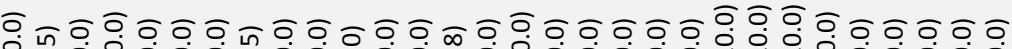

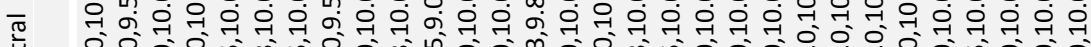

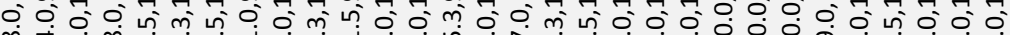
我 ம்

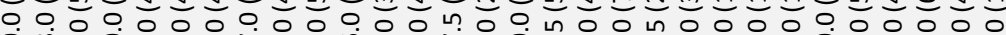

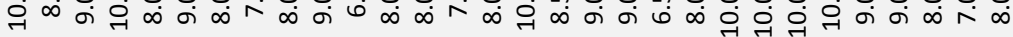

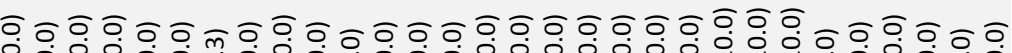

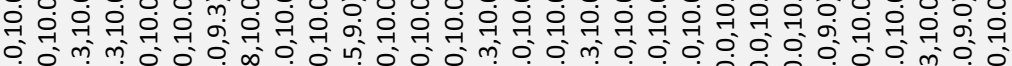
ம்

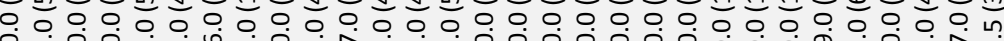

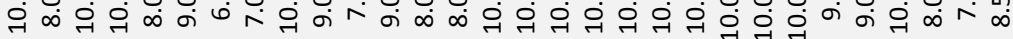

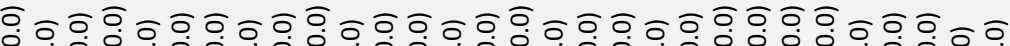

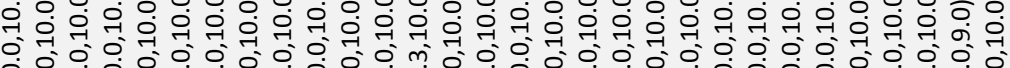
穴 구의 羊

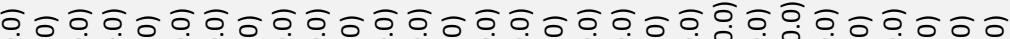

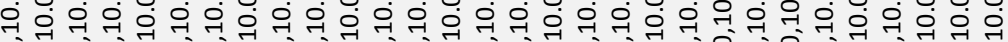

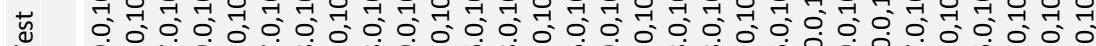

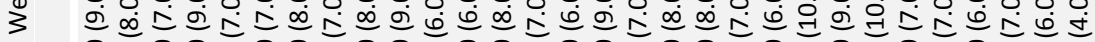

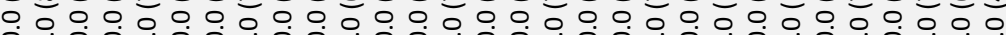
○ं

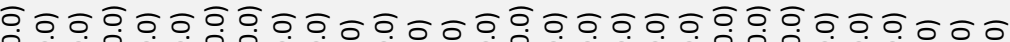
年 $0 \begin{aligned} & 0 \\ & 0\end{aligned}$

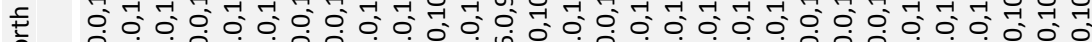

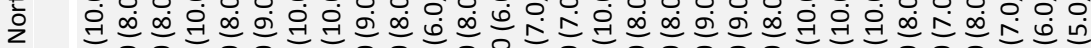

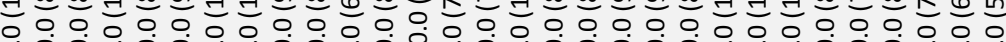

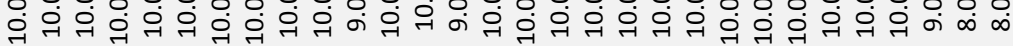




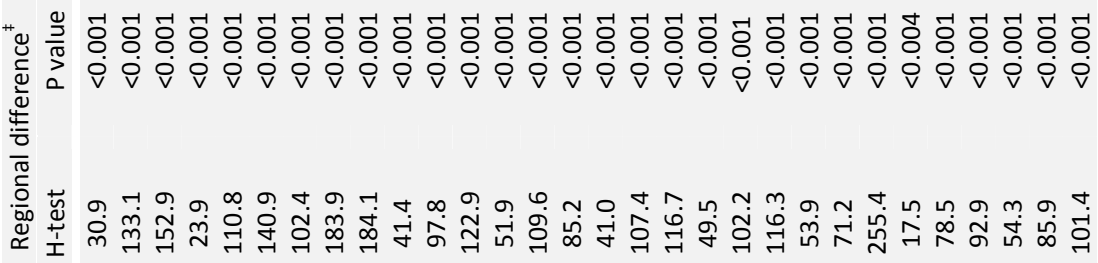

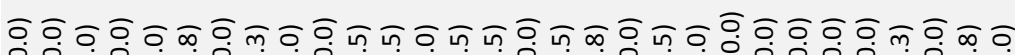

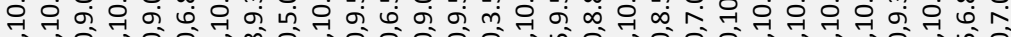

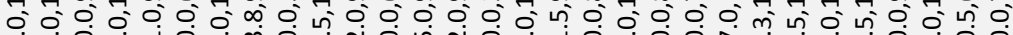

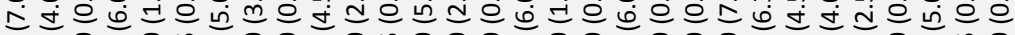

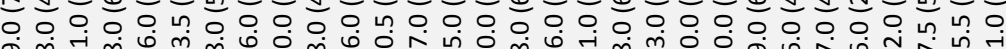

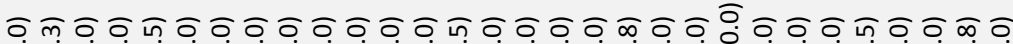

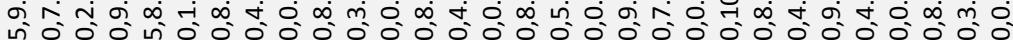
ñ

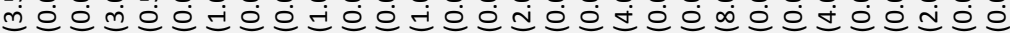

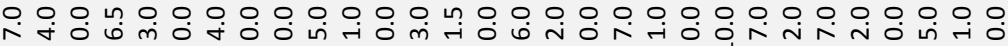

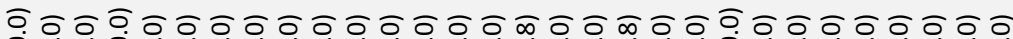

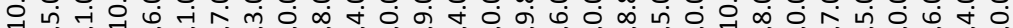
म

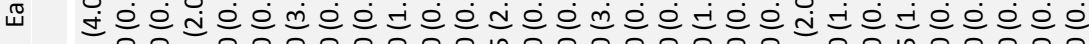

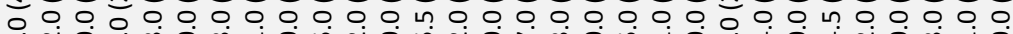
年

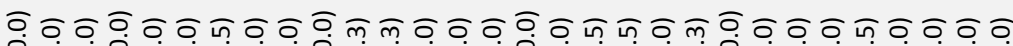
穴

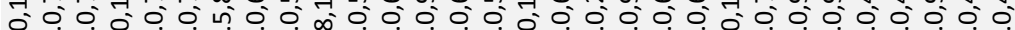

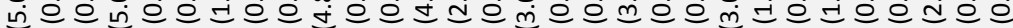
숫

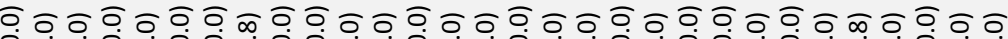
o प

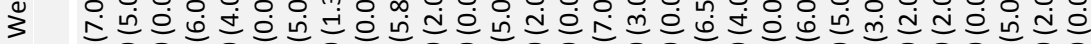

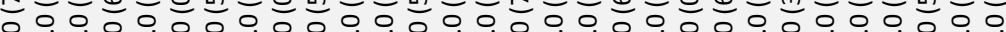

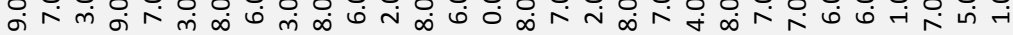

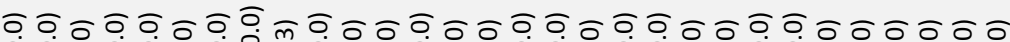

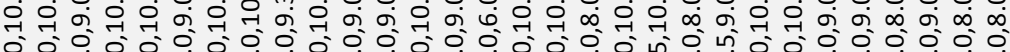

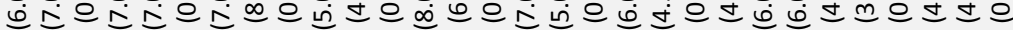

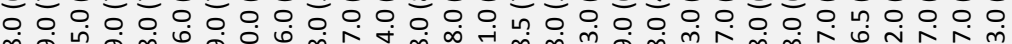
$\infty$
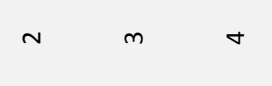

เก

6

$N$

$\infty$

a

욱 


\section{Discussion}

A large number of nurses, rheumatologists and patients participated in this survey that evaluated agreement with- and application of the EULAR recommendations for the role of the nurse in the management of CIA. The survey achieved a good range of participants across Europe and the USA, although the highest number of responses was from Northern- and Western Europe. The level of agreement was high for the recommendations, but the level of application was substantially lower. Many barriers for acceptance and application were reported and regional differences were explored.

The level of agreement was highest among nurses. The main reason nurses gave for incomplete agreement was having 'too many other responsibilities', which provides an indication of their perceived workload. The use of protocols and guidelines has been found to increase efficiency and therefore may reduce workload $[12,13]$. However, lack of appropriate protocols was frequently reported by nurses and rheumatologists. Across countries, a wide variation in the role of the nurse was found. Agreement among rheumatologists and patients was highest in regions where rheumatology nursing care on an extended level is well-established which has been shown to result in confidence and satisfaction of patients in earlier studies [14, 15].

Many barriers to the application of the recommendations were identified. All three groups mentioned 'lack of time', 'lack of sufficient number of nurses' or 'lack of resources', which all refer to the financial investments that are required if a minimum standard for rheumatology nursing care is to be implemented. The high level of agreement with the recommendations demonstrated within this survey, as well as the level of evidence for effectiveness of nurse-led care [16-19] justifies investments in education and training of nurses.

Further research is needed to develop targeted interventions for implementation and to evaluate their effectiveness. Interventions may be focussed on hindering factors at the level of the health professionals (e.g. knowledge of nurses), the social context (e.g. acceptance of rheumatology nursing care), the organisation (e.g. the position of specialised nurses), and economical and political context (e.g. availability of economic resources, policy with regard to task shifting) [9]. Specific interventions for implementation of the recommendations will likely differ per region and for the subgroups, and should be governed by the barriers identified. On a national level, key opinion leaders can play an important role in serving as a role model, in questioning existing values, and in encouraging best practices [3]. They could also contribute to defining specific interventions for further implementation in their countries. In addition, interventions are required on an international level.

Access to continuous education is one of the EULAR recommendations for the role of the nurse [1]. The high level of agreement with this recommendation shows that the knowledge base of nurses is considered important by nurses, rheumatologists and 
patients in all countries. Standardisation of education would improve knowledge and selfconfidence of nurses, and contribute to the development of nursing skills in order to achieve high quality care. Further, transparency and understanding of the objectives and content of nurses' curricula might improve confidence from rheumatologists and patients. Easy access to affordable and clinically relevant courses on basic and advanced levels in rheumatology nursing is required in order to guarantee appropriately trained rheumatology nurses. Availability of education in an individual's own language may be important to increase access and uptake of education.

Minimum standards of care have been formulated in the recommendations, but they need further definition and refinement. Several initiatives to support excellent rheumatology nursing and multidisciplinary collaboration regarding these issues have already been undertaken by the members of the former EULAR nursing task force. EULAR can play an active role in encouraging and supporting the further implementation of rheumatology nursing care. A follow-up of the survey in five years is recommended to evaluate if the intended strategies for implementation have the desired effects.

Several limitations to the survey should be addressed. While the intention was to include as many EULAR countries as possible, not all participated in the survey. All countries in which rheumatology nursing is well established participated, and fortunately we were also able to include several countries in which rheumatology nursing has only started to develop. Less than $50 \%$ of the participating patients indicated that they had access to rheumatology nursing care. Nevertheless, all participants gave their critical comments and provided important information with respect to barriers for the acceptance and application of rheumatology nursing care, which can be used in defining further implementation strategies.

Also, responses varied widely across countries and regions. Given the number of responses that were received, it is likely that many eligible people did not fill in the survey. As snowball sampling was used to disseminate the link to the survey, it is not possible to estimate a response rate. Selection bias may have occurred [11]. Possible reasons for not participating were communicated by the PIs. These included unequal access to the internet, the time period in which the survey was available coincided with summer holidays, no access to or experience with nursing care, a EULAR project instead of a project from a national association, substantial time required to obtain formal approval from medical ethical committees, and unwillingness of national associations to disseminate the link to their members.

Finally, the formal 'forward-backward' translation approach was not used in translating the questionnaires from English to target languages [20]. Nevertheless, the questionnaires were translated by the PIs and local rheumatologists in the participating countries as accurately as possible. 
In conclusion, with this survey the EULAR recommendations on the role of the nurse in the management of CIA have been disseminated among nurses, rheumatologists, and patients across Europe and the USA. The level of agreement was high in all three groups, but the level of application was substantially lower. Agreement and application differed between regions and were lowest in Eastern- and Central Europe.

Topics were identified that can be used to develop tailored strategies supporting further implementation of rheumatology nursing care.

\section{Acknowledgements}

The authors thank the following Pls for the translation of the questionnaires and the dissemination of the survey in their country:

Belgium: Rene Westhovens, An van Boxstael; Cyprus: Vasos Scoutellas, Marios Kouloumas; Czech Republic: Marta Olejárová, Jana Korandová; Denmark: Gina Kollerup, Marianne Tørper; Finland: Markku Kauppi, Marja Leena Kukkurainen; France: Martin Soubrier; Germany: Denis Poddubnyy; Italy: Ignazio Olivieri; Netherlands: Han Repping-Wuts; Norway: Till Uhlig, Hanne Kalstad Vestaby; Portugal: Jose Da Silva, Lurdes Barbosa; Romenia: Andra Balanescu, Codruta Zabalan; Russia: Anna Botchkova; Slovenia: Aleš Ambrožič, Masa Huzjak; Spain: Vega Jovaní; Sweden: Tomas Zweig, Elisabeth Welin Henriksson; Turkey: Aysen Akinci Tan, Sarah Adut.

We also thank the following Pls for the dissemination of the survey in their country: Austria: Peter Mandl; Ireland: Douglas Veale, Patricia Minnock, Claire Kinneavy; UK: Andy Hassell; USA: Clifton Bingham, Victoria Ruffing, Kevin Purcell; Switzerland: Ulrich Weber. Finally, we thank the members of the EULAR nursing task force for their contribution to the development of the questionnaires and all the participants for sharing their opinions with us in this survey. 


\section{References}

1. van Eijk-Hustings $Y$, van Tubergen A, Boström C, et al. EULAR recommendations for the role of the nurse in the management of chronic infl ammatory arthritis. Ann Rheum Dis. 2012;71:13-9.

2. Dougados M, Betteridge N, Burmester GR, et al. EULAR standardised operating procedures for the elaboration, evaluation, dissemination, and implementation of recommendations endorsed by the EULAR standing committees. Ann Rheum Dis. 2004;63:1172-6.

3. Grol R, Grimshaw J. From best evidence to best practice: effective implementation of change in patients' care. Lancet. 2003;362:1225-30.

4. Arditi C, Rège-Walther $M$, Wyatt JC, et al. Computer-generated reminders delivered on paper to healthcare professionals; effects on professional practice and health care outcomes. Cochrane Database Syst Rev. 2012;12:CD001175.doi:10.1002/14651858.CD001175.pub3.

5. Giguère A, Légaré $F$, Grimshaw J, et al. Printed educational materials: effects on professional practice and healthcare outcomes. Cochrane Database Syst Rev. 2012;10:CD004398.doi:10.1002/14651858.CD004398.pub3.

6. Ivers N, Jamtvedt G, Flottorp S, et al. Audit and feedback: effects on professional practice and healthcare outcomes. Cochrane Database Syst Rev 2012;6:CD000259.doi:10.1002/14651858.CD000259.pub3.

7. Grol R, Wensing M. Effective implementation: A model. In: Grol R, Wensing M. Improving patient care: the implementation of change in clinical practice. London: Elsevier. 2005:41-57

8. Bosch $M$, van der Weijden T, Wensing M, Grol R. Tailoring quality improvement interventions to identified barriers: a multiple case analysis. J Evaluation Clin Pract. 2007;13:161-8.

9. Grol R, Wensing M. What drives change? Barriers to and incentives for achieving evidence-based practice. Med J Aust. 2004;180(6Suppl):S57-60.

10. Stamm T, Hill J. Extended roles of non-physician health professionals and innovative models of care within Europe: Results of a web-based survey. Musculoskeletal Care. 2011;9:93-101.

11. Babbie EA. The logic of sampling. In: Babbie EA. The basic of Social Research. Belmont, CA: Wadsworth Cengage Learning. 2011:208.

12. Goh L, Samanta J, Samanta A. Rheumatology nurse practitioners' perceptions of their role. Musculoskeletal Care. 2006;4:88-100.

13. Juhola $\mathrm{H}$, Kukkurainen $\mathrm{ML}$, Suominen $\mathrm{T}$. Rheumatology nurses' work-related empowerment. Musculoskeletal Care. 2007;5:91-7.

14. Hill J, Bird A, Harmer R, et al. An evaluation of the effectiveness, safety and acceptability of a nurse practitioner in a rheumatology outpatient clinic. Br J Rheumatol. 1994;33:283-8.

15. Larsson I, Bergman S, Fridlund B, et al. Patients' experiences of a nurse-led rheumatology clinic in Sweden: a qualitative study. Nurs Health Sci. 2012;14:501-7.

16. Koksvik HS, Hagen KB, Rødevand $E$, et al. Patient satisfaction with nursing consultations in a rheumatology outpatient clinic: a 21-month randomised controlled trial in patients with inflammatory arthritides. Ann Rheum Dis. 2013;72:836-43.

17. Ndosi M, Vinall K, Hale C, et al. The effectiveness of nurse-led care in people with rheumatoid arthritis: a systematic review. Int J Nurs Stud. 2011;48:642-54.

18. Primdahl J, Sørensen J, Horn HC, et al. Shared care or nursing consultations as an alternative to rheumatologist follow-up for rheumatoid arthritis outpatients with low disease activity--patient outcomes from a 2-year, randomised controlled trial. Ann Rheum Dis. Published online first [5 February 2013]doi:10.1136/annrheumdis-2012-202695

19. Ndosi M, Lewis M, Hale C, et al. The outcome and cost-effectiveness of nurse-led care in people with rheumatoid arthritis: a multicentre randomised controlled trial. Ann Rheum Dis. Published Online First: [27 Aug 2013]doi:10.1136/annrheumdis-2013-203403

20. Beaton D, Bombardier C, Guillemin F, et al. Guidelines for the Process of Cross-Cultural Adaptation of Self-Report Measures. Spine. 2000;25:3186-91. 


\section{Chapter 8}

\section{Patients' needs and expectations with regard to rheumatology nursing care: results of multicentre focus group interviews}

Van Eijk-Hustings Y, Ammerlaan J, Voorneveld-Nieuwenhuis H, Maat L, Veldhuizen C, Repping-Wuts $\mathrm{H}$.

Annals of the Rheumatic Diseases. 2013;72(6):831-835.

Also published as

Van Eijk-Hustings Y, Ammerlaan J, Voorneveld-Nieuwenhuis H, Maat L, Veldhuizen C, Repping-Wuts $\mathrm{H}$. Behoeften en verwachtingen van patiënten met chronische inflammatoire aandoeningen ten aanzien van reumaverpleegkundige zorg: resultaten van focusgroepen in meerdere medische centra in Nederland.

Nederlands Tijdschrift voor Reumatologie. 2013;3:51-55. 


\begin{abstract}
Objective. The contribution of rheumatology nurses to improved patient outcomes is increasingly recognised, but more research is needed about the effects of interventions. The patient's role in deciding about health care quality is considered pivotal and therefore patients' opinions and expectations should be directional in defining priorities for a research agenda. The objective of this study was to explore needs and expectations with regard to rheumatology nursing care in patients with chronic inflammatory arthritis (CIA). Methods. Patients aged 18-90 years from three medical clinics in different regions in the Netherlands were invited to participate in focus group interviews. The interviews were transcribed verbatim and independently analysed by the authors. In a consensus meeting the emerging subjects were categorised into themes which were verified in a fourth interview.

Results. In total, 20 patients, mean age 57 years old, participated in the focus group interviews. The majority had rheumatoid arthritis and mean disease duration was 15 years. The focus group interviews revealed 12 subthemes that were organised into four main themes: education, self-management support, emotional support and well organised care. Additionally, patients considered opinions about 'the personality of the nurse' (e.g. easy to talk to) to be important.

Conclusion. Patients with $\mathrm{ClA}$ mentioned that many problems have to be addressed when one is faced with having a rheumatic disease. The focus group interviews yielded valuable information about the care these patients need and expect. This information will direct future research with regard to rheumatology nursing care.
\end{abstract}




\section{Introduction}

Chronic Inflammatory arthritis (CIA), more specifically rheumatoid arthritis (RA), ankylosing spondylitis (AS) and psoriatic arthritis (PsA), are characterised by inflammation, with a pattern of flares and low disease activity, and apart from pain and stiffness, patients can experience symptoms of severe fatigue [1]. Increasingly, treatment focuses on remission or, if that is not possible, low disease activity [2]. New treatment regimens have contributed to better outcomes, but many patients still perceive an impact of CIA on their daily life [2-5].

Apart from rheumatologists, other health care professionals, such as physiotherapists, occupational therapists and nurse specialists, are involved in the treatment and support of patients with $\mathrm{CIA}$ [6]. The contribution of nurses to improved patient outcome in rheumatology is recognised, as reflected in the 'EULAR recommendations for the role of the nurse in the management of $\mathrm{CIA}^{\prime}$ [7]. In the study of van Eijk-Hustings et al, 10 recommendations were formulated, seven of which focused on the contribution of nurses to care and management. This care includes monitoring of disease consequences on the level of daily activities, participation and psychosocial consequences, and in some countries monitoring disease activity, drug treatment and drug side effects. Apart from the recommendations, the study also presents a research agenda focusing on weak or lack of evidence about the contribution of nurses to outcome and the effects of nursing interventions in the short and long term [7].

A patient-centred approach is increasingly considered an important precondition for delivering high-quality care and is considered a quality dimension [8, 9]. Many definitions exist but, in general, patient-centred care is tailored to the individual's needs and preferences [9]. The patient's perspective is considered pivotal in determining the required content and organisation of care, and also in decisions about quality of care. The increased focus on patient-centredness reflects a revision of current epistemology 'from evidence based to an evidence informed way of thinking and doing' [10].

Rheumatology nursing is common in the Netherlands, but the procedure for referral to the rheumatology nurse differs in different centres. Consequently, not all patients visiting the outpatient clinic will receive nursing care. A project group from V\&VN Dutch Nurses' Association, unit Rheumatology, was set up with the intention to formulate a national research agenda regarding the extent to which nurses contribute to the quality of care in rheumatology. Patient research partners were invited into the project group from the start, and were asked to bring their expertise and thoughts [11, 12]. Based on contributions from the patient research partners, it was decided that patients' opinions about priorities for quality improvement should be the starting point and that patients should be directional in defining the scope and priorities for the research agenda.

Although the patient's perspective has been incorporated into the EULAR recommendations, patients' expectations and needs regarding rheumatology nursing care 
were not explicitly reflected. The objective of this study was to identify these expectations and needs in patients with $\mathrm{CIA}$ in the Netherlands.

\section{Patients and methods}

\section{Design}

A qualitative design was chosen to explore the patient's perspective $[13,14]$. To identify the main themes for expectations and needs, three focus group interviews were organised. The focus group discussion is a valid qualitative technique where group interaction is explicitly used to generate data. Focus groups have proven to be helpful because they provide an interactive environment and allow participants' experiences to be elicited in the context of discussion as participants query and clarify one another's statements and opinions [15]. A fourth focus group interview was scheduled to check if saturation of the themes had been achieved (i.e. if no additional themes emerged). The focus groups were conducted between August and December 2011.

\section{Patient selection}

For the first three focus group interviews, eligible patients were recruited from three large outpatient rheumatology clinics in different arias in the Netherlands. All patients were considered eligible for participation if they were 1) aged 18-90 years, 2) diagnosed with $\mathrm{CIA}$ by a rheumatologist, 3) able to speak and read the Dutch language, and 4) in contact (or have had contact) with a rheumatology nurse. Consecutive patients, 10 at each clinic, were informed about the study by the rheumatology nurse. All patients received a brief demographic questionnaire (e.g. age, level of education and disease duration) and an information letter explaining the aim of the study. The patient's consent was obtained by filling out the brief demographic questionnaire. Patients for the fourth focus group interview were invited by one of the authors (HR-W).

\section{Data collection}

Each focus group session was facilitated by an independent moderator (CV) as well as an observer (HR-W), both registered nurses but no longer in practice. To facilitate optimal interaction between participants, the moderator mainly posed open questions. A general introductory question was asked, followed by the broad question 'what (nursing) care do you need to live your life with a rheumatic disease?'. Each focus group lasted for approximately two hours. All interviews were audio taped and conducted in a quiet room at the clinics. Participants gave their permission to be tape recorded. The tape recorded discussions were transcribed verbatim. Field notes were made during or immediately after the interview to record non-verbal communication and interaction allowing for contextualising of the data. 


\section{Data analyses}

Data were analysed using Krueger's 'long-table approach' [15]. This is a structured method in which an independent content analysis is followed by consensus meetings of the project group. Three of the researchers (YvE-H, JA and HV-N) were appointed the clinics where the first three focus group interviews took place. The written transcripts of the focus group meetings were copied and sent to a researcher so that each researcher analysed the transcript of an interview from another clinic. After reading the transcripts and assessing the whole scope of the interviews, the statements that provided information for the central research question were marked. The observer (HR-W) analysed all of the interviews using the same marking method. Subsequently, the project group evaluated and discussed the selected statements. If consensus regarding the importance or relevance of a particular statement was not achieved, the statement was omitted from further analysis. In a follow-up meeting, the statements were discussed by the project group and were organised into subthemes. After this discussion, the group decided on the main themes. The fourth focus group interview was scheduled after data analysis. The procedure for the interview was similar to the first three interviews.

The study was submitted for approval to the Medical Ethical Committee of Maastricht University Medical Centre and was considered evaluation of daily practice. No further approval was required.

\section{Results}

For each of the first three focus group interviews, four out of 10 invited patients consented to participate, whereas all invited patients for the fourth interview $(n=8)$ consented. In total, 20 patients participated in the four focus groups, 15 women and five men. Main characteristics of the patients are summarised in Table 8.1.

In the focus group interviews, patients mentioned many problems that have to be addressed when faced with having a rheumatic disease. These include physical symptoms, such as pain and fatigue, emotions such as sorrow and grief, psychosocial issues and insecurities about the future, such as the fear of becoming disabled, choices to be made regarding education, work, becoming pregnant and having children, and perceived limitations with regard to fulfilling social roles. In response, patients expressed the wish to cope with their disease and to be able to manage their own problems. Patients stated that they often felt capable of dealing with their disease by themselves. However, flares or changes in personal situations may affect their sense of capability, resulting in a need for support. 
Table 8.1 Characteristics of the participants in the focus groups

\begin{tabular}{|c|c|c|c|c|c|}
\hline & $\begin{array}{l}\text { Total group } \\
\quad(n=20)\end{array}$ & $\begin{array}{l}\text { Centre } 1 \\
\quad(n=4)\end{array}$ & $\begin{array}{c}\text { Centre } 2 \\
(n=4)\end{array}$ & $\begin{array}{c}\text { Centre } 3 \\
(n=4)\end{array}$ & $\begin{array}{c}\text { Centre } 4 \\
(n=8)\end{array}$ \\
\hline Age, mean (range), years & $56.6(32-76)$ & $63.5(54-76)$ & $49.5(45-59)$ & $39.8(32-56)$ & $65.1(59-72)$ \\
\hline Gender $M: F(n)$ & $5: 15$ & $1: 3$ & $1: 3$ & $1: 3$ & $2: 6$ \\
\hline \multicolumn{6}{|l|}{ Level of education (\%) } \\
\hline Low & 15.8 & 33.3 & 25.0 & 50.0 & 12.5 \\
\hline Medium & 57.9 & 33.3 & 50.0 & 50.0 & 50.0 \\
\hline High & 26.3 & 33.3 & 25.0 & 0.0 & 37.5 \\
\hline Married/ cohabiting (\%) & 70.0 & 50.0 & 75.0 & 75.0 & 75.0 \\
\hline \multicolumn{6}{|l|}{ Work status } \\
\hline Employed (\%) & 40.0 & 25.0 & 66.7 & 50.0 & 12.5 \\
\hline Sick leave(\%) & 10.5 & 25.0 & 33.3 & 0 & 0 \\
\hline Work disability (\%) & 15.8 & 25.0 & 0 & 50.0 & 0 \\
\hline Retired (\%) & 36.8 & 25.0 & 0 & 0 & 75.0 \\
\hline Disease RA:AS (n) & $18: 2$ & $3: 1$ & $3: 1$ & $4: 0$ & $8: 0$ \\
\hline $\begin{array}{l}\text { Disease duration, } \\
\text { mean (range), years }\end{array}$ & $14.8(1.5-42)$ & $24.8(12-35)$ & $14.5(3-42)$ & $3.5(1.5-7)$ & $15.8(10-30)$ \\
\hline
\end{tabular}

Centers: 1:UMC Utrecht, 2: Maasstad Hospital Rotterdam, 3: UMC+ Maastricht, 4: UMC Nijmegen RA: rheumatoid arthritis, AS: ankylosing spondylitis

They expressed many needs and expectations with regard to care in general, and to rheumatology nursing care. In total, 200 statements were extracted from the focus group transcripts. In the analyses, 12 subthemes for needs and expectations were defined which were then organised into four main themes: education, self-management support, emotional support and well organised care. In the fourth focus group interview the main themes were verified: no additional themes emerged. The field notes did not reveal observations that influenced the results. The distribution of the statements in the themes is presented in Figure 8.1.

Regarding 'education', patients expressed their needs for appropriate, tailored and timely information about the disease, treatment and potential side effects. They also expressed their needs for education about potential self-management strategies, and their needs for practical information about assistive devices and health care facilities.

Regarding 'self-management support', patients expressed their needs for advice regarding dealing with limitations, and how to communicate with others about these limitations.

Regarding 'emotional support', patients expressed their needs for understanding, a listening ear, but also for clear and supportive communication. They stated the value of a listening ear from a professional in addition to the support from their relatives and friends; patients felt it was more convenient to share their problems with someone outside of their social environment. 


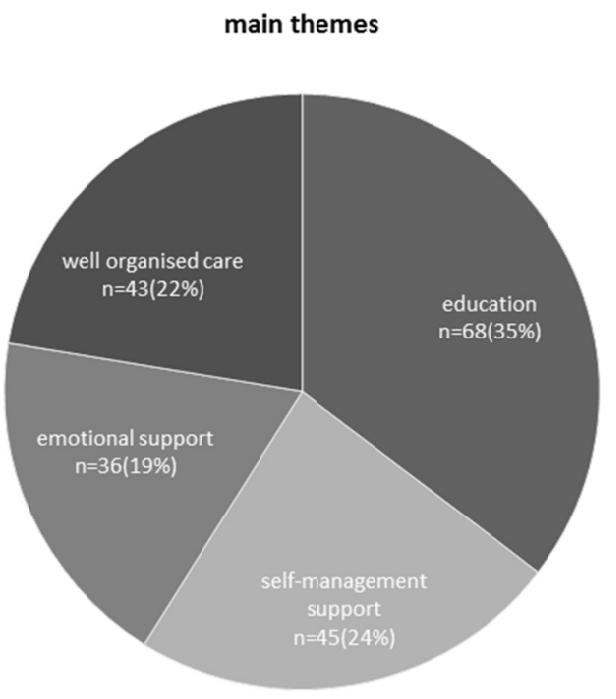

Figure 8.1 Distribution in \% of the extracted statements $(n)$ in the four main themes

In addition to their needs, patients also expressed expectations regarding the care they receive for their rheumatic disease. Patients expect well organised, well coordinated care that is easily accessible, in which knowledgeable professionals collaborate and communicate with each other. They emphasised the importance of having access to a contact person.

Patients stated that rheumatology nurses can address their needs and expectations as they are knowledgeable, work closely with the rheumatologist, have access to relevant information, have a relevant network for referral and are easy accessible, but that rheumatology nursing care is not always provided. Table 8.2 gives an overview of the themes, subthemes and illustrative quotes from patients for each subtheme.

Some extracted statements $(n=8)$ did not fit in the themes, but were not omitted from further analysis as patients considered them important. These were statements regarding opinions about the 'personality' of the nurse, for example 'the nurse is easy to talk to', 'the nurse is empathic', 'the nurse considers me as a whole'. An example is expressed in this quote from a female participant: 'They seem to have more time, ar they are closer, I do not know, but I like that and it makes me feel very comfortable'. Female, RA, 56 years old. 
Table 8.2 Main themes, subthemes ( $\mathrm{n}$ statements) and illustrating quotes of patients' needs and expectations regarding rheumatology nursing care

Main themes

Needs

I) Education

II) Self-management support

III) Emotional support

Expectations

IV) Well organised care
Sub themes and illustrating quotes

1) Understandable tailored information about the disease and its management including information about medications should be given whenever needed (35 statements). Quote:'(.......) Information is so important. I felt insecure not knowing what was going on'. Female, RA, 61 years old.

2) Education to support coping and self-management (17 statements) Quote: '(.......) I learned how to self-inject my medication, and also how to act in case of infection'. Female, RA, 56 years old.

3) Practical support including information on how to obtain help or assistive devices (16 statements)

Quote: '(......)They had a knife, a kind of saw, and a tin opener. These things are helpful, we have to be told about it'. Female, RA, 56 years old.

1) Advices on how to deal with the disease (23 statements) Quote: '(.......) If you need something, that they can help you, show the way. I think the nurse is very important. Male, AS, 76 years old.

2) Learn to clearly communicate (22 statements) Quote: '(.......) I did not know how to explain my limitations to my colleagues and consequently, I could not address them during work'. Female, RA, 47 years old.

1) A listening ear (28 statements) Quote: '(.......) People do not understand. I could talk with the nurse about all my problems. That made me feel well. And she has listened very well. Female, RA, 47 years old.

2) Clear communication (8 statements) Quote: '(.......) Trust. I think somebody should be clear, not too soft. You know I value the adequate communication. And as I say: it doesn't have to be too soft, it has to be pure and simple'. Female, RA, 59 years old.

1) Accessibility of care (13 statements)

Quote:'(.......) It is so important that someone is easy accessible, to just give that advice or support'. Female, RA, 54 years old.

2) Knowledgeable professionals (13 statements) Quote:'(.......) Other specialists and my GP do not know what biologicals are so you cannot ask even very simple questions'. Female, $R A, 32$ years old.

3) Collaborating health care professionals (6 statements)

Quote:'(.......) I think that the nurse is in line with the rheumatologist' Female, RA, 47 years old.

4) Coordinated care (5 statements) Quote:'(.......) He takes the phone and makes arrangements. The doctor does not have time for that'. Male, RA, 39 years old.

5) Contact person (6 statements)

Quote:'(.......) To know that I can call whenever that is needed makes me feel reassured'. Female, RA, 32 years old.

\section{Discussion}

In this study we identified patients' expectations and needs with regard to rheumatology nursing care in focus group interviews. We decided to start with this first step based on the advices of the patient research partners in the project group. 
Participants in the focus group interviews discussed the many needs they perceived during their journey to live with a rheumatic disease, which were organised in three main themes: education, self-management support and emotional support. They also expressed what they expected from health care resulting in a fourth theme -well organised care. Participants stated that rheumatology nurses can address their needs and can meet their expectations.

In our study, the need for education was most prominent. Patient education is a planned process aiming to improve coping strategies and increase self-care abilities [16, 17]. Patients expressed the need for reassurance, which can be addressed by tailored information. Feeling insecure, feeling confused, fear of losing independence and feeling anxious because of potential risks all have an impact on daily life [18, 19]. Rheumatology nurses have been found to contribute to increased knowledge of the disease and the treatment [20] which may contribute to reassurance, but may also play an important role in improving self-management $[21,22]$.

Self-management support appeared to be important for patients. Patients explicitly expressed the desire to manage their own problems. Self-management support comprises many interventions, performed by many health professionals. It usually includes education, but interaction with psychosocial factors, such as coping strategies and motivation, should be taken into account [23]. A variety of rheumatology nursing interventions focus on improving well-being, coping skills and self-efficacy. The literature has shown that rheumatology nurses are likely to contribute to self-efficacy and to perceived control [24. 25].

Statements with regard to emotional support were also extracted from the focus group interviews. The psychosocial impact of rheumatic diseases is recognised [26]. The patients in our study described emotional support such as understanding, a listening ear and supportive communication. They distinguished between social companionship from relatives and friends, and emotional support from health care providers which are both associated with lower psychological distress $[27,28]$. In our study, patients valued emotional support from a rheumatology nurse so that they did not overburden their relatives and friends.

Patients stated their expectations regarding the organisation of care. Knowledgeable professionals, important information, guidance, access to care, and collaboration of professionals are indicators of quality of care from a patient's perspective [29]. The contribution of rheumatology nurses to quality and continuity of care has been described before [30].

A strength of our study was the participation of the target population -patients with CIAin all parts of the study. The contribution of the patient research partners was directional for the design and validated the results of the data analyses. Furthermore, each focus group interview started with an open question that elicited a broad discussion among the 
participants. We think that this contributed to an optimal exploration of patients' needs and expectations.

Some limitations need to be addressed. Although 10 patients per clinic were invited for the first three focus group interviews, only four patients per clinic decided to participate. The reasons for not consenting are not known. Despite the small number of participants, there was a wide variation in age and disease duration, but we cannot exclude the fact that our findings may be limited. However, in the fourth focus group interview, the subthemes were verified and no other themes emerged, which suggests that saturation had been achieved. The inclusion criteria limited recruitment of participants to those patients that had contact with a rheumatology nurse. Access to rheumatology nursing care is not equally available in all countries. Our results may also reflect the opinions of patients that do not have access, but this remains unclear. Furthermore, from the participants in the focus groups, 18 patients had RA. Although education, selfmanagement support, emotional support and well organised care may also be important themes for patients with inflammatory diseases other than RA, we do not know if the results would have been different if patients with other diseases had participated in our study.

The findings of this study will direct further research that will show if the themes that have been identified in the focus group interviews also represent the opinions of a larger group of patients. Disease specific components may be of special interest as well as a comparison of the opinions of patients that have access to rheumatology nurses with the opinions of the patients who do not have access. Further research may focus on disease specific components in different European countries. Subsequently, the results will be used to assess if the care that is currently provided meets the needs and expectations of patients that may result in patient-centred care improvement strategies.

In summary, the focus group interviews yielded valuable information and provided a structured overview about the care that patients with $\mathrm{CIA}$ in the Netherlands need and expect. This is a first step in defining patients' priorities for rheumatology nursing care that can direct future research towards issues which are most relevant for patients.

\section{Acknowledgements}

We thank the patient research partners Bertha Maat, Marleen Bolech en Monique Lieon for their contribution to the design of the study and the development of the questionnaire on patients' characteristics. Furthermore we thank Linda Veldhuizen for transcribing the audio recordings. Finally, many thanks to the 20 participants in the focus group interviews. 


\section{References}

1. Repping-Wuts $\mathrm{H}$, Fransen J, van Achterberg $\mathrm{T}$ et al. Persistent severe fatigue in patients with rheumatoid arthritis. J Clin Nurs. 2007;16(11c):377-83.

2. Smolen J, Aletaha D, Bijlsma J et al. Treating rheumatoid arthritis to target: recommendations of an international task force. Ann Rheum Dis. 2010;69:631-7.

3. Hughes JG, van Middendorp H, Kool MB et al. Exploring the impact of rheumatoid arthritis on patients' lives... including commentary by van Middendorp H et al. Int J Ther Rehab. 2009;16(11):594-601.

4. Braun J, van den Berg R, Baraliakos X et al. 2010 update of the ASAS/EULAR recommendations for the management of ankylosing spondylitis. Ann Rheum Dis. 2011;70:896-904.

5. Gossec L, Smolen JS, Gaujoux-Viala C et al. European League Against Rheumatism recommendations for the management of psoriatic arthritis with pharmacological therapies. Ann Rheum Dis. 2012;71:4-12.

6. Vliet Vlieland TPM. Multidisciplinary team care and outcomes in rheumatoid arthritis. Curr Opin Rheumatol. [Review] 2004;16(2):153-6.

7. van Eijk-Hustings $Y$, van Tubergen A, Boström $C$ et al. EULAR recommendations for the role of the nurse in the management of chronic infl ammatory arthritis. Ann Rheum Dis. 2012;71(13-19).

8. Mead N, Bower P. Patient-centredness: a conceptual framework and review of the empirical literature. Soc Sci Med. 2000;51:1087-110.

9. van der Eijk M, Faber M, Al Shamma S et al. Moving towards patient-centered healthcare for patients with Parkinson's disease. Parkonsonism Relat Disord. 2011;17:360-4.

10. Miles A. Moving from a reductive anatomico-pathological medicine to an authentically anthropocentric model of healthcare: current transitions in epidemiology and epistemology and the ongoing development of person-centered clinical practice. Int J Pers Centered Med. 2012;2(4):615-21.

11. Hewlett $S$, de Wit M, Richards $P$ et al. Patients and professionals as research partners: Challenges, practicalities, and benefits. Arthritis Care Res. 2006;55(4):676-80.

12. Abma T, Nierse C, Widdershoven G. Patients as Partners in Responsive Research: Methodological Notions for Collaborations in Mixed Research Teams. Qual Health Res. 2009;19(3):401-15.

13. Ward V, Hill J, Hale C, et al. Patient priorities of care in rheumatology outpatient clinics: a qualitative study. Musculoskeletal Care. 2007;5(4):216-28.

14. Bernatsky S, Feldman D, De Civita M, et al. Optimal care for rheumatoid arthritis: a focus group study. Clin Rheumatol. 2010;29:645-57.

15. Krueger RA, Casey MA, editors. Focus groups: a practical guide for applied research.4th ed: Thousand Oaks, CA: Sage; 2009.

16. Hirano P, Laurent D, Lorig K. Arthritis patient education studies, 1987- 1991: a review of the literature. Pat Educ Counsel. 1994;24:9-54.

17. Lorig K, Konkol L, Gonzalez V. Arthritis patient education: a review of the literature. Pat Educ Counsel. 1987;10:207-52.

18. Lütze U, Archenholz B. The impact of arthritis on daily life with the patient perspective in focus. Scand J Caring Sci. 2007;21:64-70.

19. Radford S, Carr M, Hehir M et al. 'It's quite hard to grasp the enormity of it': Perceived needs of people upon diagnosis of rheumatoid arthritis. Musculoskeletal Care. 2008;6(3):155-67

20. Ndosi M, Vinall K, Hale C et al. The effectiveness of nurse-led care in people with rheumatoid arthritis: a systematic review. Int J Nurs Stud. 2011;48(5):642-54.

21. Helland Y, Kjeken I, Steen E et al. Rheumatic Diseases and Sexuality: Disease Impact and SelfManagement Strategies. Arthritis Care Res. 2011;63(5):743-50.

22. Mechlenborg Kristiansen T, Primdahl J, Antoft R et al. Everyday Life with Rheumatoid Arthritis and Implications for Patient Education and Clinical Practice: A Focus Group Study. Musculoskeletal Care. 2012;10:29-38.

23. Dures E, Hewlett S. Cognitive-behavioural approaches to self-management in rheumatic disease. Nat Rev Rheumatol. 2012;8(9):553-9.

24. Primdahl J, Wagner L, Holst R te al. The impact on self-efficacy of different types of follow-up care and disease status in patients with rheumatoid arthritis. A randomized trial. Pat Educ Counsel. 2012;88:1218.

25. Ryan $S$, Hassell $A B$, Lewis $M$ et al. Impact of a rheumatology expert nurse on the wellbeing of patients attending a drug monitoring clinic. J Adv Nurs. 2006;53(3):277-86. 
26. Vriezekolk J, Eijsbouts A, Evers A et al. Poor psychological health status among patients with inflammatory rheumatic diseases and osteoarthritis in multidisciplinary rehabilitation: need for a routine psychological assessment. Disabil Rehabil. 2010;32(10):836-44.

27. Benka J, Nagyova I, Rosenberger J et al. Social support and psychological distress in rheumatoid arthritis: a 4-year prospective study. Disabil Rehabil. 2012;34(9):754-61.

28. Strating M, Suurmeijer T, van Schuur W. Disability, Social Support, and Distress in Rheumatoid Arthritis: Results from a Thirteen-Year Prospective Study. Arthritis Rheum. 2006;55(5):736-44.

29. Zuidgeest M, Sixma H, Rademakers J. Measuring patients' experiences with rheumatic care: the consumer quality index rheumatoid arthritis. Rheumatol Int. 2009;30:159-67.

30. Temmink D, Hutten JB, Francke AL et al. Quality and continuity of care in Dutch nurse clinics for people with rheumatic diseases. Int J Qual Health Care. 2000;12(2):89-95. 
Chapter 9

Summary and general discussion 


\section{Summary of the content and main findings}

Chronic rheumatic conditions, such as fibromyalgia (FM), i.e. chronic, widespread, unexplained pain, and chronic inflammatory arthritis (CIA), have a high impact on the patient's daily life. Despite undeniable progress in the treatment and care of rheumatic diseases, there is still room for improvement. Different aspects of care delivered to patients should be addressed and more importantly, a well-coordinated approach is needed to integrate the new insights into current practice. Redesigning health care, however, is no sinecure. This thesis describes several studies addressing different aspects of care improvement and attempts to integrate the different findings into a holistic view on health care for patients with rheumatic diseases. Chapter 1 describes that efforts to improve health care should i) focus on the development of effective interventions that support self-management of patients, ii) include a clear definition of roles for all health care providers that are involved, even beyond traditional tasks, iii) offer appropriate training and education for all to fulfil these roles, iv) provide decision support for health care providers and for policy makers, and v) emphasise fine tuning between professionals and available resources.

Following the introductory Chapter of the thesis, two main parts are distinguished. The first focusses on care improvement for patients with FM by evaluating the results from a multidisciplinary intervention and by developing a proposal for stepped care to support primary care health professionals in the management of FM. The second part focusses on care improvement for patients with $\mathrm{CIA}$ by emphasising the role of the rheumatology nurse in this care.

In order to understand whether a timely and multicomponent intervention contributes to improved health care for patients with FM, an intensive multidisciplinary program with aftercare (MD) was developed and compared with aerobic exercise (AE) and with usual care (UC).

Chapter 2 describes the results of a randomised controlled trial, in which 203 patients, recently diagnosed with FM, were assigned to $M D(n=108), A E(n=47)$ and $U C(n=48)$. The primary outcomes were health care resource utilisation, participation and quality of life, three societal relevant outcomes. Mixed linear model analyses showed that in the MD and AE group most outcomes improved over time, but between the three groups differences were small. In addition, patients' willingness to participate in the interventions was limited; in total, 68 patients started with MD and 19 patients started with AE. Patients' preferences and expectations about potential treatment results of interventions, but also time required for accepting the diagnosis and for learning how to cope with limitations, might be decisive in this willingness to participate, but it is conflicting with our aim to offer a timely intervention. Based on these findings, we could not conclude about the effectiveness of the MD intervention. Notwithstanding, even though no effects on a group 
level were found, it cannot be excluded that some patients benefitted from the interventions.

In order to provide a more comprehensive view on the course of costs, the resource utilisation and costs of patients of the above described cohort were examined from the time of referral to the rheumatologists, which was well before the start of the interventions. As presented in Chapter 3, the main finding was a clear reduction of health care costs in all groups in the period following the diagnostic phase, even before starting any intervention. Mixed linear model analyses showed that health care costs (excluding the intervention costs) further decreased in the $A E$ group, but remained unchanged in the MD group, and increased in the UC group. After the intervention, average health care costs increased again in all three groups. In contrast, patient \& family costs increased in the three groups directly after diagnosis. When comparing the total direct costs, including the intervention costs, between the groups, the total costs were highest in $M D$ and $A E$, although differences were not statistically significant. In other words, program costs are not offset by subsequent savings in health care costs or patient $\&$ family costs.

Although the previous study did not show differences in effect between groups, there were individual patients that showed improvement. In the study described in Chapter 4, potential predictors for improved health of the patients in the FM study after two years follow-up were assessed using univariate and multivariate linear and logistic regression methods. The International Classification of Functioning and Health was used as a model to structure the large number of potential predictors and factor analysis was used to cluster predictors into distinct factors. Being employed and full participation in an intervention (i.e. started and followed $>70 \%$ of the scheduled sessions) were independently associated with the patient's global impression of improved health, whereas a longer duration of symptoms and higher perceived limitations in physical functioning contributed to a worse end-of-study experience of health. The study results suggest that the selection for a more intensive and expensive program should be directed towards patients with a high perceived impact of FM on their daily life that are showing signs of help-seeking behaviour. Further, a proactive approach by encouraging patients to participate in an intervention, is supported by our results. Being in full employment and motivation to participate in an intervention can be part of treatment indications.

Since the majority of the patients with FM are managed in primary care, general practitioners (GPs) and physiotherapists are the main health care providers. However, they often lack sufficient knowledge about FM and there is no consensus about appropriate management. Chapter 5 describes a project in which a multidisciplinary guideline for management and a checklist for referral to appropriate interventions were developed. Both were offered to primary health care professionals in an educational program about diagnosis and management of FM. After testing in daily practice during six months, the guideline as well as the checklist for referral were considered feasible for 
application. In interviews using the Assessment Chronic Illness Care questionnaire, 12 teams of 12 GPs and 23 physiotherapists in total thatalready had some kind of collaboration, reported improvements with regard to the care elements 'self-management support', 'decision support', 'delivery system design' and 'information systems'. In addition they considered adjustments of daily routine pivotal for implementation of the guideline and the checklist for referral in daily practice.

Care for patients with $\mathrm{CIA}$ is provided by multidisciplinary teams in which rheumatology nurses are increasingly considered important members. However, the role of the rheumatology nurse differs across countries and regions. In order to achieve standardisation in rheumatology nursing care across Europe, the European League Against Rheumatism (EULAR) supported the development of recommendations for the role of the nurse in the management of $\mathrm{CIA}$, which is described in Chapter 6. Based on evidence from a systematic review of the literature and expert opinions 10 recommendations were formulated by a multidisciplinary task force, comprising 25 professionals and patients from 14 countries, in a consensus meeting. Seven recommendations cover the role of the nurse in care and management, e.g. patient education, patient satisfaction, access to- and efficiency of care, disease management, psychosocial and self-management support, whereas three recommendations focus on professional support for nurses, e.g. access to continuous education, availability of guidelines and protocols, and encouragement to fulfil extended roles. In addition, a research and an educational agenda were formulated.

While the level of agreement with the recommendations within the task force was high, a wider adoption among nurses, rheumatologists and patients was considered necessary to support implementation. Furthermore, insight in barriers for acceptance and application of the recommendations was needed. Chapter 7 describes a web-based survey among 967 nurses, 548 rheumatologists and 2,034 patients from 22 European countries and the United States of America (USA). Agreement with and application of the recommendations were asked for on a 0-10 scale (0: none, 10: full agreement/application); additionally, reasons for disagreement and potential barriers to application of each recommendation were asked for. Regional differences with respect to agreement and application were explored. The survey revealed a high level of agreement (median between 8 and 10) with all recommendations in all three groups, but a substantially lower level of application (median between 0 and 8) in daily practice. Agreement and application were lowest in Eastern- and Central Europe. The most commonly reported reasons for disagreement with the recommendations by nurses were 'too many other responsibilities', by rheumatologists 'doubts about knowledge of the nurse', and by patients 'fear of losing contact with the rheumatologist'. In the three groups, time constraints and unavailability of services were the most commonly reported barriers to the application of the recommendations. In addition, rheumatologists reported insufficient knowledge of nurses 
to fulfil roles as stated in the recommendations. In the survey, topics were identified that can be used to develop tailored strategies supporting further implementation of the recommendations for rheumatology nursing care.

An important dimension for quality of care is patient-centredness. Care improvement activities should focus on topics that are important for patients. More insight in the quality of the care actually offered in rheumatology is needed. A task force from the Dutch Nurses Association V\&VN, unit Rheumatology, in collaboration with patient research partners, decided that patients' needs and expectations should be directional in defining priorities for a research agenda with regard to rheumatology nursing care in the Netherlands. Chapter 8 describes a first step in the development of the research agenda. Patients' needs and expectations were explored by 20 patients in focus group interviews in four medical clinics. Two hundred statements were extracted from the transcriptions of the interviews. In total, 12 subthemes emerged that were organised into four main themes. Patients needed 'education', 'self-management support' and 'emotional support', and expected 'well organised care'. The emerged themes will be main issues for future patient-centred research on rheumatology nursing.

\section{Methodological considerations}

Apart from the limitations of the studies that were described in the Chapters 2 to 8 of this thesis, two overall methodological considerations appeared and are discussed, one being the framework to understand the complexity of care improvement, and the second the outcomes needed to show if care improved.

\section{Frameworks for care improvement}

Improving care is an ongoing process and comprises many different elements. Interventions can focus on multiple dimensions of care. Many models, such as the PlanDo-Study-Act iterative Deming cycle, and Donabedian's structure-process-outcomes triangle have been developed and have shown their usefulness in a structured approach to achieve improvement, also in the field of health care [1-3]. More recently, frameworks such as the Chronic Care Model (CCM) contribute to a more integrative approach. The CCM includes an active role for society and for patients, and seems a more suitable framework for improvement of chronic illness care [4, 5]. Improvement strategies can focus on different elements of care that are interrelated. Although it is necessary to be aware of effectiveness of individual interventions, the fine tuning between all elements of improvement activities determines the final results.

In the studies that are presented in this thesis we focus on FM and CIA. Our activities for care improvement concern different elements of care, as can be seen in Figure 9.1. 


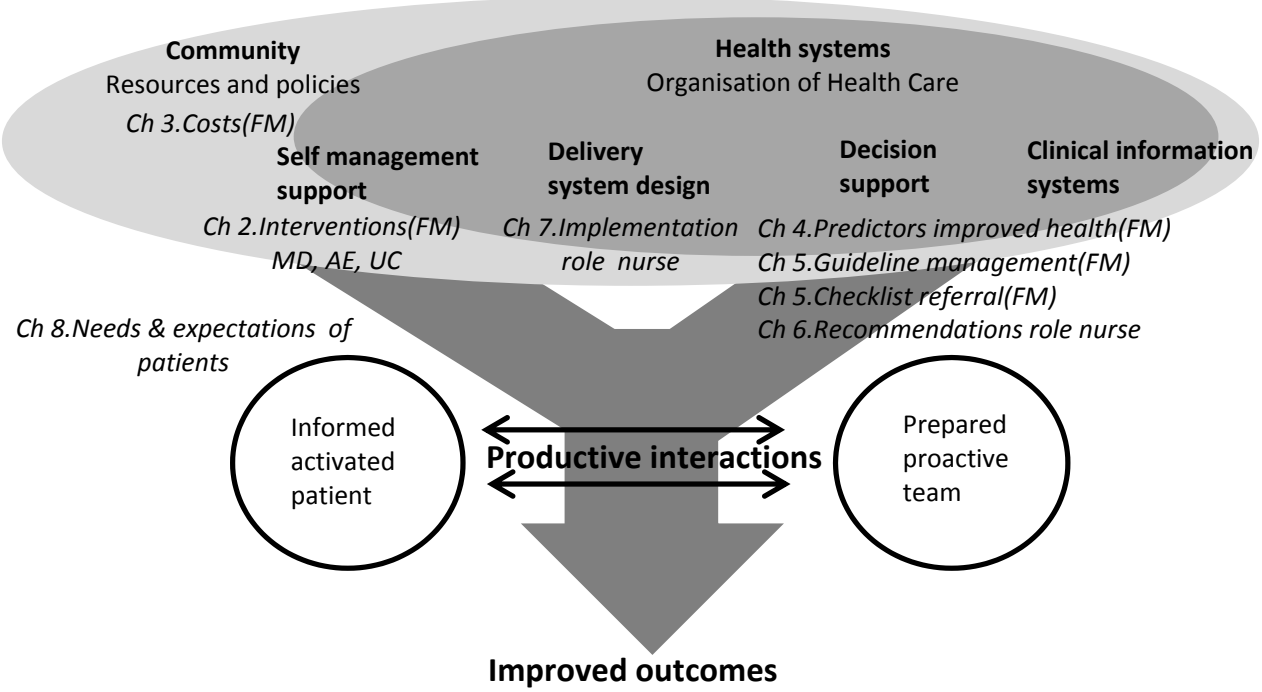

Figure 9.1 Activities for care improvement for patients with rheumatic diseases, structured in the CCM

When improving health care, results from activities for one (rheumatic) disease might be applicable to other (rheumatic) diseases and may be considered examples which can be adapted to other diseases and contexts. However, disease specific components cannot be ignored. A nice example is the implementation of cardio-vascular risk management in the care for patients with inflammatory rheumatic diseases. Although the attention for cardiovascular risk management is considered important within health care in general, and even within public health, increasing knowledge about the effects of inflammation on cardiovascular risks requires more specific interventions with regard to disease activity control in patients with $\mathrm{CIA}$ [6]. Also, disease-related aspects need to be addressed within patient education towards self-management. Many typical symptoms in rheumatology, such as pain, fatigue and stiffness, are highly responsible for perceived limitations in daily activities in patients with a wide range of rheumatic diseases. However, in-depth education about the potential cause of these symptoms and subsequent appropriate strategies for self-management, e.g. graded activity for patients with FM, may require disease specific components [7-9].

Notwithstanding, the results from our activities for care improvement with regard to FM and $\mathrm{CIA}$, and the lessons that are learned from our studies might also benefit the care for patients with other (rheumatic) diseases. 


\section{Outcomes for care improvement}

Evaluation of care improvement from several perspectives is complex and requires assessment of the connection between all activities $[5,10]$. The selection of outcome domains and the development of appropriate instruments to measure the different aspects of care improvement is another methodological consideration and will depend on the perspective. For patients, health but also quality of care may be appropriate outcomes; for health care providers, sufficient knowledge, skills and support may be of importance; for society, access to care and costs are relevant outcomes.

In our studies about FM that are described in Chapter 2, 3 and 4, the focus was on improved outcomes of societal interest and on medical outcomes on the patient's level that adhered to some extent to the Outcomes in Rheumatology (OMERACT) core set for FM [11]. As cure is an unrealistic treatment goal for FM patients, self-management skills, mediators for health, are considered of special importance. However, there are no reliable instruments available to assess self-management. We assumed that a reduced use of health care resources, and improved participation and quality of life was a consequence of better self-management, which may be arguable.

In Chapter 5, the CCM was used as a framework for improving health care. The interventions were evaluated on the level of perceived team performance in the health care system. We did not assess if the application of the tools resulted in better outcomes for patients. Notwithstanding, the improved collaboration, as stated by the health care professionals, might contribute to a better care for FM patients.

With regard to the care for patients with $\mathrm{CIA}$, Chapters 6, 7, and 8, we have focussed on the role of the nurse, an increasingly important player in the health care system.

In doing so, the literature revealed a variety of outcomes [12]. An increasing number of studies provide evidence about the contribution of rheumatology nurses to accessible and high quality of care for patients with CIA by showing improved patient outcomes in terms of knowledge, satisfaction, and self-efficacy, but also societal relevant information with regard to cost-effectiveness [13-17]. These findings justify our efforts to promote the role of the nurse, but until today there is no agreement upon main outcomes of interest for rheumatology nursing care.

\section{Implications for research}

Research with regard to holistic care for patients with FM remains a challenge. A tailored approach when offering interventions might contribute to larger effects, but given the worldwide and ongoing discussion about phenotyping FM patients, appropriate patient selection is no sinecure. Potential biomarkers as well as psychological and environmental factors have been taken into account but these efforts have not yet resulted in convincing profiles [18-21], nor have been tested in other populations, or may lack feasibility. Both appropriateness of criteria for selection and the selection process itself should be 
scrutinised in the discussion. Considering the different roles and reallocating tasks of the health care professionals, such as nurses, in this process might be a valuable topic for research [22, 23]. Our studies have shown, that patients' expectations about potential treatment results and preferences for specific interventions should be taken into account. Studies that will show improvement of care through the patient's eye and also provide insight in patients' expectations, in relevant phenotypes, and in economic consequences of this care, might require mixed methods designs. Last, but not least, when evidencebased guidelines are available, research should also study the extent to which guidelines have been implemented and appropriate referral takes place [24].

With regard to the role of the rheumatology nurse, high-quality studies on a national and international level, which include clear descriptions of nursing roles and interventions, are needed. A research agenda regarding (cost) effectiveness of nursing interventions on various outcomes, also in the long term, and regarding international comparisons, has been identified already [12]. The agenda provides a list of priorities, but also requires a spirit of cooperation among nurses. The large differences between nurses from different countries in roles and educational level might hinder a joint approach. To support nursing collaboration with regard to research, an international study group, endorsed by EULAR, has been founded [25].

In addition, the implementation of aspects of rheumatology nursing care itself and its impact on care for patients with rheumatic diseases should be monitored. Until today, research with regard to effects of rheumatology nursing interventions is limited and focussed on a variety of outcomes such as patients' experiences and perceptions, selfefficacy, self-management and knowledge, and in addition outcomes for disease activity $[13,15-17,26-31]$. All these outcome domains are measured with a variety of instruments, which hampers comparibility of the studies. The definition of a core set of outcome domains and instruments that are sensitive for nursing interventions is necessary. An intercontinental study group has been founded that will explore key outcome domains to be used in research, and will select and develop valid instruments for measurements. The group will be supported by OMERACT [32].

\section{Implications for practice}

The need to redesign our health care system is emphasised by policy makers in an attempt to control cost-of-illness while maintaining and improving health [33]. Also, health care professionals and patients in rheumatology recognise limitations in the present system in terms of quality of care, specifically patient-centredness, accessibility and efficiency of care [34-36]. Sustainable, integrated care is the future aim and this aim should be leading when implementing the required changes [37]. 
With regard to care for patients with FM, a stepped care approach, in which care is provided, based on severity of symptoms and dysfunctioning [38], might contribute to sustainability of care. This stepped care approach, designed via mutual agreement between primary, secondary and tertiary care providers, was already emphasised by a small project group in our region [39], but might be generalised. The separate steps and the role of each health care provider, adjusted to the local situation, should be clearly described. The impact of FM on patients is high [40, 41], and the help-seeking behaviour of certain patients raise the question if ongoing self-management during the entire course of their disease is a realistic goal for all patients. In addition to a tailored and stepped care approach, a structured follow-up such as in disease management programs for diabetes or asthma might be considered for these patients [42-44]. Improved training in the diagnosis and management of FM is needed for physicians, especially GPs, but also other specialties [45]. Health care providers and health insurance companies might consider to collaborate in order to improve care that remains accessible at low cost. Monitoring of health care utilisation is delicate, but might be considered.

The wider implementation of rheumatology nursing care also fits in the aim to develop a care system in which sustainable and integrated care is delivered. However, not all patients with a rheumatic disease have access to a rheumatology nurse. Further implementation of the recommendations for the role of the nurse will be faced with barriers for acceptance and application, which are partially different across regions in Europe and in the USA. Targeted strategies are needed that address the specific problems in the different countries. However, lack of time, lack of money and lack of sufficient well trained nurses were reported as important barriers for implementation, independent from country or region. More information about cost-effectiveness of nurse-led care within rheumatology might contribute to a discussion about the economic value of rheumatology nursing. Appropriate education for rheumatology nurses is a major prerequisite for a high quality of care. Roles for national and international multidisciplinary organisations are obvious; they are leading in defining a view on care for patients with rheumatic diseases, which should include a view on the role of the rheumatology nurse. Following this view, national and international standards for education of rheumatology nurses can be defined and developed. 


\section{Overall conclusions}

In this thesis we have presented several initiatives for care improvement in rheumatology. Although we could not conclude about MD to be a highly effective intervention for patients with recently diagnosed FM, our studies increased understanding of difficulties to prove (cost) effectiveness in this patient group. Taking patients' preferences and expectations, as well as the costs into account, a tailored and stepped care approach for offering interventions by knowledgeable professionals seems required. A practical approach to appropriate training for health care professionals and decision support with regard to management and patient selection resulted in a sense of improvement by health care professionals. Further research is needed to prove if this results in improved care for patients with $\mathrm{FM}$, and such research requires instruments that measure the different aspects of the complexity of care improvement.

With regard to the role of the nurse in rheumatology we have contributed to an international movement towards a professionalisation of rheumatology nursing care for patients with CIA. The evidence-based recommendations that were developed, highlight points of particular interest in nursing care and provide a basis for further optimising care. The recommendations were widely adopted by nurses, rheumatologists and patients in many European countries and in the USA. However, important barriers for implementation, such as the availability of sufficient well trained nurses, economic resources, and materials for support -e.g. protocols, guidelines- will have to be addressed and ongoing support from EULAR and other national and international organisations is needed. 


\section{References}

1. Donabedian A. Evaluating the quality of medical care. Milbank Q. 2005;83(4):691-729.

2. Moran S. Improving palliative care. Nurs Manag (Harrow). 2009;16(2):14-7.

3. Lawson EF, Yazdany J. Healthcare quality in systemic lupus erythematosus: using Donabedian's conceptual framework to understand what we know. Int J Clin Rheumtol. 2012;7(1):95-107.

4. Coleman K, Austin BT, Brach C, Wagner EH. Evidence On The Chronic Care Model In The New Milennium. Health Affairs. 2009;28(1):75-85.

5. Wagner EH, Austin BT, Von Korff M. Improving outcomes in chronic illness. Manag Care Q. 1996;4(2):1225.

6. Peters MJ, Symmons DP, McCarey D, et al. EULAR evidence-based recommendations for cardiovascular risk management in patients with rheumatoid arthritis and other forms of inflammatory arthritis. Ann Rheum Dis. 2009;69(2):325-31..

7. Hoedeman R, Krol B, Blankenstein N, Koopmans PC, Groothoff JW. Severe MUPS in a sick-listed population: a cross-sectional study on prevalence, recognition, psychiatric co-morbidity and impairment. BMC Public Health. 2009;9:440.

8. Koch $\mathrm{H}$, van Bokhoven MA, ter Riet G, van der Weijden T, Dinant GJ, Bindels PJ. Demographic characteristics and quality of life of patients with unexplained complaints: a descriptive study in general practice. Qual Life Res. 2007;16(9):1483-9.

9. Bijlsma J, Geussens P, Kallenberg C, Tak PP, Jacobs J (CD-rom), editors. Reumatologie en klinische inmmunologie: Bohn Stafleu van Loghem Houten; 2004.

10. Campbell M, Fitzpatrick R, Haines A, et al. Framework for design and evaluation of complex interventions to improve health. BMJ. 2000; 321 doi: 10.1136/bmj.321.7262.694.

11. Mease P, Arnold LM, Choy EH, et al. Fibromyalgia syndrome module at OMERACT 9: domain construct. J Rheumatol. 2009;36(10):2318-29.

12. van Eijk-Hustings $Y$, van Tubergen A, Boström $C$, et al. EULAR recommendations for the role of the nurse in the management of chronic infl ammatory arthritis. Ann Rheum Dis. 2012;71(1) (13-19).

13. Koksvik HS, Hagen KB, Rødevand E, Mowinckel P, Kvien TK, Zangi HA. Patient satisfaction with nursing consultations in a rheumatology outpatient clinic: a 21-month randomised controlled trial in patients with inflammatory arthritides. Ann Rheum Dis. 2013;72(6):836-43. (6):836-43.

14. Ndosi M, Lewis M, Hale C, et al. The outcome and cost-effectiveness of nurse-led care in people with rheumatoid arthritis: a multicentre randomized controlled trial. Ann Rheum Dis. 2013; doi:10.1136/annrheumdis-2013-203403:1-11.

15. Ndosi M, Vinall K, Hale C, Bird H, Hill J. The effectiveness of nurse-led care in people with rheumatoid arthritis: a systematic review. Int J Nurs Stud. 2011;48(5):642-54.

16. Primdahl J, Sørensen J, Horn HC, Randi Petersen R, Hørslev-Petersen K. Shared care or nursing consultations as an alternative to rheumatologist follow-up for rheumatoid arthritis outpatients with low disease activity--patient outcomes from a 2-year, randomised controlled trial. Ann Rheum Dis. 2013;00:1-8. [Epub ahead of print].

17. Zangi $H$, Mowinckel $P$, Finset $A$, et al. A mindfulness-based group intervention to reduce psychological distress and fatigue in patients with infl ammatory rheumatic joint diseases: a randomised controlled trial. Ann Rheum Dis. 2012;71:911-7.

18. Giesecke T, Williams DA, Harris RE, et al. Subgrouping of fibromyalgia patients on the basis of pressurepain thresholds and psychological factors. Arthritis Rheum. 2003;48(10):2916-22.

19. Turk DC, Okifuji A, Sinclair JD, Starz TW. Pain, disability, and physical functioning in subgroups of patients with fibromyalgia. J Rheumatol. 1996;23:1255-62.

20. van Koulil S, Kraaimaat FW, van Lankveld W, et al. Screening for pain-persistence and pain-avoidance patterns in fibromyalgia. Int J Behav Med. 2008;15(3):211-20.

21. Xiao Y, Russell IJ, Liu YG. A brain-derived neurotrophic factor polymorphism Val66Met identifies fibromyalgia syndrome subgroup with higher body mass index and C-reactive protein. Rheumatol Int. 2012;32(8):2479-85.

22. Ryan S, Packham JC, Dawes PT, Jordan KP, T P. The Impact of a Nurse-Led Chronic Musculoskeletal Pain Clinic on Healthcare Utilization. Musculoskelet Care. 10. 2012;10:196-201.

23. Ryan S, Hassell A, Thwaites C, Manley K, Home D. Developing a new model of care for patients with chronic musculoskeletal pain. J Nurs Manag. 2007;15(8):825-9. eng. 
24. Kroese ME, Schulpen GJ, Sonneveld HM, Vrijhoef HJ. Therapeutic approaches to fibromyalgia in the Netherlands: a comparison between 1998 and 2005. J Eval Clin Pract. 2008 Apr;14(2):321-5.

25. www.eular.org. Accessed March 2013

26. Arvidsson SB, Peterson A, Nilsson I, et al. A nurse-led rheumatology clinic's impact on empowering patients with rheumatoid arthritis: A qualitative study. Nursing and Health Sciences. 2006;8 (3):133-9.

27. D'Arcy Y. Controlling pain. How to treat arthritis pain. Nursing. 2002;32(7):30-1.

28. Helland Y, Kjeken I, Steen E, Kvien T, Hauge M, Daginfrud H. Rheumatic Diseases and Sexuality: Disease Impact and Self-Management Strategies. Arthritis Care \& Research. 2011;63(5):743-50.

29. Primdahl J, Wagner L, Holst R, Horslev-Petersen K. The impact on self-efficacy of different types of follow-up care and disease status in patients with rheumatoid arthritis. A randomized trial. Pat Educ Counsel. 2012;88:121-8.

30. Repping-Wuts H, Fransen J, van Achterberg T, Bleijenberg G, van Riel P. Persistent severe fatigue in patients with rheumatoid arthritis. J Clin Nurs. 2007;16(11c):377-83.

31. Ryan S, Hassell A, Dawes P, Kendall S. Perceptions of control in patients with rheumatoid arthritis. Nurs Times. 2003 2003;99 (13):36-8.

32. www.omeract.org. Accessed March 2013

33. http://www.google.nl/search?q=rijksoverheid+programmatische+zorg\&rls=com.microsoft:nlNL\&ie=UTF-8\&oe=UTF-8\&startIndex=\&startPage=1\&redir esc=\&ei=ftxrUcTXEYy1PeflgNAE. Accessed March 2013

34. Choy E, Perrot S, Leon T, et al. A patient survey of the impact of fibromyalgia and the journey to diagnosis. BMC Health Serv Res 2010;10:102.

35. Bombardier C, Mian S. Quality indicators in rheumatoid arthritis care: using measurement to promote quality improvement. Ann Rheum Dis. 2013;72 Suppl 2:ii128-ii131.

36. Briones-Vozmediano E, Vives-Cases C, Ronda-Pérez E, Gil-González D. Patients' and professionals' views on managing fibromyalgia. Pain Res Manag. 2013;18(1):19-24.

37. http://www.rijksoverheid.nl/ministeries/vws/documenten-enpublicaties/kamerstukken/2013/02/08/kamerbrief-gezamenlijke-agenda-vws-van-systemen-naarmensen.html. Accessed March 2013

38. Schröder A, Fink P, Fjordback L, Frostholm L, Rosendal M. Towards a unified treatment approach for functional somatic syndromes and somatization Ugeskr Laeger (Danish). 2010;172(24):1839-42.

39. van Eijk-Hustings $Y$, Bessems-Beks $M$, Kroese $M$. Samenwerken bij chronische pijn in het bewegingsapparaat: regionale multidisciplinaire richtlijn (in Dutch). 2011. Maastricht: Maastricht University Medical Centre.

40. Annemans L, Le Lay K, Taïeb C. Societal and Patient Burden of Fibromyalgia Syndrome. Pharmaeconomics. 2009;27(7):547-59.

41. Arnold LM, Crofford LJ, Mease PJ, et al. Patient perspectives on the impact of fibromyalgia. Patient Educ Couns. 2008;73(1):114-20.

42. Steuten L, Palmer S, Vrijhoef B, et al. Cost-utility of a disease management program for patients with asthma. Int J Technol Assess Health Care. 2007;23(2):184-91.

43. Steuten LM, Vrijhoef HJ, Landewé-Cleuren S, Schaper N, Van Merode GG, Spreeuwenberg C. A disease management programme for patients with diabetes mellitus is associated with improved quality of care within existing budgets. Diabet Med. 2007;24(10):1112-20.

44. Elissen AM, Duimel-Peeters IG, Spreeuwenberg C, Spreeuwenberg M, HJ V. Toward tailored disease management for type 2 diabetes. Am J Manag Care. 2012;18(10):619-30.

45. Perrot S, Choy E, Petersel D, Ginovker A, Kramer E. Survey of physician experiences and perceptions about the diagnosis and treatment of fibromyalgia. BMC Health Serv Res. 2012;12:356. 
Samenvatting en discussie 


\section{Hoofdstuk 1. Introductie}

De zorg voor chronisch zieken is gebaat bij een proactieve benadering. Goed gecoördineerde en geplande zorg, gebaseerd op richtlijnen en gericht op het verbeteren van zelfmanagement van patiënten, leidt tot het verbeteren van hun gezondheid. Om de toegang tot kwalitatief goede zorg in de toekomst te garanderen, zijn nieuwe modellen voor zorgverlening noodzakelijk waarin nieuwe rollen voor de professionals, nieuwe technologieën en een goede ondersteuning van het zorgproces van belang zijn.

Reumatische aandoeningen zijn klachten in het bewegingsapparaat die niet kunnen worden verklaard door een ongeval of een andere specifieke gebeurtenis. Ze zijn meestal chronisch van aard. Ook in de zorg voor reumapatiënten vinden veranderingen plaats: in de aard van behandelingen, in de organisatie van de zorg én in veranderende rollen voor professionals. De behandeling is meestal multidisciplinair. Naast eventuele medicamenteuze behandeling kan zo nodig zorg worden verleend door onder andere de fysiotherapeut, de ergotherapeut en de psycholoog.

In toenemende mate spelen gespecialiseerde verpleegkundigen een belangrijke rol in deze zorg. De verpleegkundige zorg beoogt een bijdrage te leveren aan het zelfmanagement van patiënten. Ondersteuning van patiënten vindt plaats ten aanzien van een breed scala aan ziekte gerelateerde problemen. De rol van verpleegkundigen verandert en zij worden steeds meer betrokken bij de geplande controles van groepen patiënten en bij de behandeling.

Uit de geraadpleegde literatuur bleek dat zowel de zorg voor patiënten met fibromyalgie, chronische pijn in 'weke delen', zoals spieren en pezen, alsook de zorg voor mensen met chronisch inflammatoire aandoeningen, aandoeningen gekenmerkt door chronische ontstekingen in gewrichten, kan worden verbeterd. Met dat doel zijn verschillende projecten ontwikkeld en uitgevoerd die in dit proefschrift worden beschreven.

\section{Deel 1. Het verbeteren van de zorg voor mensen met fibromyalgie}

Fibromyalgie komt het meeste voor bij vrouwen. De klachten kunnen al vroeg, rond het twintigste- of dertigste levensjaar, ontstaan. Veelal hebben patiënten, naast pijn, ook andere klachten, zoals vermoeidheid en problemen met concentreren. De oorzaak van fibromyalgie is niet bekend maar het dagelijks functioneren van patiënten kan ernstig worden belemmerd. Vaak is sprake van een hoog zorggebruik, veelvuldig en langdurig ziekteverzuim en een slechte kwaliteit van leven.

Omdat genezing vooralsnog niet voorhanden is, richt de behandeling zich op 'het leren omgaan met de klachten'. Volgens de literatuur lijken multidisciplinaire behandelingen het beste resultaat te geven, maar de effecten zijn, indien aanwezig, meestal van korte duur. Het lijkt van belang om tijdig een behandeling aan te bieden; dit om te voorkomen dat 
mensen hun leven helemaal inrichten rond hun pijn. In de regio Zuid-Limburg bestond in het jaar 2000 geen multidisciplinaire behandeling. Om die reden werd een intensieve multidisciplinaire dagbehandeling met nazorg (MD) ontwikkeld, die werd aangeboden aan recent gediagnosticeerde patiënten. De behandeling bestond uit een combinatieprogramma van fysiotherapie, sociotherapie, psychotherapie en creatieve therapie. Gedurende drie maanden werd drie keer per week een dagdeel combinatietherapie aangeboden, gevolgd door een vijftal nazorgbijeenkomsten in een periode van negen maanden.

Een ander probleem dat werd gesignaleerd, was de diversiteit van behandelingen die in de dagelijkse praktijk werden aangeboden, en het veelvuldig verwijzen van de ene naar de andere professional, vaak pas zodra sprake was van ernstig disfunctioneren. Omdat de meeste mensen met fibromyalgie worden behandeld door huisartsen en fysiotherapeuten leek ondersteuning van deze eerstelijns professionals noodzakelijk om te kunnen komen tot beter op elkaar afgestemde zorg.

\section{Hoofdstuk 2. De effecten van multidisciplinaire dagbehandeling}

Allereerst werd onderzocht of MD leidde tot minder zorggebruik, minder ziekteverzuim en een betere kwaliteit van leven. Om dit onderzoek uit te voeren, werden patiënten van het Maastrichts Universitair Medisch Centrum, het Atrium Ziekenhuis in Heerlen en het Orbis Medisch Centrum in Sittard benaderd met de vraag of ze mee wilden doen aan een studie naar het natuurlijk verloop van fibromyalgie. Indien patiënten wilden deelnemen, ontvingen ze vragenlijsten waarmee, naast algemene gegevens zoals leeftijd, geslacht en opleiding, ook gegevens over het zorggebruik, ziekteverzuim en de kwaliteit van leven werden verzameld.

Vervolgens werden de deelnemers aan de studie $(n=203)$ door loting (randomisatie) ingedeeld in drie behandelgroepen: MD ( $n=108)$, aerobe oefeningen $(A E)(n=47)$, en voorlichting en begeleiding zoals gebruikelijk was (UC) $(n=48)$. Daarna werden de patiënten, die waren ingeloot voor $M D$ of $A E$, benaderd met de vraag of ze aan deze behandeling wilden deelnemen. Alle deelnemers aan het onderzoek, ook degenen die niet aan de behandeling wilden deelnemen, ontvingen de vragenlijsten op drie momenten: na afloop van de behandeling, en één jaar en twee jaar na de start van het onderzoek. In iedere groep werd bekeken of er verbetering optrad in de loop van de tijd. Daarnaast werden de resultaten van de drie groepen aan het einde van de studie onderling vergeleken.

Uiteindelijk wilden 68 patiënten die waren ingeloot voor MD en 19 patiënten die waren ingeloot voor $A E$ deelnemen aan de behandeling. Een aantal patiënten, acht in de $M D$ groep en 11 in de AE groep, stopten om allerlei redenen vroegtijdig met de behandeling. In de drie groepen zagen we een daling in het zorggebruik en in het ziekteverzuim, en een 
verbetering van de kwaliteit van leven. De verbetering leek het grootste in de MD groep, maar de verschillen tussen de drie groepen waren klein aan het einde van de studie. Om deze reden én omdat slechts een gering aantal patiënten aan de behandelingen had deelgenomen, hebben we geconcludeerd dat we op basis van ons onderzoek geen uitspraak konden doen over de effecten van de MD behandeling. Wel droegen de resultaten van het onderzoek bij aan inzicht in het verloop van fibromyalgie, onafhankelijk van interventies, en aan inzicht in barrières die van belang zijn bij het implementeren van zorgprogramma's.

\section{Hoofdstuk 3. Het verloop van kosten}

Vanwege een hoog zorggebruik zijn de kosten voor de gezondheidszorg bij fibromyalgie aanzienlijk. Interventies moeten daarom gepaard gaan met aanvaardbare effectiviteit tegen aanvaardbare kosten. In het onderzoek, dat wordt beschreven in dit hoofdstuk, hebben we het verloop van kosten over een periode van twee jaar onderzocht in het cohort van recent gediagnosticeerde fibromyalgie patiënten $(n=203)$, die deelnamen aan de effectstudie uit hoofdstuk 2.

Zoals al beschreven, werden patiënten na het stellen van de diagnose door loting toegewezen aan MD (n=108), AE (n=47) of UC (n=48). Gegevens over kosten voor de gezondheidszorg en kosten voor patiënten en hun families werden verzameld door middel van tweemaandelijkse vragenlijsten. In de drie groepen werd het verloop van de gemiddelde kosten bij aanvang van de studie, in de periode voorafgaand aan de behandeling, tijdens de behandeling en in de periode na afloop van de behandeling onderzocht. Daarnaast werd onderzocht in hoeverre, op basis van patiënten kenmerken bij aanvang van de studie, de kosten voor de gezondheidszorg in de periode na afloop van de behandeling konden worden voorspeld.

De kosten voor de gezondheidszorg namen in de drie groepen af na aanvang van de studie, maar dit leek vanzelfsprekend omdat de kosten voor bezoeken aan huisarts en medisch specialist, ten behoeve van de diagnostiek, in de eerste meting waren meegenomen. Toch was in de AE groep nog een verdere daling te zien, zelfs voordat een behandeling was gestart. In de loop van de tijd stegen de kosten weer licht in de drie groepen. De kosten voor patiënten en hun familie stegen in de loop der tijd in iedere groep. De kosten voor de interventies, met name de MD interventie, maakten substantieel deel uit van de totale kosten voor de gezondheidszorg. Patiënten die bij aanvang van de studie een grote invloed van fibromyalgie op het dagelijkse leven aangaven, genereerden hoge zorgkosten in de periode na afloop van de behandeling. Onze resultaten suggereren dat het verloop van de kosten niet voldoende wordt beïnvloed om dure interventies te rechtvaardigen. 


\section{Hoofdstuk 4. Voorspellers van 'ervaren gezondheid'}

De impact van fibromyalgie op ervaren gezondheid is groot. Omdat het effect van interventies meestal vrij klein is, is een beter inzicht in voorspellers voor ervaren verbeterde gezondheid noodzakelijk. In dit onderzoek hebben we voorspellers van 'door de patiënt ervaren verbetering van gezondheid' en de verandering in 'gezondheidstoestand' onderzocht. We hebben hierbij gebruik gemaakt van een biopsychosociaal model voor gezondheid, dat de samenhang tussen een aandoening, het functioneren, activiteiten, persoonskenmerken en omgevingsfactoren beschrijft: de 'International Classification of Functioning, Disability and Health' (ICF).

Gegevens van het eerder beschreven cohort van recent gediagnosticeerde fibromyalgie patiënten ( $n=203$ ) werden gebruikt. Patiënten werden door toeval toegewezen aan MD $(n=108), A E(n=47)$ of UC ( $n=48)$, maar slechts een beperkt aantal patiënten startte een interventie $(n=86)$ of was $>70 \%$ van de geplande sessies aanwezig $(n=68)$. Patiënten vulden bij aanvang van de studie vragenlijsten in, die betrekking hadden op alle onderdelen van het ICF-model en op ervaren gezondheidstoestand. Na twee jaar werd gevraagd naar ervaren verbetering van de gezondheid ten opzichte van het begin van de studie, en daarnaast weer naar ervaren gezondheidstoestand. Vervolgens werd onderzocht welke kenmerken van patiënten, gerangschikt volgens het ICF-model, verbetering van gezondheid konden voorspellen.

Het hebben van werk en voldoende aanwezigheid bij een interventie voorspelden door de patiënt ervaren verbetering van gezondheid na twee jaar. Een langere duur van de klachten en ervaren fysieke beperkingen voorspelden een slechtere gezondheidstoestand na twee jaar. Patiënten met grotere fysieke en mentale beperkingen waren meer bereid om te starten met een interventie en om daar voldoende aanwezig te zijn. De resultaten lijken te wijzen op het belang van een actief aanbod van een interventie, vooral voor mensen met ernstige klachten.

\section{Hoofdstuk 5. Het ondersteunen van eerstelijns professionals}

In twee regio's in het zuiden van Nederland werd een project opgezet om eerstelijns professionals, vooral huisartsen en fysiotherapeuten, te ondersteunen in het verlenen van beter op elkaar afgestemde zorg aan mensen met fibromyalgie. In het project werd het Chronic Care Model (CCM) gebruikt als een raamwerk om gecombineerde interventies te ontwikkelen. Het CCM beschrijft de samenhang tussen verschillende activiteiten binnen de gezondheidszorg en in de maatschappij, die uiteindelijk een bijdrage leveren aan verbeterde uitkomsten van patiënten. Voorbeelden van dergelijke activiteiten zijn: het aanbieden van effectieve interventies die het zelfmanagement van patiënten verbeteren, het ondersteunen van besluitvorming van professionals en een herverdeling van taken tussen verschillende disciplines die zijn betrokken in het zorgproces. In het genoemde 
project werden de volgende gecombineerde interventies ontwikkeld: een scholingsprogramma, een multidisciplinaire richtlijn voor behandeling, en een verwijsinstrument.

In totaal namen 12 huisartsen en 23 fysiotherapeuten, die samen 12 praktijkteams - al bestaande samenwerkingsverbanden- vormden, deel aan de scholing. Nadat de scholing was gevolgd, testten de praktijkteams de richtlijn en het verwijsinstrument gedurende zes maanden in de dagelijkse praktijk. Voorafgaand aan- en na afloop van de testperiode werden de teams geïnterviewd aan de hand van een vragenlijst, de 'Assessment Chronic Illness Care' (ACIC) vragenlijst. Deze vragenlijst evalueert teamopvattingen over het niveau en de aard van verbeteringen in de zorg als gevolg van interventies.

$\mathrm{Na}$ afloop van de testperiode bleek dat alle elementen van de zorg waren verbeterd. Volgens de professionals was het gebruik van de richtlijn en het verwijsinstrument haalbaar in de dagelijkse praktijk. Het was echter moeilijk om veranderingen in hun praktijk door te voeren. In aanvulling op onze interventies zijn andere activiteiten nodig om deze zorg verder te verbeteren.

\section{Deel 2. Het verbeteren van de zorg bij chronisch inflammatoire aandoeningen}

Inflammatoire (ontsteking gerelateerde) aandoeningen worden gekenmerkt door een abnormale reactie van het afweersysteem. Als gevolg hiervan treden ontstekingen op. Bij reumatoïde artritis, chronisch gewrichtsreuma, zien we deze ontstekingen vooral in de kleine gewrichten van handen en voeten, maar daarnaast ook in de grotere gewrichten. Bij spondyloartritis, een verzamelnaam voor meerdere aandoeningen waaronder de ziekte van Bechterew en artritis psoriatica, zijn er ontstekingen in de wervelkolom, waarbij ook andere gewrichten betrokken kunnen zijn. Naast gewrichtsontstekingen kunnen ook organen zijn aangedaan, vandaar dat we deze aandoeningen systemisch noemen. De voornaamste klachten -pijn, stijfheid en vermoeidheid-, kunnen het dagelijks functioneren van patiënten ernstig belemmeren. De aandoeningen worden gekenmerkt door perioden met hoge en lage ziekteactiviteit. Het patroon waarin deze perioden optreden is onvoorspelbaar.

In de behandeling is de afgelopen decennia veel verbeterd en in toenemende mate wordt de abnormale afweerreactie van het immuunsysteem succesvol onderdrukt. Toch kunnen patiënten worden beperkt door de klachten. De intensieve behandeling zelf vraagt goede controles door professionals én zelfmanagement van patiënten. Gespecialiseerde verpleegkundigen spelen hierin een belangrijke rol. Zij verzorgen voorlichting en scholing aan patiënten, bieden steun bij het omgaan met de gevolgen van de aandoeningen, participeren in de geplande controles en dragen bij aan de toegankelijkheid van de zorg. De rol van de reumaverpleegkundige wordt in landen en zelfs in regio's verschillend 
ingevuld. In sommige landen is reumaverpleegkundige zorg niet beschikbaar. De European League Against Rheumatism (EULAR), die beoogt een bijdrage te leveren aan een gelijkwaardige kwaliteit van de zorg voor alle reumapatiënten, heeft een aantal projecten ondersteund ten einde de rol van de reumaverpleegkundige te optimaliseren en te standaardiseren.

\section{Hoofdstuk 6. EULAR aanbevelingen voor de rol van de verpleegkundige}

Een multidisciplinair expertpanel van 25 personen uit 14 Europese landen, bestaande uit verpleegkundigen, reumatologen, een ergotherapeut, een fysiotherapeut, een psycholoog, een epidemioloog en vertegenwoordigers van patiënten, was verantwoordelijk voor het ontwikkelen van aanbevelingen voor de rol van de verpleegkundige in de behandeling van mensen met chronische inflammatoire aandoeningen, in het bijzonder reumatoïde artritis en spondyloartritis.

Aan de hand van onderzoeksvragen werd een systematisch literatuuronderzoek verricht. De resultaten van dit onderzoek werden door het expertpanel besproken en bediscussieerd. Op basis van de evidentie uit de literatuur en de mening van de experts werden 10 aanbevelingen geformuleerd. Zeven aanbevelingen betreffen de bijdrage van de verpleegkundige aan zorg en behandeling: educatie, patiënttevredenheid, toegankelijkheid van de zorg, ziektecontrole, psychosociale zorg, ondersteuning van zelfmanagement en doelmatigheid. Drie aanbevelingen richten zich op professionele ondersteuning voor verpleegkundigen: beschikbaarheid van richtlijnen en protocollen, scholing en rolontwikkeling. Bovendien werden een onderzoeksagenda en een scholingsagenda geformuleerd.

\section{Hoofdstuk 7. Verspreiding en evaluatie van de EULAR aanbevelingen voor de rol van de verpleegkundige}

Bekendheid met deze aanbevelingen en instemming van de directe betrokkenen, verpleegkundigen, reumatologen en patiënten, alsook kennis van barrières voor de toepassing ervan, zijn noodzakelijke voorwaarden voor implementatie. Daarom werd besloten om de aanbevelingen te verspreiden, de instemming met- en de toepassing van de aanbevelingen te meten, navraag te doen naar eventuele redenen om het niet eens te zijn met de aanbevelingen en naar belemmeringen om deze toe te passen.

Een vragenlijst werd via internet-links verspreid onder verpleegkundigen, reumatologen en patiënten in Europa en in de Verenigde Staten (VS). Aan de deelnemers werd gevraagd om de link te verspreiden onder zoveel mogelijk collega's of medepatiënten. De mate van instemming met- en toepassing van de aanbevolen zorg kon voor iedere aanbeveling worden ingevuld op een schaal van 0-10 (0: niet, 10: volledig). Eventuele redenen voor 'niet (volledig) eens' of 'niet (volledig) toegepast', konden worden aangevinkt in een lijst 
van gegeven mogelijkheden; de lijst kon worden aangevuld met andere redenen. Regionale verschillen met betrekking tot instemming en toepassing werden verkend. In totaal namen 967 verpleegkundigen, 548 reumatologen en 2034 patiënten uit 22 Europese landen en uit de VS deel aan het onderzoek. De mate van instemming was hoog in de drie groepen en varieerde van 8-10 per aanbeveling. De toepassing was veel lager en varieerde van 0-8 per aanbeveling. Instemming en toepassing waren het laagst in Oost- en Centraal-Europa. De meest voorkomende reden voor niet (volledige) instemming was bij verpleegkundigen 'teveel andere verantwoordelijkheden', bij reumatologen 'twijfels over de kennis van verpleegkundigen' en bij patiënten 'angst om contact met de reumatoloog te verliezen'. De meest gerapporteerde barrières voor toepassing van de aanbevolen zorg waren 'tijdgebrek' en 'geen verpleegkundigen beschikbaar'. Voor reumatologen was bovendien 'onvoldoende kennis van verpleegkundigen' een belangrijke barrière om de aanbevolen zorg toe te passen.

\section{Hoofdstuk 8. Zorgbehoefte van patiënten}

De onderzoeksagenda, die samen met de aanbevelingen voor de rol van de verpleegkundige (Hoofdstuk 6) werd geformuleerd, dient als globale leidraad voor verder onderzoek in verschillende landen en voor internationaal onderzoek. Een werkgroep van de Nederlandse beroepsvereniging voor reumaverpleegkundigen (V\&VN, afdeling reumatologie), werd opgericht om de onderzoeksagenda in Nederland verder vorm te geven. Na een discussie over het prioriteren van onderwerpen werd besloten dat de behoeften en verwachtingen van patiënten leidend dienden te zijn.

Om deze behoeften en verwachtingen te inventariseren werden focusgroepen georganiseerd met reumapatiënten in Utrecht $(n=4)$, Rotterdam $(n=4)$ en Maastricht $(n=4)$. In de focusgroepen werden verschillende gevolgen van het hebben van een reumatische aandoening besproken. Het betrof lichamelijke klachten, emoties, psychosociale gevolgen van de aandoening, en ervaren beperkingen in het vervullen van sociale rollen. Patiënten maakten kenbaar dat zij in staat wilden zijn zelf om te gaan met de genoemde gevolgen en dat ook vaak waren. Echter, een toename van de ziekteactiviteit of veranderingen in de persoonlijke situatie konden -tijdelijkeondersteuning noodzakelijk maken. Aansluitend werden behoeften en verwachtingen ten aanzien van reumaverpleegkundige zorg uitgesproken, die werden geordend in 12 subthema's en uiteindelijk werden gerangschikt in vier hoofdthema's. Patiënten hadden behoefte aan educatie, ondersteuning van hun zelfmanagement en aan emotionele ondersteuning; patiënten verwachtten goed georganiseerde zorg. In een vierde focusgroep in Nijmegen $(n=8)$ werden geen nieuwe thema's genoemd en werden de hoofdthema's geverifieerd.

De patiënten onderzoekspartners in de projectgroep speelden een bepalende rol bij de 
keuze voor het onderwerp, de opzet van het onderzoek en bij het analyseren van de resultaten. De focusgroepen hebben waardevolle informatie opgeleverd voor de richting van reumaverpleegkundig onderzoek vanuit het perspectief van de patiënt en de resultaten zijn bepalend voor het vaststellen van de onderzoeksagenda voor V\&VN, reumatologie.

\section{Hoofdstuk 9. Discussie}

In dit hoofdstuk worden een tweetal algemene overwegingen ten aanzien van zorgverbetering besproken. Allereerst kan de vraag worden gesteld of activiteiten, die beogen de zorg te verbeteren, gericht dienen te zijn op specifieke aandoeningen, óf dat een meer generalistische benadering de voorkeur heeft. Vanuit het oogpunt van zorgverbetering kunnen resultaten van activiteiten voor een bepaalde groep bruikbaar zijn voor een groep mensen met andere aandoeningen. Een voorbeeld is de aandacht voor cardiovasculaire risico's. Echter, ziektespecifieke bijdragen aan deze risico's, zoals ontstekingsactiviteit bij inflammatoire reumatische aandoeningen, dienen adequaat behandeld te worden hetgeen specialistische kennis vraagt. Ook is het voor patiënten noodzakelijk om kennis en vaardigheden ten aanzien van de aard en de behandeling van klachten te hebben, zodat zij beter hiermee om kunnen gaan. We denken dat de resultaten van onze onderzoeken kunnen bijdragen aan zorgverbetering voor mensen met andere (reumatische) aandoeningen.

Een ander aandachtspunt betreft de zichtbaarheid van zorgverbetering. Hiertoe dient een keuze te worden gemaakt ten aanzien van uitkomstmaten, maar deze keuze wordt deels bepaald door het perspectief van waaruit activiteiten worden beschouwd: dat van patiënten, van zorgverleners of van de maatschappij. In onze onderzoeken naar de effecten van de MD behandeling voor mensen met fibromyalgie hebben we, naast voor patiënten relevante uitkomsten zoals kwaliteit van leven, gekozen voor maatschappelijk relevante uitkomsten zoals gebruik van gezondheidszorg en participatie. We veronderstelden dat een kleiner beroep op de gezondheidszorg en verbeterde deelname aan het arbeidsproces een resultaat konden zijn van verbeterd zelfmanagement, maar dit is discutabel. In ons project voor verbetering van de $1^{\mathrm{e}}$ lijns zorg hebben we aan zorgverleners gevraagd of zij verbetering bemerkten, maar we hebben niet gemeten of dit daadwerkelijk leidde tot betere zorg voor patiënten.

In toenemende mate laten onderzoeken zien dat reumaverpleegkundigen bijdragen aan betere zorg, maar er wordt een grote diversiteit aan uitkomstmaten gebruikt. Voor de vergelijkbaarheid van studies is het van belang om eenduidigheid hierin te realiseren. De resultaten van onze activiteiten voor zorgverbetering bij reumatische aandoeningen hebben geleid tot aanbevelingen voor onderzoek en voor de praktijk. 


\section{Aanbevelingen voor onderzoek}

$\mathrm{Er}$ is verder onderzoek nodig ten aanzien van zorg op maat voor mensen met fibromyalgie. Het gaat dan om de juiste zorg voor de juiste persoon. Kenmerken van patiënten, de inhoud en organisatie van de zorg, de hiermee gepaard gaande kosten voor de gezondheidszorg, maar ook de mate waarin bestaande richtlijnen zijn geïmplementeerd dienen te worden onderzocht.

Ten aanzien van de reumaverpleegkundige zorg is nationaal en internationaal onderzoek op hoog niveau nodig, waarin de rollen van verpleegkundigen nauwkeurig zijn beschreven. Bovendien wordt onderzoek naar het definiëren van een set van uitkomsten van verpleegkundige interventies, die ook voor patiënten relevant zijn, aanbevolen. Dit vraagt een samenwerking van verpleegkundigen op wetenschappelijk gebied, hetgeen wordt bemoeilijkt door verschillen in opleidingsniveau van verpleegkundigen. Ondersteuning van nationale en internationale organisaties is noodzakelijk.

\section{Aanbevelingen voor zorg}

Nieuwe zorgmodellen voor reumapatiënten kunnen bijdragen aan duurzame, integrale zorg. Een getrapte benadering in de behandeling van fibromyalgie, gebaseerd op ernst van de klachten en disfunctioneren, waarbij eerste-, tweede- en derdelijns zorgprofessionals met elkaar samenwerken, is een voorbeeld van een dergelijk zorgmodel. Voor sommige patiënten met fibromyalgie is het omgaan met de klachten een steeds terugkerende opgave en voor deze groep zou laagdrempelige, frequente toegang tot een proactieve follow-up te overwegen zijn. Daarnaast blijkt, dat voor eerstelijns zorgverleners, maar ook voor specialismen buiten de reumatologie, voldoende kennis over de aandoening en de behandeling ontbreekt en goede scholing noodzakelijk is.

De implementatie van reumaverpleegkundige zorg past in het streven naar duurzame en integrale zorg. Nationale en internationale organisaties voor reumatologie kunnen de ontwikkeling van de reumaverpleegkundige zorg ondersteunen door het vaststellen van een visie op goede kwaliteit van zorg en het definiëren van adequate scholing voor verpleegkundigen.

Samenvattend hebben we geconcludeerd dat onze activiteiten, die beoogden om de zorg voor mensen met fibromyalgie te verbeteren, hebben geleid tot een beter inzicht in knelpunten voor goede zorg, hetgeen kan bijdragen aan zorgverbetering.

Voor wat betreft de zorg voor mensen met inflammatoire aandoeningen hebben onze activiteiten, met betrekking tot de rol van de reumaverpleegkundige, bijgedragen aan een internationale beweging naar verdere professionalisering van de reumaverpleegkundige zorg. 
Dankwoord 
'Alles heeft betekenis'. ledereen die je ontmoet en alles wat je doet en meemaakt, draagt bij aan je persoonlijke groei: het zo optimaal mogelijk verkennen en benutten van álle talenten, op welk terrein dan ook. Zo ook het proces dat nu resulteert in de verdediging van mijn proefschrift, ik heb er heel veel plezier aan beleefd.

Een dergelijk proces is ondenkbaar zonder de hulp en steun van velen. 'Zelf doen' is niet hetzelfde als 'alleen doen', en een dankwoord is zeker op zijn plaats. Het risico van een dankwoord is dat je belangrijke mensen vergeet. Met het vorderen van de leeftijd wordt de kans op geheugenproblemen groter én wordt de lijst van mensen die kunnen worden vergeten langer. Een voordeel van ouder worden is echter dat het relativeringsvermogen groter wordt. Ik ben geen 'junior' meer en daarom durf ik het risico van onvolledigheid te nemen. In dit dankwoord beperk ik mij tot de periode in mijn leven die direct leidde naar deze dag. In aanvulling gaat mijn dank uit naar alle mensen die ik, zowel privé als in diverse werksituaties, heb ontmoet en waarvan ik heb mogen leren.

Allereerst een woord van dank aan mijn promotieteam. Professor Landewé, beste Robert, het was een plezierig traject met jou. Dat had ik ook verwacht $(-)$. Het was even wennen voor ons beiden: jij kende mij als reumaconsulent en ik had als onderzoeker veel te leren, dus er ging wel eens wat mis met.......data. Uiteindelijk had je voldoende vertrouwen in mij om mij voor te stellen als onderzoeker in het EULAR project. Daar heb ik je al eerder voor bedankt. Ik waardeer je betrokkenheid en je kennis, je positieve feedback en je humor. Indien gevraagd was je er steeds voor mij. Professor Boonen, beste Annelies, met jou is het sinds jaar en dag heerlijk samenwerken. Je bent een grote inspirator voor mij en ondanks je eigen drukke programma ben je altijd bereid om mee te denken en je kennis over vele onderwerpen te delen. Mijn allereerste stap op het wetenschappelijk pad was het 'infliximab naar Blankenberg' project. Voor mij was alles nieuw dus jij hebt heel veel geregeld, maar de basis voor onze, door ons beide gewaardeerde, brainstormsessies is toen gelegd. Dr. Kroese, beste Mariëlle, jij zette de trial op die de data voor drie hoofdstukken van dit proefschrift leverde. We hebben in het begin intensief samengewerkt, daarna gingen we ieder 'ons weegs'. Het zou leuk zijn als onze gezamenlijke activiteiten voor mensen met fibromyalgie uiteindelijk bijdragen aan een verdere zorgverbetering voor deze patiënten. Dr. van Tubergen, beste Astrid, ik vond het een genoegen om een aantal voor mij heel belangrijke projecten uit deze thesis samen met jou te doen. Het was behalve leuk ook erg leerzaam, net zoals het samen reviewen van artikelen. Bovendien heb jij een belangrijke rol gespeeld bij mijn terugkeer naar reumatologie. We zijn beiden betrokken in vervolgactiviteiten, dus onze samenwerking gaat gelukkig gewoon door. Fijn dat je mijn copromotor bent.

Professor Metsemakers, professor Hazes, professor Schuurmans en dr. Vosse, beste Job, Mieke, Marieke en Debby, leden van de beoordelingscommissie. Ik wil jullie hartelijk danken voor de genomen tijd en moeite om mijn proefschrift te beoordelen op 
wetenschappelijke kwaliteit. Marieke, jammer dat je niet in de gelegenheid bent om te opponeren tijdens de verdediging. Professor Westhovens, dr. Fiolet en dr. De Wit, beste Rene, Hans en Maarten, fijn dat jullie de promotiecommissie willen completeren.

Anderen hebben op verschillende wijzen een essentiële bijdrage geleverd aan de totstandkoming van dit proefschrift, waarvoor mijn hartelijke dank.

Monique Bessems-Beks, beste Monique, je was bekend met álle ins en outs van de fibromyalgieprojecten en bent bovendien altijd bereid om een handje te helpen bij een project waar je niet op bent 'gelabeld'. Leuk dat we weer samenwerken in het project van Daisy.

Professor Vrijhoef, beste Bert, jou leerde ik kennen als promovendus in het project 'Spreeuwenberg'. Daarna werd je een van mijn coaches op het pad van de wetenschap. Gelukkig werken we ook nu nog steeds constructief en plezierig samen.

Dr. Tan, beste Frans, mijn grote steun en toeverlaat in de statistiek; zonder onze gezamenlijke sessies in het begin was het vast niet goed gekomen.

Dr. Creemers, beste An, je hebt veel werk gehad aan de imputatie van de kostendata, maar de zorgvuldigheid waarmee je dat hebt gedaan, zorgt ervoor dat ik met een gerust hart mijn uitspraken ten aanzien van de kosten kan doen.

Dr. Repping-Wuts, beste Han, ik ben erg blij met onze gezamenlijke activiteiten in onze Nederlandse werkgroep 'verpleegkundig onderzoek'. Het was een genoegen om met jou en met Judy, Hanneke en Conny samen te werken in onze eerste onderzoeken en ik verheug me op de voortzetting. Ik hoop ook dat wij in de toekomst meer verpleegkundigen kunnen inspireren om onderzoek te doen.

Chris Leenders en Heleen Schillings + , jullie zijn uren bezig geweest met het uitzoeken en invoeren van de kostendata, een belangrijk maar tijdrovend karwei.

Patient research partners, Marieke Scholte, Maarten de Wit, Marianne Osseweijer, Bertha Maat, Monique Lieon, Marleen Bolech, Ed Pourquié, Marlou Essers †, en al die anderen: ik ben blij met onze activiteiten en jullie inbreng is daarbij van onschatbare waarde.

Dr. Hill, dear Jackie, your work has been inspiring for many rheumatology nurses and certainly for me. I enjoyed meeting you and working together with you and the other members of the EULAR nursing task force in our recommendations project.

Dear colleague nurses, HPs and patient partners in EULAR task forces, EULAR study groups and committees, members of the RNS, ACR-ARHP, and in other parts of the world, I am happy with our expanding network and with the current international activities regarding care improvement for patients with rheumatic diseases. Dear Sue, our collaboration increases: we have a lot of work to do and I am looking forward to it. Thank you for your inspiration and your ongoing support.

Er zijn een aantal mensen die in de aanloop naar- en gedurende dit promotietraject op geheel eigen wijze van belang waren en die daarvoor hartelijk worden bedankt. 
Beste leden van de vakgroep reumatologie, de samenwerking met jullie inspireerde me tot de keuze voor de studie Gezondheidswetenschappen en daarna heb ik de wereld buiten de reumatologie verkend. Na een omweg ben ik weer terug! Ik werd met open armen ontvangen en inmiddels geven we vorm aan nieuwe, gezamenlijke activiteiten. Professor van der Linden, beste Sjef, onze eerste tocht naar de Rheumaklinik Aachen luidde voor ons beiden een spannende en niet altijd gemakkelijke zoektocht in naar wat die verpleegkundige wel en niet kon in de reumatologie. Vandaag de dag weten we heel wat meer, maar nog lang niet alles.

Ilse KleinGoldewijk, we gingen samen naar 'Bunnik' en we hebben de functie van verpleegkundig reumaconsulent in Maastricht vormgegeven. Het was mooi dat we dat samen hebben kunnen doen en fijn dat we nog steeds af en toe samen gaan eten of borrelen en lekker bijpraten over onszelf en 'onze jongens'. Mehmet Elmacioglu, jij kwam erbij en versterkte ons reumaconsulententeampje. Ik vind onze filosofische beschouwingen erg plezierig en ik ben blij dat wij weer collega's zijn. Claudia Vaessens, we delen 1 bureau en zien elkaar tot nu toe nauwelijks; als alle plannen doorgaan, leren we elkaar vast beter kennen.

Drs. Hollands, beste Louk, je liefde voor kwaliteitszorg, je vermogen dat over te brengen en je enthousiasme om samen te werken, stonden mede aan de wieg van deze wetenschappelijke carrière.

Transmurale zorg, onderdeel van het tegenwoordige Patiënt \& Zorg, heeft een speciaal plekje in mijn hart. Vanaf de oprichting van de toenmalige BZE 7 heb ik mij er als een vis in het water gevoeld. Kansen creëer je zelf, daar ben ik het helemaal mee eens, maar zonder het scheppen van voorwaarden is excelleren een stuk ingewikkelder, zo niet onmogelijk. Dr. Fiolet, beste Hans, jouw vermogen die voorwaarden te willen en te kunnen scheppen speelt daarbij een cruciale rol.

Drs. de Bruijn-Geraets, beste Daisy, ik ben blij dat ik bij je project ben betrokken; ik vind het een eer om jou te begeleiden. Het is een leuk project, jij bent een uitstekende onderzoeker en samen met Bert en Monique vormen we een superteam.

Beste (oud)collega's onderzoekers en onderzoeksassistenten van Transmurale zorg, Bert, Guy, Caro, Liesbeth, Henk, Joyce, Pytha, Ron, Angelique, Monique, Wendy, Carla, Diana †, Helene, Juliane, Jody, Alied, Trudy, Daisy, Manon, Greet, Mariëlle, Inge, Anneke, Josiane, George, Ron, Susan, Carin: toen waren er nog.............! Van een grote enthousiaste onderzoeksgroep naar een klein clubje. Dat viel niet altijd mee. Gelukkig weten we elkaar nog steeds te vinden. Josiane, promoveren op vrijdag de $13^{\mathrm{e}}$ ! Dat doet niet iedereen je na. En ja hoor, in het vervolg sluiten we weer de gelederen na de BBQ bij Hans.

Beste collega's van HSR, ik ben benieuwd naar onze toekomstige samenwerking. Professor Ruwaard, beste Dirk en dr. Spreeuwenberg, beste Marieke, fijn dat de koffie en de vlaai letterlijk en figuurlijk klaarstonden. 
Beste mede-reumatologie-promovendi, jullie 'mama' ben ik niet en wordt ik niet maar naast een gezamenlijk bezoek aan de Old Spaghetti Factory oid zijn er in de toekomst vast mogelijkheden om samen te werken.

Al degenen die in allerlei projecten hebben geparticipeerd, zowel professionals als patiënten, wil ik expliciet bedanken. Zonder jullie bereidheid om mee te denken en te experimenteren is geen verandering mogelijk.

En dan.....

Familie en vrienden, tot mijn schande moet ik bekennen dat jullie er bekaaid vanaf komen. Het is vaak balanceren tussen werken, waar ik veel plezier aan beleef, én de tijd nemen om te genieten van jullie aanwezigheid en samen leuke dingen te doen. (Schoon)moeder, (schoon)zus(sen), (schoon)broers, (achter)neven en (achter)nichten, vrienden, allen bedankt voor je geduld om af te wachten tot een moment dat we iets kunnen afspreken, voor het accepteren van deze werkelijkheid én voor je steun.

Jef en Mieke, vrienden van het eerste uur, geweldig dat jullie je artistieke talenten hebben gebruikt om de prachtige omslag van dit proefschrift te ontwerpen.

Lief mamaatje, ik zou graag meer tijd met je doorbrengen. Weet dat ik geniet van de uurtjes die we wél samen hebben.

Mijn (schoon) kinderen Siemen en Mirjam, Pepijn en Jeltsje, lieve allemaal: ik ben trots op jullie. Om wie je bent en om wat je doet. Ik vind het een heel prettig idee, mijn zonen als paranimfen; bedankt dat jullie dat voor mij willen doen.

Lieve Paul, de laatste regels zijn voor jou. Al heel lang mijn beste maatje. Niemand kent mij zo goed als jij. Mijn keuzes zijn zeker niet altijd de jouwe, maar desondanks kan ik rekenen op je onvoorwaardelijke steun en dat is heel bijzonder. Dank je! 


\section{Curriculum Vitae}


Yvonne van Eijk-Hustings was born in Heerlen, the Netherlands, 10 July 1958. Ever since her childhood she intended to be a nurse. After graduating from Higher General Secondary Education at Coriovallum College, Heerlen, in 1976, she moved to Nijmegen to study nursing at the Higher Vocational Nursing School where she obtained her Bachelor degree in 1980. As a registered nurse she worked in the care for drug and alcohol addicts, for psychiatric patients, for mentally retarded patients, and in the community. She always had a special interest in the care for chronically ill patients and eventually she has specialised as a rheumatology nurse.

From 1997 to 2005, she worked at the rheumatology outpatient clinic of Maastricht University Medical Centre (MUMC+) and from September 2000 she combined this work with a part-time study Health Sciences at Maastricht University. Her interest in research increased during her study so, after obtaining her Master degree in 2004, she chose to continue her career in science. She performed research projects with regard to the care for patients with chronic obstructive pulmonary diseases and for patients with diabetes mellitus at the Department of Patient \& Care (MUMC+). She additionally started her research with regard to improving care for patients with rheumatic diseases, that has resulted in this dissertation, in 2007.

Since 2012, she combines research and practice. She participates in international and national multidisciplinary research groups that aim to contribute to improved quality of care for patients with rheumatic diseases and she participates in international and national research initiatives that emphasise the role of the rheumatology nurse. Also, she is founder and chair of two international working groups: the nurses study group for Research and Strategy (REST), endorsed by the European League Against Rheumatism (EULAR), and the 'Defining and measuring nurse sensitive outcomes' working group, supported by Outcome Measures in Rheumatology (OMERACT). She is a co-opted member of the EULAR Health Professionals scientific subcommittee; she is a board member of- and research fellow for $V \& V N$, unit rheumatology, and she is actively involved in the founding of an international rheumatology nurses network.

Furthermore, she is involved in the development of the nursing profession towards extended roles. She is an advisory member of the 'College Specialismen Verpleegkunde', and co-supervisor in a project initiated by the Ministery of Welfare, Health and Sports in the Netherlands that evaluates the impact of granting independent authorisations for reserved procedures to nurse practitioners and physician assistants.

Finally, she provides outpatient nursing care for rheumatology patients and she contributes to initiatives for care improvement within the Department of Rheumatology and the Department of Patient \& Care (MUMC+), in collaboration with CAPHRI, School for Public Health and Primary Care of Maastricht University. 
Yvonne van Eijk-Hustings werd op 10 juli 1958 geboren in Heerlen. Al in haar kindertijd wilde zij verpleegkundige worden. $\mathrm{Na}$ het behalen van het Hoger Algemeen Vormend Onderwijs (HAVO) diploma, 1976, aan het Coriovallum College te Heerlen, studeerde zij verpleegkunde aan de Hogere Beroepsopleiding voor Verpleegkundigen (HBO-V) te Nijmegen, waar zij in 1980 haar diploma behaalde. Als gediplomeerd verpleegkundige werkte zij achtereenvolgens in de verslavingszorg, de psychiatrie, de zorg voor mensen met een verstandelijke beperking en de wijkzorg. Zij was altijd een bijzondere interesse in de zorg voor chronisch zieken en uiteindelijk heeft zij zich gespecialiseerd als reumaverpleegkundige.

Van 1997 tot 2005 werkte ze op de polikliniek reumatologie van het Maastrichts Universitair Medisch Centrum (MUMC+) en vanaf 2000 combineerde ze dit werk met een studie Gezondheidswetenschappen aan de Universiteit Maastricht. Haar interesse in onderzoek nam gedurende haar studietijd toe en daarom koos ze, na het behalen van haar bul, voor een baan als onderzoeker. Ze deed onderzoeksprojecten voor de afdeling Patiënt en Zorg van MUMC+ met betrekking tot de zorg voor mensen met chronisch longlijden en met diabetes mellitus. In aanvulling hierop startte ze in 2007 met de onderzoeken die beschreven zijn in dit proefschrift.

Sinds 2012 combineert ze onderzoek en praktijk. Ze maakt deel uit van een aantal nationale en internationale onderzoeksgroepen, die beogen de zorg voor patiënten met reumatische aandoeningen te verbeteren en de rol van de reumaverpleegkundige te verduidelijken en te versterken. $Z e$ is oprichter en voorzitter van twee internationale verpleegkundige werkgroepen: de European League Against Rheumatism (EULAR) studiegroep voor onderzoek en beleid (REST) en de intercontinentale werkgroep voor het definiëren van relevante uitkomsten van reumaverpleegkundige interventies in onderzoek, ondersteund door Outcome Measures in Rheumatology (OMERACT). Ze is (op uitnodiging) lid van het wetenschappelijk subcomité van de EULAR Health Professionals, ze is bestuurlid van- en onderzoeker voor V\&VN, reumatologie, en ze is betrokken bij de oprichting van een internationaal netwerk voor reumaverpleegkundigen.

Ook is ze betrokken bij initiatieven die de ontwikkeling van het verpleegkundig beroep in zijn algemeenheid, door verdere specialisatie van verpleegkundigen, ondersteunen; ze is adviserend lid van het 'College Specialismen Verpleegkunde' en copromotor in een onderzoeksproject van het Ministerie van Volksgezondheid, Welzijn en Sport, dat de zelfstandige bevoegdheid voor het indiceren van voorbehouden handelingen door verpleegkundig specialisten en physician assistants evalueert.

Daarnaast verleent ze gespecialiseerde zorg aan patiënten met reumatische aandoeningen op de polikliniek reumatologie en draagt ze bij aan projecten voor zorgverbetering binnen de afdeling Reumatologie en de afdeling Patiënt \& Zorg, MUMC+, in samenwerking met CAPHRI, onderzoeksschool voor publieke gezondheid en de eerstelijn van de Universiteit Maastricht. 
List of publications 


\section{International publications}

- Van Eijk-Hustings $Y$, Kroese $M$, Boonen A, Bessems-Beks $M$, Landewé R. Predictors for health improvement in patients with fibromyalgia: a 2-year followup study. Clin Rheumatol. 2013;doi: 10.1007/s10067-013-2371-7 [Epub ahead of print].

- Van Eijk-Hustings Y, Ammerlaan J, Voorneveld-Nieuwenhuis H, Maat B, Veldhuizen C, Repping-Wuts $H$. Patients' needs and expectations with regard to rheumatology nursing care: results of multicentre focus group interviews. Ann Rheum Dis. 2013;72(6):831-835. doi:10.1136/annrheumdis-2012-202810.

- Van Eijk-Hustings Y, Kroese M, Tan F, Boonen A, Bessems-Beks M, Landewé R. Challenges in demonstrating effectiveness of multidisciplinary treatment on quality of life, participation and health care utilisation in patients with fibromyalgia. A randomised controlled trial. Clin Rheumatol. 2013;32(2):199209.doi:10.1007/s10067-012-2100-7.

- Van Eijk-Hustings $Y$, Kroese $M$, Bessems-Beks $M$, Landewé $R$, Vrijhoef $H$. Supporting health care professionals systematically to improve the quality and person-centredness of fibromyalgia management in primary health care. Int J Pers Cent Med. 2012;2(4):837-844. org/10.5750\%2Fijpcm.v2i4.297.

- Van Eijk-Hustings $Y$, van Tubergen A, Boström C, et al. EULAR recommendations for the role of the nurse in the management of chronic inflammatory arthritis. Ann Rheum Dis. 2012;71(1):13-19.doi:10.1136/annrheumdis-2011-200185.

- Van Eijk-Hustings $Y$, Landewé R, van Tubergen A. European League Against Rheumatism (EULAR): le rôle des infirmiers dans le traitement de l'arthrite inflammatoire chronique (also in Dutch). Ortho-Rhumato. 2012;10(1):10-16.

- Van Eijk-Hustings Y, Daemen L, Schaper N, Vrijhoef H. Implementation of Motivational Interviewing in a diabetes care management initiative in the Netherlands. Patient Educ Couns. 2011;84:10-15. doi:10.1016/j.pec.2010.06.016.

- Van Eijk-Hustings Y, Boonen A, Landewé R. A randomized trial of Tai Chi for fibromyalgia (author reply). N Engl J Med. 2010;363(23):2265-7.doi: 10.1056/NEJMc10104782266-7.

- Van Eijk-Hustings Y, Kroese M, Bessems-Beks M, Boonen A, Landewé R. Predicting outcome. Determining clusters of patients' characteristics which can be useful in predicting outcome in fibromyalgia [abstract]. Ann Rheum Dis. 2010;69(Suppl3):707.

- Van Eijk Y, Boonen A, Schulpen G, Schrijnemaekers V, Fiolet H, van der Linden Sj. Safety and patient satisfaction of infliximab administration in an extra mural setting supervised by a rheumatology specialist nurse. Ann Rheum Dis. 2006;65(2);276. doi:10.1136/ard.2005.036566. 


\section{National publications}

- Van Eijk-Hustings Y, Ammerlaan J, Voorneveld-Nieuwenhuis H, Maat B, Veldhuizen $\mathrm{C}$, Repping-Wuts $\mathrm{H}$. Behoeften en verwachtingen van patiënten met chronische inflammatoire aandoeningen ten aanzien van reumaverpleegkundige zorg: resultaten van focusgroepen in meerdere medische centra in Nederland. Nederlands Tijdschrift voor Reumatologie. 2013;3:51-55.

- Van Eijk-Hustings Y, Daemen L, Schaper N, Vrijhoef H. Implementatie van Motivational Interviewing in een zorgprogramma voor mensen met diabetes mellitus in Maastricht en Heuvelland. Nederlands Tijdschrift voor Behavioral Medicine, uitgave van de Nederlandse Behavioral Medicine Federatie. 2012;23(2).

- Van Eijk-Hustings Y, Daemen L. Motivational Interviewing in 2012: een korte update van de nieuwste inzichten over training. EADV magazine. 2012;27(1):1012.

- Van Eijk-Hustings Y, Landewé R, van Tubergen A. EULAR aanbevelingen voor de rol van de verpleegkundige in de behandeling van mensen met chronische inflammatoire artritis. Nederlands Tijdschrift voor Reumatologie. 2011;4:9-14.

- Van Eijk-Hustings $Y$, Kroese M, Bessems-Beks M. Ontwikkelen van ketenzorg voor mensen met chronische, gegeneraliseerde pijn oftewel fibromyalgie in de regio Zuid-Limburg. Beweegreden, vakblad voor oefentherapeuten Cesar en Mensendieck. 2010;6(3):13-15.

- Van Eijk-Hustings Y, Daemen L, Schaper N, Vrijhoef H. Motivational Interviewing? Doen! Implementatie van Motivational Interviewing in een disease management programma voor mensen met diabetes mellitus in Maastricht en Heuvelland. EADV magazine. 2009;9:44-46.

- Van Eijk-Hustings $Y$, Vrijhoef H, Wesseling G, Tange H, Muris J. Systematische kwaliteitsborging in een disease management programma: eerst meten, dan weten en verbeteren. Tijdschrift voor Gezondheidswetenschappen.

2008;86(1):31-38.doi:10.1007/BF03082005. 
Presentations related to this thesis 


\section{International presentations}

- Van Eijk-Hustings Y. Defining the roles of the rheumatology nurse Internationally: a perspective from the Netherlands. Oral presentation (invited). Annual meeting American College of Rheumatology/Association of Rheumatology Health Professionals, San Diego CA USA, 29 October 2013.

- Van Eijk-Hustings $Y$, on behalf of the research task force Dutch Nurses Association, unit Rheumatology. Patients' view on rheumatology nursing care. Oral presentation (invited). First International Rheumatology Nurses Conference 'Rheumatology Care: Challenges for nurses', Rotterdam NL, 12 October 2013.

- Van Eijk-Hustings Y. Development and implementation of standards for rheumatology nursing care. Oral presentation (invited). First International Rheumatology Nurses Conference 'Rheumatology Care: Challenges for nurses', Rotterdam NL, 11 October 2013.

- Van Eijk-Hustings Y, Ammerlaan J, Voorneveld H, Veldhuizen C, Repping-Wuts H. The patient's view on rheumatology nursing care: results of a survey [abstract]. Ann Rheum Dis 2013;72(Suppl3):360. Poster presentation. Annual meeting European League Against Rheumatism, Madrid ES, 13 June 2013.

- Van Eijk-Hustings Y, Buss B, Fayet F, Moretti A, Ndosi N, Ryan S, Savel C, ScholteVoshaar M, de la Torre-Aboki J, van Tubergen A. Dissemination and evaluation of the EULAR recommendations for the role of the nurse in the management of chronic inflammatory arthritis [abstract]. Ann Rheum Dis 2013;72(Suppl3):367. Postertour presentation. Annual meeting European League Against Rheumatism, Madrid ES, 13 June 2013.

- Van Eijk-Hustings Y. European League Against Rheumatism (EULAR) guidelines for rheumatology nursing care: development, consensus and implementation. Inaugural meeting ' Knowledgeable Nurses One World'. Oral presentation (invited), previous to the Annual Meeting American College of Rheumatology, Washington DC USA, 10 November 2012.

- Van Eijk-Hustings Y, Firth J. Improving patient outcomes: have you considered a nurse? Mini-symposium (invited). International Immunology Masterclass, Bad Nauheim DE, 12-13 October 2012.

- Van Eijk-Hustings Y. Kroese M, Bessems-Beks M, Boonen A, Landewé R A biopsycho-social approach for assessing associations with changes in perceived health in recently diagnosed patients with fibromyalgia [abstract]. Ann Rheum Dis 2012;71(Suppl3):277. Poster presentation. Annual meeting European League Against Rheumatism, Berlin DE, 7 June 2012.

- Van Eijk-Hustings Y, Ammerlaan J, Voorneveld H, Veldhuizen C, Repping-Wuts H. Patients' expectations and needs with regard to rheumatology nursing care: results of multi-centre focus group interview among patients with chronic 
inflammatory arthritis [abstract]. Ann Rheum Dis 2012;71(Suppl3):736. Poster presentation. Annual meeting European League Against Rheumatism, Berlin DE, 7 June 2012.

- Van Eijk-Hustings Y. Patient-physician communication, the contribution of the nurse. Oral presentation (invited). Rheumatoid Arthritis Patient Group Roundtable Patient-physician communication, Brussels BE, 20 December 2011.

- Van Eijk-Hustings $Y$, on behalf of the EULAR nursing task force. EULAR recommendations for the role of the nurse in the management of chronic inflammatory arthritis. Poster presentation (invited). Belgisch Congres voor Reumatologie, Antwerpen BE, 30 September 2011.

- Van Eijk-Hustings Y, Esselens G. 'EULAR aanbevelingen voor de rol van de verpleegkundige in de behandeling van mensen met chronische inflammatoire artritis: wat vinden we ervan en hoe gaan we ermee aan de slag?'. Workshop reumaverpleegkundigen (invited). Belgisch Congres voor Reumatologie, Antwerpen BE, 28 September 2011.

- Van Eijk-Hustings Y. Development of EULAR recommendations for the role of the nurse in the management of chronic inflammatory arthritis. Oral presentation (invited). Annual Conference Rheumatology Nurses Society, Kansas City MI USA, August 13, 2011.

- Van Eijk-Hustings Y. Kroese M, Bessems-Beks M, Landewé R, Vrijhoef H. Quality Improvement in the management of fibromyalgia in primary care [abstract]. Ann Rheum Dis 2011;70(Suppl3):773. Postertour presentation. Annual meeting European League Against Rheumatism, London UK, 28 May 2011.

- Van Eijk-Hustings $\mathrm{Y}$, on behalf of the EULAR nursing task force. EULAR recommendations for the role of the nurse in the management of chronic inflammatory arthritis [abstract]. Ann Rheum Dis 2011;70(Suppl3):3. Oral presentation (invited). Annual meeting European League Against Rheumatism, London UK, 25 May 2011.

- Van Eijk-Hustings $Y$, Kroese $M$, Bessems-Beks $M$, Boonen A, Landewé R. Multidisciplinary treatment with aftercare meetings compared to aerobic exercise and usual care in fibromyalgia. First results of a randomised controlled trial [abstract]. Ann Rheum Dis 2008;67(Suppl II):262. Poster presentation. Annual meeting European League Against Rheumatism, Paris FR, 12 June 2008. 


\section{National presentations}

- Van Eijk-Hustings Y, Buss B, Fayet F, Moretti A, Ndosi N, Ryan S, Savel C, ScholteVoshaar M, de la Torre-Aboki J, van Tubergen A. Disseminatie en evaluatie van de EULAR aanbevelingen voor de rol van de verpleegkundige. Orale presentatie. Najaarsdagen Nederlandse Vereniging voor Reumatologie, Arnhem NL, 27 September 2013.

- Van Eijk-Hustings Y. Ammerlaan J, Voorneveld H, Veldhuizen C, Repping-Wuts H. Verwachtingen en behoeften aan reumaverpleegkundige zorg van patiënten met een chronisch inflammatoire aandoening: resultaten van focusgroep interviews in vier centra in Nederland. Posterpresentatie. Najaarsdagen Nederlandse Vereniging voor Reumatologie, Arnhem NL, 28 September 2012.

- Van Eijk-Hustings Y. Patients' expectations and needs as a basis for a research agenda for rheumatology nursing: results of multi-centre focus group interviews among patients with chronic inflammatory arthritis. Posterpresentatie. Annual research meeting CAPHRI, School for Primary Care and Public Health, Maastricht NL, 3 April 2012.

- Van Eijk-Hustings $Y$, namens de EULAR werkgroep voor de ontwikkeling van aanbevelingen voor verpleegkundige zorg. EULAR aanbevelingen voor de rol van de verpleegkundige in de behandeling van mensen met chronische inflammatoire artritis. Orale presentatie. Najaarsdagen Nederlandse Vereniging voor Reumatologie, Arnhem NL, 30 September 2011.

- Van Eijk-Hustings Y. Quality Improvement in the management of fibromyalgia in primary care. Posterpresentatie. Annual research meeting CAPHRI, School for Primary Care and Public Health, Maastricht NL, 19 May 2011.

- Van Eijk-Hustings Y, Vrijhoef HJM. Verbeteren van de kwaliteit van chronische zorg: zorgontwikkelingen bij fibromyalgie. Orale presentatie. Sociaal Wetenschappelijk Onderzoek bij Reumatische Aandoeningen (SWORA), Utrecht NL, 26 March 2010.

- Van Eijk-Hustings $Y$, Kroese $M$, Bessems-Beks $M$, Boonen A, Landewé R. Multidisciplinaire behandeling met nazorgbijeenkomsten vergeleken met aerobic exercise en gebruikelijke zorg. Eerste resultaten van een gerandomiseerde, gecontroleerde studie. Orale presentatie. Najaarsdagen Nederlandse Vereniging voor Reumatologie, Arnhem NL, 26 September 2008. 